\title{
Risk and Benefit Analysis of Herbal Products from Indonesia
}

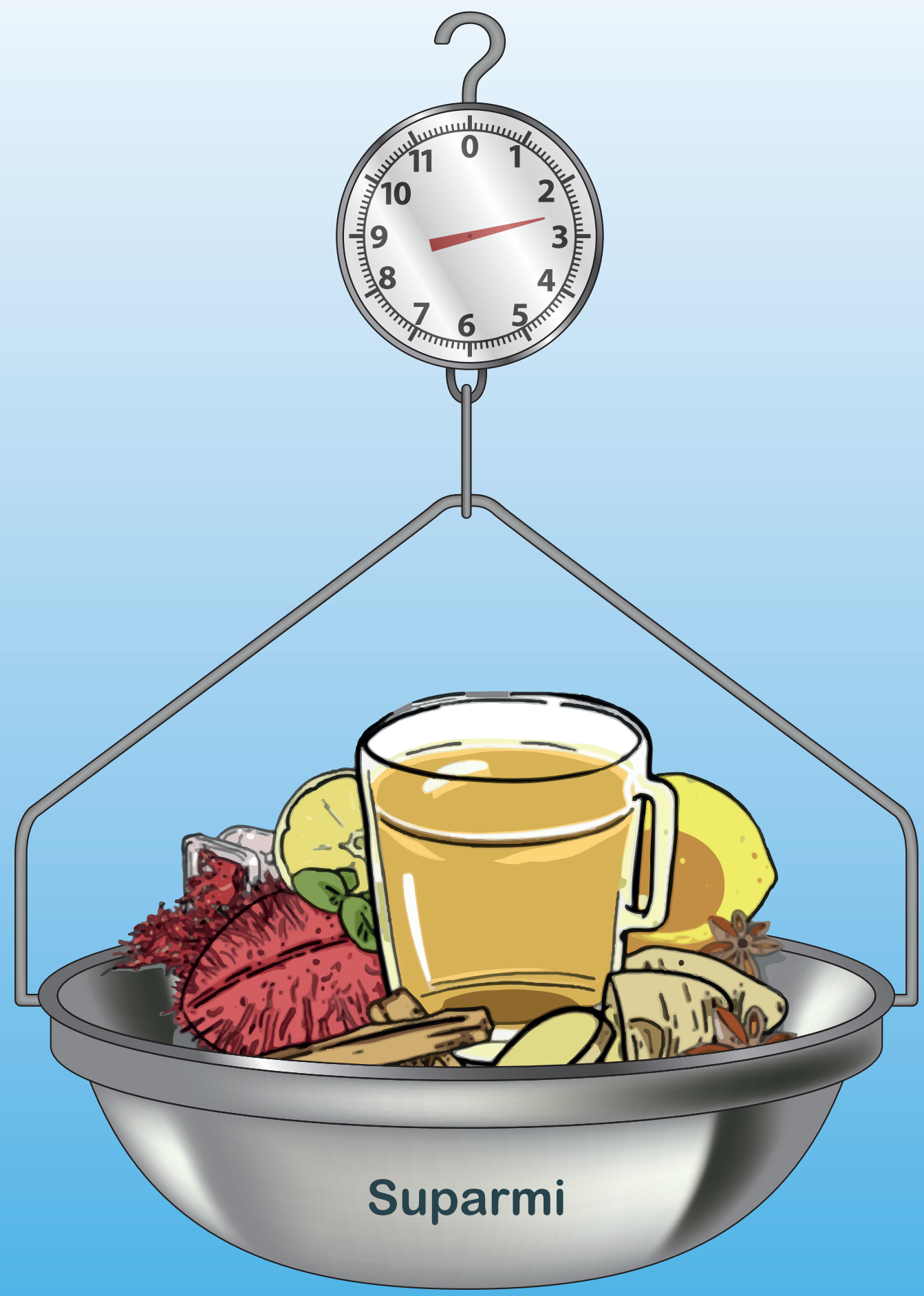





\section{Propositions}

1. The type and level of genotoxic carcinogens in Indonesian herbal products are a risk for human health.

\section{(this thesis)}

2. Combining in vitro toxicity with physiologically based kinetic modeling fills data gaps in the toxicological database of pyrrolizidine alkaloids.

(this thesis)

3. The adverse effects of noise pollution in the marine ecosystem are underestimated.

4. The health benefits of regular fasting are underestimated.

5. Children are good advisors for parents with PhDrelated stress.

6. A cultural shock supports success.

Propositions belonging to the $\mathrm{PhD}$ thesis entitled:

Risk and benefit analysis of herbal products from Indonesia

Suparmi

Wageningen, 21 April 2020 

Risk and Benefit Analysis of Herbal Products from Indonesia

\section{Suparmi}


Thesis committee

Promotor

Prof. Dr I.M.C.M. Rietjens

Professor of Toxicology

Wageningen University \& Research

Other members

Prof. Dr E.J.M. Feskens, Wageningen University \& Research (WUR)

Dr M. Lahaniatis, German Federal Institute for Risk Assessment (BfR), Berlin, Germany

Prof. Dr Taufiqurrachman Nasihun, M.Kes, Sp.And, Universitas Islam Sultan Agung (UNISSULA), Indonesia

Dr D. Wahidin, Badan Pengawas Obat dan Makanan (BPOM), Indonesia

This research was conducted under the auspices of the Graduate School VLAG (Advanced Studies in Food Technology, Agrobiotechnology, Nutrition and Health Sciences) 


\title{
Risk and Benefit Analysis of Herbal Products from Indonesia
}

\author{
Suparmi
}

Thesis

submitted in fulfilment of the requirements for the degree of doctor at Wageningen University

by the authority of the Rector Magnificus

Prof. Dr A.P.J. Mol,

in the presence of the

Thesis Committee appointed by the Academic Board

to be defended in public

on Tuesday 21 April 2020

at 04.00 p.m. in the Aula 


\section{Suparmi}

Risk and Benefit Analysis of Herbal Products from Indonesia 226 pages

PhD thesis, Wageningen University, Wageningen, The Netherlands (2020) With references, with summary in English

ISBN 978-94-6395-290-3

DOI: https:// doi.org/10.18174/512309 
Contents

Chapter 1 General Introduction 7-34

Chapter 2 Natural occurrence of genotoxic and carcinogenic $37-67$ alkenylbenzenes in Indonesian jamu and evaluation of consumer risks

Chapter 3 Levels of methyleugenol and eugenol in instant $69-95$ herbal beverages available on the Indonesian market and related risk assessment

Chapter 4 Detection of pyrrolizidine alkaloids in jamu 97-124 available on the Indonesian market and accompanying safety assessment for human consumption

Chapter 5 Prediction of in vivo monocrotaline-induced liver $127-152$ toxicity in rat using a combined in vitrophysiologically based kinetic modeling approach

\begin{tabular}{clc}
\hline Chapter 6 & $\begin{array}{l}\text { Combining in vitro data and physiologically based } \\
\text { kinetic modeling facilitated reverse dosimetry to } \\
\text { define in vivo dose-response curves for bixin- and } \\
\text { crocetin-induced activation of PPARy in humans }\end{array}$ & \\
\hline Chapter 7 & General Discussion & $175-173$ \\
& & \\
\hline Chapter 8 & Summary & $211-215$ \\
& & 217 \\
\hline Appendices & Acknowledgements & $218-221$ \\
& About the Author & 222 \\
& List of publications & $223-224$ \\
& Overview of completed training activities & 225 \\
\hline
\end{tabular}




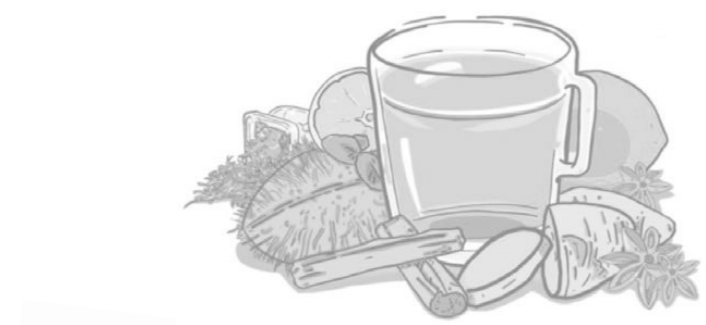

BENEFIT

RISK 
Chapter 1

General introduction

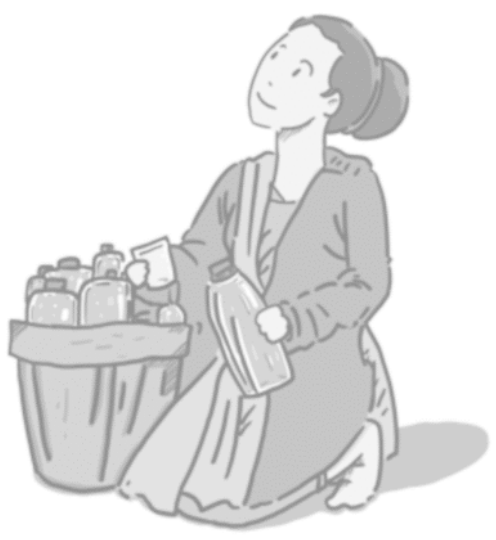




\subsection{The aim of the thesis}

The aim of the present thesis was to perform an assessment of potential risks and also some benefits of herbal products available on the Indonesian market. The model compounds chosen included naturally occurring genotoxic and carcinogenic botanical constituents including alkenylbenzenes and pyrrolizidine alkaloids. Beneficial effects focussed on potential PPAR $\gamma$ activation by the carotenoids bixin and crocetin. Existing but also novel testing strategies were used to evaluate the relevance of effects at estimated human intake levels. The botanicals and botanical preparations used for the studies were collected on the Indonesian market and consisted of herbal products including especially jamu and herbal beverages.

\subsection{Herbal products in Indonesia}

The healthcare system in Indonesia uses medicinal botanicals in many types of herbal products. Providing cultivation possibilities for 30,000 out of 40,000 medicinal botanicals available in the world potentially serves as an enormous supply to develop herbal products in Indonesia. Badan Pengawas Obat dan Makanan, Republik Indonesia (BPOM RI) (The National Agency for Drug and Food Control, Republic of Indonesia) has divided the herbal products in Indonesia into 3 categories based on preparation methods of the products and the level of proof required for their efficacy; i.e jamu, standardized herbal medicines, and fitofarmaka (phytomedicines) which are all regulated under regulation HK. 00.05.4.2411.[1]

Jamu is recognized as Indonesian traditional medicine for which the therapeutic effects are mainly based on empirical data, inherited across generations. ${ }^{[2]}$ The efficacy of standardized herbal medicines has to be proven in preclinical studies and the standardisation of the level of their active ingredients is required, while the efficacy of fitofarmaka has to be proven in clinical studies.[1]

Herbal products have been industrialised for various kind of applications and in a variety of preparations. Use of herbal products may relate to for example medicine, health care, or beauty-care (cosmetics). ${ }^{[2]}$ Since ancient times, the use of jamu has been mainly directed at maintaining well-being and the prevention of ailments, or as medicines used to cure a disease or relieve its symptoms. In the past, people consumed the freshly picked leaves or other parts of the plants, drank the decoction of jamu materials prepared in boiled water or rubbed their body with the preparation for topical treatment. Nowadays, people tend to consume herbal products rather in forms similar to other modern medicines such as in the form of pills, tablets, powders, pastilles, capsules, extracts, cream or ointments.[2] Furthermore, exposure to functional herbal products may originate from use of herbal teas, spices, coffees and/or natural food colorants. ${ }^{[3]}$ 


\subsection{Consumption and regulatory trends of herbal products at the current state- of-the art in Indonesia}

Nowadays herbal products and dietary supplements are widespread in the global market, being easily accessible to consumers via supermarkets, drugstores, natural health/food stores, herbal shops, and gyms while there are also ample possibilities to purchase these products via the internet. The notorious growth in the consumption of herbal products has been associated with the increasing demand for alternative therapies, in part due to the mistrust in conventional medicine and pharmaceutical drugs, and building on the perception that herbal product are "safe" and "natural" and thus "healthy", while at the same time facilitating the tendency for self-medication aiming for increased control over one's own health.[4-6]

In Indonesia, the market demand for jamu and other herbal products keeps growing, and as a result jamu increasingly provides economic and perceived clinical benefits. The developments already mentioned above, including easy accessibility of the products without a need for prescription and the trend of consumers to favour natural products also stimulate the production of herbal based jamu. As a result many jamu manufacturers keep developing the products and their potential health claims communicating the products and their potential benefits to consumers.[7] Nowadays, the Indonesian government established a task force to promote jamu to become fitofarmaka by improving the quality of raw materials, the manufacturing process, the standardization of the technology, the preclinical and clinical trials required to prove efficacy, traditional health service development, and the introduction and promotion of these traditional products in international markets. ${ }^{[8]}$ In addition substantial research efforts focus on the exploration of Indonesia's indigenous botanicals and their potential beneficial effects providing a rationale for their use as sources of new therapeutic agents. In contrast, however, the research on potential adverse health effect of these herbal products that could be caused by toxic botanical constituents, remains limited.

As a result, the increasing use of herbal products has raised concerns among scientific and regulatory communities especially given the case studies related to cases of intoxication from misuse, misidentification of the botanical species or contamination with extraneous plants. $[9,10]$ Consumers sometimes only focus on the beneficial effects of the products while they may not be aware of the potential adverse health effects that can occur due to the presence of toxic botanical constituents. An effective system of risk assessment and control by competent authorities is needed in order to prevent the presence of potentially toxic constituents, possible adulterations, and/or to implement quality control in order to enforce measures to safeguard public health.[11] In this regard it is of interest to note 
that BPOM RI reported that in 2018 there were some unscrupulous manufacturers and distributors who deliberately adulterated jamu through the addition of pharmaceutical drugs or analogue substances in order to increase product effectiveness. ${ }^{[8]}$

\subsection{Existing regulatory status of herbal products in Indonesia and other countries}

The safety, efficacy and standardization of herbal products should be controlled strictly to reach safer and more effective products to better guarantee consumer safety.[5, 7, 12] Within this framework it is interesting to note that the legislation and the risk assessment criteria for botanical supplements vary among different countries. ${ }^{[13]}$

The European Food Safety Authority (EFSA) published a compendium of botanicals that are reported to contain toxic, addictive, psychotropic, or other substances of concern ${ }^{[14]}$ which was updated in 2012[15]. In the United States, the Food and Drug Administration (FDA) under the Dietary Supplement Health and Education Act of 1994 (DSHEA) recognized plant food supplements (PSF) as a separate category of foods and established its own requirements for safety and labeling. ${ }^{[16]}$

BPOM RI supervises the quality and safety of herbal products in Indonesia.[17] In case of jamu, criteria for safety and efficacy assessment of these products to assure the protection of consumers still need to be established. ${ }^{[12]}$ Under regulation of the Ministry of Health (No. 659/MENKES/SK/X/1991) and the renewed regulation No. HK.00.05.4.1380 the producers and small-scale industries of herbal products have to refer to good manufacturing practice guidelines for traditional medicine, called СРОТВ (Cara Pembuatan Obat Tradisional yang Baik) which provide guidelines for raw materials, the production process, quality control, factory building, workers, management, instrumentation, and sanitation. ${ }^{[18]}$

\subsection{Risk assessment of genotoxic and carcinogenic compounds in herbal products using Margin of Exposure (MOE) approach}

Although most people and even some medical practitioners assume that herbal products have fewer side effects than conventional drugs, the health risks associated with the use of herbal products cannot be neglected. The adverse health effect of consuming herbal products is influenced by many factors including natural occurrence of toxins in the plants, the dose of consumption and also consumerrelated factors such as age, genetics, concomitant diseases and co-medication (herbherb and herb-drug interactions). ${ }^{[10]}$ Botanicals may contain a wide variety of toxic constituents (see EFSA compendium ${ }^{[15]}$ ) and this may include even compounds that 
are both genotoxic and carcinogenic. Genotoxic and carcinogenic compounds that may naturally occur in botanicals include especially alkenylbenzenes (ABs), pyrrolizidine alkaloids (PAs) and aristolochic acid (AAs) ${ }^{[19]}$ and previous risk assessment studies on botanicals and botanical preparations are available that report these type of constituents to pose a concern for human health indicating a priority for risk management action of the corresponding herbal products ${ }^{[19-24]}$.

This risk assessment of the botanical constituents that are genotoxic and carcinogenic may be performed following the so-called Margin of Exposure (MOE) approach. The MOE approach is recommended by the European Food Safety Authority (EFSA), the Joint FAO/WHO Expert Committee on Food Additives (JECFA) and the International Life Sciences Institute (ILSI) for evaluating the risk of compounds that are both genotoxic and carcinogenic.[25-28] The result of the MOE approach can be used to determine priorities for risk management ${ }^{[26]}$ taking relevant human exposure scenario's into account ${ }^{[29]}$. The MOEs are calculated by dividing a relevant reference point, for instance the $\mathrm{BMDL}_{10}$, which is the lower confidence limit of the benchmark dose giving $10 \%$ extra tumour incidence above background levels, by the Estimated Daily Intake (EDI). The BMDL 10 , is considered the most appropriate point of departure (POD) for calculating the MOE. An outcome of the MOE below 10,000 is considered a priority for risk management when the MOE is based on a BMDL 10 for carcinogenicity and an EDI for daily lifetime exposure. Exposure to the chemical would be considered a low concern for human health and a low priority for risk management when the MOE is higher than 10,000.[27] This MOE cut off value of 10,000 takes into account four uncertainty factors including a factor 10 for species differences in kinetics and dynamics, a factor 10 for human variability in kinetics and dynamics, a factor 10 for the variability in cell cycle control and DNA repair within humans, and a factor of 10 because the $\mathrm{BMDL}_{10}$ is not a no observed adverse effect level (NOAEL). [27]

\subsection{The genotoxic and carcinogenic herbal constituents evaluated in this thesis}

\subsubsection{Alkenylbenzenes (ABs)}

ABs, including elemicin (3,4,5-trimethoxyallylbenzene), methyleugenol (1allyl-3,4-dimethoxybenzene), myristicin (1-allyl-4,5-methylenedioxy-3methoxybenzene), safrole (1-allyl-3,4- methylene dioxy benzene), apiol (1-allyl-3,4dimethoxybenzene), and estragole (4-allyl-1-methoxybenzene) (Figure 1.1) occur naturally in botanicals used for the production of herbal products. Botanicals such as nutmeg, cinnamon, anise, black pepper, and basil are reported to contain safrole. Methyleugenol occurs mostly in nutmeg, lemongrass, star anise, ginger and fennel. Estragole mainly originates from tarragon, basil, fennel, and star anise. Whereas, 
apiol and myristicin are mostly found in parsley, dill, and nutmeg.[5, 30-32] Humans can be exposed when consuming herbal products containing AB-producingbotanicals. In addition, exposure can result from food products formulated with the essential oils derived from these AB-producing-botanicals. This may include for example food products such as candy, ice cream, soft drinks, alcoholic beverages, sauces and spreads. ${ }^{30-34]}$<smiles>C=CCc1ccc(OC)cc1</smiles>

estragole<smiles>C=CCc1ccc2c(c1)OCO2</smiles>

safrole<smiles>C=CCc1ccc(OC)c(OC)c1</smiles>

methyleugenol<smiles>C=CCc1cc(OC)c2c(c1)OCO2</smiles>

myristicin<smiles>C=CCc1cc(OC)c(OC)c(OC)c1</smiles>

elemicin<smiles>C=CCc1cc(OC)c2c(c1OC)OCO2</smiles>

apiol

Figure 1.1. Chemical structures of the six alkenylbenzenes of interest.

The genotoxicity and carcinogenicity of the ABs require metabolic activation occurring mainly in the liver.[35] Figure 1.2 explains the metabolic pathways of safrole which are also relevant for methyleugenol, estragole and the other ABs. The bioactivation pathway starts with the formation of 1 '-hydroxysafrole in a reaction catalysed by cytochromes P450 (CYP450s).[36, 37] The bioactivation process is continued by the sulfonation of $1^{\prime}$-hydroxysafrole resulting in the formation the ultimate carcinogenic metabolite identified as $1^{\prime}$-sulfoxysafrole in a reaction catalysed by sulfotransferases (SULTs). ${ }^{[38,}$ 39] The unstable $1^{\prime}$-sulfoxysafrole metabolite deteriorates in the aqueous environment to generate a reactive carbocation that covalently binds to various nucleophilic molecules such a proteins, glutathione, RNA, and DNA. Consequently, DNA adducts are formed due to the conjugation of the carbocation at the 1'- position of the $\mathrm{AB}$ and the DNA adducts thus formed are considered to play a role in the subsequent tumor induction. $[5,35,40]$ Figure 1.2 also present the various alternative metabolic pathways that can be considered to represent detoxification pathways. 


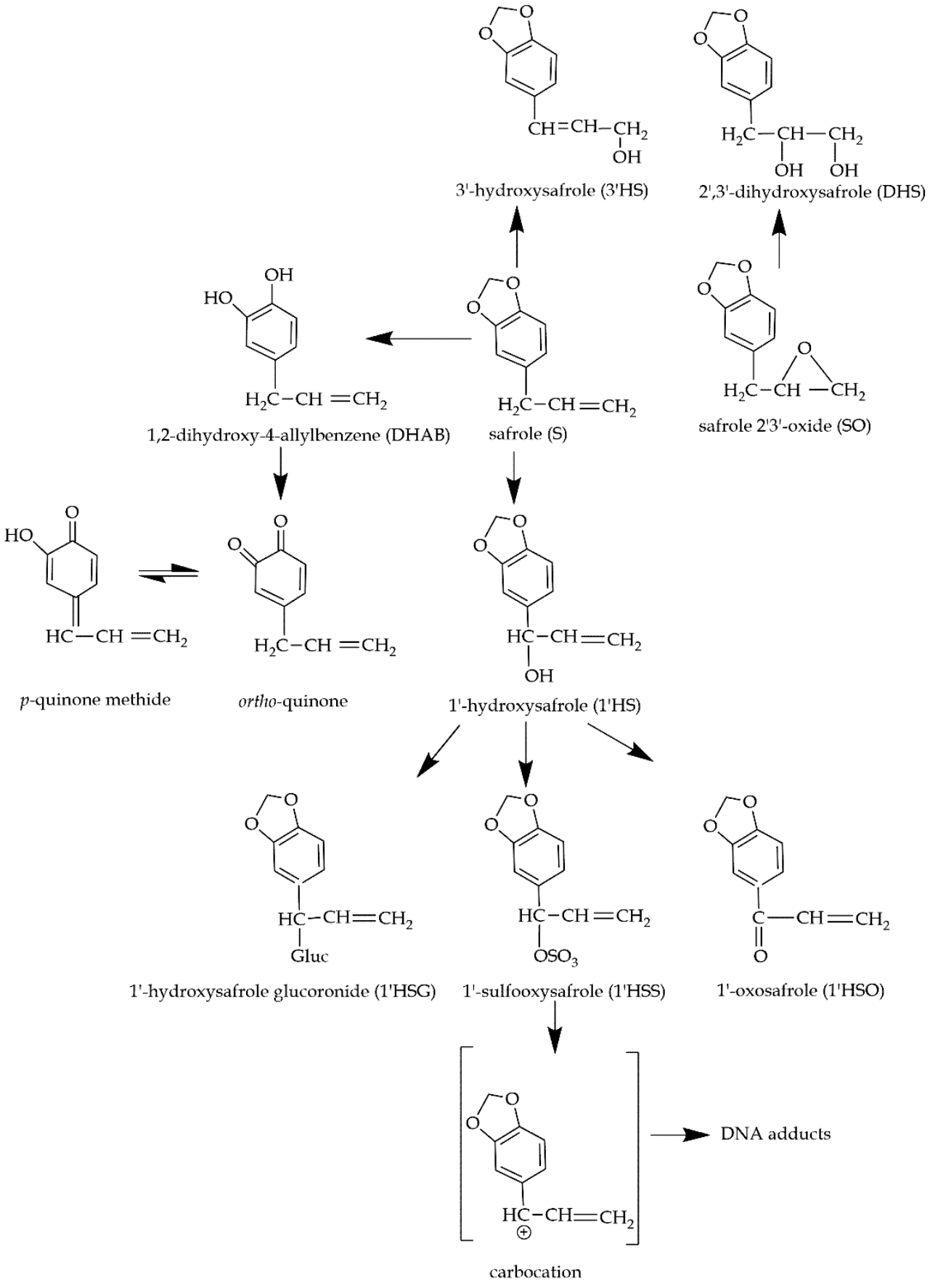

Figure 1.2. Bioactivation pathways of safrole to the proximate and ultimate carcinogen and additional detoxification pathways. 
Given the presence of ABs in botanicals and botanical preparations, recent studies reported on their occurrence, actual levels detected and accompanying risk assessment in plant supplements and other foods. ${ }^{[19,41-45]}$ In these studies the MOE approach was used to assess the risk of $\mathrm{AB}$-containing plant food supplements containing basil, cinnamon, sassafras, nutmeg, fennel or calamus ${ }^{[19,41]}$, dry fennel preparations and related infusions ${ }^{[2]}$, parsley and dill based teas ${ }^{[46],}$ nutmeg-based plant food supplements ${ }^{[4]]}$, basil-based pesto sauces ${ }^{[47]}$ and plant food supplements and traditional Chinese medicines (TCM) and herbal teas ${ }^{[45]}$. Overall these studies showed that the consumption of AB-containing botanicals via these botanical preparations daily during a lifetime period would result in MOE values below 10,000 indicating a potential priority for risk management.

These MOE values are based on daily chronic lifetime exposure, although a shorter period of consumption of the herbal products should be taken into account to better reflect the real-life exposure scenario in which people do not consume these preparations every day during their lifetime. Given that these herbal preparations are often especially consumed during periods of illness it seems essential to also consider shorter than life time exposure scenario's. Although there is no officially established method to evaluate shorter than lifetime exposure to a genotoxic carcinogen, it has been suggested to use Haber's rule to estimate the effects for different exposure duration. ${ }^{[48,49]}$ Haber's rule states that the dose times the effect is constant, $(\mathrm{C} 1 \times \mathrm{T} 1=$ constant $=\mathrm{C} 2 \times \mathrm{T} 2)$ which implies that one could correct for shorter time of exposure in a linear way. Following Haber's rule and assuming consumption only for 2 weeks every year during periods of illness, the EDI values will be 52 weeks per year $/ 2$ weeks $=26$ times lower and thus the MOE values 26 times higher than for lifetime exposure scenario's. In addition, Haber's rule can also be used to calculate the number of weeks of daily consumption of the different herbal products that would result in an MOE value above 10,000, the threshold for risk management concern. ${ }^{[27]}$

\subsubsection{Pyrrolizidine alkaloids (PAs)}

PAs consist of a group of more than 660 naturally occurring plant metabolites derived from an estimated over 600 different species, which are for the most part from the families Asteraceae (Compositae), Boraginaceae and Fabaceae (Leguminosae). ${ }^{[50,51]}$ PAs also may occur in botanical food products due to the contamination of the products with PA-producing botanicals like Symphytum, Petasites, Tussilago, coharvested as weeds. ${ }^{21,24,52]}$

PAs share a common structure based on a 1-hydroxymethylpyrrolizidine (necine base) and are divided into four different structure types, i.e retronecine, 
heliotridine, otonecine, and platynecine type PAs (Figure 1.3A). A necine base is coupled with 1 or 2 necine acids via ester linkages, which based on their esterification patterns result in PAs being categorized as monoesters, cyclic diesters (including monocrotaline and riddeliine) and open diester, like lasiocarpine (Figure 1.3B). In the present thesis, the occurrence of PAs in jamu was studied. Furthermore, the toxicity of monocrotaline a cyclic retronecine-type PA was studied in some more detail. Monocrotaline is categorized as being possibly carcinogenic in humans (category 2B) a classification also applicable for the related PAs lasiocarpine and riddeliine (Figure 1.3B). ${ }^{[53]}$ Recently EFSA (2017) ${ }^{[24]}$ listed monocrotaline as one of the 17 PAs to be monitored for their presence in food and feed due to the possible concern for human health to the exposure to PAs via consumption of tea and herbal infusions.

A

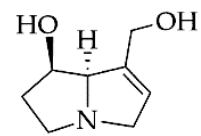

retronecine

B

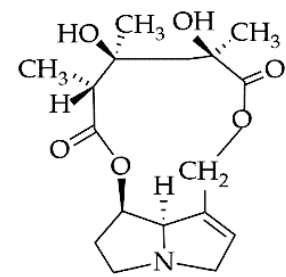

Monocrotaline

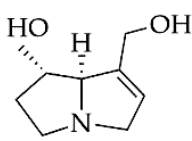

heliotridine

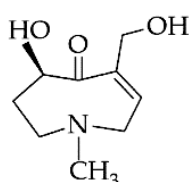

otonecine

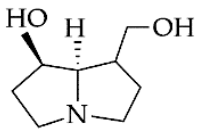

platynecine

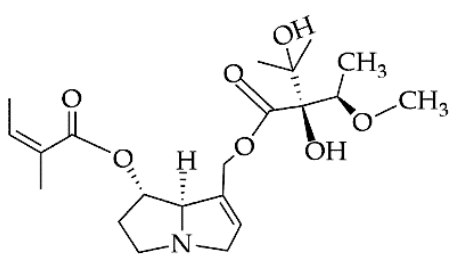

Lasiocarpine

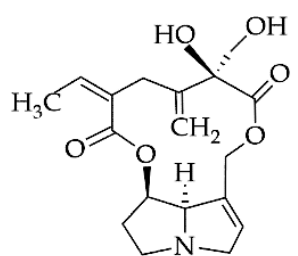

Riddelliine

Figure 1.3. Overview of the 4 types of PAs based on necine bases (A) and the chemical structure of monocrotaline, lasiocarpine and riddeliine (B).

The double bond in 1,2-position of the necine base is required for toxicity of the PAs and at least one hydroxyl group at the ring system has to be esterified for exerting toxic effects. [54] Like all 1,2-unsaturated PAs monocrotaline itself is a protoxin (unreactive compound) requiring metabolic activation by cytochromes P450 to exert hepatic and pulmonary toxicity. ${ }^{[54]}$ CYP3A4 and the CYP2B6 were found to be the major P450 enzymes in metabolic activation of monocrotaline in rat liver.[55, 56] According to another study Ruan et al. (2004) ${ }^{[57]}$, the metabolism of PAs is generally occurring via three pathways, namely hydrolysis, N-oxidation, and dehydrogenation (Figure 1.4). 


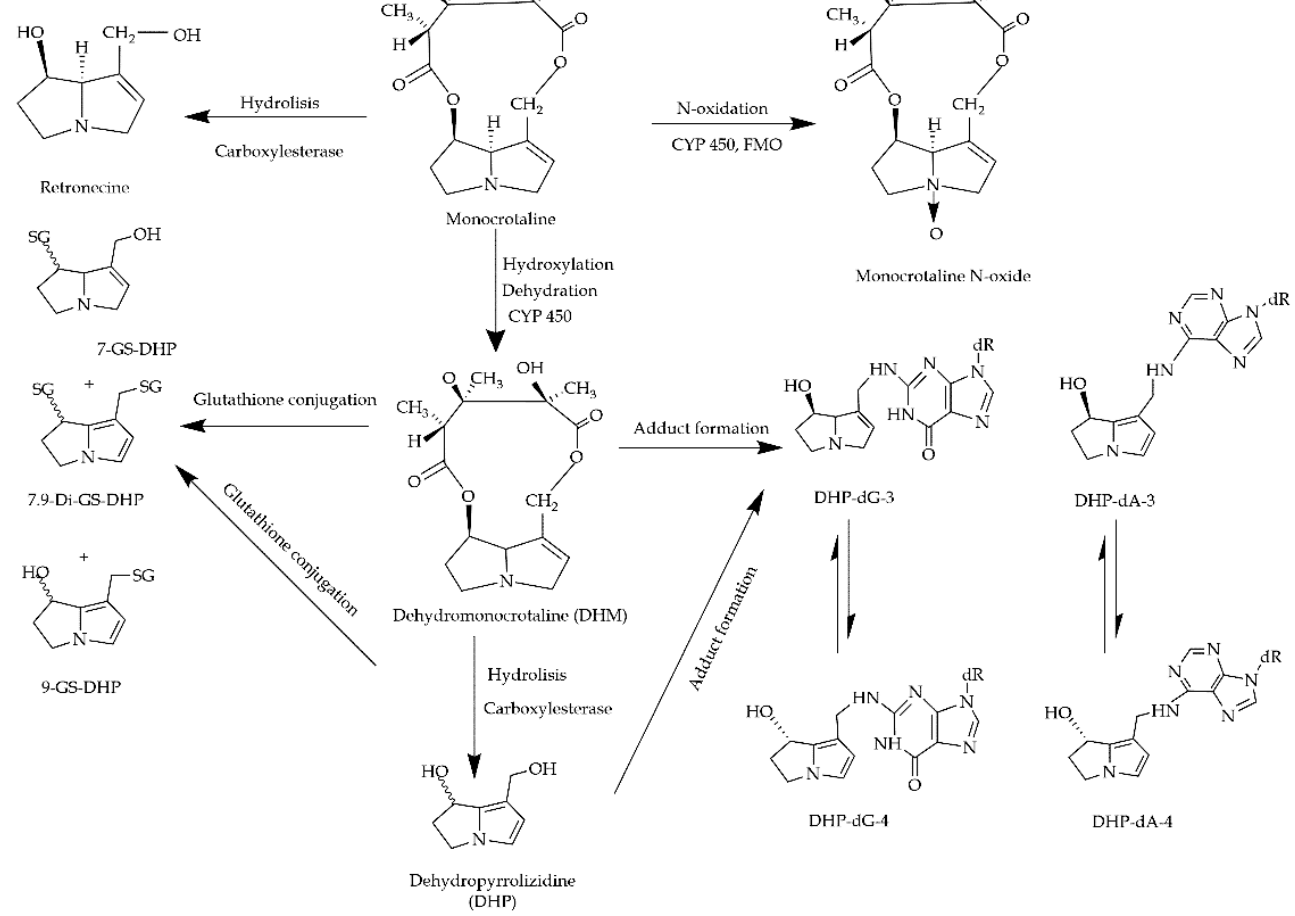

Figure 1.4. Schematic diagram of the metabolic pathways of monocrotaline and DNA adduct formation by monocrotaline metabolites relevant for rat and human. $[55,58,59]$ FMO = flavin-containing monooxygenase, CYP $450=$ cytochromes P450.

Upon dehydrogenation of monocrotaline, an unstable and highly reactive intermediate, named dehydromonocrotaline (DHM) is formed. Eventually, DHM can react with macromolecules including proteins and DNA to form protein- and DNA-adducts, which are considered to be responsible for the toxicity including the genotoxicity and carcinogenicity of monocrotaline. ${ }^{[60-62]}$ Upon hydrolysis of DHM 6,7-dihydro-7-hydroxy-1-hydroxymethyl-5H-pyrrolizine (DHP) is formed that is also able to react with cellular macromolecules including glutathione (GSH) the latter resulting in formation of GSH-DHP and di-GSH-DHP. These conjugates are considered less toxic and more stable, ${ }^{[57,63]}$ although they may still also react with proteins and DNA to form the same DNA adducts formed by DHM and DHP themselves.[64]

For only a few PAs actual tumor data that enable definition of a $\mathrm{BMDL}_{10}$ value for risk management using the MOE approach are available. Initially EFSA (2011) established a $\mathrm{BMDL}_{10}$ value of $0.07 \mathrm{mg} / \mathrm{kg}$ bw/day for lasiocarpine derived from data obtained in a 2-year carcinogenicity study on induction of liver haemangiosarcomas in male rats.[65] A risk assessment based on the MOE approach 
was performed using this $\mathrm{BMDL}_{10}$ value and mean PA levels reported in literature for herbal teas and PFS. The results obtained indicated that consumption of one cup of tea a day during a whole lifetime would result in MOE values lower than 10,000 for several types of herbal teas, indicating a priority for risk management for these products. A refined risk assessment using interim relative potency (REP) factors for different PAs showed that there was a concern for 7 (54\%) of 13 types of herbal teas and $1(14 \%)$ of 7 types of PFS included in the study. A concern for risk management action was also raised for the preparations containing non-PA-producing botanicals, which may contain PAs as a result of co-harvesting of PA containing weeds.

Recently, the EFSA Panel on Contaminants in the Food Chain (CONTAM) established a BMDL 10 of $237 \mu \mathrm{g} / \mathrm{kg}$ body weight per day as POD for calculating the MOE for chronic exposure to PAs, based on tumor data for riddelliine as the reference PA.[24] Using this value of BMDL $_{10}$ Chen et al. (2019) performed a risk assessment for Chinese herbal products.[66] Total PA concentrations that ranged from 404 to $7,883 \mu \mathrm{g} / \mathrm{kg}$ sample in 4 out of 8 samples of Chinese herbal medicines containing PA-producing botanicals, which resulted EDI values of $0.02-0.45 \mu \mathrm{g} / \mathrm{kg}$ bw. MOE values were between 110 and $530(<10,000)$ when assuming lifetime daily consumption indicating that chronic use of these herbal medicines may pose a potential risk for human health. An amount of 4.0-4.2 $\mu \mathrm{g} / \mathrm{kg}$ PAs detected in 2 out of 4 samples containing non-PAs-producing botanicals resulting in EDI values of $0.0003-0.001 \mu \mathrm{g} / \mathrm{kg}$ bw also indicated MOE values < 10,000 when daily consumption for a whole lifetime would be considered, indicating a concern for human health and a priority for risk management action.

The current existing risk assessment on PAs is mainly based on the assumption of equal potency of all PAs detected in the samples and comparison to the $\mathrm{BMDL}_{10}$ of riddelliine, without taking into account differences in relative potency of the PAs present in the samples. Merz and Schrenk (2016) ${ }^{[67]}$ defined interim Relative Potency (REP) factors for the toxic and genotoxic potency of 1,2unsaturated PAs based on the available data on the genotoxic potency in Drosophila melanogaster, the cytotoxic potency in vitro in chicken hepatocellular carcinoma (CLR-2118) cells and their acute toxicity in adult rodents. More recently Louisse et al. (2019) ${ }^{[68]}$ proposed REP factors based on results obtained in the $\gamma \mathrm{H} 2 \mathrm{AX}$ assay in HepaRG human liver cells for 37 PAs showing that open diester PAs (including lasiocarpine) and cyclic diester PAs (including riddelliine) display the highest potency. However due to the limited data on liver toxicity and carcinogenicity upon oral exposure to PAs, available for only lasiocarpine and riddelliine[69, 70], an alternative testing strategy instead of animal studies for estimating the relative toxicity of different PAs would be of use. Furthermore, a translation of the result of 
alternative testing methods to the in vivo situation is required converting in vitro concentration-response curves to in vivo dose-response curves. This can be achieved by using physiologically based kinetic (PBK) modeling-based reverse dosimetry which is explained further in the Section 1.8.

\subsubsection{Aristolochic acids}

Aristolochic acids (AAs) are a group of nephrotoxic and carcinogenic compounds of which the most important congeners are 8-methoxy-6nitrophenanthro-(3,4-d)-1,3-dioxolo-5-carboxylic acid (AA-I) and its 8demethoxylated form (AA-II) ${ }^{[1]}$ (Figure 1.5). Aristolochia debilis, Aristolochia clematitis, Clematis armandii, C. montana, C. chinensis, Akebia quinata, A. trifolatia, Aucklandii lappa, Saussurea lappa and Asarum species are reported as AA-containing botanicals. ${ }^{[72]}$ Herbal medicines containing AA-producing botanicals are reported to be carcinogenic in humans, and as a result IARC [73] classified these preparations as group 1 carcinogens. In addition, AAs are also listed among the most potent $2 \%$ of known carcinogens ${ }^{[53,74]}$.<smiles>COc1cccc2c1cc([N+](=O)[O-])c1c(C(=O)O)cc3c(c12)OCO3</smiles>

Aristolochic Acid I<smiles></smiles>

Aristolochic Acid II

Figure 1.5. Structural formulas of aristolochic acid I (AAI) and aristolochic acid II (AA-II).

Aristolochic Acid Nephropathy (AAN) is potentially a crucial problem in the Asian area since a lot of people in this region still are convinced that traditional Chinese herbal medicines, which frequently contain AA producing plants, are safer than chemically produced 'Western' drugs. ${ }^{[75]}$ AAN was reported in Belgium in 1991, where over 100 young women suffered from end-stage renal disease and in several cases cancer in the kidneys and the upper urinary tract due to the confusing nomenclature, resulting in a replacement of Stephania tetrandra ('Han Fang Ji') by Aristolochia fangchi ('Guang Fang Ji') in a Chinese herb-based weight-loss preparation. ${ }^{[76]}$ Similar to incidences of AAN, Balkan Endemic Nephropathy (BEN) occurring in Balkan regions in the 1950's, was ascribed to flour contaminated with Aristolochia clematitis. ${ }^{[77,78]}$ More cases of AAN were reported in other countries including Spain, Japan, France, Belgium, UK, Taiwan, USA, Germany, China, Korea, Hong Kong, Australia and Bangladesh. The use of AA containing botanicals in food 
was banned worldwide.[79, 80] BPOM RI based on regulation No. 7, 2018, is banning use of the AA-containing botanicals, Aristolochia spp, Stephania tetrandra S.Moore, Magnolia officinalis Rehder \& E.H.Wilson, and their preparations, as ingredients in foods in Indonesia.[81]

In spite of the ban installed in 2001 in The Netherlands, Martena et al. (2007) ${ }^{[82]}$ found that from the 190 Chinese herbal medicines that were collected on the Dutch market between 2002 and 2006 using a targeted approach, 25 still contained AA-I and 13 of these 25 also contained AA-II. Furthermore, in a another study a risk assessment on AA-containing herbal supplements showed that 3 out of 18 samples contained AAs at levels that would result in intakes and corresponding MOE values that point at a priority for risk management.[20]

\subsection{The carotenoids analysed in the thesis for their beneficial effects}

In addition to potential hazards and risks of selected botanical constituents, the thesis also included a study on potential beneficial effects of some selected botanical ingredients. This included the carotenoids bixin and crocetin (Figure 1.6). Carotenoids are red, yellow, and orange pigments that are part of the human diet due to their presence in a variety of fruits, vegetables and other food products. There are two types of carotenoids; the carotenes, which consist of a long-chain conjugated polyene structure without oxygen and the xanthophylls, that possess one or more oxygen containing substituents at particular sites on the terminal rings. ${ }^{[83]}$ The majority of the 600 carotenoids found in nature belong to the carotene group, and include compounds such as lycopene, a-carotene, $\beta$-carotene, $\gamma$-carotene, and $\zeta$ carotene, which contain a long-chain conjugated polyene structure, no oxygen atoms, and are usually orange and red in colour. The xanthophyll group contains constituents like lutein, zeaxanthin, which possess one or more oxygen containing functional groups at particular sites on the terminal rings Figure 1.6 shows the chemicals structures of some carotenoids, including bixin, norbixin and crocetin which are the model carotenoids of the studies in the present thesis. The beneficial effects of carotenoids are considered to be influenced by their number of conjugated double bonds. ${ }^{[83,84]}$ Kiokias and Gordon (2003) ${ }^{[85]}$ reported that polarity also influenced their beneficial effect, with the less polar carotenoids ( $\alpha$-carotenes, $\beta$ carotenes, lycopene and lutein) being more potent than the more polar carotenoids (bixin, capsanthin and capsorubin). 


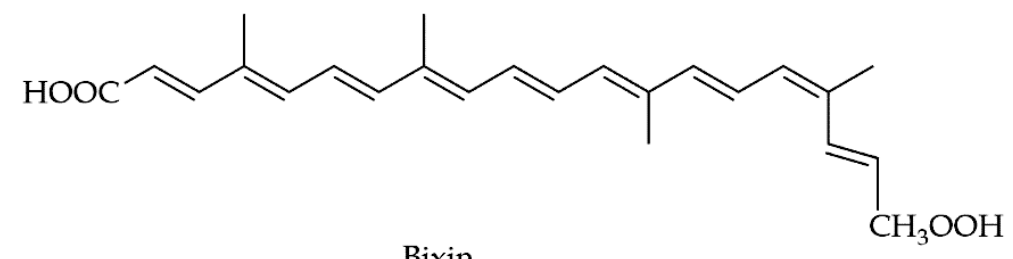

Bixin<smiles>CC(/C=C/C=C(C)/C=C/C(=O)O)=C\C=C\C=C(C)\C=C\C=C(C)\C=C\C(=O)O</smiles><smiles>CC(/C=C/C=C(\C)C(=O)O)=C\C=C\C=C(C)\C=C\C=C(/C)C(=O)O</smiles><smiles>CC1=C[C@H](O)CC(C)(C)[C@H]1/C=C/C(C)=C/C=C/C(C)=C/C=C/C=C(C)/C=C/C=C(C)/C=C/C1=C(C)C[C@@H](O)CC1(C)C</smiles>
Lutein<smiles>CC1=C(/C=C/C(C)=C/C=C/C(C)=C/C=C/C=C(C)/C=C/C=C(C)/C=C/C2=C(C)C[C@@H](O)CC2(C)C)C(C)(C)CCC1</smiles>

Figure 1.6. Chemical structures of some carotenoids including $\beta$-carotene, lycopene, bixin, norbixin and crocetin (carotene group) and lutein and cryptoxanthin (xanthophyll group).

Carotenoid and also bixin and crocetin containing botanical preparations are consumed in many countries, such as India, China, Japan, as a herbal medicine to treat type 2 diabetes mellitus (T2DM).[86, 87] The effects of intake of herbal preparations containing the aforementioned carotenoids on insulin sensitivity is suggested to be due to activation of peroxisome proliferator-activated receptor $\gamma$ (PPARY), a ligand-activated transcription factor and the receptor of the T2DM thiazolidinediones drugs.[88] The activation of PPARY starts by ligand binding, leading to a conformational change in the ligand binding domain. Subsequently PPAR $\gamma$ forms a complex with retinoid $X$ receptor (RXR) (Figure 1.7) upon which the 
complex binds to peroxisome proliferator response elements (PPRE) to regulate gene transcription.

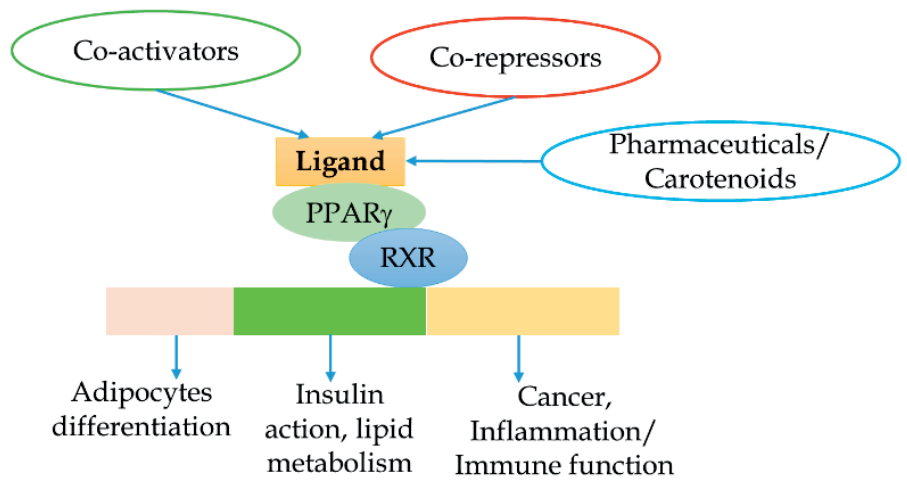

Figure 1.7. Mechanism of gene transcription by PPAR-ץ as modified from Houseknecht et al. (2002).[89]

Upon activation of PPAR $\gamma$, insulin-stimulated glucose uptake increases, free fatty acid levels partly decrease and lipid storage in adipose tissue increases. ${ }^{90]}$ Carotenoids and retinoids inhibited the adipocyte differentiation in 3T3-L1 adipose cells via RAR up-regulation and PPARY2 suppression. [91] The direct interaction of the carotenoid molecules or their derivatives with ligand-activated nuclear receptors, or indirect modification of transcriptional activity of non-liganded transcription factors changes the expression of multiple proteins as the starting event of carotenoid mediated effects on gene transcription. ${ }^{[92]}$ Sharoni and colleagues $(2004)^{[92]}$ reviewed that lycopene, phytoene, phytofluene, and $\beta$-carotene activated peroxisome proliferator response elements (PPREs) in cells co-transfected with PPAR- $\gamma$, although the activation by these compounds was lower than that of wellknown PPAR ligands, like 15-deoxy-D12,14-prostaglandin J2 and ciglitazone. The exploration of carotenoids as alternative drugs to activate PPARY is also of interest given that insulin-sensitizing medications such as synthetic ligands like rosiglitazone, were found to induce adverse side effects, for example weight gain, heart failure and edema, leading to limitations of their use in diabetic patients.[93]

\subsubsection{Bixin}

Bixin (methyl hydrogen 9'-cis-6,6'-diapocarotene-6,6'-dioate, $\mathrm{C}_{25} \mathrm{H}_{30} \mathrm{O}_{4}$ ) belongs to the carotene group. A bixin containing extract prepared from the seed coat of the achiote tree (Bixa orellana $\mathrm{L}$ ) is used as an approved food colorant (E160B) in many products such as butter, cheese, bakery products, oils, ice creams, sausages, and cereals. [94, 95] Also JECFA evaluated bixin containing annatto extracts as food colorant (E160b) and concluded that when all the pigment ingested would be bixin, 
the estimated dietary exposure of $1.5 \mathrm{mg} /$ day would result in an intake of bixin of $26 \mu \mathrm{g} / \mathrm{kg}$ bw per day, which would be below the established acceptable daily intake (ADI) of $6 \mathrm{mg} / \mathrm{kg}$ bw.[96] According to Code of Federal Regulation Tittle 21 (21CFR73.30) of FDA annatto extracts are categorized as colour additives exempt from batch certification, and there is "no maximum level" of annatto usage indicated as long as the use is consistent with good manufacturing practice (GMP). ${ }^{[97]}$ EFSA also evaluated bixin containing annatto extracts (E160b) for use as food additive and concluded the safety of the currently authorised solvent-extracted bixin could not be assessed due to the lack of data, both in terms of identification and toxicological studies. EFSA also indicated that the exposure to bixin of the European population for all age groups was estimated to be below the established ADI of $6 \mathrm{mg} / \mathrm{kg}$ bw per day. ${ }^{[98,99]}$ BPOM RI approved annatto extracts (bixin based) as natural food colorant with Colour Index (CI) Number 75120 and an ADI of 0-12 mg/kg bw. The regulation also determined maximum permitted levels (MPLs) for bixin in many food products in $\mathrm{mg}$ bixin $/ \mathrm{kg}$ food product also defining specifications limiting the amount of norbixin, the hydrolysed form of bixin (Figure 1.6) to $28 \%$ of the bixin level.[100]

Bixin served as an agonist for PPARY in vitro, thus it can be considered a potential functional food-derived compound to regulate adipocyte functions for T2DM treatment. ${ }^{[101-104]}$ Bixin at $70 \mu \mathrm{M}$ significantly activated PPARY 8.2 fold of solvent control in a chimera protein of PPAR $\gamma$ model, at a level that was 2.5-fold in the another luciferase assay using a full-length PPARY protein and PPRE-luciferase reporter plasmid.[102] Studies in experimental animals revealed that bixin shows hypoglycemic activity, while norbixin appeared ineffective to protect against the hyperglycemia and dyslipidemia in streptozotocin-induced diabetic rats. ${ }^{[104]}$ Studies in humans showed that plasma bixin level of volunteers in Quito, Equador reached a maximum, $11.6 \mu \mathrm{g} / \mathrm{L}$ (range $0-18)(0-0.046 \mu \mathrm{M})$ at $2 \mathrm{~h}$ and returned to zero at $8 \mathrm{~h}$ after ingestion of $1 \mathrm{ml}$ of a commercial Annatto Food Color containing $16 \mathrm{mg}$ of bixin ${ }^{[105]}$ showing the systemic bioavailability of the compound upon oral intake.

\subsubsection{Crocetin}

Another carotenoid that is frequently consumed due to its use as food colorant is crocetin $\left(8,8^{\prime}\right.$-diapocarotene- $8,8^{\prime}$-dioic acid) (Figure 1.6). Crocetin occurs naturally in the fruits of gardenia (Gardenia jasminoides Ellis) and in saffron (Crocus sativus L.). ${ }^{[106-109]}$ JECFA recognized saffron, CI. (1975) No 75100, as a food ingredient rather than a food additive, so an ADI was not established for this compound.[110] FDA in 21CFR73.500 exempted saffron (E164), which is known to contain crocetin, from food additives certification.[111] The amount of saffron added to the food is considered safe as long as the procedures follow GMP. In the European Union (EU) 
saffron is not authorized as food additive but is generally considered as a food colorant without E number. ${ }^{[112]}$

Crocetin was reported to enhance insulin sensitivity in insulin resistant rats,[113-116] suggesting its potential preventive and/or therapeutic roles in T2DM. The pharmacokinetic profile of crocetin was described in 10 healthy Filipino volunteers (5 men and 5 women) who consumed a capsule containing crocetin extracted from dried gardenia fruits at three single doses $(7.5,15$ and $22.5 \mathrm{mg})$ with a one-week interval. Maximum plasma concentrations ranged from 100.9 to 279.7 $\mathrm{ng} / \mathrm{mL}(0.31-0.85 \mu \mathrm{M})$ at 4.0 to $4.8 \mathrm{~h}$ after administration, and the compound was eliminated from human plasma with a mean elimination half-life $\left(\mathrm{T}_{1 / 2}\right)$ of 6.1 to 7.5 h. [117]

Given information on the beneficial effects and the pharmacokinetic data of bixin and crocetin in human mentioned above, in the thesis a novel strategy called physiologically based kinetic (PBK) modeling facilitated reverse dosimetry ${ }^{[118]}$ was used to investigate whether at realistic human intake levels actual PPAR $\gamma$ mediated health effects of these compounds can be expected.

\subsection{PBK modeling-based reverse dosimetry as a novel method for the prediction of in vivo toxicity and beneficial effects}

A physiologically based kinetic (PBK) model is a set of mathematical equations which describe the absorption, distribution, metabolism and excretion (ADME) characteristics of a compound within an organism based on three types of parameters. These type of parameters include: i) physiological and anatomical parameters (e.g. cardiac output, tissue volumes and tissue blood flows), (ii) physicochemical parameters (e.g. blood/tissue partition coefficients) and (iii) kinetic parameters (e.g. kinetic constants for metabolic reactions and/or metabolic clearance).[118] The translation of in vitro effective concentrations into in vivo effective dose levels can be achieved using PBK modeling with a reverse dosimetry approach. In this approach in vitro effect concentrations are considered as blood or tissue concentrations that would cause a relevant biological effect in the in vivo situation, upon which the PBK model can calculate the doses which are required to reach these blood or tissue concentrations.[118,119] In this way concentration response curves obtained in vitro can be translated to in vivo dose response curves needed to judge the risks or benefits upon in vivo exposure of the human population.

So far, this approach has been used to translate in vitro toxicity data to in vivo dose response curves for a range of different endpoints, including for example liver toxicity, kidney toxicity, developmental toxicity, genistein induced estrogenicity, and hesperitin induced effects on inhibition of protein kinase A activity.[120-127] The 
approach can be considered a novel non-animal-based testing strategy, contributing to the replacement, reduction and refinement (3Rs) of animal experiments. Recently, Chen et al. (2018) ${ }^{[128]}$ and Ning et al. (2019) ${ }^{[129]}$ developed PBK models and applied PBK model based reverse dosimetry to predict the in vivo liver toxicity of the PAs lasiocarpine and riddeliine in rat and human (Figure 1.8). In this thesis, a similar study was performed for monocrotaline as a model 1,2-unsaturated PAs in order to further investigate if this approach can assist in filling existing gaps in the toxicological data base for PAs.[24]

PBK modeling-facilitated reverse dosimetry approach applied in the present thesis includes the establishment of in vitro concentration-response curves for liver toxicity using rat hepatocytes, development of a PBK model using kinetic parameters based on in vitro assays, translation of the in vitro concentrationresponse curve into an in vivo dose-response curve for liver toxicity using PBK modeling-facilitated reverse dosimetry. Subsequently BMD analysis is applied to the dose-response data in order to obtain a potential POD for risk assessment. In a final step the predicted PBK model and obtained POD are evaluated against available literature data. ${ }^{[128,129]}$ This last step is also why monocrotaline was selected as the model PA given that in vivo data on its kinetics and liver toxicity are available[130-134], enabling evaluation of the PBK model and of predictions made.

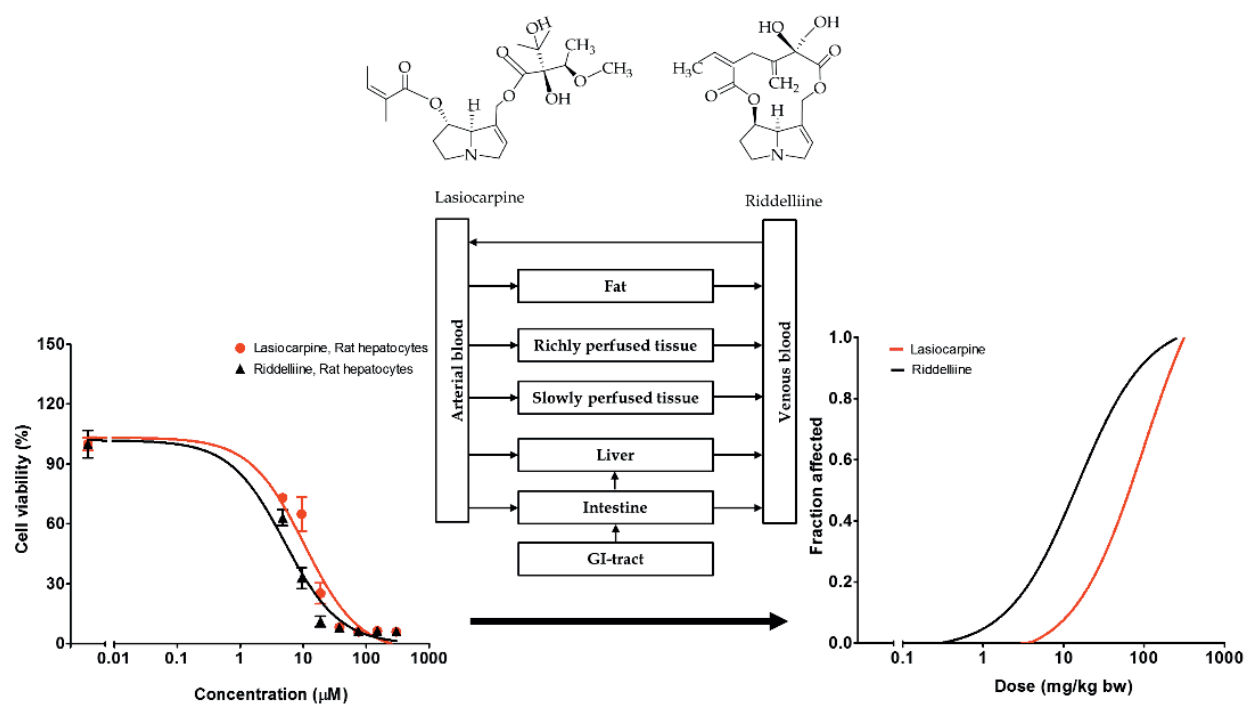

Figure 1.8. Schematic presentation of the PBK model based reverse dosimetry approach to predict the in vivo liver toxicity of lasiocarpine and riddeliine in rats based on an in vitro toxicity curve in rat hepatocytes and a rat PBK model. For further details see literature.[128] 
Apart from its use in novel methods for the assessment of adverse health effects in the process of risk assessment, the PBK modeling-facilitated reverse dosimetry approach can also be used for benefit analysis. In the present study the approach was used to investigate whether PPAR $\gamma$ activating characteristics of bixin and crocetin may be expected at realistic human daily intake levels without the need to perform a human intervention study.

\subsection{Outline of the thesis}

As already explained, the aim of the present thesis was to perform an assessment of potential risks and also some benefits of herbal products available on the Indonesian market. In order to meet this aim, the thesis consists of 7 chapters, the content of which is schematically summarised in Figure 1.9.

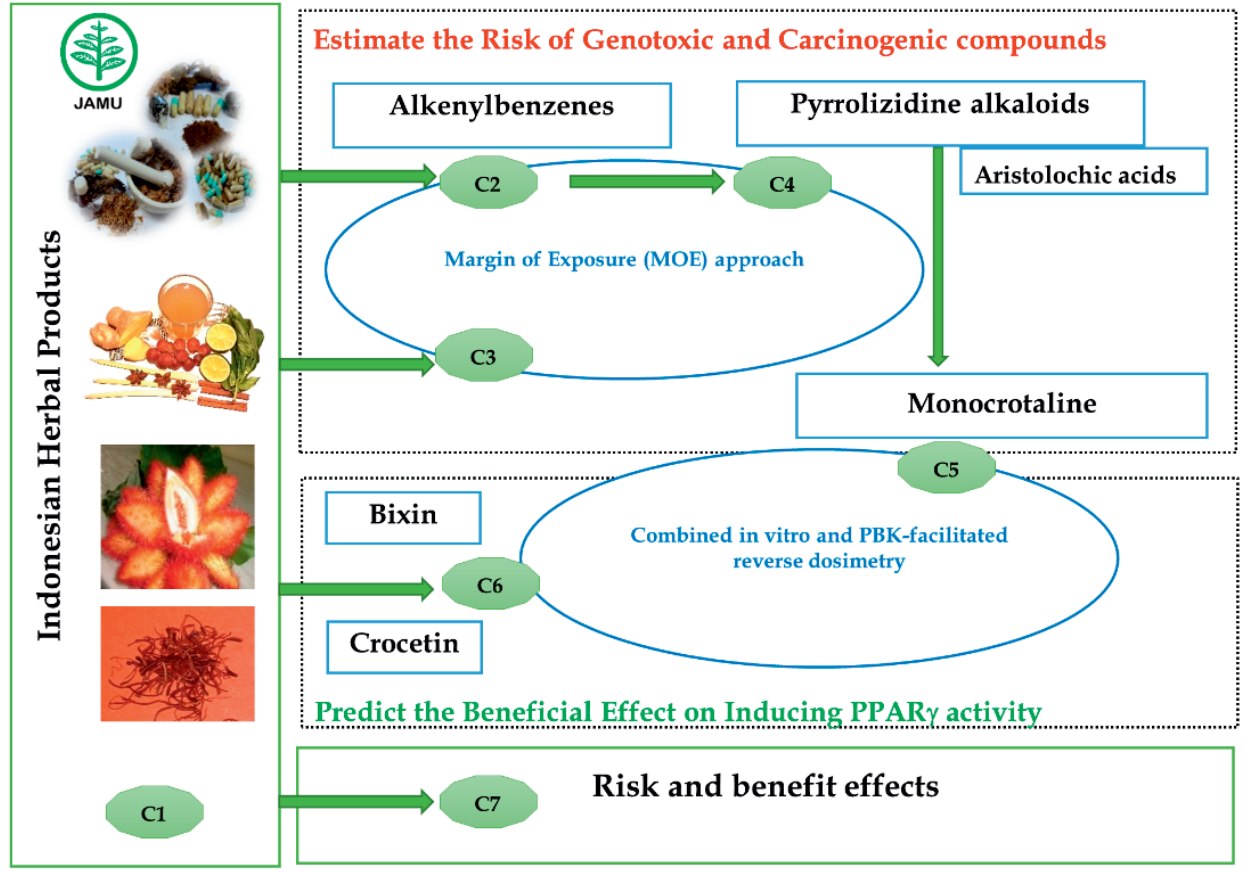

Figure 1.9. Flowchart illustrating the key content of each chapter related to aim of this thesis $(\mathrm{C}=\mathrm{Chapter})$.

The graphical abstract presented in Figure 1.9 summarises the following content of the different chapters of the thesis.

Chapter 1 of the thesis (this chapter) starts with the aim of the thesis followed by an overview about herbal products in Indonesia, consumption trends of herbal products, and the existing regulatory status of herbal products in Indonesia and 
other countries. This is followed by a description of the model compounds selected and used in the studies of the thesis and of the methods used for their evaluation, including the MOE approach for risk assessment of the genotoxic and carcinogenic botanical constituents and the PBK model based reverse dosimetry approach to translate in vitro data to in vivo data. This quantitative in vitro to in vivo extrapolation (QIVIVE) enables comparison of realistic exposure scenarios with estimated human intake levels to evaluate if beneficial or adverse effects could be expected upon intake of relevant preparations.

Chapter 2 of the thesis evaluates the consumer risks of jamu, Indonesian traditional herbal medicines. The levels of ABs in 25 samples collected by a targeted sampling strategy, collecting samples with AB-containing botanical ingredients, were quantified and the amount of $A B s$ that would be consumed through consumption of the respective preparations was quantified. Three different approaches were used for estimating the EDI and subsequent calculation of the MOE values including: considering the individual $A B s$ using their $B_{M D L} 10$ values, combined exposure assuming equal potency of all $A B s$ using the $B_{M D L}$ value of the major $\mathrm{AB}$ in the mixture, and combined exposure using a toxic equivalency (TEQ) approach.

Chapter 3 evaluates whether the level of methyleugenol and related ABs in instant herbal beverages obtained on the Indonesian market would be safe for human consumption. Analysis of the methyleugenol and related AB levels and resulting EDI and MOE values was performed for 114 samples collected on the Indonesian market by a targeted sampling strategy. Model averaging as an update on BMD modeling for toxicological risk assessment was applied to calculate an updated $\mathrm{BMDL}_{10}$ for methyleugenol. An overview was made of the current product registration type indicated on the label of the various herbal beverages to evaluate whether there is a need for establishment of maximum permitted levels (MPLs) in Indonesia also for methyleugenol, given MPLs for the related ABs estragole and safrole are already defined.

Chapter 4 investigates the occurrence of PAs in 58 Indonesian jamu products containing various mixed medicinal plants, including 35 samples containing PAproducing botanicals and 23 samples containing non-PA producing botanicals. Based on the levels of PAs present and directions for use given by the producers, an exposure and safety assessment of consumption of these jamu was performed. In addition, the risk assessment based on PA levels in the samples containing non-PAproducing botanicals was compared to the risk assessment of these samples based on their levels of ABs (detected in Chapter 2) and the AAs detected in 2 of the samples containing AA-producing botanicals. 
Chapter 5 investigates whether an alternative testing strategy including quantitative in vitro to in vivo extrapolation (QIVIVE) can adequately predict the liver toxicity for monocrotaline. Monocrotaline was selected as the model compound because this PA appeared to be one of the few other PAs for which in vivo data on kinetics and liver toxicity are available thus enabling evaluations of the PBK model and of predictions made. PBK modeling facilitated reverse dosimetry was used for conversion of in vitro data for toxicity in primary hepatocytes to quantitatively predict in vivo acute liver toxicity for rat.

Chapter 6 investigates whether the same approach as applied in Chapter 5 would also adequately predict whether a potential therapeutic effect of bixin and crocetin via their supposed PPAR $\gamma$ activating activity may be expected at realistic human daily intake levels. To this end concentration response curves for bixin and crocetin induced activation of PPAR $\gamma$ mediated gene expression in U2OS PPAR $\gamma 2$ reporter gene cells were converted to expected in vivo dose response curves using PBK modeling based reverse dosimetry.

Chapter 7 summarizes the main outcomes obtained in the thesis and compiles the overall discussion. This chapter provides insight regarding the potential of risk assessments to support risk management in formulating regulatory actions to minimize the potential health risk for herbal products for consumers in Indonesia due to the occurrence of toxic ABs, PAs and AAs in these products. Furthermore, this chapter discusses the potential for the application of the PBK model based QIVIVE approach for predicting beneficial as well as adverse effects, without the need for animal experiments and/or human intervention studies. The chapter also present some future perspectives for research on the risks and benefits of botanicals and botanical preparations.

\section{References}

[1] BPOM-RI, Keputusan Kepala Badan Pengawas Obat dan Makanan Republik Indonesia Nomor HK. 00.05.4.2411 tentang Ketentuan Pokok Pengelompokan dan Penandaan Obat Bahan Alam Indonesia, Kepala Badan Pengawas Obat dan Makanan Republik Indonesia 2004. Available at: https://jdih.pom.go.id/. Accessed 24 December 2019.

[2] Riswan, S., Sangat-Roemantyo, H., Jamu as traditional medicine in Java, Indonesia. South Pacific study 2002, 23, 1-10.

[3] Schilter, B., Andersson, C., Anton, R., Constable, A., Kleiner, J., O'Brien, J., Renwick, A. G., Korver, O., Smit, F., Walker, R., Guidance for the safety assessment of botanicals and botanical preparations for use in food and food supplements. Food and Chemical Toxicology 2003, 41, 1625-1649.

[4] Hasler, C. M., Functional foods: Benefits, concerns and challenges-A position paper from the American Council on Science and Health. The Journal of Nutrition 2002, 132, 3772-3781.

[5] Rietjens, I. M. C. M., Slob, W., Galli, C., Silano, V., Risk assessment of botanicals and botanical preparations intended for use in food and food supplements: Emerging issues. Toxicology Letters 2008, 180, 131-136.

[6] Vargas-Murga, L., Garcia-Alvarez, A., Roman-Viñas, B., Ngo, J., Ribas-Barba, L., van den Berg, S. J. P. L., Williamson, G., Serra-Majem, L., Plant food supplement (PFS) market structure in EC Member 
States, methods and techniques for the assessment of individual PFS intake. Food \& Function 2011, 2, 731-739.

[7] Greger, J. L., Dietary Supplement Use: Consumer Characteristics and Interests. The Journal of Nutrition 2001, 131, 1339S-1343S.

[8] BPOM-RI, Dukungan Penuh dalam Percepatan Pengembangan dan Pemanfaatan Jamu dan Fitofarmaka, 2019 Available at: https://www.pom.go.id/new/view/more/berita/17062/Dukungan-Penuhdalam-Percepatan-Pengembangan-dan-Pemanfaatan-Jamu-dan-Fitofarmaka.html. Accessed 22 October 2019.

[9] Walker, R., Criteria for risk assessment of botanical food supplements. Toxicology Letters 2004, 149, 187-195.

[10] Ernst, E., Pittler, M. H., Risks associated with herbal medicinal products. Wiener Medizinische Wochenschrift 2002, 152, 183-189.

[11] Rocha, T., Amaral, J. S., Oliveira, M. B. P. P., Adulteration of dietary supplements by the illegal addition of synthetic drugs: A Review. Comprehensive Reviews in Food Science and Food Safety 2016, 15, 43-62.

[12] Elfahmi, Woerdenbag, H. J., Kayser, O., Jamu: Indonesian traditional herbal medicine towards rational phytopharmacological use. Journal of Herbal Medicine 2014, 4, 51-73.

[13] Low, T. Y., Wong, K. O., Yap, A. L. L., Haan, L. H. J., Rietjens, I. M. C. M., The regulatory framework across international jurisdictions for risks associated with consumption of botanical food supplements. Comprehensive Reviews in Food Science and Food Safety 2017, 16, 821-834.

[14] EFSA, Guidance on safety assessment of botanicals and botanical preparations intended for use as ingredients in food supplements. EFSA Journal 2009, 7(9):1249,1-19.

[15] EFSA, Compendium of botanicals reported to contain naturally occuring substances of possible concern for human health when used in food and food supplements. EFSA Journal 2012, 10(5): 2663, 1-60.

[16] FDA, Dietary Supplement Products \& Ingredients, US Food and Drug Administration 2017 Available at: $\quad$ https://www.fda.gov/Food/DietarySupplements/ProductsIngredients/default.htm. Accessed 16 February 2018.

[17] BPOM-RI, Laporan Tahunan Badan POM 2015. Available at: http://www.pom.go.id/ppid/rar/2016/laptah2014.pdf. Accessed 16 February 2017.

[18] BPOM-RI, Peraturan Kepala Badan Pengawas Obat Dan Makanan Republik Indonesia Nomor : HK.00.05.41.1384 Tentang Kriteria Dan Tata Laksana Pendaftaran Obat Tradisional, Obat Herbal Terstandar Dan Fitofarmaka. 2005, pp. 1-14. Available at: https:// sireka.pom.go.id/requirement/HK.00.05.41.1384-2005.pdf. Accessed 16 March 2017.

[19] van Den Berg, S. J., Restani, P., Boersma, M. G., Delmulle, L., Rietjens, I., Levels of genotoxic and carcinogenic compounds in plant food supplements and associated risk assessment. Food and Nutrition Sciences 2011, 2, 989-1010.

[20] Abdullah, R., Diaz, L. N., Wesseling, S., Rietjens, I. M. C. M., Risk assessment of plant food supplements and other herbal products containing aristolochic acids using the margin of exposure (MOE) approach. Food Additives \& Contaminants: Part A 2017, 34, 135-144.

[21] Bodi, D., Ronczka, S., Gottschalk, C., Behr, N., Skibba, A., Wagner, M., Lahrssen-Wiederholt, M., Preiss-Weigert, A., These, A., Determination of pyrrolizidine alkaloids in tea, herbal drugs and honey. Food Additives and Contaminants - Part A Chemistry, Analysis, Control, Exposure and Risk Assessment 2014, 31, 1886-1895.

[22] Mulder, P. P. J., López, P., Castelari, M., Bodi, D., Ronczka, S., Preiss-Weigert, A., These, A., Occurrence of pyrrolizidine alkaloids in animal- and plant-derived food: results of a survey across Europe. Food Additives \& Contaminants: Part A 2018, 35, 118-133.

[23] Raffo, A., Nicoli, S., Leclercq, C., Quantification of estragole in fennel herbal teas: Implications on the assessment of dietary exposure to estragole. Food and Chemical Toxicology 2011, 49, 370-375.

[24] EFSA, Risks for human health related to the presence of pyrrolizidine alkaloids in honey, tea, herbal infusions and food supplements. EFSA Journal 2017, 15(7): 4908, 1-34.

[25] Barlow, S., Renwick, A. G., Kleiner, J., Bridges, J. W., Busk, L., Dybing, E., Edler, L., Eisenbrand, G., Fink-Gremmels, J., Knaap, A., Kroes, R., Liem, D., Muller, D. J., Page, S., Rolland, V., Schlatter, J., Tritscher, A., Tueting, W., Wurtzen, G., Risk assessment of substances that are both genotoxic and carcinogenic report of an International Conference organized by EFSA and WHO with support of ILSI Europe. Food and Chemical Toxicology : an international journal published for the British Industrial Biological Research Association 2006, 44, 1636-1650. 
[26] Benford, D., DiNovi, M., Setzer, R. W., Application of the margin-of-exposure (MOE) approach to substances in food that are genotoxic and carcinogenic e.g.: Benzo[a]pyrene and polycyclic aromatic hydrocarbons. Food and Chemical Toxicology 2010, 48, S42-S48.

[27] EFSA, Opinion of the Scientific Committee on a request from EFSA related to A Harmonised Approach for Risk Assessment of Substances Which are both Genotoxic and Carcinogenic. EFSA Journal 2005, 282, 1-31.

[28] FAO/WHO, Safety evaluation of certain contaminants in food, World Health Organization 2006.

[29] Cartus, A., Schrenk, D., Current methods in risk assessment of genotoxic chemicals. Food and Chemical Toxicology 2017, 106, 574-582.

[30] SCF, Opinion of the Scientific Committee on Food on Estragole (1-allyl-4-methoxybenzene), Scientific Committee on Food, Belgium 2001. Available at: https:/ / ec.europa.eu/food/sites/food/files/safety/docs/sci-com_scf_out104_en.pdf. Accessed 20 March 2017.

[31] SCF, Opinion of the Scientific Committee on Food on Methyleugenol (4-Allyl-1,2dimethoxybenzene), Scientific Committee on Food, Belgium 2001. Available at: https:/ / ec.europa.eu/food/sites/food/files/safety/docs/sci-com_scf_out102_en.pdf. Accessed 30 April 2017.

[32] SCF, Opinion of the Scientific Committee on Food on the safety of the presence of safrole (1-allyl3,4-methylene dioxybenzene) in flavourings and other food ingredients with flavouring properties. 2002. Available at https://ec.europa.eu/food/sites/food/files/safety/docs/fs_foodimprovement-agents_flavourings-out116.pdf. Accessed 2 April 2017.

[33] Smith, B., Cadby, P., Leblanc, J.-C., Setzer, R. W., Application of the margin of exposure (MOE) approach to substances in food that are genotoxic and carcinogenic: Example: Methyleugenol, CASRN: 93-15-2. Food and Chemical Toxicology 2010, 48, S89-S97.

[34] Smith, R. L., Adams, T. B., Doull, J., Feron, V. J., Goodman, J. I., Marnett, L. J., Portoghese, P. S., Waddell, W. J., Wagner, B. M., Rogers, A. E., Caldwell, J., Sipes, I. G., Safety assessment of allylalkoxybenzene derivatives used as flavouring substances - methyl eugenol and estragole. Food and Chemical Toxicology 2002, 40, 851-870.

[35] Rietjens, I. M. C. M., Boersma, M. G., van der Woude, H., Jeurissen, S. M. F., Schutte, M. E., Alink, G. M., Flavonoids and alkenylbenzenes: Mechanisms of mutagenic action and carcinogenic risk. Mutation Research/Fundamental and Molecular Mechanisms of Mutagenesis 2005, 574, 124-138.

[36] Jeurissen, S. M. F., Punt, A., Boersma, M. G., Bogaards, J. J. P., Fiamegos, Y. C., Schilter, B., van Bladeren, P. J., Cnubben, N. H. P., Rietjens, I. M. C. M., Human cytochrome P450 enzyme specificity for the bioactivation of estragole and related alkenylbenzenes. Chemical Research in Toxicology 2007, 20, 798-806.

[37] Ueng, Y.-F., Hsieh, C.-H., Don, M.-J., Inhibition of human cytochrome P450 enzymes by the natural hepatotoxin safrole. Food and Chemical Toxicology 2005, 43, 707-712.

[38] Ioannides, C., Delaforge, M., Parke, D. V., Safrole: Its metabolism, carcinogenicity and interactions with cytochrome P-450. Food and Cosmetics Toxicology 1981, 19, 657-666.

[39] Wislocki, P. G., Miller, E. C., Miller, J. A., McCoy, E. C., Rosenkranz, H. S., Carcinogenic and mutagenic activities of safrole, 1'-hydroxysafrole, and some known or possible metabolites. Cancer Research 1977, 37, 1883-1891.

[40] Wiseman, R. W., Fennell, T. R., Miller, J. A., Miller, E. C., Further characterization of the DNA adducts formed by electrophilic esters of the hepatocarcinogens 1'-hydroxysafrole and 1'hydroxyestragole in vitro and in mouse liver in vivo, including new adducts at C-8 and N-7 of guanine residues. Cancer research 1985, 45, 3096-3105.

[41] van den Berg, S. J. P. L., Klaus, V., Alhusainy, W., Rietjens, I. M. C. M., Matrix-derived combination effect and risk assessment for estragole from basil-containing plant food supplements (PFS). Food and Chemical Toxicology 2013, 62, 32-40.

[42] van der Linden, S. C., von Bergh, A. R. M., van Vught-Lussenburg, B. M. A., Jonker, L. R. A., Teunis, M., Krul, C. A. M., van der Burg, B., Development of a panel of high-throughput reporter-gene assays to detect genotoxicity and oxidative stress. Mutation Research - Genetic Toxicology and Environmental Mutagenesis 2014, 760, 23-32.

[43] Alajlouni, A. M., Al-Malahmeh, A. J., Isnaeni, F. N., Wesseling, S., Vervoort, J., Rietjens, I. M., Level of alkenylbenzenes in parsley and dill based teas and associated risk assessment using the margin of exposure approach. Journal of Agricultural And Food Chemistry 2016, 64, 8640-8646. 
[44] Al-Malahmeh, A. J., Alajlouni, A. M., Ning, J., Wesseling, S., Vervoort, J., Rietjens, I. M. C. M. C., Determination and risk assessment of naturally occurring genotoxic and carcinogenic alkenylbenzenes in nutmeg-based plant food supplements. Journal of Applied Toxicology 2017, 37, 1254-1264.

[45] Ning, J., Cui, X., Kong, X., Tang, Y., Wulandari, R., Chen, L., Wesseling, S., Rietjens, I. M. C. M., Risk assessment of genotoxic and carcinogenic alkenylbenzenes in botanical containing products present on the Chinese market. Food and Chemical Toxicology 2018, 115, 344-357.

[46] Alajlouni, A. M., Al_Malahmeh, A. J., Kiwamoto, R., Wesseling, S., Soffers, A. E. M. F., Al-Subeihi, A. A. A., Vervoort, J., Rietjens, I. M. C. M., Mode of action based risk assessment of the botanical food-borne alkenylbenzene apiol from parsley using physiologically based kinetic (PBK) modelling and read-across from safrole. Food and Chemical Toxicology 2016, 89, 138-150.

[47] Al-Malahmeh, A. J., Al-ajlouni, A. M., Wesseling, S., Vervoort, J., Rietjens, I. M. C. M., Determination and risk assessment of naturally occurring genotoxic and carcinogenic alkenylbenzenes in basil-containing sauce of pesto. Toxicology Reports 2017, 4, 1-8.

[48] Doull, J., Rozman, K. K., Using Haber's Law to define the margin of exposure. Toxicology 2000, 149, 1-2.

[49] Gaylor, D. W., The use of Haber's Law in standard setting and risk assessment. Toxicology 2000, 149, 17-19.

[50] El-Shazly, A., Wink, M., Diversity of pyrrolizidine alkaloids in the boraginaceae structures, distribution, and biological properties. Diversity 2014, 6, 188-282.

[51] Langel, D., Ober, D., Pelser, P. B., The evolution of pyrrolizidine alkaloid biosynthesis and diversity in the Senecioneae. Phytochemistry Reviews 2011, 10, 3-74.

[52] Schulz, M., Meins, J., Diemert, S., Zagermann-Muncke, P., Goebel, R., Schrenk, D., SchubertZsilavecz, M., Abdel-Tawab, M., Detection of pyrrolizidine alkaloids in German licensed herbal medicinal teas. Phytomedicine 2015, 22, 648-656.

[53] IARC, Agents classified by the IARC Monographs. IARC Monographs on The Identification Of Carcinogenic Hazards To Humans 2017, 1-124.

[54] Mattocks, A. R., Toxicity of pyrrolizidine alkaloids. Nature 1968, 217, 723-728.

[55] Yao, J., Li, C.-g., Gong, L.-k., Feng, C.-c., Li, C.-z., Gao, M., Luan, Y., Qi, X.-m., Ren, J., Hepatic cytochrome P450s play a major role in monocrotaline-induced renal toxicity in mice. Acta Pharmacologica Sinica 2014, 35, 292-300.

[56] Ruan, J., Yang, M., Fu, P., Ye, Y., Lin, G., Metabolic activation of pyrrolizidine alkaloids: Insights into the structural and enzymatic basis. Chemical Research in Toxicology 2014, 27, 1030-1039.

[57] Fu, P. P., Xia, Q., Lin, G., Chou, M. W., Pyrrolizidine alkaloids - genotoxicity, metabolism enzymes, metabolic activation, and mechanisms. Drug Metabolism Reviews 2004, 36, 1-55.

[58] Yang, X., Li, W., Sun, Y., Guo, X., Huang, W., Peng, Y., Zheng, J., Comparative study of hepatotoxicity of pyrrolizidine alkaloids retrorsine and monocrotaline. Chemical Research in Toxicology 2017, 30, 532-539.

[59] Wang, J., Yang, L., Wang, C., Wang, Z., The action of cytochrome p450 enzymes and flavincontaining monooxygenases on the N-oxide of pyrrolizidine alkaloid monocrotaline. Asian Journal of Traditional Medicines 2008, 4, 41-50.

[60] Butler, W. H., Mattocks, A. R., Barnes, A. J. M., Lesions in the liver and lungs of rats given pyrrole derivatives of pyrrolizidine alkaloids. The Journal of Pathology 1970, 100, 169-175.

[61] Lafranconi, M. W., Huxtable, R. J., Hepatic metabolism and pulmonary toxicity of monocrotaline using isolated perfused liver and lung. Biochemical Pharmacology 1984, 33, 2479-2484.

[62] Reid, M. J., Lamé, M. W., Morin, D., Wilson, D. W., Segall, H. J., Involvement of cytochrome P450 $3 \mathrm{~A}$ in the metabolism and covalent binding of ${ }^{14} \mathrm{C}$-monocrotaline in rat liver microsomes. Journal of Biochemical and Molecular Toxicology 1998, 12, 157-166.

[63] Li, W., Wang, K., Lin, G., Peng, Y., Zheng, J., Lysine adduction by reactive metabolite(s) of monocrotaline. Chemical Research in Toxicology 2016, 29, 333-341.

[64] Xia, Q., He, X., Ma, L., Chen, S., Fu, P. P., Pyrrolizidine alkaloid secondary pyrrolic metabolites construct multiple activation pathways leading to DNA adduct formation and potential liver tumor initiation. Chemical Research in Toxicology 2018, 31, 619-628.

[65] EFSA, Scientific opinion on pyrrolizidine alkaloids in food and feed. EFSA Journal 2011, 9(11):2406, $1-134$. 
[66] Chen, L., Mulder, P. P. J., Peijnenburg, A., Rietjens, I. M. C. M., Risk assessment of intake of pyrrolizidine alkaloids from herbal teas and medicines following realistic exposure scenarios. Food and Chemical Toxicology 2019, 130, 142-153.

[67] Merz, K.-H., Schrenk, D., Interim relative potency factors for the toxicological risk assessment of pyrrolizidine alkaloids in food and herbal medicines. Toxicology Letters 2016, 263, 44-57.

[68] Louisse, J., Rijkers, D., Stoopen, G., Holleboom, W. J., Delagrange, M., Molthof, E., Mulder, P. P. J., Hoogenboom, R. L. A. P., Audebert, M., Peijnenburg, A. A. C. M., Determination of genotoxic potencies of pyrrolizidine alkaloids in HepaRG cells using the $\gamma \mathrm{H} 2 \mathrm{AX}$ assay. Food and Chemical Toxicology 2019, 131, 110532,1-12.

[69] NTP, Toxicology and carcinogenesis studies of riddelliine (CAS No. 23246-96-0) in F344/ N rats and B6C3F1 mice (gavage studies). National Toxicology Program Technical Report Series 2003, 1-280.

[70] NTP, Bioassay of lasiocarpine for possible carcinogenicity. National Cancer Institute carcinogenesis technical report series 1978, 39, 1-66.

[71] Kumar, V., Poonam, Prasad, A. K., Parmar, V. S., Naturally occurring aristolactams, aristolochic acids and dioxoaporphines and their biological activities. Natural Product Reports 2003, 20, 565-583.

[72] Heinrich, M., Chan, J., Wanke, S., Neinhuis, C., Simmonds, M. S. J., Local uses of Aristolochia species and content of nephrotoxic aristolochic acid 1 and 2-A global assessment based on bibliographic sources. Journal of Ethnopharmacology 2009, 125, 108-144.

[73] IARC, IARC Monographs on he valuation of carcinogenic risks to humans, IARCPress Lyon France 2002.

[74] Stiborova, M., Frei, E., Arlt, V. M., Schmeiser, H. H., The role of biotransformation enzymes in the development of renal injury and urothelial cancer caused by aristolochic acid: urgent questions and difficult answers. Biomedical papers of the Medical Faculty of the University Palacky, Olomouc, Czechoslovakia 2009, 153, 5-11.

[75] Hong, Y.-T., Fu, L.-S., Chung, L.-H., Hung, S.-C., Huang, Y.-T., Chi, C.-S., Fanconi's syndrome, interstitial fibrosis and renal failure by aristolochic acid in Chinese herbs. Pediatric Nephrology 2006, 21, 577-579.

[76] Gillerot, G., Jadoul, M., Arlt, V. M., de Strihou, C. v. Y., Schmeiser, H. H., But, P. P. H., Bieler, C. A., Cosyns, J.-P., Aristolochic acid nephropathy in a Chinese patient: Time to abandon the term "Chinese herbs nephropathy"? American Journal of Kidney Diseases 2001, 38, E26,1-5.

[77] Arlt, V. M., Stiborova, M., Schmeiser, H. H., Aristolochic acid as a probable human cancer hazard in herbal remedies: a review. Mutagenesis 2002, 17, 265-277.

[78] Jelaković, B., Nikolić, J., Radovanović, Z., Nortier, J., Cosyns, J.-P., Grollman, A. P., Bašić-Jukić, N., Belicza, M., Bukvić, D., Čavaljuga, S., Čvorišćec, D., Cvitković, A., Dika, Ž., Dimitrov, P., Đukanović, L., Edwards, K., Ferluga, D., Fuštar-Preradović, L., Gluhovschi, G., Imamović, G., Consensus statement on screening, diagnosis, classification and treatment of endemic (Balkan) nephropathy. Nephrology, dialysis, transplantation : official publication of the European Dialysis and Transplant Association - European Renal Association 2014, 29, 2020-2027.

[79] Jadot, I., Declèves, A.-E., Nortier, J., Caron, N., An integrated view of aristolochic acid nephropathy: Update of the literature. International Journal of Molecular Sciences 2017, 18, 297, 1-24.

[80] Debelle, F. D., Vanherweghem, J.-L., Nortier, J. L., Aristolochic acid nephropathy: A worldwide problem. Kidney International 2008, 74, 158-169.

[81] BPOM-RI, Peraturan Badan Pengawas Obat dan Makanan Nomor 7 Tahun 2018 Tentang Bahan Baku yang Dilarang dalam Pangan Olahan, Kementerian Hukum dan Hak Asasi Manusia Republik Indonesia, Jakarata 20187. Available at: https://jdih.pom.go.id/. Accessed 12 October 2019.

[82] Martena, M. J., van der Wielen, J. C. A., van de Laak, L. F. J., Konings, E. J. M., de Groot, H. N., Rietjens, I. M. C. M., Enforcement of the ban on aristolochic acids in Chinese traditional herbal preparations on the Dutch market. Analytical and Bioanalytical Chemistry 2007, 389, 263-275.

[83] Krinsky, N. I., The antioxidant and biological properties of the carotenoids. Annals of the New York Academy of Sciences 1998, 854, 443-447.

[84] Britton, G., Structure and properties of carotenoids in relation to function. FASEB journal : official publication of the Federation of American Societies for Experimental Biology 1995, 9, 1551-1558.

[85] Kiokias, S., Gordon, M. H., Dietary supplementation with a natural carotenoid mixture decreases oxidative stress. European Journal of Clinical Nutrition 2003, 57, 1135-1140

[86] Hosseinzadeh, H., Nassiri-Asl, M., Avicenna's (Ibn Sina) the canon of medicine and saffron (Crocus satious): A Review. Phytotherapy Research. 2013, 27, 475-483.

[87] Vilar, D. d. A., Vilar, M. S. d. A., de Lima e Moura, T. F. A., Raffin, F. N., de Oliveira, M. R., Franco, C. F. d. O., de Athayde-Filho, P. F., Diniz, M. d. F. F. M., Barbosa-Filho, J. M., Traditional uses, 
chemical constituents, and biological activities of Bixa orellana L.: a review. The Scientific World Journal 2014, 2014, 857292-857292.

[88] Lehrke, M., Lazar, M. A., The many faces of PPARy. Cell 2005, 123, 993-999.

[89] Houseknecht, K. L., Cole, B. M., Steele, P. J., Peroxisome proliferator-activated receptor gamma (PPARY) and its ligands: A review. Domestic Animal Endocrinology 2002, 22, 1-23.

[90] Grygiel-Górniak, B., Peroxisome proliferator-activated receptors and their ligands: Nutritional and clinical implications - A review. Nutrition Journal 2014, 13, 1-10.

[91] Kawada, T., Kamei, Y., Fujita, A., Hida, Y., Takahashi, N., Sugimoto, E., Fushiki, T., Carotenoids and retinoids as suppressors on adipocyte differentiation via nuclear receptors. BioFactors 2000, 13, 103-109.

[92] Sharoni, Y., Danilenko, M., Dubi, N., Ben-Dor, A., Levy, J., Carotenoids and transcription. Archives of Biochemistry and Biophysics 2004, 430, 89-96.

[93] Rubenstrunk, A., Hanf, R., Hum, D. W., Fruchart, J.-C., Staels, B., Safety issues and prospects for future generations of PPAR modulators. Biochimica et Biophysica Acta (BBA) - Molecular and Cell Biology of Lipids 2007, 1771, 1065-1081.

[94] Chisté, R. C., Yamashita, F., Gozzo, F. C., Mercadante, A. Z., Simultaneous extraction and analysis by high performance liquid chromatography coupled to diode array and mass spectrometric detectors of bixin and phenolic compounds from annatto seeds. Journal of Chromatography A 2011, 1218, 57-63.

[95] Mercadante, A. Z., Steck, A., Pfander, H., Isolation and identification of new apocarotenoids from annatto (Bixa orellana) seeds. Journal of Agricultural and Food Chemistry 1997, 45, 1050-1054.

[96] JECFA, Safety evaluation of certain food additives and contaminants: prepared by the Seventy fourth meeting of the Joint $F A$ 2012. Available at: http://apps.who.int/iris/bitstream/10665/43645/1/9789241660587_eng.pdf. Accessed. 20 march 2018.

[97] FDA, U., 21 CFR 73 30: Annatto Extract, 2009a. Available at: https://www.accessdata.fda.gov/scripts/cdrh/cfdocs/cfcfr/CFRSearch.cfm?fr=73.30. Accessed 20 October 2017.

[98] EFSA and Tard, A., Exposure assessment of annatto colouring principles bixin and norbixin (E 160b) when used as food additives. EFSA Journal 2017, 15(8):4966, 1-17.

[99] EFSA, The safety of annatto extracts (E 160b) as a food additive Panel on Food Additives and Nutrient Sources Added to Food. EFSA Journal 2016;14(8):4544, 1-87.

[100] BPOM-RI, Peraturan Kepala Badan Pengawas obat dan Makanan Republik Indonesia Nomor 37 Tahu 2017 tentang Batas Maksimal Penggunaan Bahan Tambahan Pangan Pewarna, Menteri Hukum dan Hak Asasi Manusia Republik Indonesia, Jakarta 2013.1. Available at: http://jdih.pom.go.id/produk/PERATURAN\%20KEPALA\%20BPOM/Per\%20KBPOM\%20No\% 2037\%20Tahun\%202013\%20Batas\%20Maksimum\%20Penggunaan\%20BTP\%20Pewarna.pdf. Accessed 28 April 2018.

[101] Goto, T., Takahashi, N., Kato, S., Kim, Y.-I., Kusudo, T., Taimatsu, A., Egawa, K., Kang, M.-S., Hiramatsu, T., Sakamoto, T., Uemura, T., Hirai, S., Kobayashi, M., Horio, F., Kawada, T., Bixin activates PPARa and improves obesity-induced abnormalities of carbohydrate and lipid metabolism in mice. Journal of Agricultural and Food Chemistry 2012, 60, 11952-11958.

[102] Takahashi, N., Goto, T., Taimatsu, A., Egawa, K., Katoh, S., Kusudo, T., Sakamoto, T., Ohyane, C., Lee, J. Y., Kim, Y. i., Uemura, T., Hirai, S., Kawada, T., Bixin regulates mRNA expression involved in adipogenesis and enhances insulin sensitivity in 3T3-L1 adipocytes through PPARY activation. Biochemical and Biophysical Research Communications 2009, 390, 1372-1376.

[103] Takahashi, N., Kawada, T., Goto, T., Yamamoto, T., Taimatsu, A., Matsui, N., Kimura, K., Saito, M., Hosokawa, M., Miyashita, K., Fushiki, T., Dual action of isoprenols from herbal medicines on both PPARY and PPARa in 3T3-L1 adipocytes and HepG2 hepatocytes. FEBS Letters 2002, 514, 315-322.

[104] Roehrs, M., Figueiredo, C. G., Zanchi, M. M., Bochi, G. V., Moresco, R. N., Quatrin, A., Somacal, S., Conte, L., Emanuelli, T., Bixin and norbixin have opposite effects on glycemia, lipidemia, and oxidative stress in streptozotocin-induced diabetic rats. International Journal of Endocrinology 2014, 2014.

[105] Levy, L. W., Regalado, E., Navarrete, S., Watkins, R. H., Bixin and norbixin in human plasma: Determination and study of the absorption of a single-dose of annatto food color. Analyst 1997, 122, 977-980. 
[106] Giaccio, M., Crocetin from saffron: An active component of an ancient spice. Critical Reviews in Food Science and Nutrition 2004, 44, 155-172.

[107] Solymosi, K., Latruffe, N., Morant-Manceau, A., Schoefs, B., Colour Additives for Foods and Beverages, Woodhead Publishing, Oxford 2015, pp. 3-34.

[108] Bauernfeind, J. C., Carotenoid vitamin A precursors and analogs in foods and feeds. Journal of Agricultural And Food Chemistry 1972, 20, 456-473.

[109] Carmona, M., Zalacain, A., Sánchez, A. M., Novella, J. L., Alonso, G. L., Crocetin esters, picrocrocin and its related compounds present in Crocus sativus Stigmas and Gardenia jasminoides fruits. Tentative identification of seven new compounds by LC-ESI-MS. Journal of Agricultural and Food Chemistry 2006, 54, 973-979.

[110] JECFA, Safety Evaluation of Certain Food Additives. WHO Food Additives Series 56 2006, 155-161.

[111] FDA, U., 21 CFR 73 500: Saffron, 2009b. Available at: https://www.accessdata.fda.gov/scripts/cdrh/cfdocs/cfcfr/cfrsearch.cfm?fr=73.500. Accessed 20 October 2017.

[112] IACM, Saffron, The International Association of Color Manufacturers (IACM), Washington DC 2017 Available at: https://www.iacmcolor.org/safety-of-color/natural-colors/saffron/. Accessed 4 October 2017.

[113] Xi, L., Qian, Z., Shen, X., Wen, N., Zhang, Y., Crocetin prevents dexamethasone-induced insulin resistance in rats. Planta Medica 2005, 71, 917-922.

[114] Xi, L., Qian, Z., Xu, G., Zheng, S., Sun, S., Wen, N., Sheng, L., Shi, Y., Zhang, Y., Beneficial impact of crocetin, a carotenoid from saffron, on insulin sensitivity in fructose-fed rats. Journal of Nutritional Biochemistry 2007, 18, 64-72.

[115] Sheng, L., Qian, Z., Shi, Y., Yang, L., Xi, L., Zhao, B., Xu, X., Ji, H., Crocetin improves the insulin resistance induced by high-fat diet in rats. British Journal of Pharmacology 2008, 154, 1016-1024.

[116] Hazman, O., Aksoy, L., Buyukben, A., Effects of crocin on experimental obesity and type-2 diabetes. Turkish Journal of Medical Sciences 2016, 46, 1593-1602.

[117] Umigai, N., Murakami, K., Ulit, M. V., Antonio, L. S., Shirotori, M., Morikawa, H., Nakano, T., The pharmacokinetic profile of crocetin in healthy adult human volunteers after a single oral administration. Phytomedicine 2011, 18, 575-578.

[118] Rietjens, I. M. C. M., Louisse, J., Punt, A., Tutorial on physiologically based kinetic modeling in molecular nutrition and food research. Molecular Nutrition and Food Research 2011, 55, 941-956.

[119] Louisse, J., Beekmann, K., Rietjens, I. M., Use of physiologically based kinetic modeling-based reverse dosimetry to predict in vivo toxicity from in vitro data. Chemical Research in Toxicology 2017, 30, 114-125.

[120] Abdullah, R., Alhusainy, W., Woutersen, J., Rietjens, I. M. C. M., Punt, A., Predicting points of departure for risk assessment based on in vitro cytotoxicity data and physiologically based kinetic (PBK) modeling: The case of kidney toxicity induced by aristolochic acid I. Food and Chemical Toxicology 2016, 92, 104-116.

[121] Al-Subeihi, A. A. A., Spenkelink, B., Punt, A., Boersma, M. G., van Bladeren, P. J., Rietjens, I. M. C. M., Physiologically based kinetic modeling of bioactivation and detoxification of the alkenylbenzene methyleugenol in human as compared with rat. Toxicology and Applied Pharmacology 2012, 260, 271-284.

[122] Gargas, M. L., Tyler, T. R., Sweeney, L. M., Corley, R. A., Weitz, K. K., Mast, T. J., Paustenbach, D. J., Hays, S. M., A toxicokinetic study of inhaled ethylene glycol monomethyl ether (2-ME) and validation of a physiologically based pharmacokinetic model for the pregnant rat and human. Toxicology and Applied Pharmacology 2000, 165, 53-62.

[123] Adam, A. H. B., Zhang, M., de Haan, L. H. J., van Ravenzwaay, B., Louisse, J., Rietjens, I. M. C. M., The in vivo developmental toxicity of diethylstilbestrol (DES) in rat evaluated by an alternative testing strategy. Archives of Toxicology 2019, 93, 2021-2033

[124] Li, H., Zhang, M., Vervoort, J., Rietjens, I. M. C. M., van Ravenzwaay, B., Louisse, J., Use of physiologically based kinetic modeling-facilitated reverse dosimetry of in vitro toxicity data for prediction of in vivo developmental toxicity of tebuconazole in rats. Toxicology Letters 2017, 266, 8593.

[125] Punt, A., Paini, A., Boersma, M. G., Freidig, A. P., Delatour, T., Scholz, G., Schilter, B., Bladeren, P. J. v., Rietjens, I. M. C. M., Use of physiologically based biokinetic (PBBK) modeling to study estragole bioactivation and detoxification in humans as compared with male rats. Toxicological Sciences 2009, 110, 255-269. 
[126] Boonpawa, R., Spenkelink, A., Punt, A., Rietjens, I. M. C. M., Physiologically based kinetic modeling of hesperidin metabolism and its use to predict in vivo effective doses in humans. Molecular Nutrition \& Food Research. 2017a, 1600894, 1-14.

[127] Boonpawa, R., Spenkelink, A., Punt, A., Rietjens, I. M. C. M., In vitro-in silico-based analysis of the dose-dependent in vivo oestrogenicity of the soy phytoestrogen genistein in humans. British Journal of Pharmacology 2017b, 174, 2739-2757.

[128] Chen, L., Ning, J., Louisse, J., Wesseling, S., Rietjens, I. M. C. M., Use of physiologically based kinetic modelling-facilitated reverse dosimetry to convert in vitro cytotoxicity data to predicted in vivo liver toxicity of lasiocarpine and riddelliine in rat. Food and Chemical Toxicology 2018, 116, 216-226.

[129] Ning, J., Chen, L., Strikwold, M., Louisse, J., Wesseling, S., Rietjens, I. M. C. M., Use of an in vitroin silico testing strategy to predict inter-species and inter-ethnic human differences in liver toxicity of the pyrrolizidine alkaloids lasiocarpine and riddelliine. Archives of Toxicology 2019, 93, 801-818

[130] Estep, J. E., Lame, M. W., Morin, D., Jones, A. D., Wilson, D. W., Segall, H. J., [ $\left.{ }^{14} \mathrm{C}\right]$ monocrotaline kinetics and metabolism in the rat. Drug Metabolism and Disposition: The Biological Fate of Chemicals 1991, 19, 135-139.

[131] Mattocks, A. R., Acute hepatotoxicity and pyrrolic metabolites in rats dosed with pyrrolizidine alkaloids. Chemico-Biological Interactions 1972, 5, 227-242.

[132] Copple, B. L., Rondelli, C. M., Maddox, J. F., Hoglen, N. C., Ganey, P. E., Roth, R. A., Modes of cell death in rat liver after monocrotaline exposure. Toxicological Sciences 2004, 77, 172-182.

[133] Copple, B. L., Ganey, P. E., Roth, R. A., Liver inflammation during monocrotaline hepatotoxicity. Toxicology 2003, 190, 155-169.

[134] Lachant, D. J., Meoli, D. F., Haight, D., Lyons, J. A., Swarthout, R. F., White, R. J., Low dose monocrotaline causes a selective pulmonary vascular lesion in male and female pneumonectomized rats. Experimental Lung Research 2018, 44, 51-61. 


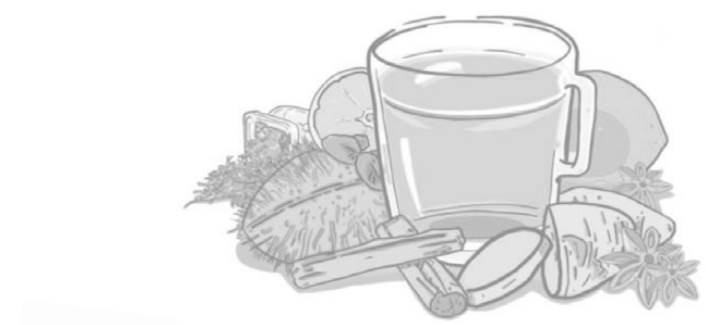

BENEFIT

RISK 


\section{Chapter 2}

Natural occurrence of genotoxic and carcinogenic alkenylbenzenes in Indonesian jamu and evaluation of consumer risks

Suparmi Suparmi

Diana Widiastuti

Sebastiaan Wesseling

Ivonne M.C.M. Rietjens

Published in: Food and Chemical Toxicology, 118 (2018): 53-67 DOI: 10.1016/j.fct.2018.04.059

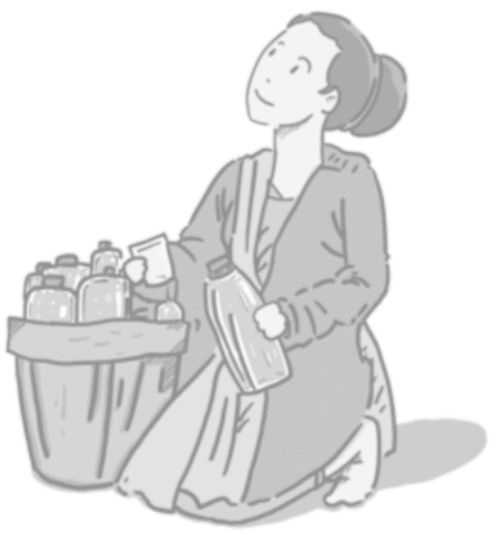




\section{Abstract}

The consumer risks of jamu, Indonesian traditional herbal medicines, was assessed focussing on the presence of alkenylbenzene containing botanical ingredients. Twenty-three out of 25 samples contained alkenylbenzenes at levels ranging from $3.8-440 \mu \mathrm{g} / \mathrm{kg}$, with methyleugenol being the most frequently encountered alkenylbenzene. The estimated daily intake (EDI) resulting from jamu consumption was estimated to amount to $0.2-171 \mu \mathrm{g} / \mathrm{kg}$ bw/day for individual alkenylbenzenes, to $0.9-203 \mu \mathrm{g} / \mathrm{kg}$ bw/day when adding up all alkenylbenzenes detected, and to 0.9$551 \mu \mathrm{g} / \mathrm{kg} \mathrm{bw} /$ day when expressed in methyleugenol equivalents using interim relative potency (REP) factors. The margin of exposure (MOE) values obtained were generally $<10,000$ indicating a priority for risk management when assuming daily consumption. Using Haber's rule it was estimated that two weeks consumption of these jamu only once would not raise a concern (MOE $>10,000)$. However, when considering use for two weeks every year during a lifetime, 5 samples still raise a concern. It is concluded that the consumption of alkenylbenzene containing jamu can be of concern especially when consumed on a daily basis for longer periods of time on a regular basis. 


\subsection{Introduction}

Indonesian jamu represents one of the traditional herbal medicines, for which the efficacy claims are mainly based on user experiences for many decades or even hundreds of years. ${ }^{[1]}$ Generally, the formula of jamu consist of selected and mixed medicinal plants to get the desired efficacy, usually from whole, fragmented or cut plants, and parts of plants. ${ }^{[2]}$ In Indonesia, jamu is commercially available in many forms, including powder, liquid and/or plant simplicia, which are readily consumed by adding hot water and drinking the resulting preparation. The manufactures of jamu generally recommend daily uses, regularly 1-3 times a day for treatment of one or versatile diseases. Currently, jamu represents a major traditional medicine system in the world, being applied especially in Malaysia, Singapore, Hong Kong, Australia, and the Netherlands, where Indonesian communities are large. In order to support the development of jamu, most of the available scientific studies focused on their efficacy, ${ }^{[3-6]}$ while the safety and risks of frequent and prolonged consumption of jamu have not yet been evaluated.

It has been recognised that the safety, efficacy, quality and standardization of botanical ingredients in general and/or of jamu should be controlled to reach safer and more effective products. ${ }^{[7-9]}$ The existing law in Indonesia has not explicitly regulated the maximum limit of natural compounds present in jamu. The National Agency for Drug and Food Control, Republic of Indonesia (NADFC RI) reported that there were 48 and 16 electronic reports related to the adverse effects of consumption of traditional herbal medicines and health supplements in 2015 and 2016, respectively. ${ }^{[10,11]}$ An example is the detection of carcinogenic aflatoxin B1, B2 and G2 in 14 jamu preparations.[12] In addition to these mycotoxin contaminants, jamu may also contain botanical ingredients that may raise a concern because they are genotoxic and carcinogenic. This includes for example the presence of botanicals that contain alkenylbenzenes, including compounds like estragole, methyleugenol, elemicin, safrole, myristicin, and apiol (Figure 2.1) which have previously been shown to be naturally occurring in plant food supplement (PFS) and herbal teas and a possible priority for risk management,[13-18] Alkenylbenzenes can occur in one or more of the medicinal herbs and plants used in jamu. Cinnamon (Cinnamomum burmannii Blume.) as one of the well-known spices in Indonesia and present in almost all jamu products may contain safrole,[19] myristicin, ${ }^{[20]}$ and estragole.[16] Nutmeg (Myristica fragnan Houtt.) contains myristicin, estragole, safrole, elemicin, and methyeugenol.[16, 21] Thymus vulgaris L. folium contains estragole and methyleugenol.[22] And estragole, myristicin and apiol are occurring in semen of Nigella sativa L.[23] and fennel (Foeniculum vulgare Mill.).[24] 
<smiles>C=CCc1ccc(OC)cc1</smiles>

estragole<smiles>C=CCc1ccc2c(c1)OCO2</smiles>

safrole<smiles>C=CCc1ccc(OC)c(OC)c1</smiles>

methyleugenol<smiles>C=CCc1cc(OC)c2c(c1)OCO2</smiles>

myristicin<smiles>C=CCc1cc(OC)c(OC)c(OC)c1</smiles>

elemicin<smiles>C=CCc1cc(OC)c2c(c1OC)OCO2</smiles>

apiol

Figure 2.1. Structural formulas of alkenylbenzenes that are genotoxic and carcinogenic.

The DNA reactive properties of alkenylbenzenes have been well documented in in vitro and in vivo studies and even in humans. ${ }^{[22,25]}$ In human liver samples $N^{2}-$ (trans-methylisoeugenol-3'-yl)-2'-deoxyguanosine adducts were detected.[26-28] Safrole is categorized in IARC group 2B, probably carcinogenic to humans based on its carcinogenicity in rodent bioassays at high dose levels.[29-31] Estragole and methyleugenol are considered to be genotoxic and carcinogenic. [16, 32, 33]

The aim of the present study was to analyse the natural occurrence of alkenylbenzenes in 25 Indonesian jamu containing various mixed medicinal plants, and to evaluate the consumer risk of use of these jamu using the margin of exposure (MOE) approach. This MOE approach is recommended by expert groups of the European Food Safety Authority (EFSA), the Joint FAO/WHO expert committee on Food Additives (JECFA) and the International Life Sciences Institute (ILSI) for risk assessment of exposure to compounds that are both genotoxic and carcinogenic. ${ }^{[34-}$ 37] The results can be used to inform risk management to prioritize regulatory actions to reduce potential risks connected to jamu consumption and to define a safe jamu policy in Indonesia.

\subsection{Materials and methods}

\subsubsection{Preparation of samples}

A total of 25 jamu were collected from the traditional markets or jamu stores focussing on jamu samples with the name of possible alkenylbenzene containing botanicals on the label. The botanical names used in this targeted sampling were fennel (Foeniculum vulgare Mill.), bettel pepper (Piper betle L.), cinnamon (Cinnamomum burmannii Blume.), nutmeg (Myristica fragrans Houtt.), and ginger 
(Zingiber officinale Rosc.). Details on the 25 jamu samples are presented in Table 2.1. The health claims written on the label are also presented in Table 2.1, while the class of disease listed in Table 2.1 was based on the International Classification of Diseases ver. 10.[38] The 25 jamu samples were purchased from jamu stores in Tegal (one store, 6 samples), Semarang (3 stores, each providing 2-3 samples), Surakarta (one store, 4 samples), and Nganjuk (3 stores, each providing 2-5 samples), as depicted in Figure 2.2 .

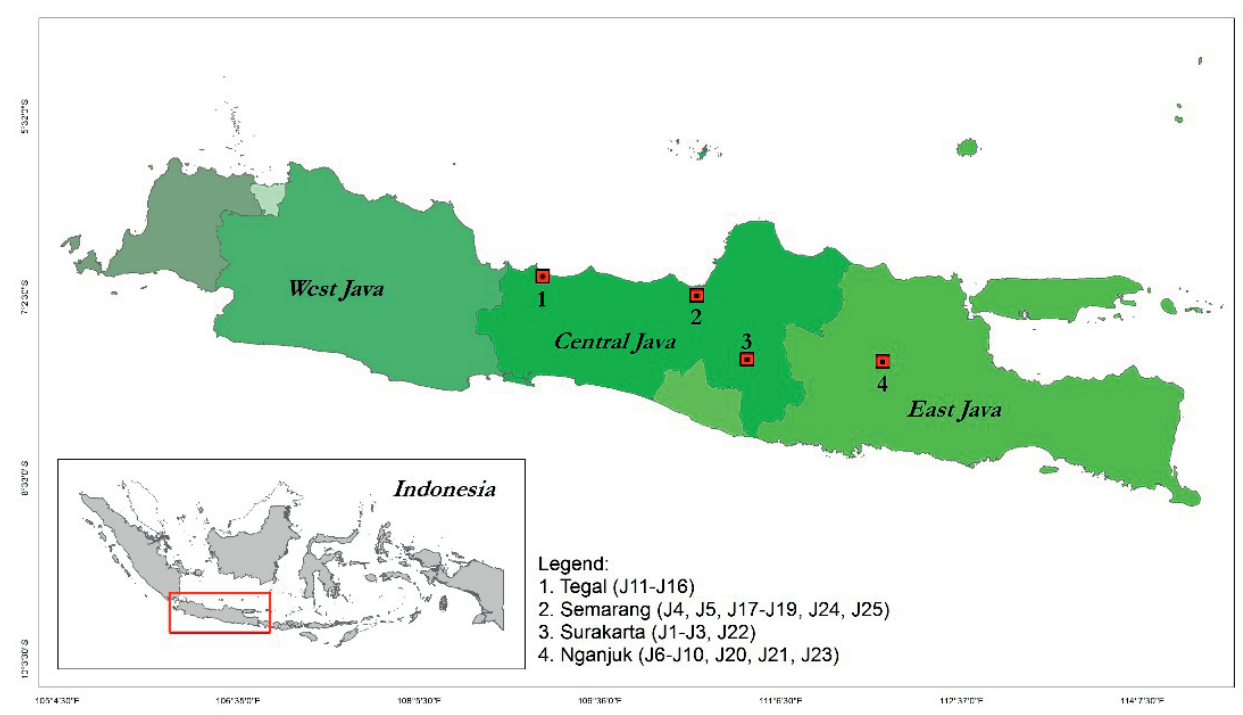

Figure 2.2. Sampling locations of jamu in East Java and Central Java Provinces, Indonesia. J1 until J25 represent the sample IDs used in the present study.

All of these samples were in powder form, packaged in sealed and labelled plastic sachet with net weights ranging between 5-7 g each (Table 2.1). The homogeneity of each sample was ensured by mixing manually in a ziplock plastic packet before taking samples for analysis. 


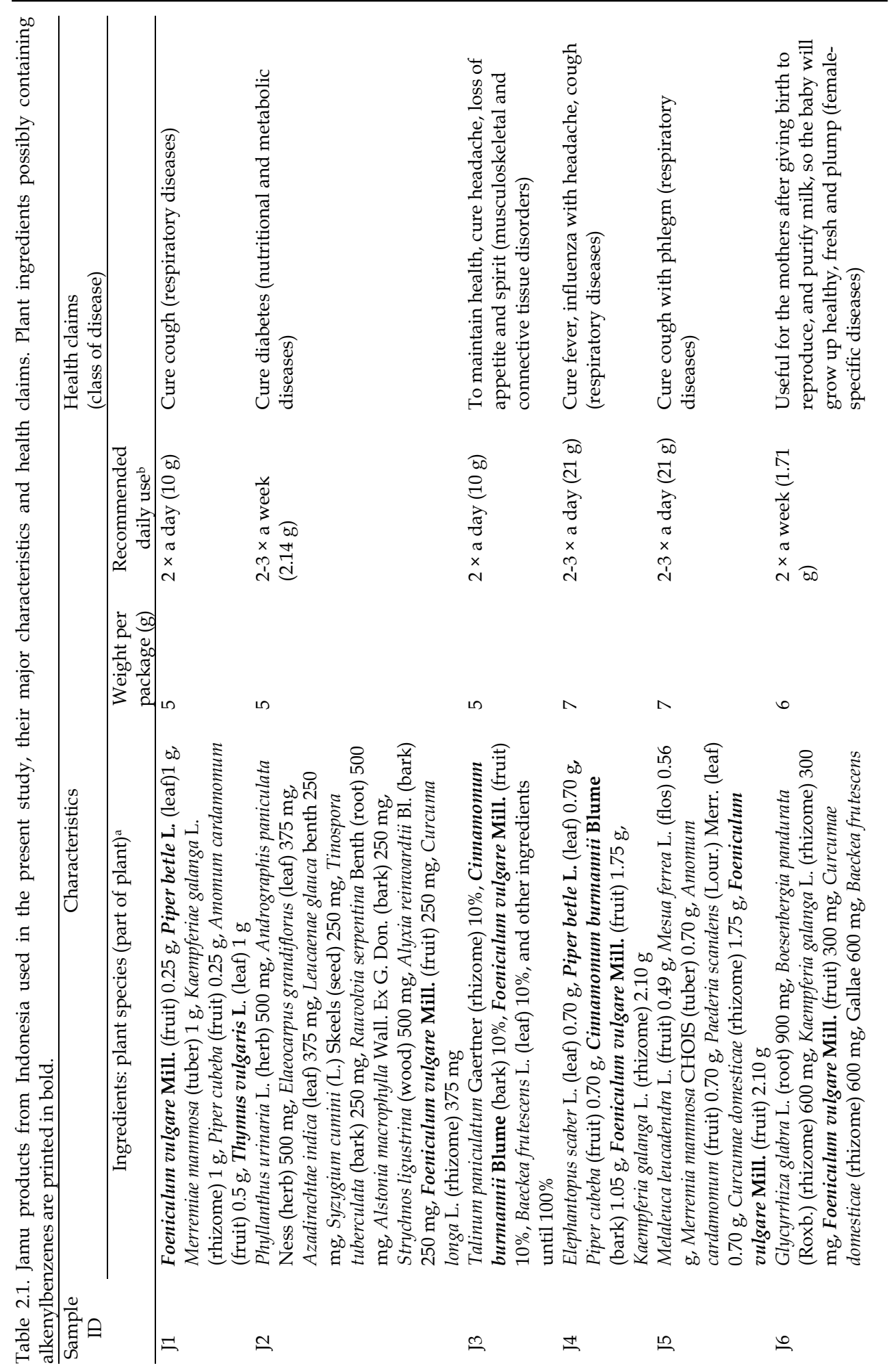




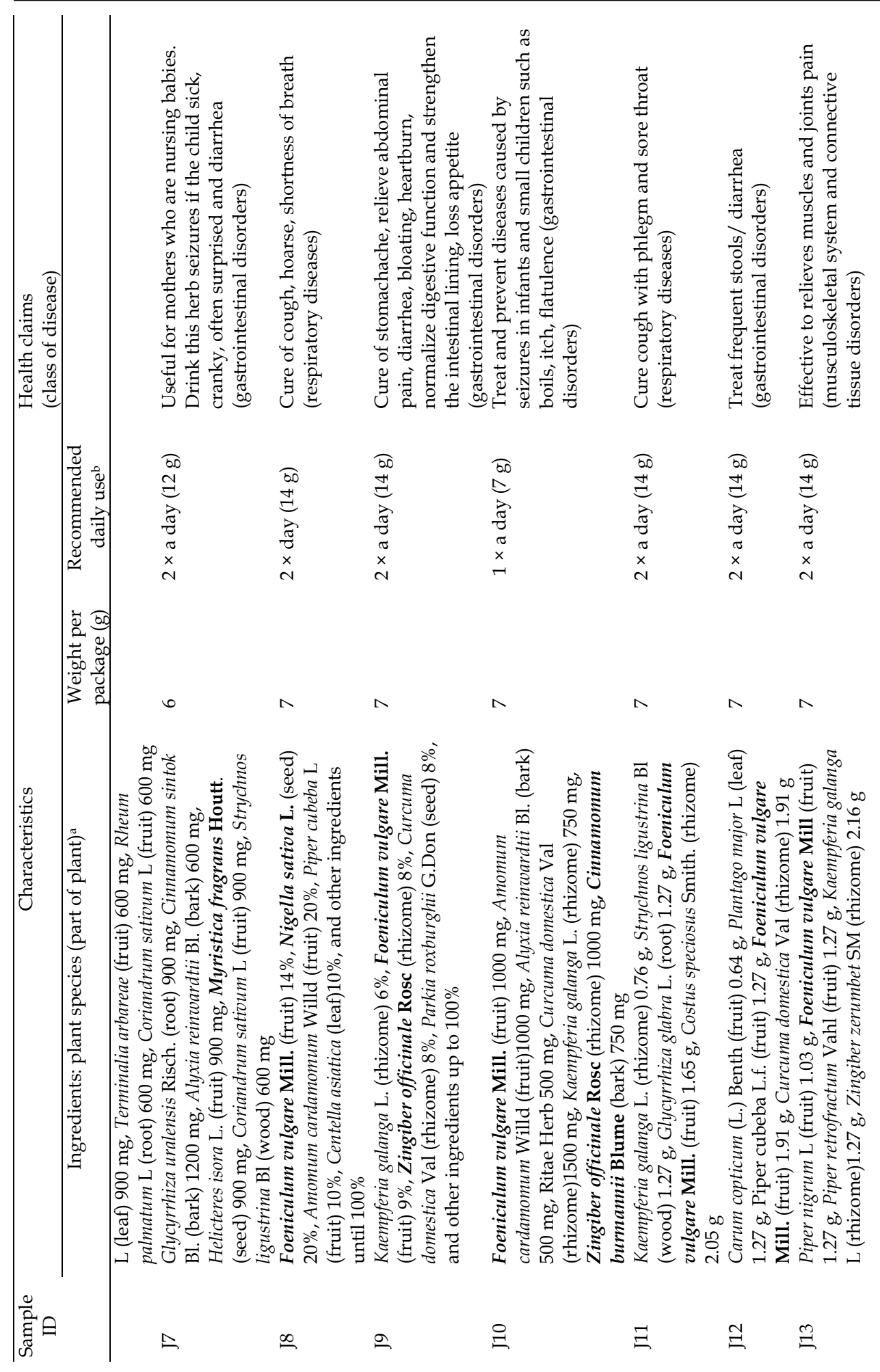




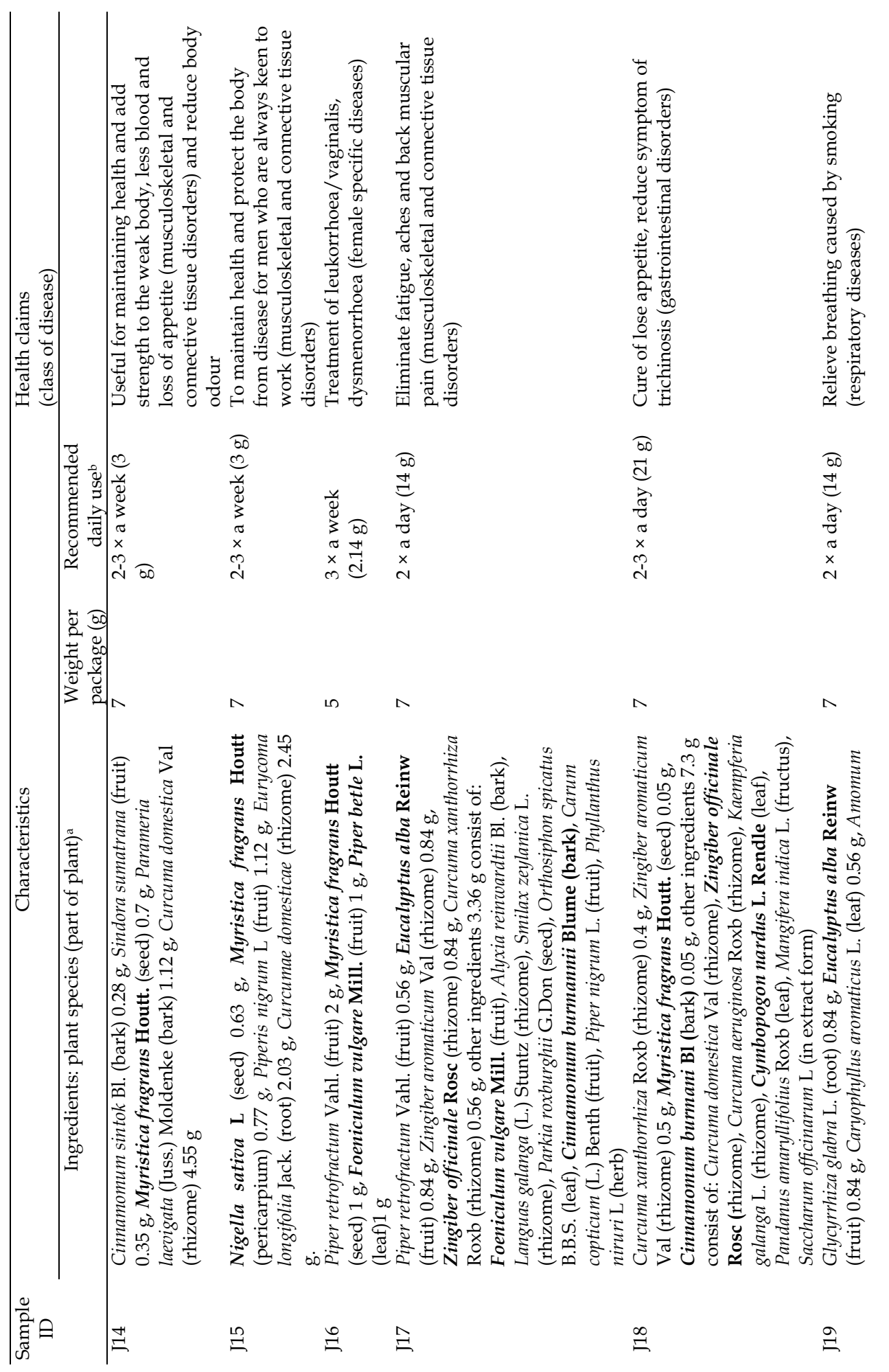




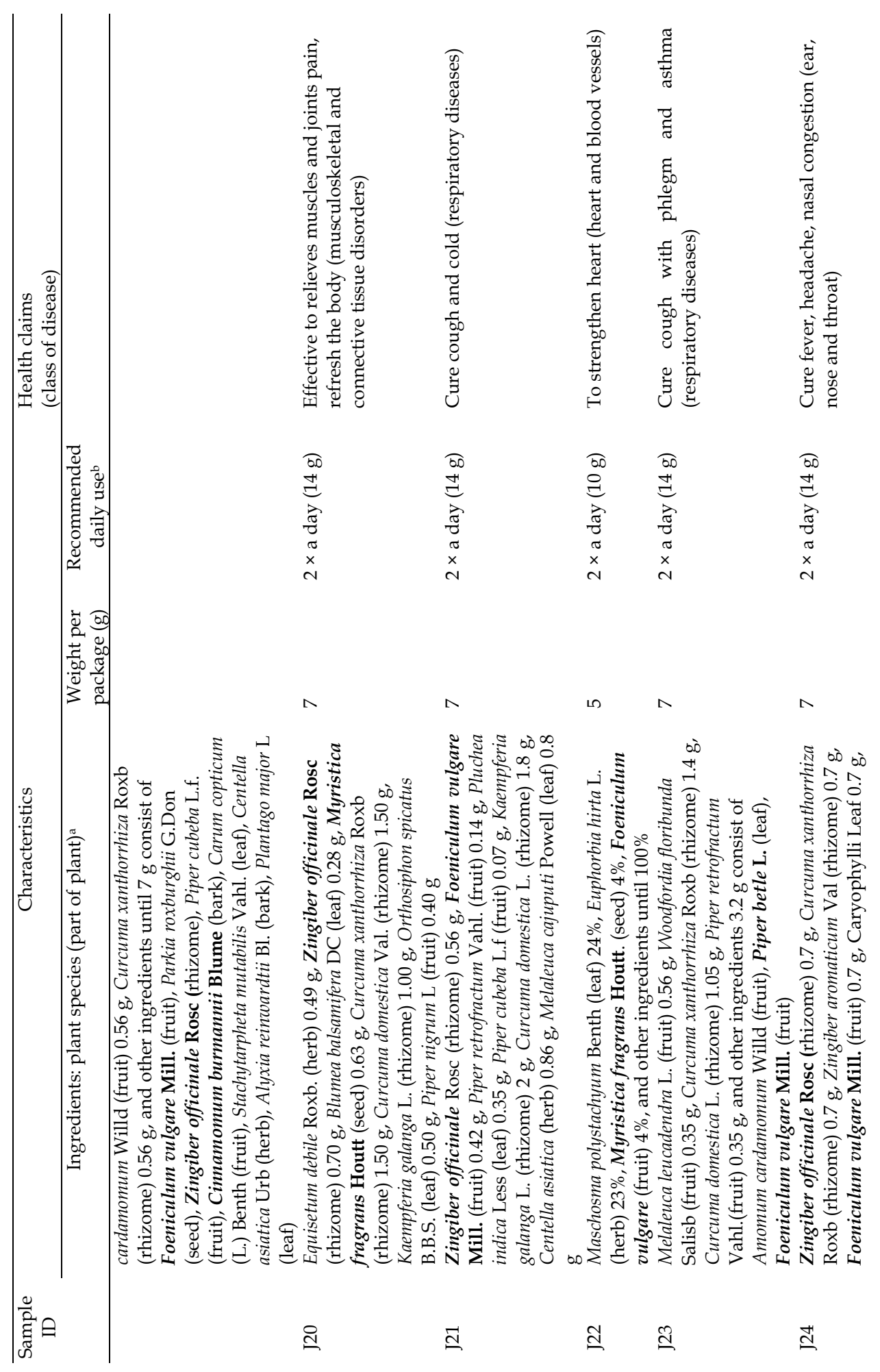




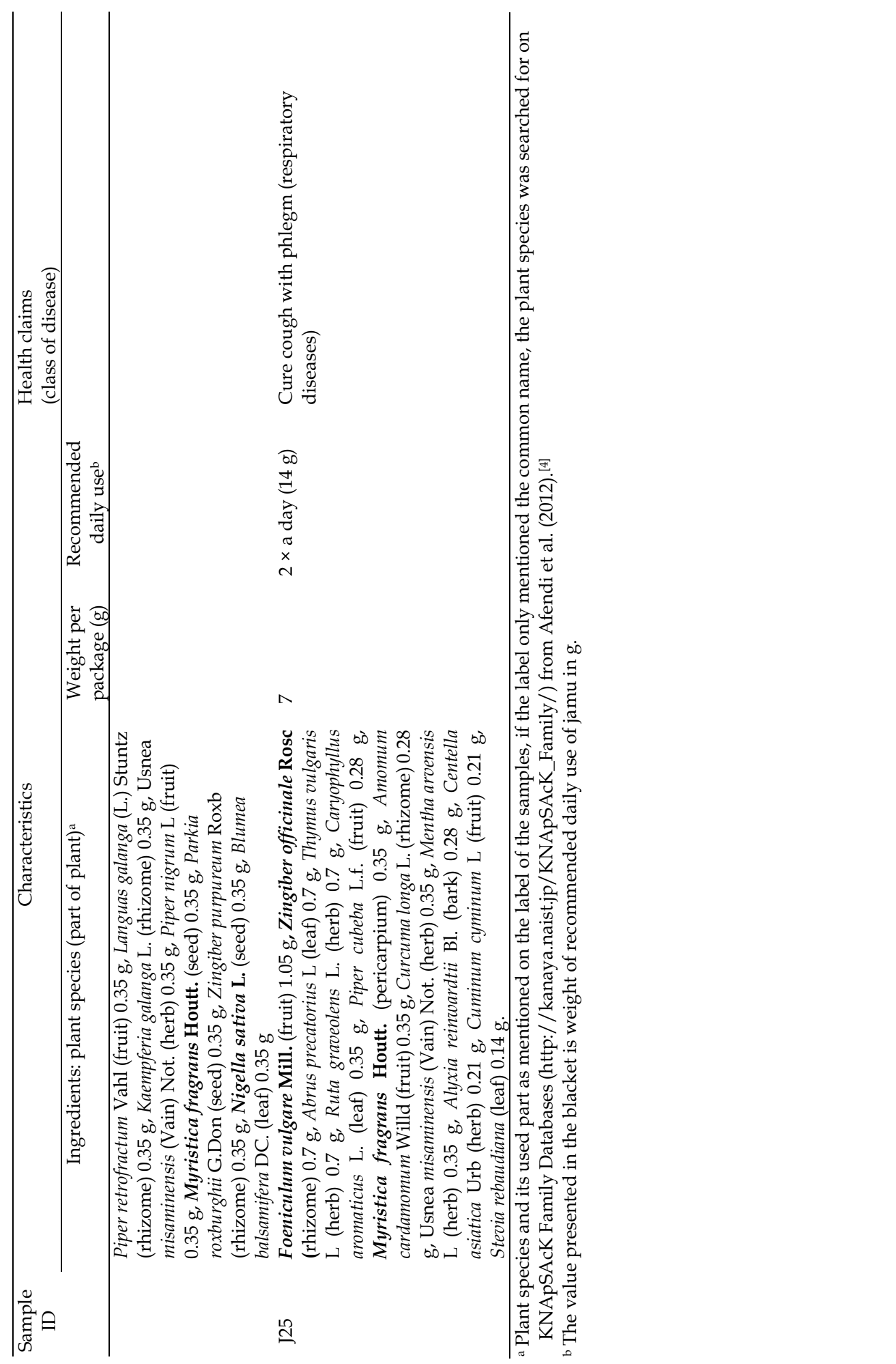




\subsubsection{Chemicals and reagents}

Estragole (purity 98\% w/w), methyleugenol (purity 99\% w/w), safrole (purity $>97 \% \mathrm{w} / \mathrm{w}$ ), and myristicin (purity $>97 \% \mathrm{w} / \mathrm{w}$ ) were purchased from Sigma-Aldrich (Zwijdrecht, The Netherlands). Apiol (purity >99\%) was obtained from Extrasynthese (Genay Cedex, France). Elemicin was obtained from Synchem OHG (Felsberg, Germany). Methanol (HPLC supra gradient) was acquired from Sigma-Aldrich. Acetonitrile (ACN) (ULC/MS gradient), trifluoroacetic acid (TFA), and dimethyl sulfoxide (DMSO) was purchased from Merck. Nanopure water was obtained from an Arium pro UF/VF water purification system (Sartorius Weighting Technology $\mathrm{GmbH}$, Goettingen, Germany).

\subsubsection{Methanol extraction}

Methanolic extraction was applied to optimally extract and quantify the total amount of different alkenylbenzenes present in the samples. Extraction was performed based on the method described by Gursale at al. (2010) ${ }^{[39]}$ with minor modifications. Briefly, $10 \mathrm{~mL}$ of methanol was added to $1 \mathrm{~g}$ of jamu followed by sonication for $15 \mathrm{~min}$. Upon sonication the extract was filtered using a $0.45 \mu \mathrm{m}$ syringe filter and the filtrate was directly analysed using ultraperformance liquid chromatography (UPLC) analysis. Samples were extracted and analysed on UPLC in three independent experiments.

The accuracy of the developed method was assessed using a recovery study to account for possible losses during the extraction process. For recovery studies, $1 \mathrm{~g}$ of sample J18 was spiked with mixtures of 6 pure standards of alkenylbenzenes each in a final concentration of $10 \mu \mathrm{M}$. The spiked sample was analyzed by the same procedure as described above. The recoveries of elemicin, methyleugenol, myristicin, safrole, and estragole are $108.12 \pm 1.77 ; 103.83 \pm 0.13,96.11 \pm 1.25$, $105.59 \pm 2.98,99.73 \pm 3.41 \%$, respectively. These results of sample recovery were used to correct the levels of the alkenylbenzenes detected in the different jamu samples. To show the linearity of the extraction procedure J18 was analysed in a range of weight per volume of methanol ratio at $2.5 \%, 5 \%, 10 \%, 20 \%$ and $40 \% \mathrm{w} / \mathrm{v}$.

\subsubsection{UPLC analysis}

The methanol extract was analyzed in undiluted form, and $3.5 \mu \mathrm{l}$ aliquot of each sample was subjected to UPLC analysis as described before. ${ }^{[17]}$ The sample analysis was carried out using a UPLC-DAD system consisting of a Waters (Milford, MA) Acquity binary solvent manager, sample manager, and photodiode array detector, equipped with a Waters Acquity UPLC BEH RP 18 column $(1.7 \mu \mathrm{m}, 2.1 \times$ $50 \mathrm{~mm})$. The column and sample temperature were set at $22^{\circ} \mathrm{C}$ and $10^{\circ} \mathrm{C}$ 
respectively. The mobile phase used in UPLC consisted of nanopure water containing $0.1 \%(\mathrm{v} / \mathrm{v})$ TFA (as eluent $\mathrm{A}$ ) and $\mathrm{ACN}$ (as eluent B) with a flow rate of $0.6 \mathrm{~mL} / \mathrm{min}$. After equilibrating the column at the starting conditions of $30.5 \% \mathrm{ACN}$, the ACN was kept at this level for $15 \mathrm{~min}$ and then increased to $80 \%$ over $1 \mathrm{~min}$ and kept at $80 \%$ for $0.5 \mathrm{~min}$, then decreased to $0 \%$ over $1.5 \mathrm{~min}$ and kept at $0 \%$ for $1 \mathrm{~min}$ after which the ACN was returned to the starting conditions. The levels of the alkenylbenzenes of interest were quantified based on the peak areas of the UV absorption at $206 \mathrm{~nm}$ for elemicin, $202 \mathrm{~nm}$ for methyleugenol and safrole, $210 \mathrm{~nm}$ for myristicin and apiol, $225 \mathrm{~nm}$ for estragole and comparison to the calibration curves of these compounds derived from commercially available standards.

The UPLC method was characterised by the limit of detection (LOD) and the limit of quantification (LOQ) according to the International Conference on Harmonization Guidance for the Validation of Analytic Methods..40] The LOD and LOQ were determined for each alkenylbenzene using the standard of the response method, using the following equations:

$$
\begin{aligned}
& L O D=(3.3 \sigma) / S \\
& L O Q=(10 \sigma) / S
\end{aligned}
$$

where $\sigma$ is the standard deviation of the peak areas and $S$ the slope of the calibration curve. Table 2.2 presents the LOD and LOQ obtained for analysis of the 6 alkenylbenzenes elemicin, methyleugenol, myristicin, apiol, safrole and estragole. Values varied somewhat among different alkenylbenzenes, but followed a similar trend when comparing the LOD and LOQ values.

Table 2.2. Limits of Detection (LOD, $\mu V^{*} \mathrm{Sec}$ ) and Quantification (LOQ, $\mu \mathrm{V}^{*} \mathrm{Sec}$ ) for analysis of the 6 alkenylbenzes by UPLC.

\begin{tabular}{lll}
\hline Type of alkenylbenzene & LOD of area $\left(\mu \mathrm{V}^{*} \mathrm{Sec}\right)$ & LOQ of area $\left(\mu \mathrm{V}^{*} \mathrm{Sec}\right)$ \\
\hline Elemicin & 129.34 & 373.76 \\
Methyleugenol & 124.05 & 375.92 \\
Myristicin & 125.52 & 380.36 \\
Safrole & 125.89 & 381.48 \\
Apiol & 126.51 & 383.37 \\
Estragole & 128.03 & 387.96 \\
\hline
\end{tabular}

\subsubsection{Calculation of interim relative potency (REP) factors}

Interim relative potency (REP) factors were determined to estimate the combined exposure of different alkenylbenzenes in the same sample using a toxic equivalency (TEQ) approach. Methyleugenol was chosen as the reference compound with a REP value of 1.00 because methyleugenol appeared to be the main alkenylbenzene detected in the samples (see Results section). The interim REP values (Table 2.3) were calculated as the average of interim REP values obtained from (1) DNA adduct formation by the different alkenylbenzenes in CD-1 mice ${ }^{[41]}$, 
(ii) physiologically based kinetic (PBK) modelling predicted relative formation of the proximate hepatocarcinogenic 1'-sulfoxy metabolite representing the relative importance of the bioactivation route at a dose level of $0.01 \mathrm{mg} / \mathrm{kg} \mathrm{bw}^{[42-46]}$, and (iii) the lower confidence limit of the benchmark dose giving $10 \%$ extra tumor incidence $\left(\mathrm{BMDL}_{10}\right)$ values derived from the carcinogenicity data ${ }^{29,47]}$ and read-accross from safrole for myristicin and apiol[42,44] and from estragole and methyleugenol for elemicin. ${ }^{48]}$ These average interim REP values are considered a suitable first estimate to take into account the differences in potency of the alkenylbenzenes. The accuracy of these interim REP values can obviously be further refined. However, given that the actual outcomes for the risk assessment when using just adding up the alkenylbenzene levels or using a TEQ based approach did not differ substantially we feel further refinement of the interim REP values is not required or indicated at this stage.

Table 2.3. Interim REP values as defined based on different available data set and the average interim REP values used in this study.

\begin{tabular}{|c|c|c|c|c|}
\hline Compound & $\begin{array}{l}\text { Interim REP } \\
\text { derived from DNA } \\
\text { adduct } \\
\text { information }\end{array}$ & $\begin{array}{l}\text { Interim REP derived } \\
\text { from human PBK model } \\
\text { based prediction of } 1^{\prime}- \\
\text { sulfoxy formation }\end{array}$ & $\begin{array}{l}\text { Interim REP } \\
\text { derived from the } \\
\text { BMDL }_{10} \text { for liver } \\
\text { tumor formation }\end{array}$ & $\begin{array}{l}\text { Average } \\
\text { Interim } \\
\text { REP } \\
\text { value }\end{array}$ \\
\hline Safrole & 1.05 & 1.08 & 8.05 & 3.39 \\
\hline Myristicin & 0.24 & 0.8 & 8.05 & 3.03 \\
\hline Apiol & 0.07 & 0.53 & 2.68 & 1.09 \\
\hline Estragole & 1.55 & 4.62 & 4.64 & 3.60 \\
\hline Methyleugenol & 1.00 & 1.00 & 1.00 & 1.00 \\
\hline Elemicin & 0.09 & 0.39 & 0.50 & 0.33 \\
\hline
\end{tabular}

\subsubsection{Estimation of daily intakes of alkenylbenzenes resulting from the consumption of jamu}

In order to evaluate consumer risks, the estimated daily intake (EDI) was calculated based on the individual alkenylbenzene levels present in the samples, the recommended daily use as written on the labels (Table 2.1) and a mean Indonesian body weight (bw) of $54 \mathrm{~kg} /$ person. ${ }^{[49]}$ For calculation of EDI values it was assumed that 1 sachet jamu would be added to one cup of hot water $( \pm 100 \mathrm{~mL})$ followed by drinking all of the preparation. When the label lists use of 2-3 times a day, 3 times consumption was chosen to calculate the EDI. In the present study three different exposure scenario's were considered for calculating lifetime exposure. These included (i) calculation of the EDI for each individual alkenylbenzene for all the samples, expressed in $\mu \mathrm{g} / \mathrm{kg}$ bw/ day using the following equation:

$\mathrm{EDI}=\frac{\text { recommended daily use }(\mathrm{g}) \times \text { level of alkenylbenzene }(\mu \mathrm{g} / \mathrm{g})}{\mathrm{bw}(54 \mathrm{~kg})}$

(Equation 2.3)

Since several samples were found to contain more than one alkenylbenzenes, the EDI values were also estimated taking combined exposure into account. (ii) In 
this second approach, the EDI for combined exposure was calculated by assuming equal potency of the different alkenylbenzenes, adding up the EDIs of the individual alkenylbenzene.[13,15] (iii) In a third approach, the combined EDI was calculated by a toxic equivalency (TEQ) approach using the average interim REP values presented in Table 2.3 taking methyleugenol as the reference compound. These EDI values were expressed in $\mu \mathrm{g}$ methyleugenol equivalents $/ \mathrm{kg}$ bw/day, and calculated using the following equation:

$E D I(\mu \mathrm{g}$ methyleugenol equivalents $/ \mathrm{kg}$ bw/day $)=\sum(E D I \times R E P) i \quad($ Equation 2.4)

In addition, also 3 scenarios were included to take into account durations of exposure shorter than lifetime exposure. For these scenario's only the combined total alkenylbenzene exposures were taken into account. The 3 scenarios compared for differences in duration of exposure included: i) chronic lifetime exposure, which is the exposure generally considered in the MOE approach and described also above as the second scenario with the combined exposure based on equal potency, ii) short term exposure for only two weeks, correcting for the shorter than lifetime exposure by applying Haber's rule, and iii) regular short term exposure to mimic the situation where people use jamu as a remedy during periods of illness and thus likely will use it for short period of time but on a regular basis. For this last exposure scenario, it was assumed that people would use the preparations two weeks, once every year during a lifetime.

Although there is no formally accepted procedure for correcting the EDI and thus the MOE approach for shorter than lifetime exposure, previously it was suggested to apply, as a first approximation, Haber's rule. ${ }^{[50-52]}$ Based on this rule the toxic outcome will be similar for situations where the product of the exposure time and the dose will be constant, $(k=C \times T ; C 1 \times T 1=C 2 \times T 2$, where $\mathrm{k}$ is the toxic outcome, $\mathrm{C}$ is the concentration (or dose) of the toxic chemical and $\mathrm{T}$ is the time of exposure). Using Haber's rule and a lifetime expectancy of Indonesian people of 69 years[53], the EDI of the total level of alkenylbenzenes could be corrected as follows: EDI for $\mathrm{n}$ week exposure corrected to lifetime exposure $=$ $\frac{\text { recommended daily use }(\mathrm{g}) \times \text { level of alkenylbenzene }(\mu \mathrm{g} / \mathrm{g})}{b w(54 \mathrm{~kg})}:\left(\frac{69 \text { years } \times 52 \text { weeks }}{n \text { week }}\right)$

(Equation 2.5)

\subsubsection{Calculation of the Margin of Exposure}

The MOE approach was used to perform a risk assessment of jamu. First, MOEs for individual alkenylbenzenes were calculated by dividing the $\mathrm{BMDL}_{10}$ values for the individual alkenylbenzenes, $15.3 \mathrm{mg} / \mathrm{kg}$ bw for methyleugenol,[17] 1.9 $\mathrm{mg} / \mathrm{kg}$ bw for safrole[54] and myristicin[42], and $3.3 \mathrm{mg} / \mathrm{kg}$ bw for estragole ${ }^{[55]}$ by the EDI values of the individual alkenylbenzenes, using the following equation: 
$M O E=\frac{B M D L_{10}}{E D I}$

(Equation 2.6)

Second, the MOE values were calculated using a combined exposure assessment assuming equal potency of all alkenylbenzenes. For these MOE calculation Equation 2.6 was applied using the BMDL 10 of $15.3 \mathrm{mg} / \mathrm{kg}$ bw for the major alkenylbenzene in the mixture, methyleugenol, and the EDI resulting from summing up the EDIs of the individual alkenylbenzenes assuming equal potency. Third, the MOE values were calculated based on a TEQ approach calculating the combined exposure in methyleugenol equivalents (Equation 2.4) and using the $\mathrm{BMDL}_{10}$ of methyleugenol of $15.3 \mathrm{mg} / \mathrm{kg}$ bw.

For calculating MOE values for shorter than lifetime exposure the same equation was applied only using the corrected EDI values (Equation 2.5) assuming equal potency and the BMDL 10 of methyleugenol of $15.3 \mathrm{mg} / \mathrm{kg} \mathrm{bw}$. To further illustrate how short term exposure would affect the MOE values, the number of weeks of daily consumption of jamu samples analysed in this study that would result in a MOE of 10,000 indicating a low priority for risk management was also calculated using Equations 2.5 and 2.6.

\subsection{Results}

\subsubsection{Levels of alkenylbenzenes in Indonesian jamu}

As shown in Table 2.4, four different alkenylbenzenes, methyleugenol, myristicin, safrole, and estragole were detected in 23 out of 25 samples of Indonesian jamu, at levels ranging from $3.8-440 \mu \mathrm{g} / \mathrm{g}$. Methyleugenol was the major alkenylbenzene detected in most (91.3\%) of the positives samples (Table 2.5). Apiol and elemicin were not detected in the samples. Two positive samples contained 3 different alkenylbenzenes; methyleugenol, safrole and estragole in J7, and methyleugenol, safrole and myristicin in J24. Only 2 (J14 and 18) out of 25 samples did not contain detectable levels of any alkenylbenzene. 


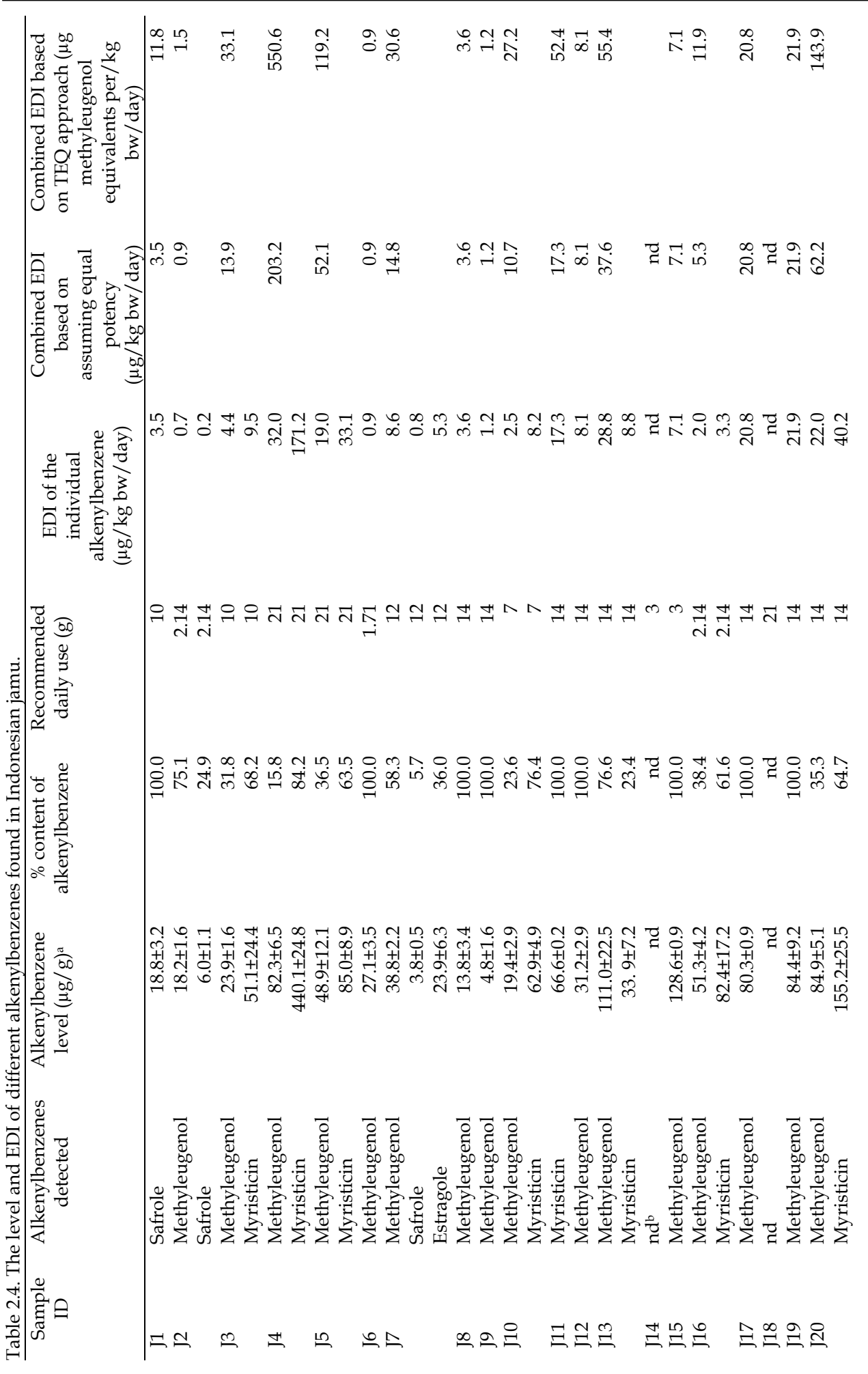




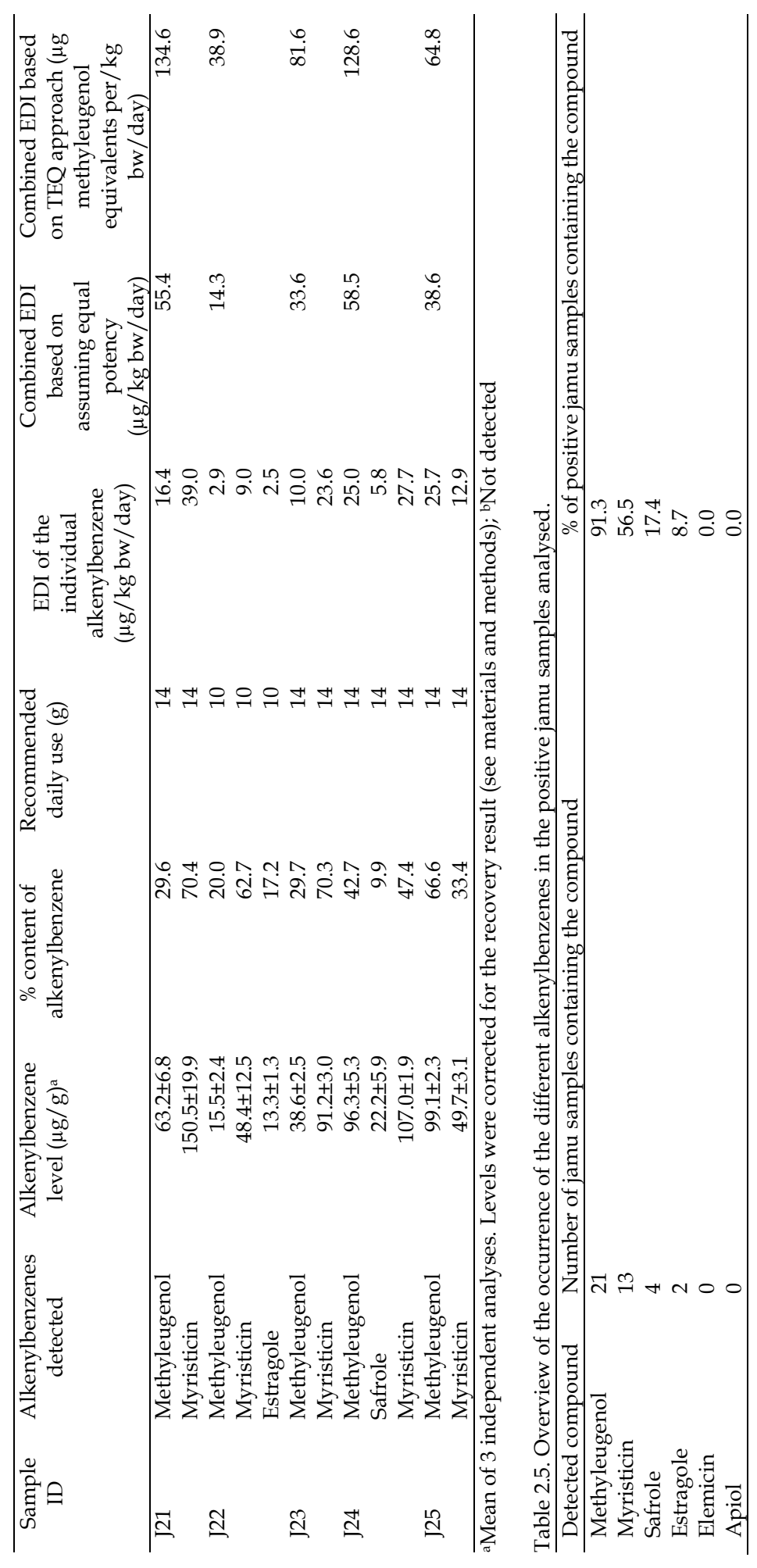




\subsubsection{EDI of individual and combined alkenylbenzenes}

Table 2.4 presents the EDI values obtained for the individual alkenylbenzene, amounting for the positive samples from 0.2 to $171 \mu \mathrm{g} / \mathrm{kg}$ bw/day. The EDI values estimated taking combined exposure into account by assuming similar potency amounted to 0.9 to $203 \mu \mathrm{g} / \mathrm{kg}$ bw/day. Using the TEQ approach EDI values expressed in methyleugenol equivalents $/ \mathrm{kg}$ bw resulted in EDI values ranging from 0.9 to $551 \mu \mathrm{g}$ methyleugenol equivalents $/ \mathrm{kg}$ bw/day.

\subsubsection{Risk assessment of jamu using the MOE}

The MOE values for the individual alkenylbenzene occurring in the jamu samples are depicted in the Figure 2.3A. The MOE values obtained when considering combined exposure assuming equal potency of the alkenylbenzene and using the $\mathrm{BMDL}_{10}$ of the major alkenylbenzene present in the samples, methyleugenol, are shown in Figure 2.3B. Only 3 samples (J2, J6 and J9) out of 23 positives samples were shown to give rise to MOE values higher than 10,000. For J2 the safrole level resulted in an MOE of less than 10,000. The observation that the MOE of most of the jamu samples (87\%) were lower than 10,000 indicates a priority for risk management when these jamu would be consumed for long periods of time.

Figure $2.3 \mathrm{C}$ reveals the $\mathrm{MOE}$ values that resulted from dividing the $\mathrm{BMDL}_{10}$ of $15.3 \mathrm{mg} / \mathrm{kg}$ bw/day for methyleugenol by the EDI for the respective jamu samples expressed in methyleugenol equivalents. In line with the MOE results from the 2 other approaches, also the combined risk assessment based on the TEQ approach, resulted in MOE values that were lower than 10,000 for a large number $(87 \%)(20 / 23)$ of samples with the values for $65 \%(15 / 23)$ of the samples being even below 1,000 . The results obtained using the combined risk assesment based on equal potency and the TEQ approach were comparable, with the MOE being lower than 10,000 for all samples except for samples J2, J6 and J9 for which the MOE values were above 10,000 for both methods. MOE values resulting from the TEQ approach were generally somewhat lower than the MOE values obtained when adding up the levels of the different alkenylbenzenes, mainly because the alkenylbenzenes being present in addition to methyleugenol have interim REP values higher than 1.00. Together the results depicted in Figure 2.3 indicate that the MOE values resulting from regular daily consumption of the majority of Indonesian jamu preparations indicate a priority for risk management. 

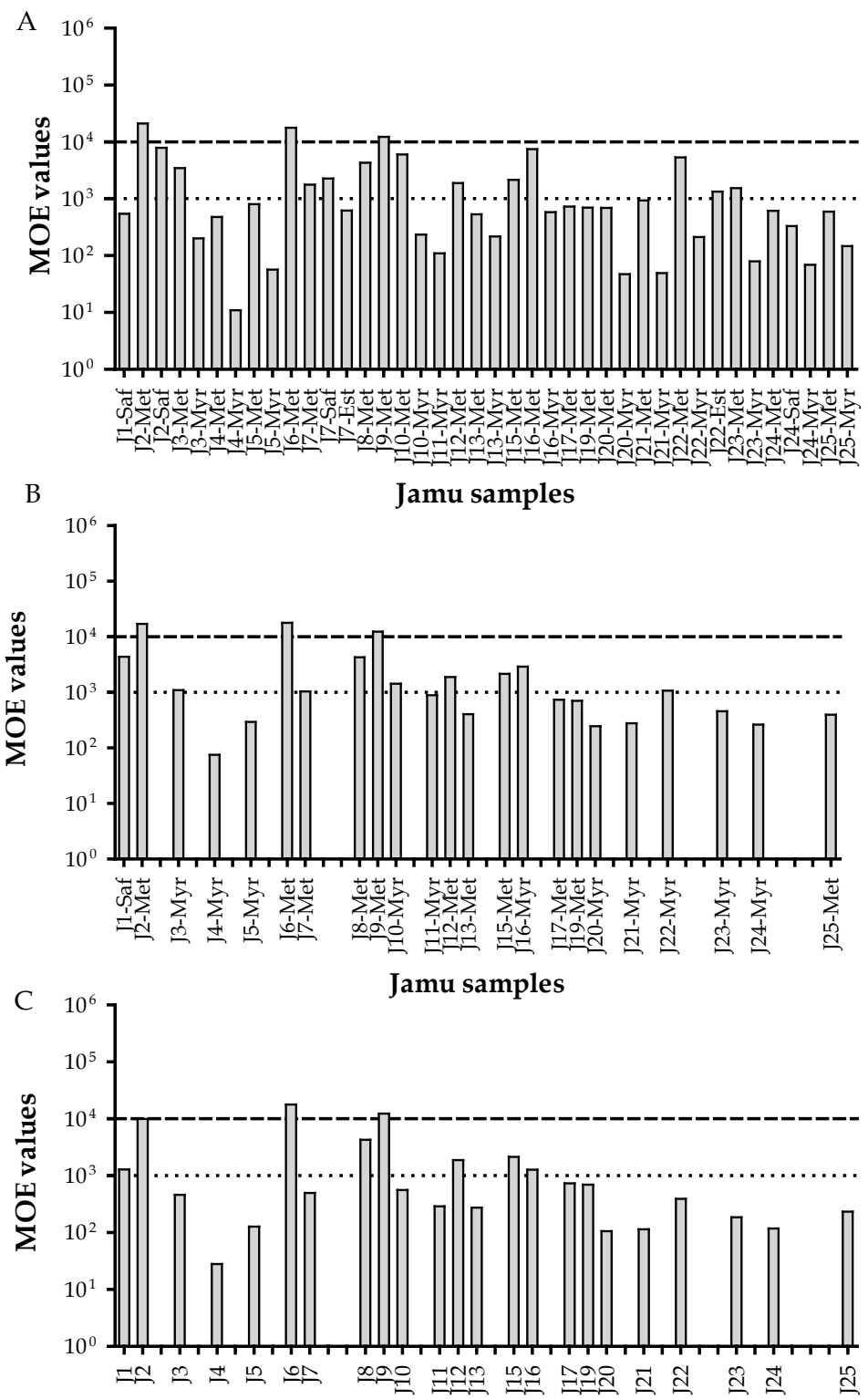

Jamu samples

Figure 2.3. MOE values obtained for use of the jamu preparations on a daily basis during a lifetime based on the three approaches: A) considering the individual alkenylbenzenes using their BMDL10 values, B) the combined exposure assuming equal potency of all alkenylbenzenes and using the BMDL 10 value of the major alkenylbenzene in the mixture, and C) the combined exposure using the TEQ approach based on methyleugenol equivalents and using the $\mathrm{BMDL}_{10}$ value of methyleugenol. EDI and MOE values were calculated as explained in the Materials and Methods section (Equations 2.3, 2.4 and 2.6). The horizontal dashed and dotted lines represent MOE values of 10,000 (----) and 1,000 (.....), while Saf, Met, Myr, and Est, represent the alkenylbenzenes safrole, methyleugenol, myristicin and estragole, respectively. 
The range of daily recommended consumption of jamu samples of $1.7 \mathrm{~g}$ to 21 $\mathrm{g}$ (Table 2.1) will be of low priority of risk management (MOE > 10 000) when the total alkenylbenzene level in the jamu sample would be less than 48 to $4 \mu \mathrm{g} / \mathrm{g}$, respectively. This could be calculated using Equations 2.3 and 2.6 and considering lifetime exposure, a BMDL 10 of methyleugenol of $15.3 \mathrm{mg} / \mathrm{kg}$ bw and a $54 \mathrm{~kg}$ body weight. ${ }^{[49]}$ When instead of lifetime use, two weeks of use of the jamu samples is considered, and Haber's rule is used for linear correction of the correponding intake estimates, the EDI values will be 69 year (=lifetime) $\times 52$ weeks per year $/ 2$ weeks $=$ 1,794 times lower (Equation 2.5) and thus, alkenylbenzene levels in the jamu samples can be 1,794 times higher before an MOE of 10,000 is reached (Equation 2.6). Thus, with a BMDL 10 of $15.3 \mathrm{mg} / \mathrm{kg}$ bw/ day, two weeks intake of 1.7 or $21 \mathrm{~g}$ jamu (Table 2.1) would not raise a concern (MOE of more than 10,000 ) if the total alkenylbenzene level would be lower than 86 or $7 \mathrm{mg} / \mathrm{g}$, respectively. Taken together the results indicate that at the current levels of alkenylbenzenes in Indonesian jamu, their consumption would be a concern especially for people who consume these jamu for long periods of time.

Figure 2.4 depicts the MOE values that would be obtained for the jamu samples of the present study assuming two weeks consumption. From this result it follows that when consumption of jamu is limited to two weeks the MOE values of all samples are higher than 10,000 indicating there would no priority for risk management. However, in real life people tend to consume jamu for short periods but on a rather regular basis especially when considering its use as medicine. To take this regular short term use into account we finally estimated the MOE values assuming use for two weeks once every year during a whole lifetime. This lowers all MOE values obtained for 2 weeks exposure by a factor of 69, assuming 69 years to represent the average Indonesian lifetime.[53] The results thus obtained are depicted in Figure 2.5. Together the results depicted in Figure 2.5B indicate that the MOE values resulting from regular consumption during two weeks every year during a whole lifetime suggest a priority for risk management, for 5 out of 23 $(21.7 \%)$ of the positives samples. 
A
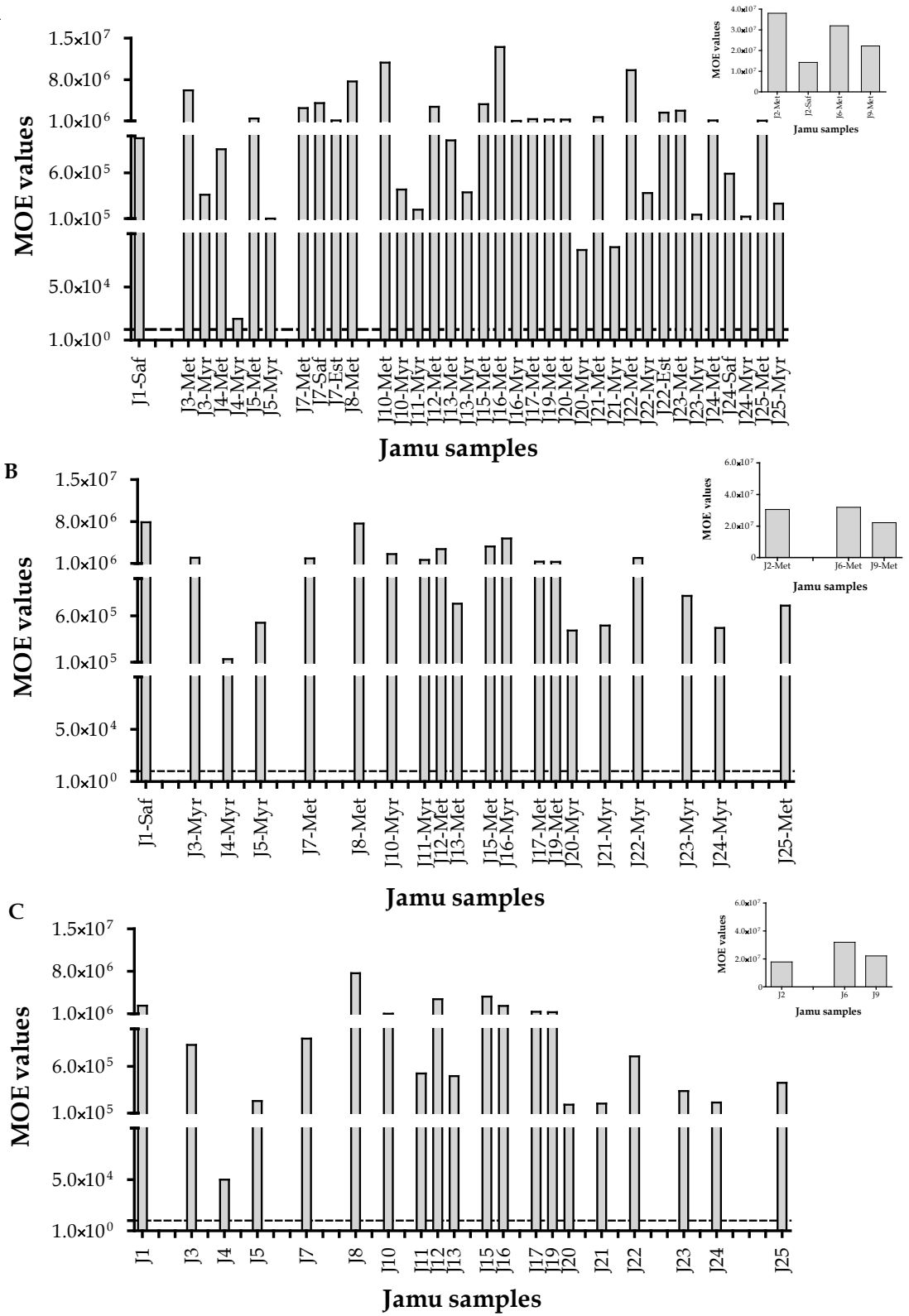

Figure 2.4. MOE values assuming 2 weeks consumption based on the three approaches: A) the individual alkenylbenzenes using their $\mathrm{BMDL}_{10}$ values, $\mathrm{B}$ ) the combined exposure assuming equal potency of all alkenylbenzenes and using the BMDL 10 value of the major alkenylbenzene in the mixture, and $\mathrm{C}$ ) the combined exposure using the TEQ approach based on methyleugenol equivalents and using the BMDL 10 value of methyleugenol. EDI and MOE values were calculated as explained in the Materials and Methods section (Equations 2.5 and 2.6). The $Y$ axis was dirrupted in 3 segments at $1-10^{5}, 10^{5}-10^{6}$ and $10^{6}-1.5 \times 10^{7}$ for bottom, center and top segment, respectively. The inserted graph shows the MOE values for J2, J6 and J9. The horizontal dashed line (----) represents MOE values of 10,000, while Saf, Met, Myr, and Est, represent the alkenylbenzenes safrole, methyleugenol, myristicin and estragole, respectively. 

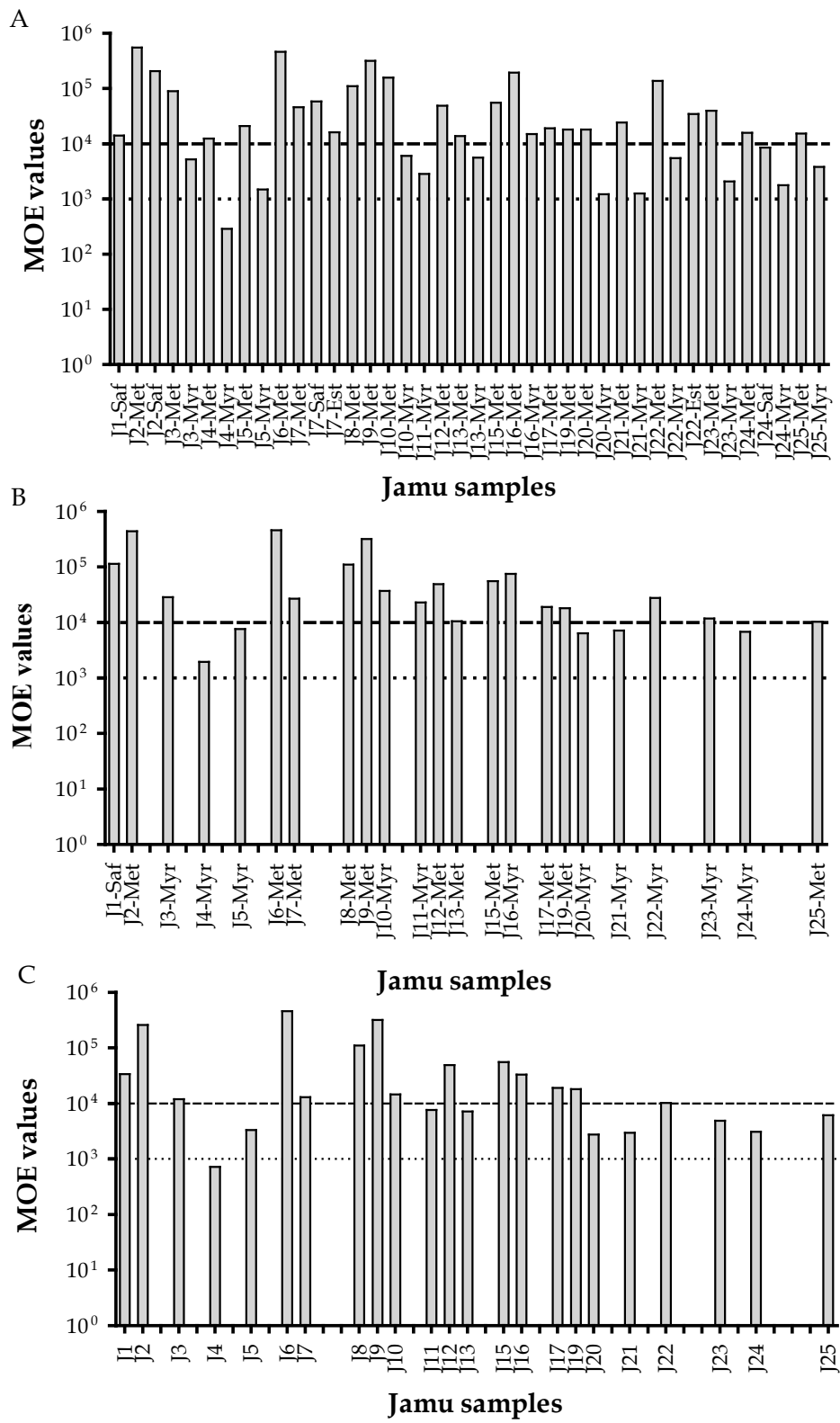

Figure 2.5. MOE values assuming jamu consumption 2 weeks every year for a whole lifetime (69 years) ${ }^{[53]}$ based on the three approaches: A) the individual alkenylbenzenes using their BMDL 10 values, B) the combined exposure assuming equal potency of all alkenylbenzenes and using the BMDL 10 value of the major alkenylbenzene in the mixture, and C) the combined exposure using the TEQ approach based on methyleugenol equivalents and using the $\mathrm{BMDL}_{10}$ value of methyleugenol. EDI and MOE values were calculated as explained in the Materials and Methods section (Equations 2.5 and 2.6). The horizontal dashed and dotted lines (----) represent MOE values of 10,000 and 1000 (.....), while Saf, Met, Myr, and Est, represent the alkenylbenzenes safrole, methyleugenol, myristicin and estragole, respectively. 
Figure 2.6 shows the number of weeks of daily consumption of jamu samples analysed in this study that would result in a MOE value of 10,000 as calculated using Haber's rule (Equations 2.4 and 2.5) and assuming the equal potency approach. From the results obtained it can be seen that the shortest time of daily combined exposure to make the risk of low priority was for J4 (the sample with the highest EDI; $203.1 \mu \mathrm{g} / \mathrm{kg} / \mathrm{bw} /$ day) amounting to 27 weeks. This implies that use of this sample is considered of low concern when during a whole lifetime it would be consumed for less than 27 weeks. When considering consumption for 2 weeks every year during a lifetime, there are 5 out of 23 positive samples that would raise a concern and be a priority for risk management.

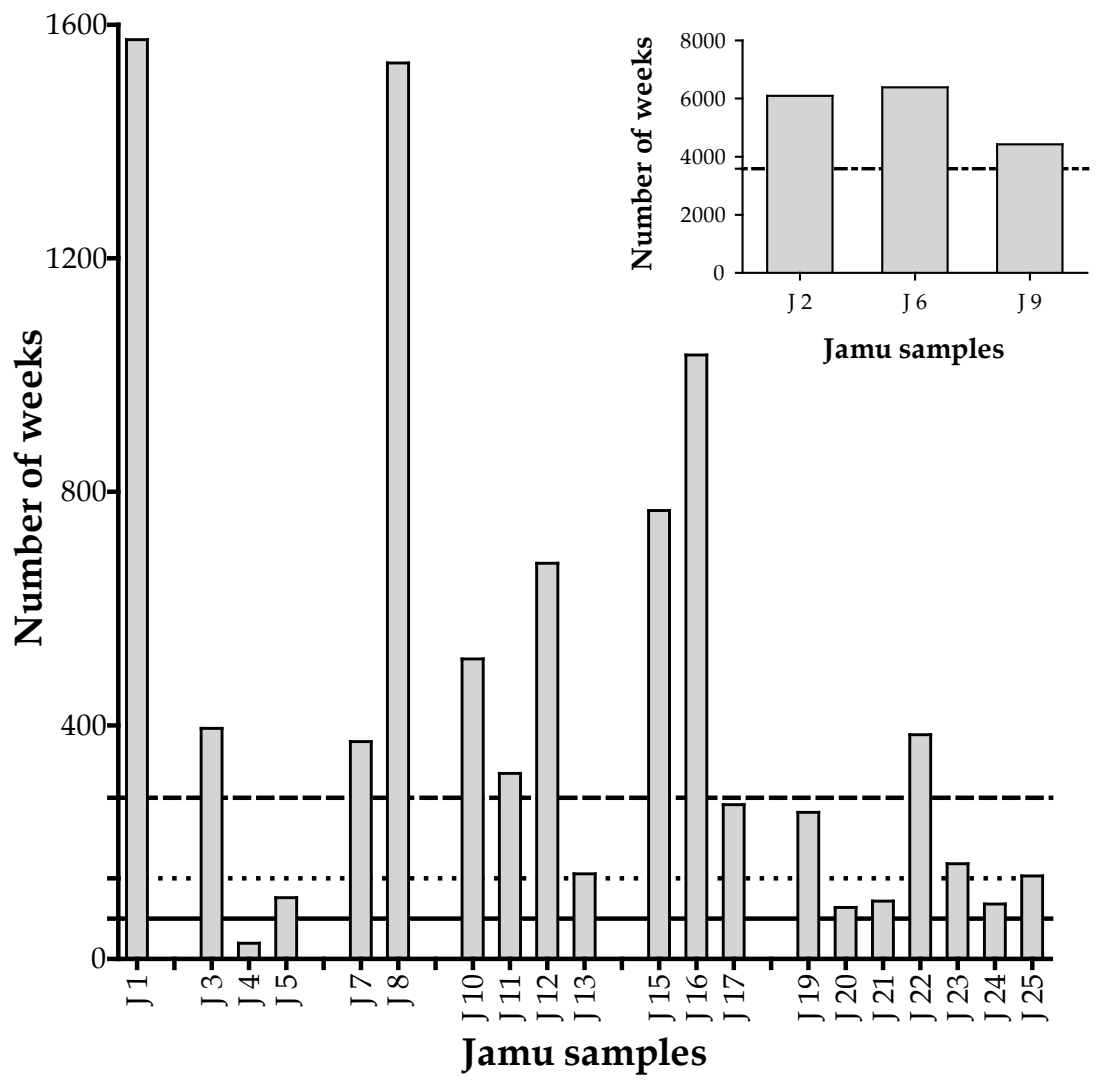

Figure 2.6. The number of weeks of use that would result in a MOE of 10,000 upon daily consumption of jamu samples analysed in the present study. The calculations assumed combined exposure and equal potency of the different alkenylbenzenes using the BMDL 10 of methyleugenol. The horizontal line ( - ), dotted line (.......), and dashed line (----) represent one week, 2 weeks, and 4 weeks intake during lifetime. The inserted graph shows the number of weeks for J2, J6 and J9, dashed dotted line (-·-· ) represents the number of weeks when use these jamu for 3,588 weeks $=69$ years so a whole lifetime. 


\subsection{Discussion}

This study was conducted to obtain insight in possible consumer risks of jamu due to the natural occurance of alkenylbenzenes. This assessment is of interest considering the high number of jamu consumers, and the fact that alkenylbenzenes are genotoxic and carcinogenic compound that that can be naturally present in jamu. The Health Minister (MoH) of Indonesia in (2013) reported that about $49.0 \%$ out of 294,962 Indonesian households are actually consuming concoction that include jamu preparations for many reasons including; to maintain health and physical fitness $(52.7 \%)$, more efficacious $(18.4 \%)$, as a tradition and because the consumers belief that natural is always good for health (12.3\%), low cost (6.8\%), trial and error $(2.8 \%)$, and as an option when medicinal treatment did not work (1.8\%). ${ }^{[56]}$

Jamu preparations analysed in the present paper are generally consumed by mixing the powders with hot water. This may extract some of the active ingredients, while others remain bound to the matrix, which is however consumed as such with the beverage prepared. Thus, as a worst case assumption for risk assessment, it was assumed that all alkenylbenzenes present in a powder would become available in the gastrointestinal tract for uptake. For this reason, the powders were extracted with methanol in order to optimise the extraction. Methanol can break down the cell wall thereby improving release of the cellular substances,[14] moreover, the ultrasonification used in the extraction process provides an additional destructive effect on the cell wall and increases the permeability of the methanol to the cell and the extraction efficiency.[57] The extraction efficiency is also affected by the powder size, since previous studies with alkenylbenzene containing teas showed that extraction from course material is lower than from fine cut material.[14, 18]

The level and type of alkenybenzenes detected varies with the nature of the targeted plants in the samples. Fruit of fennel (Foeniculum vulgare Mill) is the main targeted plant, being present as an ingredients in most (80\%) of the jamu samples at a variable amount or percentage. The remainder $20 \%$ (J7, J14, J15, J18 and J20) of the samples contained seed of nutmeg (Myristica fragrans Houtt). These two medicinal plants are known to naturally contain methyleugenol (4-allyl-1,2dimethoxybenzene), ${ }^{[58]}$ and this is in line with the observation that methyleugenol was detected in $91 \%(21 / 23)$ of the samples. The highest level of myristicin of 440 $\pm 25 \mu \mathrm{g} / \mathrm{g}$ was detected in $\mathrm{J} 4$ which contains 3 myristicin-based plants, i.e: $25 \% \mathrm{w} / \mathrm{w}$ of fennel fruit, $14.71 \% \mathrm{w} / \mathrm{w}$ of cinnamon (Cinnamomum burmannii Blume) bark and $10 \% \mathrm{w} / \mathrm{w}$ of betel pepper (Piper betle L.) leaf. Safrole was detected as a minor alkenylbenzene in 4 samples, either as the only alkenylbenzene present (J1) or present in combination with other alkenylbenzenes including methyleugenol, myristicin and estragole. None of the sample appreared to contain dill or parsley as 
an ingredient and this explains why apiol was not detected in the samples. The variability in the actual alkenylbenzene levels detected in the samples can also in part be due to the ecological factors at the different plant locations, ${ }^{[59]}$ plant maturity at harvest, harvesting techniques, storage conditions, processing (e.g. drying), and method of measurement. ${ }^{[60,61]}$

The MOE is a dimensionless ratio resulting from comparing the BMDL 10 with the EDI in humans.[62] This method has been used before to assess the risk of alkenylbenzene containing supplements,[17] fennel based tea, ${ }^{[18]}$ parsley and dill based teas, ${ }^{[14]}$ basil-based pesto sauces, ${ }^{[13]}$ and nutmeg-based plant food supplements. ${ }^{[63]}$ The same method was applied in the present study.

It is of interest to compare the three different approaches used for estimating the EDI and MOE values including: 1) considering the individual alkenylbenzenes using their $\mathrm{BMDL}_{10}$ values, 2) combined exposure assuming equal potency of all alkenylbenzenes and using the $\mathrm{BMDL}_{10}$ value of the major alkenylbenzene in the mixture, and 3) combined exposure using a TEQ approach.

Evaluating the risks associated with exposure to the individual alkenylbenzenes already indicated that several of the jamu preparations pose a concern with methyleugenol, the major alkenylbenzene present, giving rise to $\mathrm{MOE}$ values that range from 11 to 21,191 . However, since several samples appeared to contain more than one alkenylbenzenes also a combined exposure and risk assessment was considered. Given the fact that alkenylbenzenes act by a similar mode of action and on a similar target organ, ${ }^{[64-67]}$ it is at the current state of knowledge most logic to assume that combined exposure could best be modelled by dose addition, summing up the doses of the components considering equal potency. Thus, in the second approach the EDIs of the alkenylbenzenes were added up and combined exposure was used to calculate the MOE. For these MOE calculations the $\mathrm{BMDL}_{10}$ of the major alkenylbenzene detected in the mixture, methyleugenol, was used. This approach may somewhat underestimate the risk when alkenylbenzenes like estragole, safrole and/or myristicin would be present in the mixture which are known to have higher relative potency than methyleugenol. Thus, in a third approach added exposure was calculated using a TEQ approach correcting for differences in relative potency between the different alkenylbenzenes using REP values and methyleugenol as the reference compound.

Definition of the interim REP values in Table 2.3 thus includes some surrogate endpoints for tumor formation. Such an approach to define interim REP values based on surrogate endpoints was used previously for pyrrolizidine alkaloids (PA) ${ }^{[68]}$ calculating the average of data on the genotoxic potency in Drosophila melanogaster, the cytotoxic potency in vitro in chicken hepatocellular carcinoma 
(CLR-2118) cells and their acute toxicity in adult rodents. In the present study interim REP values were calculated using methyleugenol as the reference compound $($ REP value $=1.00)$ since this appeared to be the major alkenylbenzene detected in 91.3\% of the positives samples. Given that the interim REP values for other alkenylbenzenes detected in the jamu samples (estragole, safrole and myristicin) were higher than 1.00, the MOE values obtained when calculating the EDI values using the TEQ approach were lower than those obtained assuming equal potency albeit not to a large extent.

In addition to the three approaches for combined exposure and risk assessment also three approaches for the duration of exposure were evaluated. These include i) lifetime exposure as used for the three methods for (combined) exposure discussed above, but also two additional scenario's including different exposure durations to better reflect real life exposure and including ii) exposure for only two weeks and iii) exposure for two weeks on a regular (yearly) basis during a lifetime. The latter scenario better reflects the possible use of jamu preparations for short periods during periods of illness. For these approaches only combined exposure based on the sum of the total alkenylbenzenes was considered. This was possible because, as outlined above the different scenario's for calculating combined exposure did not vary substantially. To assess the risk for short term exposure Haber's rule was used (Equation 2.5).

It is important to note that in real life, Indonesian people do not consume jamu for their whole lifetime, but that the jamu preparations are generally consumed only during periods of illness. Using Haber's rule, the MOE values were corrected to take into account this shorter exposure. Applying this linear correction method results in MOE values for for example two weeks consumption that would be 1,794 times (69 years $\times 52$ weeks/year/2 weeks) higher than MOE values based on daily consumption of jamu over a whole lifetime (69 years) ${ }^{[53]}$, indicating far lower priority of risk management. However, given that in real life situations jamu is used for medical puposes Indonesian people tend to use the preparations for short intervals but on a regular basis for example two weeks once every year during a lifetime. Using this asumption, the MOE values for 5 out of 23 (21.7\%) of positives samples analysed would indicate a priority for risk management. Gaylor (2000) ${ }^{[52]}$ reported that Haber's rule can be applied for extrapolation from lifetime cancer incidences to different exposure periods when dose rate is not the determining factor and only total dose dictates the biological effect. The application of the rule is based on the assumption that there is a linear relationship between tumor incidence and low doses of genotoxic carcinogens or carcinogens that enhance background 
carcinogenic processes. ${ }^{[69]}$ Applying this rule to an MOE based risk assessment implies that shorter exposure will result in lower EDI and higher MOE values.[51]

It is important to note that at the present state of the art evidence supporting such linear behaviour of the adverse effects of alkenlbenzenes is limited to studies on bioactivation to the ultimate carcinogenic 1 '-sulfoxymetabolites and linearity in DNA adducts formation from dose levels causing significant tumor formation down to realistic dietary exposure levels. $[43,46,54,70]$ To what extent this also holds for the tumor formation remains to be demonstrated. Nevertheless, these observations provide some support for the application of Haber's rule for the current risk assessment. It is however acknowledged that at the present state-of-the-art there is no formally adopted method to take short term exposure into account in an MOE based risk assessment. Nevertheless, applying Haber's rule provides a reasonable first approach to evaluate the risks connected to shorter than lifetime exposure.

Previously DNA adduct formation induced by dietary intake of methyleugenol was detected in human liver samples.[27] Given the use of jamu contaning alkenylbenzenes it would be of interest to study whether such DNA adducts can also be detected in Indonesian human liver samples although that remains a topic of interest for future research. In addition, further studies on repair of DNA adduct resulting from alkenylbenzene exposure might help to clarify the risks of consumption alkenylbenzene-containing jamu.

It is concluded that the consumption of alkenylbenzene containing jamu can be of concern especially when consumed on a daily basis for longer periods of time on a regular basis.

\section{Conflict of Interest}

The authors state no conflict of interest regarding this manuscript.

\section{Acknowledgements}

This research was supported by a grant from Beasiswa Pendidikan Indonesia/ Lembaga Pengelola Dana Pendidikan (the Indonesian Endowment Fund for Education, Ministry of Finance of Republic of Indonesia) [contract number: PRJ365/LPDP/2016] for Suparmi.

\section{References}

[1] MoH, National Policy on Traditional Medicine, Jakarta 2007. Available at: http://www.searo.who.int/entity/medicines/topics/national_policy_on_traditional_medicines_ ministry_of_health.pdf. Accessed 20 July 2017.

[2] WHO, Traditional, complementary and integrative medicine, 2017 Available at: http://who.int/traditional-complementary-integrative-medicine/about/en/. Accessed 28 September 2017. 
[3] Afendi, F. M., Darusman, L. K., Morita, A. H., Altaf-Ul-Amin, M., Takahashi, H., Nakamura, K., Tanaka, K., Kanaya, S., Efficacy prediction of jamu formulations by PLS modeling. Current Computeraided Drug Design 2013, 9, 46-59.

[4] Afendi, F. M., Okada, T., Yamazaki, M., Hirai-Morita, A., Nakamura, Y., Nakamura, K., Ikeda, S., Takahashi, H., Altaf-Ul-Amin, M., Darusman, L. K., Saito, K., Kanaya, S., KNApSAcK family databases: Integrated metabolite-plant species databases for multifaceted plant research. Plant and Cell Physiology 2012, 53(e1), 1-12.

[5] Wijaya, S. H., Batubara, I., Nishioka, T., Altaf-Ul-Amin, M., Kanaya, S., Metabolomic studies of Indonesian jamu medicines: Prediction of jamu efficacy and identification of important metabolites. Molecular Informatics 2017, 1700050, 1-15.

[6] Wijaya, S. H., Husnawati, H., Afendi, F. M., Batubara, I., Darusman, L. K., Altaf-Ul-Amin, M., Sato, T., Ono, N., Sugiura, T., Kanaya, S., Supervised clustering based on DPClusO: Prediction of plantdisease relations using jamu formulas of KNApSAcK database. BioMed Research International 2014, $1-15$.

[7] Elfahmi, Woerdenbag, H. J., Kayser, O., Jamu: Indonesian traditional herbal medicine towards rational phytopharmacological use. Journal of Herbal Medicine 2014, 4, 51-73.

[8] Greger, J. L., Dietary supplement use: Consumer characteristics and interests. The Journal of Nutrition 2001, 131, 1339S-1343S.

[9] Rietjens, I. M. C. M., Slob, W., Galli, C., Silano, V., Risk assessment of botanicals and botanical preparations intended for use in food and food supplements: Emerging issues. Toxicology Letters 2008, 180, 131-136.

[10] BPOM-RI, Laporan Tahunan 2015, Badan Pengawas Obat dan Makanan, Jakarta 2016. Available at: http:/ / www.pom.go.id/ppid/rar/2016/laptah2014.pdf. Accessed 26 June 2017.

[11] BPOM-RI, Laporan Tahunan 2016 Badan Pengawas Obat dan Makanan, Jakarta 2017. Available at: http:/ / www.pom.go.id/new/admin/dat/20171127/laptah2016.pdf. Accessed 26 June 2017.

[12] Ali, N., Hashim, N. H., Saad, B., Safan, K., Nakajima, M., Yoshizawa, T., Evaluation of a method to determine the natural occurrence of aflatoxins in commercial traditional herbal medicines from Malaysia and Indonesia. Food and Chemical Toxicology 2005, 43, 1763-1772.

[13] Al-Malahmeh, A. J., Al-ajlouni, A. M., Wesseling, S., Vervoort, J., Rietjens, I. M. C. M., Determination and risk assessment of naturally occurring genotoxic and carcinogenic alkenylbenzenes in basilcontaining sauce of pesto. Toxicology Reports 2017, 4, 1-8.

[14] Alajlouni, A. M., Al-Malahmeh, A. J., Isnaeni, F. N., Wesseling, S., Vervoort, J., Rietjens, I. M.C.M, Level of alkenylbenzenes in parsley and dill based teas and associated risk assessment using the Margin of Exposure Approach. Journal of Agricultural and Food Chemistry 2016, 64, 8640-8646.

[15] Alajlouni, A. M., Al-Malahmeh, A. J., Wesseling, S., Kalli, M., Vervoort, J., Rietjens, I.M.C.M, Risk assessment of combined exposure to alkenylbenzenes through consumption of plant food supplements containing parsley and dill. Food Additives $\mathcal{E}$ Contaminants. Part A, Chemistry, analysis, control, exposure $\mathcal{E}$ risk assessment 2017, 1-11.

[16] EFSA, Compendium of botanicals reported to contain naturally occuring substances of possible concern for human health when used in food and food supplements. EFSA Journal 2012, 10(5):2663, $1-60$.

[17] van Den Berg, S. J., Restani, P., Boersma, M. G., Delmulle, L., Rietjens, I.M.C.M, Levels of genotoxic and carcinogenic compounds in plant food supplements and associated risk assessment. Food and Nutrition Sciences 2011, 2, 989-1010.

[18] van den Berg, S. J. P. L., Alhusainy, W., Restani, P., Rietjens, I. M. C. M., Chemical analysis of estragole in fennel based teas and associated safety assessment using the Margin of Exposure (MOE) approach. Food and Chemical Toxicology 2014, 65, 147-154.

[19] Woehrlin, F., Fry, H., Abraham, K., Preiss-Weigert, A., Quantification of flavoring constituents in cinnamon: high variation of coumarin in cassia bark from the German retail market and in authentic samples from Indonesia. Journal of A gricultural and Food Chemistry 2010, 58, 10568-10575.

[20] Ji, X.-d., Pu, Q.-l., Garraffo, H. M., Pannell, L. K., Essential Oils of the Leaf, Bark and Branch of Cinnamomum buramannii Blume. Journal of Essential Oil Research 1991, 3, 373-375.

[21] Rietjens, I. M.C.M, Cohen, S. M., Fukushima, S., Gooderham, N. J., Hecht, S., Marnett, L. J., Smith, R. L., Adams, T. B., Bastaki, M., Harman, C. G., Taylor, S. V., Impact of structural and metabolic variations on the toxicity and carcinogenicity of hydroxy- and alkoxy-substituted allyl- and propenylbenzenes. Chemical Research in Toxicology 2014, 27, 1092-1103. 
[22] Lee, B. K., Kim, J. H., Jung, J. W., Choi, J. W., Han, E. S., Lee, S. H., Ko, K. H., Ryu, J. H., Myristicininduced neurotoxicity in human neuroblastoma SK-N-SH cells. Toxicology Letters 2005, 157, 49-56.

[23] Nickavar, B., Mojab, F., Javidnia, K., Amoli, M. A., Chemical composition of the fixed and volatile oils of Nigella sativa L. from Iran. Zeitschrift fur Naturforschung. C, Journal of Biosciences 2003, 58, 629631.

[24] Mimica-Dukić, N., Kujundžić, S., Soković, M., Couladis, M., Essential oil composition and antifungal activity of Foeniculum vulgare Mill. obtained by different distillation conditions. Phytotherapy Research 2003, 17, 368-371.

[25] Groh, I. A. M., Esselen, M., Methyleugenol and selected oxidative metabolites affect DNA-Damage signalling pathways and induce apoptosis in human colon tumour HT29 cells. Food and Chemical Toxicology 2017, 108, 267-275.

[26] Herrmann, K., Engst, W., Meinl, W., Florian, S., Cartus, A. T., Schrenk, D., Appel, K. E., Nolden, T., Himmelbauer, H., Glatt, H., Formation of hepatic DNA adducts by methyleugenol in mouse models: drastic decrease by Sult1a1 knockout and strong increase by transgenic human SULT1A1/2. Carcinogenesis 2014, 35, 935-941.

[27] Herrmann, K., Schumacher, F., Engst, W., Appel, K. E., Klein, K., Zanger, U. M., Glatt, H., Abundance of DNA adducts of methyleugenol, a rodent hepatocarcinogen, in human liver samples. Carcinogenesis 2013, 34, 1025-1030.

[28] Tremmel, R., Herrmann, K., Engst, W., Meinl, W., Klein, K., Glatt, H., Zanger, U. M., Methyleugenol DNA adducts in human liver are associated with SULT1A1 copy number variations and expression levels. Archives of Toxicology 2017, 91, 3329-3339.

[29] Miller, E. C., Swanson, A. B., Phillips, D. H., Fletcher, L., Liem, A., Miller, J. A., Structure-activity studies of the carcinogenicities in the mouse and rat of some naturally occurring and synthetic alkenylbenzene derivatives related to safrole and estragole. Cancer Research 1983, 43, 1124-1134.

[30] Phillips, D. H., Reddy, M. V., Randerath, K., 32P-post-labelling analysis of DNA adducts formed in the livers of animals treated with safrole, estragole and other naturally-occurring alkenylbenzenes. II. Newborn male B6C3F1 mice. Carcinogenesis 1984, 5, 1623-1628.

[31] NIH, Safrole, U.S. National Library of Medicine 2017 Available at: https://toxnet.nlm.nih.gov/cgibin/sis/search2/r?dbs+hsdb:@term+@DOCNO+2653. Accessed 27 September 2017.

[32] Rietjens, I. M. C. M., Martena, M. J., Boersma, M. G., Spiegelenberg, W., Alink, G. M., Molecular mechanisms of toxicity of important food-borne phytotoxins. Molecular Nutrition and Food Research. 2005, 49, 131-158.

[33] Zeller, A., Horst, K., Rychlik, M., Study of the metabolism of estragole in humans consuming fennel tea. Chemical Research in Toxicology 2009, 22, 1929-1937.

[34] Barlow, S., Renwick, A. G., Kleiner, J., Bridges, J. W., Busk, L., Dybing, E., Edler, L., Eisenbrand, G., Fink-Gremmels, J., Knaap, A., Kroes, R., Liem, D., Muller, D. J., Page, S., Rolland, V., Schlatter, J., Tritscher, A., Tueting, W., Wurtzen, G., Risk assessment of substances that are both genotoxic and carcinogenic report of an International Conference organized by EFSA and WHO with support of ILSI Europe. Food and Chemical Toxicology : An International Journal Published for The British Industrial Biological Research Association 2006, 44, 1636-1650.

[35] EFSA, Opinion of the Scientific Committee on a request from EFSA related to A Harmonised Approach for Risk Assessment of Substances Which are both Genotoxic and Carcinogenic. EFSA Journal 2005, 282, 1-31.

[36] EPA., The use of the benchmark dose approach in health risk assessment, US Environmental Protection Agency, Washington, DC. 1995.

[37] WHO, Safety evaluation of certain food additives/prepared by the sixty-ninth meeting of the Joint FAO/WHO Expert Committee on Food Additives (JEFCA), 2009. Available at: http://whqlibdoc.who.int/publications/2009/9789241660600_eng.pdf. Accessed.

[38] WHO, International Classification of Diseases (ICD) 10, 2010 Available at: http://www.who.int/classifications/icd/en/. Accessed 13 August 2017.

[39] Gursale, A., Dighe, V., Parekh, G., Simultaneous quantitative determination of cinnamaldehyde and methyl eugenol from stem bark of Cinnamomum zeylanicum Blume using RP-HPLC. Journal of Chromatographic Science 2010, 48, 59-62.

[40] Guideline, I. H. T., International Conference on Harmonization, Geneva, Switzerland 2005, pp. 11-12.

[41] Randerath, K., Haglund, R. E., Phillips, D. H., Reddy, M. V., ${ }^{32}$ P-post-labelling analysis of DNA adducts formed in the livers of animals treated with safrole, estragole and other naturally-occurring alkenylbenzenes. I. Adult female CD-1 mice. Carcinogenesis 1984, 5, 1613-1622. 
[42] Al-Malahmeh, A. J., Al-Ajlouni, A., Wesseling, S., Soffers, A. E. M. F., Al-Subeihi, A., Kiwamoto, R., Vervoort, J., Rietjens, I. M. C. M., Physiologically based kinetic modeling of the bioactivation of myristicin. Archives of Toxicology 2017, 91, 713-734.

[43] Al-Subeihi, A. A. A., Spenkelink, B., Punt, A., Boersma, M. G., van Bladeren, P. J., Rietjens, I. M. C. M., Physiologically based kinetic modeling of bioactivation and detoxification of the alkenylbenzene methyleugenol in human as compared with rat. Toxicology and Applied Pharmacology 2012, 260, 271284.

[44] Alajlouni, A. M., Al_Malahmeh, A. J., Kiwamoto, R., Wesseling, S., Soffers, A. E. M. F., Al-Subeihi, A. A. A., Vervoort, J., Rietjens, I. M. C. M., Mode of action based risk assessment of the botanical food-borne alkenylbenzene apiol from parsley using physiologically based kinetic (PBK) modelling and read-across from safrole. Food and Chemical Toxicology 2016, 89, 138-150.

[45] Punt, A., Freidig, A. P., Delatour, T., Scholz, G., Boersma, M. G., Schilter, B., van Bladeren, P. J., Rietjens, I. M. C. M., A physiologically based biokinetic (PBBK) model for estragole bioactivation and detoxification in rat. Toxicology and Applied Pharmacology 2008, 231, 248-259.

[46] Punt, A., Paini, A., Boersma, M. G., Freidig, A. P., Delatour, T., Scholz, G., Schilter, B., Bladeren, P. J. v., Rietjens, I. M. C. M., Use of physiologically based biokinetic (PBBK) modeling to study estragole bioactivation and detoxification in humans as compared with male rats. Toxicological Sciences 2009, 110, 255-269.

[47] NTP, NTP toxicology and carcinogenesis studies of methyleugenol (CAS NO. 93-15-2) in F344/N rats and B6C3F1 mice (Gavage studies). National Toxicology Program Technical Report Series 2000, 491, $1-412$.

[48] van den Berg, S. J. P. L., Punt, A., Soffers, A. E. M. F., Vervoort, J., Ngeleja, S., Spenkelink, B., Rietjens, I. M. C. M., Physiologically based kinetic models for the alkenylbenzene elemicin in rat and human and possible implications for risk assessment. Chemical Research in Toxicology 2012, 25, 2352-2367.

[49] FAO, Body Weights and Heights by Countries, Agriculture and Consumer Protection 2017 Available at: http:/ / www.fao.org/docrep/meeting/004/M2846E/M2846E07.htm. Accessed 30 May 2017.

[50] Doull, J., Rozman, K. K., Using Haber's Law to define the margin of exposure. Toxicology 2000, 149, $1-2$.

[51] Felter, S. P., Conolly, R. B., Bercu, J. P., Bolger, P. M., Boobis, A. R., Bos, P. M. J., Carthew, P., Doerrer, N. G., Goodman, J. I., Harrouk, W. A., Kirkland, D. J., Lau, S. S., Llewellyn, G. C., Preston, R. J., Schoeny, R., Schnatter, A. R., Tritscher, A., van Velsen, F., Williams, G. M., A proposed framework for assessing risk from less-than-lifetime exposures to carcinogens. Critical Reviews in Toxicology 2011, 41, 507-544.

[52] Gaylor, D. W., The use of Haber's Law in standard setting and risk assessment. Toxicology 2000, 149, 17-19.

[53] WB, Indonesia, The World Bank Group 2017 Available at: https:/ / data.worldbank.org/country/indonesia?view=chart. Accessed 7 December 2017.

[54] Martati, E., Boersma, M. G., Spenkelink, A., Khadka, D. B., van Bladeren, P. J., Rietjens, I. M. C. M., Punt, A., Physiologically based biokinetic (PBBK) modeling of safrole bioactivation and detoxification in humans as compared with rats. Toxicological Sciences 2012, 128, 301-316.

[55] van den Berg, S. J., Punt, A., Soffers, A. E., Vervoort, J., Ngeleja, S., Spenkelink, B., Rietjens, I. M., Physiologically based kinetic models for the alkenylbenzene elemicin in rat and human and possible implications for risk assessment. Chemical Research in Toxicology 2012, 25, 2352-2367.

[56] Kemenkes-RI, Riset Kesehatan Dasar Riskesdas 2013, Jakarta 2013. Available at: http:/ / www.depkes.go.id/resources/download/general/Hasil\%20Riskesdas\%202013.pdf. Accessed 27 September 2017.

[57] Zayas, J. F., Effect of ultrasonic treatment on the extraction of chymosin. Journal of Dairy Science 1986, $69,1767-1775$.

[58] SCF, 2001. Opinion of the scientific committee on food on methyleugenol (1-allyl-1,2dimethoxybenzene). $\quad$ https://ec.europa.eu/food/sites/food/files/safety/docs/scicom_scf_out102_en.pdf. Accessed 27 September 2017.

[59] Liu, W., Liu, J., Yin, D., Zhao, X., Influence of ecological factors on the production of active substances in the anti-cancer plant Sinopodophyllum hexandrum (Royle) T.S. Ying. PloS one 2015, 10, e0122981, 1-22.

[60] Smith, R. L., Adams, T. B., Doull, J., Feron, V. J., Goodman, J. I., Marnett, L. J., Portoghese, P. S., Waddell, W. J., Wagner, B. M., Rogers, A. E., Caldwell, J., Sipes, I. G., Safety assessment of 
allylalkoxybenzene derivatives used as flavouring substances - methyl eugenol and estragole. Food and Chemical Toxicology 2002, 40, 851-870.

[61] Di Cesare, L. F., Forni, E., Viscardi, D., Nani, R. C., Changes in the chemical composition of basil caused by different drying procedures. Journal of Agricultural and Food Chemistry 2003, 51, 3575-3581.

[62] Cartus, A., Schrenk, D., Current methods in risk assessment of genotoxic chemicals. Food and Chemical Toxicology 2017, 106, 574-582.

[63] Al-Malahmeh, A. J., Alajlouni, A. M., Ning, J., Wesseling, S., Vervoort, J., Rietjens, I. M. C. M., Determination and risk assessment of naturally occurring genotoxic and carcinogenic alkenylbenzenes in nutmeg-based plant food supplements. Journal of Applied Toxicology. 2017, 37, 1254-1264

[64] Wiseman, R. W., Fennell, T. R., Miller, J. A., Miller, E. C., Further characterization of the DNA adducts formed by electrophilic esters of the hepatocarcinogens 1'-hydroxysafrole and 1'hydroxyestragole in vitro and in mouse liver in vivo, including new adducts at C-8 and N-7 of guanine residues. Cancer Research 1985, 45, 3096-3105.

[65] Kobets, T., Duan, J.-D., Brunnemann, K. D., Etter, S., Smith, B., Williams, G. M., Structure-activity relationships for DNA damage by alkenylbenzenes in Turkey egg fetal liver. Toxicological Sciences 2016, 150, 301-311.

[66] Borchert, P., Miller, J. A., Miller, E. C., Shires, T. K., 1'-Hydroxysafrole, a proximate carcinogenic metabolite of safrole in the rat and mouse. Cancer Research 1973, 33, 590-600.

[67] EPA, Supplementary Guidance for Conducting Health Risk Assessment of Chemical Mixtures, U.S. Environmental Protection Agency, Washington, DC 2000EPA/630/R-00/002. Available at. Accessed 27 July 2017.

[68] Merz, K.-H., Schrenk, D., Interim relative potency factors for the toxicological risk assessment of pyrrolizidine alkaloids in food and herbal medicines. Toxicology Letters 2016, 263, 44-57.

[69] Crump, K. S., Hoel, D. G., Langley, C. H., Peto, R., Fundamental carcinogenic processes and their implications for low dose risk assessment. Cancer Research 1976, 36, 2973-2979.

[70] Rietjens, I. M. C. M., Punt, A., Schilter, B., Scholz, G., Delatour, T., van Bladeren, P. J., In silico methods for physiologically based biokinetic models describing bioactivation and detoxification of coumarin and estragole: Implications for risk assessment. Molecular Nutrition and Food Research 2010, 54, 195-207. 


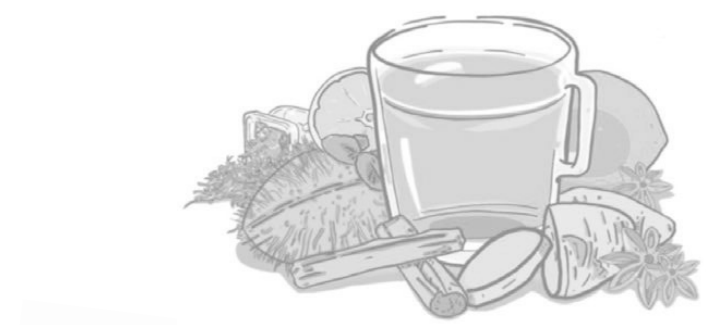

BENEFIT

RISK 


\section{Chapter 3}

\section{Levels of methyleugenol and eugenol in instant herbal beverages available on the Indonesian market and related risk assessment}

Suparmi Suparmi

Alex Junico Ginting

Siti Mariyam

Sebastiaan Wesseling

Ivonne M.C.M. Rietjens

Published in: Food and Chemical Toxicology, 125 (2019):467-478

DOI: 10.1016/j.fct.2019.02.001

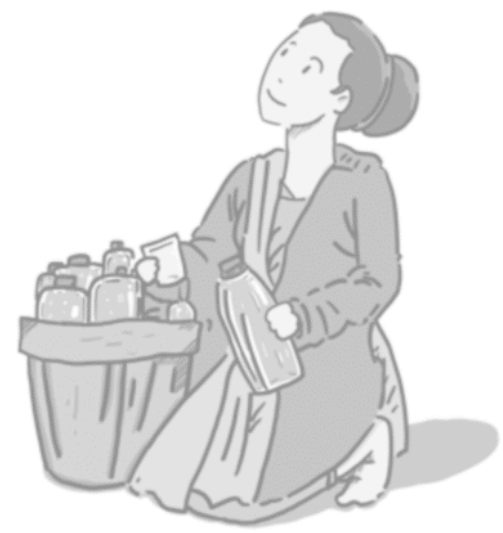




\section{Abstract}

The presence and accompanying risks of methyleugenol and eugenol in herbal beverages available on the Indonesian market were evaluated. Methyleugenol was detected in 49 out of 114 samples, at levels amounting to 2.6-443.7 $\mu \mathrm{g} / \mathrm{g}$, while 4 samples contained eugenol at 21.4-101.2 $\mu \mathrm{g} / \mathrm{g}$. The EDI resulting from drinking these preparations amounted to $0.1-51.2 \mu \mathrm{g} / \mathrm{kg}$ bw/ day and 1.1-3.3 $\mu \mathrm{g} / \mathrm{kg} \mathrm{bw} /$ day, respectively for samples targeted at adults and children. A BMDL 10 value of 22.2 $\mathrm{mg} / \mathrm{kg}$ bw/day for methyleugenol was defined using literature data and model averaging. MOE values were below 10,000 for 46 samples (40.4\%), indicating a priority for risk management when assuming daily lifelong consumption, while the EDI for 4 samples containing eugenol did not exceed the ADI of $2.5 \mathrm{mg} / \mathrm{kg}$ bw thus did not raise a concern for human health. Using Haber's rule to correct for less than lifetime exposure, consumption of methyleugenol via these beverages would be of low concern when consumed for less than 2 weeks/year during a lifetime. This conclusion holds for herbal beverages collected by targeted sampling, not for all herbal beverages on the Indonesian market. The study provides data that can support establishment of a maximum permitted level (MPL) for methyleugenol in herbal beverages in Indonesia. 


\subsection{Introduction}

Herbal beverages can be enriched in herbs such as ginger (Zingiber officinale Rosc), cloves (Syzygium aromaticum L.), cinnamon (Cinnamomum burmannii Blume), fennel (Foeniculum vulgare Mill.), betel pepper (Piper betle L.), star anise (Illicium verum), nutmeg (Myristica fragnan) or other herbs. Generally, such enrichment of herbal beverages with selected or mixed herbs is aiming at possible beneficial health effects.[1] Ginger containing beverages including preparations like wedang jahe, bandrek, ronde, bajigur, and sekoteng, are among the most popular herbal beverages consumed in Indonesia, because ginger has a long history as a thermogenic and antiemetic drink. ${ }^{[2]}$ Traditionally, Indonesian people need to prepare the herbal beverages by using mixed fresh herbs, but nowadays more people tend to choose instant herbal beverages which are commercially available. These products are usually in powder form, packaged in sealed and labelled plastic sachet, and readily consumed upon adding hot water and then drinking the resulting preparation.

Nowadays, consuming instant herbal beverages in Indonesia shows an increasing trend due to the easy online access and the fact that websites provide information about all kind of possible beneficial health effects of these products including: maintaining and increasing health, prevention of diseases, counteracting cold, increasing vitality after work, and slimming and cosmetic effects especially for women. ${ }^{[3]}$ In addition, the majority of people consider these herbal beverages to be safe, even during pregnancy, with less side effects than conventional medicines. ${ }^{[4]}$ The limitation of knowledge related to possible adverse health effects of herbal beverages may put consumers at risk that may arise from (over)consumption of herbal beverages, and therefore the quality and safety of these products should be assessed and monitored.[5]

The safety regulation of herbal products varies internationally among jurisdictions.[6] Herbal products are classified by the US Food and Drug Administration (FDA) as dietary supplements or foods and are marketed pursuant to the Dietary Supplement Health and Education Act (DSHEA) of 1994. This implies that a dietary supplement cannot carry any health claim or medical advice on the label..7] Similarly, in the European Union botanical preparations are considered food and these preparations should comply with broader requirements as defined for safe food while any health claim used needs scientific evaluation and approval by the European Food Safety Authority (EFSA). ${ }^{[8]}$ Australia formed the Advisory Committee on Complementary Medicines (ACCM) in 2010 to address regulatory issues regarding the safety, efficacy and manufacturing quality of herbal remedies. ${ }^{[9]}$ In Indonesia, botanical preparations can be registered as food[10] but also as traditional medicine. ${ }^{[11]}$ 
According to the Government Regulation 28/2004 on Food Safety, Quality and Nutrition, in Indonesia the food producer will receive a register approval number and get the marketing authorization number after passing the standard of safety and quality.[12] The product registration type is based on two parameters including: (1) the safety regulatory body in Indonesia where the product is registered, being either BPOM RI (Badan Pengawas Obat dan Makanan Republik Indonesia/National Agency for Drug and Food Control Republic of Indonesia, NADFC RI,) or Depkes RI (Departemen Kesehatan Republik Indonesia/Ministry of Health of Republic Indonesia, MoH RI) and (2) the category of the product being: MD (Pangan Olahan Dalam Negeri/Domestic Processed Food), ML (Pangan Olahan Luar Negeri/Foreign Processed Food), SD (Suplemen Dalam Negeri/Domestic Supplement), SL (Suplemen Luar Negeri/Foreign Supplement), TR (Obat Tradisional Produksi Dalam Negeri/ Indonesian Traditional Medicine), TI (Obat Tradisional Impor/Imported Traditional Medicine), TL (Obat Tradisional Lisensi/Licensed Traditional Medicine), and P-IRT (Pangan Industri Rumah Tangga/Food Household Industry). So far, all products with the label MD, ML, SD, SL, TR, TI and TL were registered by BPOM RI, therefore they are labelled BPOM RI MD, BPOM RI ML, BPOM RI SD, BPOM RI SL and BPOM RI TR, BPOM TI, BPOM TL respectively, while the household food product were labelled by Depkes RI P-IRT.[10]

The awareness and knowledge of herbal beverage producers in Indonesia related to the food safety and registration procedure is still limited.[13, 14] Therefore, the risks of consumption of the herbal beverages produced may not be adequately evaluated and/or regulated or guaranteed. The Indonesia Risk Assessment Center (INARAC), a body under the NADFC RI, after its initiation in November 2014 so far presented a Microbiology Risk Assessment (MRA) of chicken Salmonella and a risk assessment on Aflatoxin B1 (AFB1) levels in peanuts and their processed products in $2016,{ }^{[3]}$ while the safety and risks of frequent and prolonged consumption of herbal beverages have not yet been assessed.

Methyleugenol is a genotoxic and carcinogenic herbal ingredient that can be detected in basil (Ocimum basilicum L.) leaf,[15] star anise (Illicium anisatum L.) fruit, bay Laurel (Laurus nobilis L.) leaf, and ginger (Zingiber officinale Rosc) rhizome.[16] Recently, Suparmi et al. (2018) ${ }^{[17]}$ reported that methyleugenol was the major alkenylbenzene detected in most $(91.3 \%)$ of the samples testing positive for the presence of alkenylbenzenes in Indonesian jamu. The consumer risk based on the Margin of Exposure (MOE) approach showed that the consumption of jamu for two weeks once every year during a whole lifetime of Indonesian people presents a priority for risk management for 5 out of $23(21.7 \%)$ of the positively tested samples. Herrmann et al. (2013) ${ }^{[18]}$ reported that the exposure to methyleugenol leads to 
substantial levels of hepatic DNA adducts in the liver of human subjects. Twentynine out of 30 human liver samples were reported to contain the $N^{2}$-(transmethylisoeugenol-3'-yl)-2'-deoxyguanosine adduct. And based on experimental animal studies the induction of liver carcinogenesis upon exposure to high dose levels of methyleugenol is well established.[19]

Eugenol is another alkenylbenzene present in the herbs mentioned above and in the essential oils of botanicals frequently used in the herbal beverages including clove (Syzygium aromaticum L.), cinnamon (Cinnamomum burmannii Blume), and fennel (Foeniculum vulgare Mill.).[20, 21] In studies with eugenol in rats no carcinogenicity was observed while in a 2-year bioassay in mice the incidences of hepatocellular neoplasms were considered not significant and not dose-related.[22-25] Also, eugenol was considered not genotoxic at concentrations that did not result in cytotoxicity.[26-28] This lack of genotoxicity and carcinogencity of eugenol resulted in establishment of an acceptable daily intake (ADI) of $0-2.5 \mathrm{mg} / \mathrm{kg}$ bw/day by JECFA (1982) ${ }^{[26]}$ and of $1.0 \mathrm{mg} / \mathrm{kg}$ bw/ day by EFSA (2012), ${ }^{[28]}$ while also a risk assessment by the Research Institute for Fragrance Materials (RIFM) Expert Panel concluded that eugenol does not present a concern for genetic toxicity in human health. ${ }^{[20]}$ In line with this eugenol is listed as a permitted flavouring agent in the USA, EU, Australia and Indonesia. ${ }^{[29-32]}$

Based on these results it was anticipated that methyleugenol and eugenol may also be present and pose a risk in Indonesian instant herbal beverages. Therefore, the objective of the present study was to analyse methyleugenol and eugenol in a large number (114 samples) of instant herbal beverages containing various mixed herbs collected on the Indonesian market by a targeted sampling strategy, and to perform an associated human risk assessment using the MOE approach for methyleugenol and the ADI for eugenol. Also, an overview was made of their current product registration type indicated on the label. The results of this study may give information relevant for risk management aiming at prioritizing regulatory actions to reduce potential risks connected to instant herbal beverage consumption in Indonesia.

\subsection{Materials and Methods}

\subsubsection{Herbal beverage samples}

A targeted sampling approach was applied, collecting herbal samples with the name of possible methyleugenol containing herbs on the label. These herbs included ginger (Zingiber officinale Rosc), cloves (Syzygium aromaticum L.), cinnamon (Cinnamomum burmannii Blume), fennel (Foeniculum vulgare Mill.), betel pepper (Piper betle L.), star anise (Illicium verum), nutmeg (Myristica fragnan), lemongrass 
(Cymbopogon nardus L. Rendle), carrot (Daucus carota subsp. sativus), and galangal (Kaempferia galanga), all known to contain methyleugenol.[23] One-hundred-fourteen samples of herbal instant beverages from different brands were purchased from traditional markets or supermarkets as depicted in Figure 3.1, including sampling in Medan ( 1 store, $n=2)$, Semarang (11 stores, $n=54$ ), Bawen ( 1 store, $n=9$ ), Magelang (1 store, $n=6$ ), Purworejo (1 store, $n=1$ ), Yogyakarta (2 stores, $n=9$ ), Surakarta (2 stores, $n=7)$, Nganjuk (4 stores, $n=19)$, Kediri ( 1 store, $n=4)$, and Mojokerto (1 store, $n=3)$.

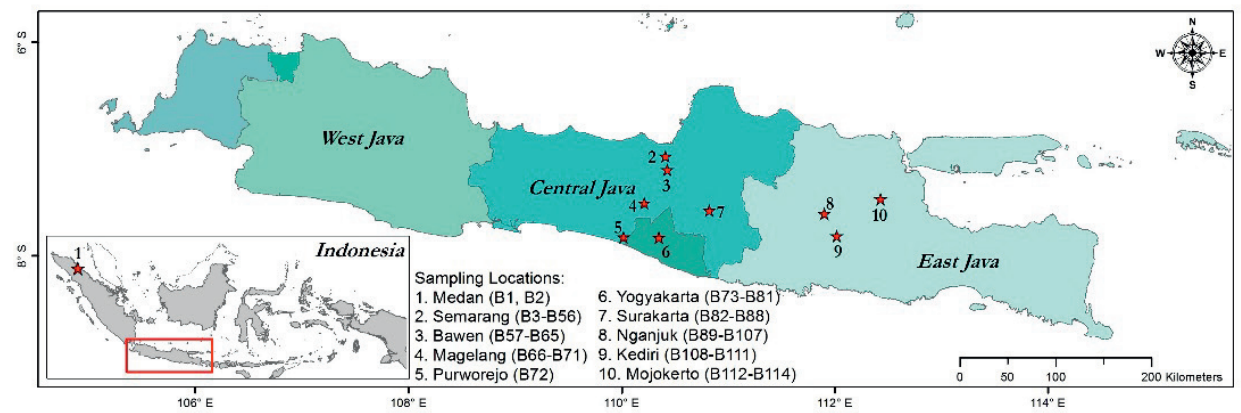

Figure 3.1. Sampling locations of the Indonesian instant herbal beverages used in this study. B1-B114 represent the sample IDs used in the present study.

Detailed information, including information on the respective herbs of concern present in the samples, the instructions for preparation and consumption of the beverages, beneficial effects claimed, and product registration according to the Indonesian system for labelling of these herbal samples outlined in the introduction, all as indicated on the label of each sample, are summarised in Supplementary materials (Table 1). All samples, denoted B1-B114 in the present study, were in powder form and packaged in sachets. Among the 114 samples 98 samples were targeted to be consumed by adults, and 16 samples were dedicated to use by children.

\subsubsection{Chemicals and Reagents}

Methyleugenol (purity 99\%), estragole (purity 98\%), safrole (purity $97 \%$ ) and eugenol (purity 99\%) were obtained from Sigma-Aldrich (Zwijdrecht, The Netherlands). Acetonitrile ULC/MS gradient, trifluoracetic acid (TFA) and dimethyl sulfoxide (DMSO) were purchased from Merck (Felsberg, Germany). Methanol ULC/MS gradient was purchased from Sigma-Aldrich, and nanopure water was obtained from an Arium pro UF/VF water purification system (Sartorius Weighing Technology GmbH, Gottingen, Germany). 


\subsubsection{Analysis of methyleugenol and eugenol levels}

\subsubsection{Methanol extract}

The level of alkenylbenzenes present in the samples was determined by methanol extraction followed by UPLC analysis performed as described by Gursale et al. (2010)[33] with minor modifications. The homogeneity of each sample was ensured by mixing manually $100 \mathrm{~g}$ from 6-20 sachets of sample in a ziplock plastic packet before taking samples for extraction. For the extraction methanol $(10 \mathrm{ml})$ was poured over $1 \mathrm{~g}$ of homogenized sample in a brown glass extraction bottle, and the sample was mixed and sonicated for $15 \mathrm{~min}$ at room temperature. Upon sonication, the sample solution was filtered using a $0.45 \mu \mathrm{m}$ syringe filter (VWR international). The filtrate was placed into a $1 \mathrm{ml}$ Ultra Performance Chromatography (UPLC) vial and subsequently injected into the chromatographic system. Every sample was prepared and analysed in triplicate.

The extraction efficiency was evaluated based on the Guidance for Industry Bioanalytical Method Validation ${ }^{[34]}$ by spiking and mixing $1 \mathrm{~g}$ of sample B89, B114, with a methyleugenol standard dissolved in DMSO at a concentration that would give a final concentration of $10 \mu \mathrm{M}$ upon addition of $10 \mathrm{ml}$ methanol in the extraction procedure performed as described above. The average percentage of recovery was used to correct the levels of methyleugenol detected for the different instant herbal beverages samples. To confirm linearity of the method, samples were analysed in five different ratios of weight per volume of methanol in the range from 2.5 to $40 \%$ $(\mathrm{w} / \mathrm{v})$. In a separate recovery experiment the samples B89, B114 were also spiked with a mixture of eugenol and methyleugenol to determine recoveries. Eugenol was included in the studies because some samples appeared to contain eugenol (see Results section). Since safrole and estragole were not detected in the respective samples their recovery was not further quantified. The limits of detection (LOD) amounted to $1.2,3.0$ and $5.5 \mu \mathrm{M}$ for methyleugenol, safrole and estragole, respectively.

\subsubsection{UPLC analysis}

The methanol extracts were analysed in undiluted form. To this end $3.5 \mu \mathrm{l}$ of each sample was subjected to UPLC analysis performed as described before.[35] The UPLC used was a UPLC-DAD system consisting of a Waters (Milford, MA) Acquity binary solvent manager, sample manager, and photodiode array detector, equipped with a Waters Acquity UPLC BEH RP 18 column $(1.7 \mu \mathrm{m}, 2.1 \times 50 \mathrm{~mm})$. The column was kept at $22^{\circ} \mathrm{C}$, while the sample temperature was set at $10^{\circ} \mathrm{C}$. UPLC analysis was performed using a mobile phase A of nanopure water containing $0.1 \%(\mathrm{v} / \mathrm{v})$ TFA and mobile phase B consisting of acetonitrile and a gradient program with a flow 
rate of $0.6 \mathrm{ml} / \mathrm{min}$. The mobile phase composition started with $30.5 \% \mathrm{~B}$, which was maintained for $15 \mathrm{~min}$, followed by an increase to $80 \%$ B over $1 \mathrm{~min}$ and holding this for $0.5 \mathrm{~min}$, followed by a decrease to $0 \% \mathrm{~B}$ in $1.5 \mathrm{~min}$ and keeping it at $0 \%$ for $1 \mathrm{~min}$ after which the eluents was returned to the initial conditions of $30.5 \% \mathrm{~B}$ for the next run in $20.5 \mathrm{~min}$. Under the specified chromatographic conditions, the retention times for eugenol, methyleugenol, safrole and estragole were 2.2, 4.3, 8.1 and $9.0 \mathrm{~min}$, respectively. Detection of safrole and estragole was done at $202 \mathrm{~nm}$ and used $225 \mathrm{~nm}$ respectively. For detection and quantitative analysis of methyleugenol, and eugenol, the wavelength was $202 \mathrm{~nm}$. The peak intensity at this wavelength was compared to calibration curves of the compounds prepared using commercially available standards.

\subsubsection{Exposure assessment resulting from the drinking of instants herbal beverages based on methyleugenol and eugenol levels detected}

In order to assess the potential exposure to methyleugenol or eugenol resulting from drinking the herbal beverages, the estimated daily intake (EDI) was calculated. The EDI values were expressed in $\mu \mathrm{g} / \mathrm{kg}$ bw/day using a body weight (bw) of $54 \mathrm{~kg}$, the average bw for Indonesian male and female.[36] For the products targeted at children as their consumers, the EDI was calculated using a bw of 27.21 $\mathrm{kg}$, the average bw of Indonesian boys and girls under the age of 1-17 years old.[36]

The EDI calculation was done using the levels detected in the various samples and the recommended daily consumption of these samples as presented on the product labels (Table 3.1). The weight of the recommended daily consumption (g) was based on the preparation method indicated on the label (see Table 1 at Supplementary materials), assuming that 1 teaspoon equals $6 \mathrm{~g}$, and 1 tablespoon equals $10 \mathrm{~g}$, representing the average of weighting the respective samples using a full tea spoon and tablespoon from Indonesia (3 replications). When there was no information on the label (unknown) the weight and frequency of consumption were assumed to be equal to 3 full teaspoons once a day. In line with the habits for use of the herbal beverages, it was assumed that consumption of the herbal beverage implies consumption of the whole preparation mixed with water. EDI values were calculated following Equation 3.1:

$E D I\left(\frac{\mu \mathrm{g} / \mathrm{kg} \mathrm{bw} / \text { day }}{\text { day }}\right)=$

$\underline{\text { recommended daily consumption }(\mathrm{g} / \text { day }) \times \text { level of detected methyleugenol }(\mu \mathrm{g} / \mathrm{g})}$ bw $(k g)$

(Equation 3.1) 


\subsubsection{Benchmark Dose (BMD) modelling for methyleugenol}

To define the lower confidence limit of the benchmark dose resulting in a 10\% extra cancer incidence $\left(\mathrm{BMDL}_{10}\right)$ the quantal dose-response data for induction of hepatocellular carcinoma in male and female F344/ $\mathrm{N}$ rat induced by methyleugenol and reported by the NTP (2000) ${ }^{[19]}$ (see Supplementary materials at Table 2) were used for BMD modelling. In the 2-years study, 50 rats per group for both sexes, were administered methyleugenol orally in $0.5 \%$ methylcellulose at doses of $0,37,75$, or $150 \mathrm{mg} / \mathrm{kg}$, 5 days per week for 105 weeks. For the modelling, these experimental dose levels were converted to the time-adjusted dose levels $(\mathrm{mg} / \mathrm{kg}$ bw/day) by multiplying the actual dose by $5 / 7$ (to correct for the 5 instead of 7 days per week dosing regimen) in line with what was reported before by van den Berg et al. (2011) ${ }^{[35]}$ and Benford et al. (2010) ${ }^{[37]}$.

Previously $\mathrm{BMDL}_{10}$ values for methyleugenol were obtained using EPA BMDS software version 2.6.0.1 using different models, including the Gamma, Logistic, Log-logistic, Probit, Log-probit, Multistage, Weibull and Quantal linear model.[35] This resulted in values between $15.3-34.0 \mathrm{mg} / \mathrm{kg}$ bw/ day resulting from male and female rat data. In the present study the data were analyzed using model averaging, as recommended by the EFSA Scientific Committee (2017) ${ }^{[38]}$, to derive the final $\mathrm{BMDL}_{10}$ from multiple fitted benchmark dose models. To this end the online EFSA's web-tool for BMD analysis (https://shinyefsa.openanalytics.eu/app/bmd), which implements statistical methods for Rpackage PROAST, version 65.7 Proast ${ }^{[39]}$ was used. The BMDL ${ }_{10}$ model averaging was performed using the default settings.

\subsubsection{Safety assessment using the Margin of Exposure (MOE) approach for methyleugenol}

The MOE approach was applied to assess the risk posed by the use of the methyleugenol containing herbal beverages, in line with the recommendations of EFSA for risk assessment of compounds that are both genotoxic and carcinogenic. ${ }^{40]}$ The final $\mathrm{BMDL}_{10}$ resulting from model averaging using male rat data (providing a lower value than obtained from the female data, see Results section) and EDI values were used to calculate the MOE values according to Equation 3.2. MOE values were rounded to a single significant figure.

$M O E=\frac{B M D L_{10}}{E D I}$

(Equation 3.2)

The MOE values are based on chronic lifetime exposure, although realistic use of the herbal drinks may be for shorter periods of time. Although there is no officially established method to evaluate shorter than lifetime exposure to a genotoxic carcinogen, it has been suggested to use Haber's rule to estimate the effects for 


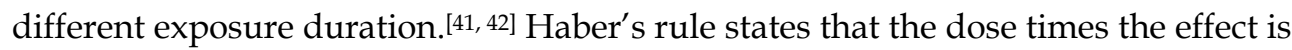
constant, $(\mathrm{C} 1 \times \mathrm{T} 1=$ constant $=\mathrm{C} 2 \times \mathrm{T} 2)$ which implies that one could correct for shorter time of exposure in a linear way. Using this approach, the MOE values were also calculated for regular short term exposure, i.e. 2 weeks, once every year during a lifetime. This exposure scenario was chosen to mimic the situation where people consume a herbal beverage as a supplement to counteract cold or during periods of illness. In addition, Haber's rule was also used to calculate the number of weeks of daily consumption of the different herbal beverage samples that would result in an MOE value of 10,000 , the threshold for risk management concern. ${ }^{[40]}$

\subsubsection{Safety assessment of eugenol containing herbal beverages}

The risk of consuming herbal beverages which contained eugenol was assessed using the Acceptable Daily Intake (ADI) of $0-2.5 \mathrm{mg} / \mathrm{kg}$ bw established by JECFA (2006)[27] and the ADI of $1 \mathrm{mg} / \mathrm{kg}$ bw/day established by EFSA (2012)[28], in line with the recommendations of EFSA for risk assessment of compounds that are non-genotoxic ${ }^{[43]}$.

\subsubsection{Evaluation of the product registration established in Indonesia based on the safety assessment results and product registration type}

To evaluate the product registration as applied in Indonesia during the product registration, this product registration was reviewed based on the results of the safety assessment in the present study. The product registration on the label of 114 samples indicated BPOM RI MD (domestic processed food, 31 samples), BPOM RI ML (foreign processed food, 1 sample), BPOM RI SD (domestic supplement, 9 samples), BPOM RI TR traditional medicine (traditional medicine, 30 samples) and Depkes RI P-IRT samples sold as regular home industry food product (food household industry, 43 samples).

\subsection{Results}

\subsubsection{Methyleugenol and eugenol levels in Indonesian instant herbal beverages}

Table 3.1 presents the level of the alkenylbenzenes, methyleugenol and eugenol, as detected and quantified in the herbal beverage samples. Estragole and safrole were not detected. Methyleugenol was detected in 49 out of 114 samples, at levels ranging from 2.6 to $443.7 \mu \mathrm{g} / \mathrm{g}$. Sample B91, sold as a household industry food product (labelled as P-IRT), appears to contain the highest methyleugenol level at $443.7 \mu \mathrm{g} / \mathrm{g}$. In 65 of the 114 samples 65 levels of all three alkenylbenzenes were below their respective limit of detection (LOD) of 1.2, 3.0 and $5.5 \mu \mathrm{M}$ for methyleugenol, safrole and estragole, respectively. Interestingly, 4 out of 114 
samples, B5, B19, B83 and B109 appeared to contain eugenol at a level of $21.4-101.2$ $\mu \mathrm{g} / \mathrm{g}$.

Table 3.1. The level of methyleugenol and eugenol detected in the instant herbal beverages and the resulting estimated daily intake (EDI) calculated using the recommendations for daily consumption on the label and assuming the level to equal the LOD of $1.2 \mathrm{mM}(1.9 \mu \mathrm{g} / \mathrm{g})$ for samples where methyleugenol was below the LOD to provide an upper bound EDI.

\begin{tabular}{|c|c|c|c|c|c|}
\hline $\begin{array}{l}\text { Sample } \\
\text { ID }\end{array}$ & $\begin{array}{l}\text { Detected } \\
\text { compound }\end{array}$ & $\begin{array}{c}\text { Level } \\
(\mu \mathrm{g} / \mathrm{g})^{\mathrm{a}}\end{array}$ & $\begin{array}{l}\text { Recommended } \\
\text { daily consumption } \\
\text { (g) of the sample }\end{array}$ & $\begin{array}{l}\text { Specified } \\
\text { consumer }\end{array}$ & $\begin{array}{c}\text { EDI } \\
(\mu \mathrm{g} / \mathrm{kg} \text { bw/day })\end{array}$ \\
\hline B1 & Methyleugenol & $14.0 \pm 1.6$ & 20 & Adult & 5.2 \\
\hline B2 & Methyleugenol & $94.2 \pm 1.4$ & 18 & Adult & 31.4 \\
\hline B3 & $n d^{b}$ & & 11 & Adult & 0.40 (upper bound) \\
\hline B4 & nd & & 14 & Adult & 0.51 (upper bound) \\
\hline B5 & Eugenol & $101.2 \pm 20.6$ & 25 & Adult & 46.9 \\
\hline B6 & nd & & 8 & Adult & 0.3 (upper bound) \\
\hline B7 & nd & & 8 & Adult & 0.3 (upper bound) \\
\hline B8 & nd & & 8 & Adult & 0.3 (upper bound) $^{c}$ \\
\hline B9 & nd & & 25 & Adult & 0.9 (upper bound) \\
\hline B10 & nd & & 11 & Adult & 0.4 (upper bound) \\
\hline B11 & nd & & 5 & Adult & 0.2 (upper bound) $^{\mathrm{c}}$ \\
\hline B12 & nd & & 6.3 & Adult & 0.2 (upper bound) \\
\hline B13 & nd & & 21 & Adult & 0.8 (upper bound) \\
\hline B14 & nd & & 4 & Adult & 0.1 (upper bound) \\
\hline B15 & nd & & 7 & Adult & 0.3 (upper bound) \\
\hline B16 & nd & & 10 & Adult & 0.4 (upper bound) \\
\hline B17 & nd & & 13.5 & Adult & 0.5 (upper bound) \\
\hline B18 & nd & & 12 & Adult & 0.4 (upper bound) \\
\hline B19 & Eugenol & $21.4 \pm 3.3$ & 12.6 & Adult & 5.0 \\
\hline B20 & nd & & 12.6 & Adult & 0.5 (upper bound) \\
\hline B21 & nd & & 30 & Adult & 1.1 (upper bound) \\
\hline B22 & nd & & 25 & Adult & 0.9 (upper bound) \\
\hline B23 & nd & & 8 & Adult & 0.3 (upper bound) \\
\hline B24 & Methyleugenol & $18.2 \pm 4.8$ & 60 & Adult & 20.3 \\
\hline B25 & Methyleugenol & $34.3 \pm 1.6$ & 20 & Adult & 12.7 \\
\hline B26 & nd & & 15 & Children & 1.1 (upper bound) \\
\hline B27 & nd & & 15 & Children & 1.1 (upper bound) $^{\mathrm{c}}$ \\
\hline B28 & nd & & 21 & Children & 1.5 (upper bound) $^{\mathrm{c}}$ \\
\hline B29 & nd & & 21 & Children & 1.5 (upper bound) \\
\hline B30 & nd & & 21 & Children & 1.5 (upper bound) \\
\hline B31 & nd & & 21 & Children & 1.5 (upper bound) \\
\hline B32 & Methyleugenol & $110.6 \pm 0.5$ & 25 & Adult & 51.2 \\
\hline B33 & nd & & 15 & Children & 1.1 (upper bound) \\
\hline B34 & nd & & 15 & Children & 1.1 (upper bound) \\
\hline B35 & nd & & 15 & Children & 1.1 (upper bound) \\
\hline B36 & nd & & 15 & Children & 1.1 (upper bound) \\
\hline B37 & nd & & 15 & Children & 1.1 (upper bound) \\
\hline B38 & nd & & 15 & Children & 1.1 (upper bound) \\
\hline B39 & nd & & 15 & Children & 1.1(upper bound) \\
\hline B40 & nd & & 21 & Adult & 0.8 (upper bound) \\
\hline B41 & nd & & 8 & Adult & 0.3 (upper bound) \\
\hline B42 & Methyleugenol & $65.06 \pm 48.05$ & 23 & Adult & 27.7 \\
\hline B43 & nd & & 28 & Adult & 1.0 (upper bound) $^{\mathrm{c}}$ \\
\hline B44 & nd & & 25 & Adult & 0.9 (upper bound) \\
\hline
\end{tabular}




\begin{tabular}{|c|c|c|c|c|c|}
\hline $\begin{array}{l}\text { Sample } \\
\text { ID }\end{array}$ & $\begin{array}{c}\text { Detected } \\
\text { compound }\end{array}$ & $\begin{array}{c}\text { Level } \\
(\mu \mathrm{g} / \mathrm{g})^{\mathrm{a}}\end{array}$ & $\begin{array}{l}\text { Recommended } \\
\text { daily consumption } \\
\text { (g) of the sample }\end{array}$ & $\begin{array}{l}\text { Specified } \\
\text { consumer }\end{array}$ & $\begin{array}{c}\text { EDI } \\
(\mu \mathrm{g} / \mathrm{kg} \mathrm{bw} / \text { day })\end{array}$ \\
\hline B45 & nd & & 12.6 & Adult & 0.5 (upper bound) ${ }^{c}$ \\
\hline B46 & nd & & 25 & Adult & 0.9 (upper bound) \\
\hline B47 & nd & & 25 & Adult & 0.9 (upper bound) \\
\hline B48 & Methyleugenol & $16.1 \pm 2.5$ & 25 & Adult & 7.5 \\
\hline B49 & Methyleugenol & $17.5 \pm 6.8$ & 26 & Adult & 8.4 \\
\hline B50 & nd & & 21 & Children & 1.5 (upper bound) ${ }^{c}$ \\
\hline B51 & nd & & 25 & Adult & 0.9 (upper bound) ${ }^{c}$ \\
\hline B52 & nd & & 8 & Adult & 0.3 (upper bound) \\
\hline B53 & nd & & 8 & Adult & 0.3 (upper bound) ${ }^{c}$ \\
\hline B54 & nd & & 8 & Adult & 0.3 (upper bound) \\
\hline B55 & Methyleugenol & $9.6 \pm 0.2$ & 22.5 & Adult & 4.0 \\
\hline B56 & Methyleugenol & $31.2 \pm 0.3$ & 30 & Adult & 17.3 \\
\hline B57 & Methyleugenol & $7.1 \pm 0.4$ & 25 & Adult & 3.3 \\
\hline B58 & nd & & 25 & Adult & 0.9 (upper bound) $^{c}$ \\
\hline B59 & Methyleugenol & $4.2 \pm 0.3$ & 25 & Adult & 1.9 \\
\hline B60 & nd & & 21 & Children & 1.5 (upper bound) \\
\hline B61 & nd & & 21 & Adult & 0.8 (upper bound) \\
\hline B62 & Methyleugenol & $4.2 \pm 1.7$ & 21 & Children & 3.3 \\
\hline B63 & nd & & 30 & Adult & 1.1 (upper bound) \\
\hline B64 & Methyleugenol & $11.9 \pm 2.0$ & 25 & Adult & 5.5 \\
\hline B65 & nd & & 27 & Adult & 1.0 (upper bound) \\
\hline B66 & nd & & 25 & Adult & 0.9 (upper bound) \\
\hline B67 & Methyleugenol & $35.9 \pm 15.5$ & 15 & Adult & 10.0 \\
\hline B68 & Methyleugenol & $28.4 \pm 17.5$ & 15 & Adult & 7.9 \\
\hline B69 & nd & & 15 & Adult & 0.5 (upper bound) \\
\hline $\mathrm{B} 70$ & nd & & 15 & Adult & 0.5 (upper bound) \\
\hline B71 & nd & & 15 & Adult & 0.5 (upper bound) \\
\hline B72 & nd & & 10 & Adult & 0.4 (upper bound) \\
\hline B73 & Methyleugenol & $13.0 \pm 0.1$ & 25 & Adult & 6.0 \\
\hline B74 & Methyleugenol & $16.1 \pm 1.3$ & 10 & Adult & 3.0 \\
\hline B75 & Methyleugenol & $51.6 \pm 1.5$ & 10 & Adult & 9.6 \\
\hline B76 & Methyleugenol & $19.8 \pm 1.6$ & 25 & Adult & 9.2 \\
\hline B77 & Methyleugenol & $12.7 \pm 2.2$ & 30 & Adult & 7.0 \\
\hline B78 & Methyleugenol & $11.4 \pm 9.1$ & 20 & Adult & 4.2 \\
\hline B79 & Methyleugenol & $14.2 \pm 2.3$ & 20 & Adult & 5.3 \\
\hline B80 & Methyleugenol & $11.4 \pm 1.3$ & 18 & Adult & 3.8 \\
\hline B81 & nd & & 18 & Adult & 0.7 (upper bound) \\
\hline B82 & Methyleugenol & $2.7 \pm 1.2$ & 23 & Adult & 1.1 \\
\hline B83 & Eugenol & $37.8 \pm 6.9$ & 25 & Adult & 17.5 \\
\hline B84 & Methyleugenol & $14.2 \pm 0.8$ & 10 & Adult & 2.6 \\
\hline B85 & Methyleugenol & $42.6 \pm 6.6$ & 33 & Adult & 26.1 \\
\hline B86 & Methyleugenol & $66.9 \pm 2.9$ & 25 & Adult & 31.0 \\
\hline B87 & Methyleugenol & $24.0 \pm 3.7$ & 40 & Adult & 17.8 \\
\hline B88 & Methyleugenol & $28.7 \pm 1.7$ & 22 & Adult & 11.7 \\
\hline B89 & nd & & 28 & Adult & 1.0 (upper bound) \\
\hline B90 & nd & & 75 & Adult & 2.7 (upper bound) \\
\hline B91 & Methyleugenol & $443.7 \pm 31.5$ & 6 & Adult & 49.3 \\
\hline B92 & Methyleugenol & $10.1 \pm 0.4$ & 30 & Adult & 5.6 \\
\hline B93 & Methyleugenol & $9.3 \pm 0.4$ & 15 & Adult & 2.6 \\
\hline B94 & Methyleugenol & $28.9 \pm 5.7$ & 15 & Adult & 8.0 \\
\hline B95 & Methyleugenol & $36.9 \pm 1.2$ & 15 & Adult & 10.2 \\
\hline B96 & Methyleugenol & $23.2 \pm 1.0$ & 22 & Adult & 9.5 \\
\hline B97 & Methyleugenol & $36.3 \pm 3.0$ & 23 & Adult & 15.5 \\
\hline
\end{tabular}


Risk assessment based on methyleugenol level in herbal beverages

\begin{tabular}{|c|c|c|c|c|c|}
\hline $\begin{array}{l}\text { Sample } \\
\text { ID }\end{array}$ & $\begin{array}{c}\text { Detected } \\
\text { compound }\end{array}$ & $\begin{array}{l}\text { Level } \\
(\mu \mathrm{g} / \mathrm{g})^{\mathrm{a}}\end{array}$ & $\begin{array}{l}\text { Recommended } \\
\text { daily consumption } \\
\text { (g) of the sample }\end{array}$ & $\begin{array}{l}\text { Specified } \\
\text { consumer }\end{array}$ & $\begin{array}{c}\text { EDI } \\
(\mu \mathrm{g} / \mathrm{kg} \text { bw } / \text { day })\end{array}$ \\
\hline B98 & Methyleugenol & $24.1 \pm 1.3$ & 20 & Adult & 8.9 \\
\hline B99 & Methyleugenol & $21.2 \pm 1.0$ & 27.5 & Adult & 10.8 \\
\hline B100 & Methyleugenol & $2.6 \pm 0.3$ & 25 & Adult & 1.2 \\
\hline B101 & Methyleugenol & $2.6 \pm 1.1$ & 22.5 & Adult & 1. \\
\hline B102 & Methyleugenol & $50.8 \pm 3.3$ & 25 & Adult & 23.5 \\
\hline B103 & Methyleugenol & $85.0 \pm 6.5$ & 20 & Adult & 31.5 \\
\hline B104 & Methyleugenol & $109.3 \pm 9.5$ & 25 & Adult & 50.6 \\
\hline B105 & Methyleugenol & $33.1 \pm 0.3$ & 25 & Adult & 15.3 \\
\hline B106 & nd & & 25 & Adult & 0.9 (upper bound) ${ }^{c}$ \\
\hline B107 & nd & & 24 & Adult & 0.9 (upper bound) \\
\hline B108 & Methyleugenol & $15.8 \pm 4.3$ & 20 & Adult & 5.9 (upper bound) ${ }^{c}$ \\
\hline B109 & Eugenol & $26.2 \pm 5.7$ & 30 & Adult & 14.6 \\
\hline B110 & Methyleugenol & $17.0 \pm 1.4$ & 25 & Adult & 7.9 \\
\hline B111 & Methyleugenol & $31.5 \pm 1.5$ & 10 & Adult & 5.8 \\
\hline B112 & Methyleugenol & $58.4 \pm 1.1$ & 20 & Adult & 21.6 \\
\hline B113 & nd & & 20 & Adult & 0.7 (upper bound) \\
\hline B114 & nd & & 25 & Adult & 0.9 (upper bound) \\
\hline
\end{tabular}

aMean of 3 independent analyses. Levels were corrected for the recovery result (see materials and methods)

bNot detected

cThe EDI values of samples in which levels were below the LOD, were calculated using the LOD of methyleugenol of $1.2 \mu \mathrm{M}$ corresponding to $1.9 \mu \mathrm{g} / \mathrm{g}$ sample thus representing an upper bound.

\subsubsection{EDIs of methyleugenol and eugenol resulting from daily consumption of the herbal beverages}

Using the quantified levels of methyleugenol and eugenol in the various samples and the direction for their use as indicated on the labels (Supplementary materials Table 1), EDI values were calculated using Equation 3.1. EDI values thus obtained range from 1.1 to $51.2 \mu \mathrm{g}$ methyleugenol/ $\mathrm{kg}$ bw/day for the 49 positive samples containing methyleugenol (see Table 3.1). Sample B32, sold as a traditional medicine (labelled BPOM RI TR), appears to result in the highest EDI, followed by B104 (labelled BPOM RI MD) and B91 (labelled Depkes RI P-IRT) with EDI values amounting to respectively 50.6 and $49.3 \mu \mathrm{g} / \mathrm{kg}$ bw/ day. For samples in which levels of methyleugenol were below the LOD, EDI values were calculated by a so-called upper bound approach, assuming levels to be at the LOD of $1.9 \mu \mathrm{g} / \mathrm{g}$ sample. The EDI values thus obtained for these 65 samples in which methyleugenol was below the LOD ranged from 0.1 to $2.7 \mu \mathrm{g} / \mathrm{kg}$ bw/day. This approach to use the LOD to substitute the results below the LOD to define an upper bound for the exposure was recommended by the WHO GEMS/Food EURO workshop. ${ }^{[4]}$ Fifteen out of the 16 samples $(94 \%)$ specified to be consumed by children appeared to contain no methyleugenol resulting, using the same upper bound approach, in upper bound EDI values of 1.1 to $1.5 \mu \mathrm{g} / \mathrm{kg}$ bw/day. The EDI of eugenol calculated for the 4 eugenol containing samples (out of 114) ranged from 5.0 to $46.9 \mu \mathrm{g} / \mathrm{kg} \mathrm{bw} /$ day. 


\subsection{3. $\mathrm{BMDL}_{10}$ value for methyleugenol obtained by model averaging}

Given that $\mathrm{BMDL}_{10}$ values for methyleugenol available in the literature were derived from single model fits in some cases selecting the lowest value, and that at the present state-of-the-art model averaging is considered the preferred method, the $\mathrm{BMDL}_{10}$ value for methyleugenol was recalculated using model averaging. Tumor data analyzed were the data from the NTP study reporting dose-dependent incidences of hepatocellular carcinoma in rats exposed to methyleugenol via gavage for 2 years ${ }^{[19]}$ (Supplementary Table 2). The time-adjusted dose levels (mg/kg bw/day) calculated by multiplying the actual dose by $5 / 7$ were used to correct for the 5 instead of 7 days per week dosing regimen. ${ }^{[35,37]}$ The final $\mathrm{BMDL}_{10}$ values resulting from model averaging were $22.2 \mathrm{mg} / \mathrm{kg}$ bw/day for male rats (Table 3.2) and $66.5 \mathrm{mg} / \mathrm{kg} \mathrm{bw/day} \mathrm{for} \mathrm{female} \mathrm{rats} \mathrm{(Table} 3$ of Supplementary materials). Figures representing the model fits are also presented in the Supplementary materials (Figure 1 and 2). 


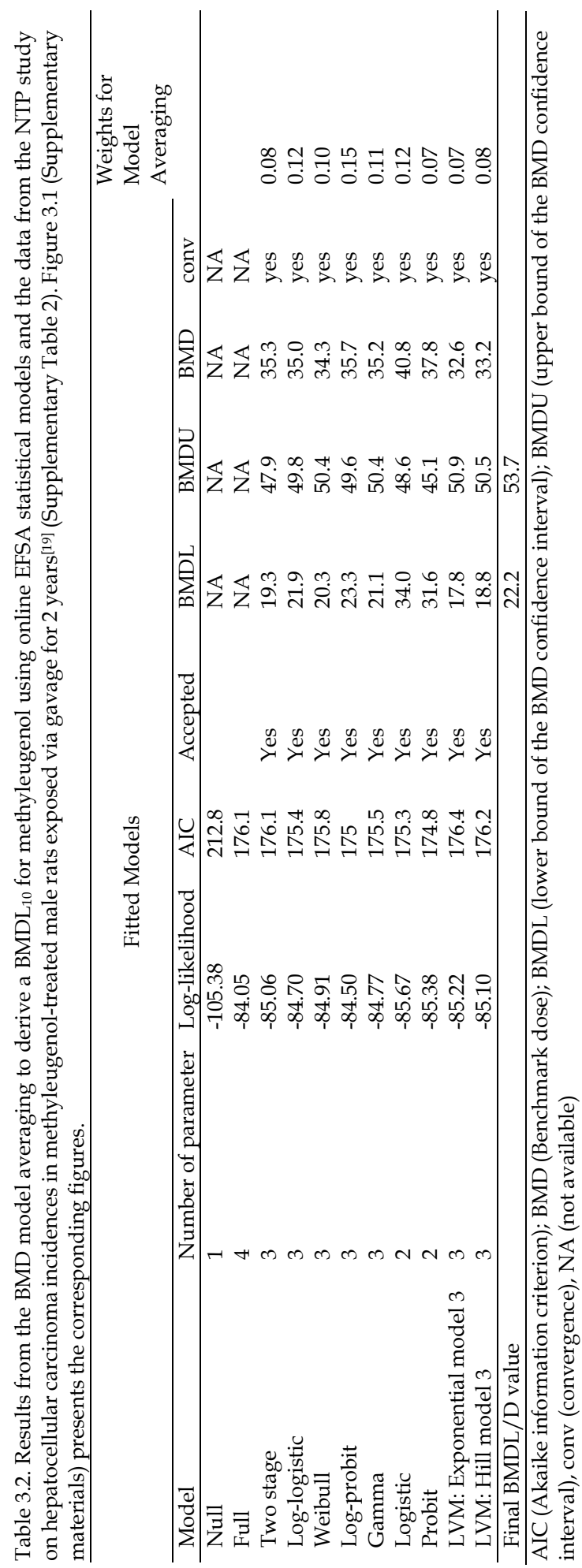




\subsubsection{MOE based risk assessment for methyleugenol}

Considering the target consumer for the herbal beverages samples, the MOE based risk assessment in this study separated into adults and children (Table 3.1). Figure $3.2 \mathrm{~A}$ presents the MOE values calculated using the $\mathrm{BMDL}_{10}$ of $22.2 \mathrm{mg} / \mathrm{kg}$ $\mathrm{bw} /$ day and the EDIs resulting from regular daily consumption of the 114 samples targeted at adults and children. The results presented in Figure 3.2A reveal that for 45 out of the 98 samples (45.9\%) of Indonesian instant herbal beverages targeted at adults and 1 out of 16 samples $(6.3 \%)$ targeted at children the MOE values based on the upper bound EDI were $<10,000$ indicating there is a priority for risk management when these herbal beverages would be used every day during a lifetime. For sample B90, which showed analytical results for methyleugenol below the LOD, use of the upper bound level and corresponding EDI resulted in MOE values that amounted to 8,200 . For the samples targeted at children only 1, B62 in which methyleugenol could be detected and quantified indicated a priority for risk management $(\mathrm{MOE}<10,000)$. Most of the herbal beverage samples which were sold as traditional medicine (labelled BPOM RI TR) to cure trichinosis for children are a low priority for risk management (MOE > 10,000). Of the 49 samples in which methyleugenol could be quantified only 4 samples, B59, B82, B100 and B101, resulted in MOE values $>10,000$ indicating a low concern for human health and a low priority for risk management when they would be consumed every day during a lifetime.

Considering that a scenario in which people consume the herbal beverage every day of their life for a whole lifetime seems unrealistic, a risk assessment for other, more realistic exposure scenario's was performed as well. Although there is no formal method to apply the MOE approach for less than lifetime exposures, previous studies have used Haber's rule to correct for shorter than lifetime exposure in a linear way. ${ }^{[41]}$ In a more realistic scenario people might consume herbal beverages regularly for short periods of time, for example 2 weeks, every year during a lifetime. Following Haber's rule and thus a linear correction of the intake estimates, the EDI values will be 52 weeks per year $/ 2$ weeks $=26$ times lower and thus the MOE values 26 times higher than what was presented in Figure 3.2A adult (98 samples) and children (16 samples) for lifetime exposure scenario's. This resulted in the MOE values depicted in Figure 3.2B in which all MOE values are $>10,000$ indicating no priority for risk management for all 114 herbal beverages. 


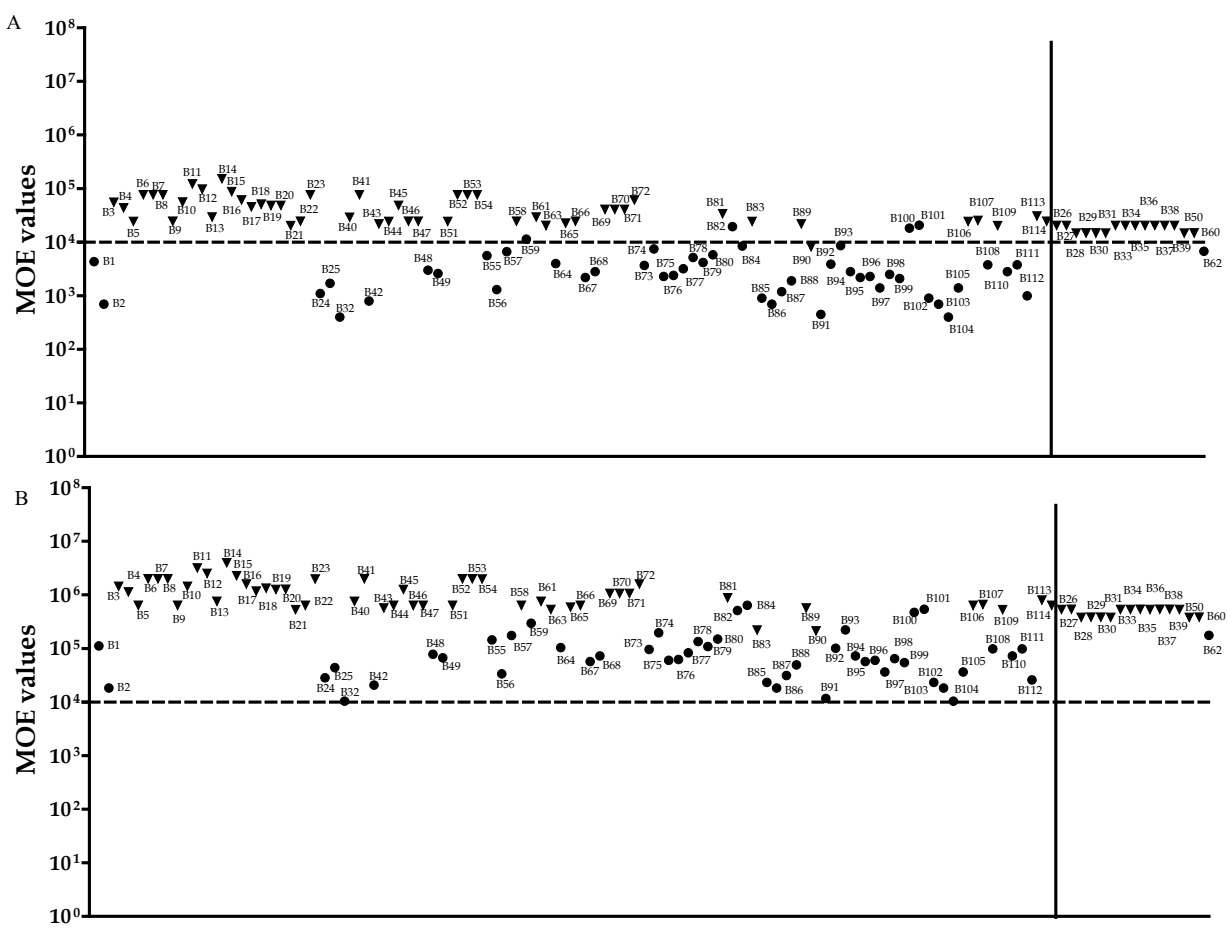

Figure 3.2. MOE values obtained for the evaluation of drinking the 114 herbal beverage samples targeted at adults (left of vertical black bar) and children (right side of the black vertical line) based on: A. daily lifetime exposure, B. 2 weeks every year exposure. MOE values were calculated as explained in the Materials and Methods section (Equation 3.2), using the BMDL 10 of $22.2 \mathrm{mg} / \mathrm{kg} \mathrm{bw} /$ day resulting from model averaging (Table 3.2). The triangles show the MOE values calculated for the samples in which methyleugenol levels were below the LOD and EDI values were calculated as the upper bound (LOD) setting the levels equal to the LOD. The circles represent samples which contained methyleugenol above the LOD. The horizontal dashed line represents the MOE value of 10,000 (----) as a threshold for risk management action. ${ }^{[40]}$

In a final assessment it was calculated for the 46 herbal beverage samples that showed MOE values below 10,000 in the initial assessment (Figure 3.2A), how many weeks of exposure would result in an MOE value that is 10,000 or higher and thus would not raise a concern. Figure 3.3 depicts the results obtained and reveals that the shortest time of daily exposure without raising a concern was for B32 and B104 (the samples with the highest EDIs of $51.2 \mu \mathrm{g} / \mathrm{kg} / \mathrm{bw} /$ day and 50.6 $\mu \mathrm{g} / \mathrm{kg} / \mathrm{bw} /$ day respectively) amounting to 144 weeks equal to about 2 weeks per year during a lifetime. Thus, it can be concluded that overall, if the herbal beverages would be consumed for less than 144 weeks (about 2 weeks a year) during a lifetime their level of methyleugenol would not raise a concern. 


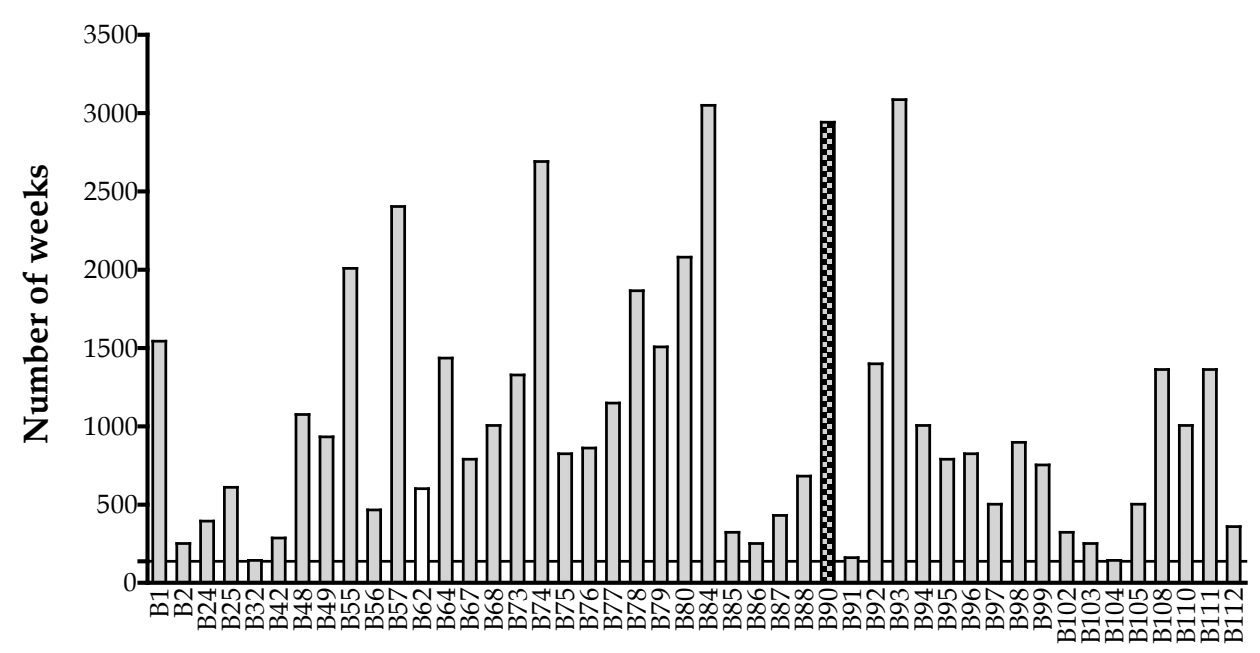

Sample ID

Figure 3.3. The number of weeks of exposure that would result in an MOE of 10,000 upon daily consumption of 46 Indonesian herbal beverage samples which showed concern for risk management. White bar represents a sample for children, while the grey patterned bar shows a sample in which methyleugenol levels were below the LOD. The horizontal black line represents 138 weeks, ( 2 weeks intake a year) during a lifetime.

\subsubsection{Eugenol safety assessment}

In 4 of the 114 samples eugenol was detected at a level that could be quantified. Given that eugenol is known to be non-genotoxic its risk assessment can be based on an ADI of $0-2.5 \mathrm{mg} / \mathrm{kg}$ bw/ day established by JECFA (2006)[27] or the ADI of $1.0 \mathrm{~g} / \mathrm{kg}$ bw/ day established by EFSA (2012) ${ }^{[28]}$. All of the eugenol containing samples are specified to be consumed by adults. The EDI of eugenol calculated for the 4 eugenol containing samples ranged from 5.0 to $46.9 \mu \mathrm{g} / \mathrm{kg}$ bw/day, far lower than both ADI values, indicating there is no concern.

\subsubsection{Evaluation of the safety assessment result based on the product registration type}

Considering the product registration category, it appears that 31 out of the 43 samples $(72.1 \%)$ produced and labelled as household herbal beverages (labelled Depkes RI P-IRT) appeared to result in MOE values $<10,000$ and thus present a possible priority for risk management action upon lifetime consumption (Table 3.3). Seven out of 31 samples (22.6\%) of the herbal beverages categorized as domestic processed food resulted in methyleugenol intakes that did raise a concern for human health. For traditional medicines this number amounted to 7 out of $30(23.3 \%)$. This 
analysis indicates that product registration may need to include a more detailed safety and/or risk-benefit assessment.

Table 3.3. Overview of the risk characterization using the MOE approach for the different Indonesian instant herbal beverages.

\begin{tabular}{|c|c|c|c|c|}
\hline \multirow{2}{*}{$\begin{array}{l}\text { Registration code } \\
\text { per target consumer }\end{array}$} & \multirow{2}{*}{ Category of product } & \multirow{2}{*}{$\begin{array}{l}\text { Total } \\
\text { samples }\end{array}$} & \multicolumn{2}{|c|}{ Concern for risk management } \\
\hline & & & Yes & No \\
\hline \multicolumn{5}{|l|}{ Children } \\
\hline BPOM RI TR & Traditional medicine & 16 & 1 & 15 \\
\hline \multicolumn{5}{|l|}{ Adult } \\
\hline Depkes RI P-IRT & Food household industry & 43 & 31 & 12 \\
\hline BPOM RI MD & Domestic processed food & 31 & 7 & 24 \\
\hline BPOM RI TR & Traditional medicine & 14 & 6 & 8 \\
\hline BPOM RI SD & Domestic supplement & 9 & 0 & 9 \\
\hline \multirow[t]{2}{*}{ BPOM RI ML } & Foreign processed food & 1 & 1 & 0 \\
\hline & $\begin{array}{rr}\text { Total } \\
\end{array}$ & 114 & 46 & 68 \\
\hline
\end{tabular}

\subsection{Discussion}

The aim of the present study was to evaluate whether the level of methyleugenol in instant herbal beverages obtained by a targeted sampling strategy on the Indonesian market would be safe for human consumption. In this targeted sampling strategy samples were collected on the Indonesian market focussing on samples that listed methyleugenol-containing botanicals on their label followed by analysis of their methyleugenol content and resulting EDI and MOE values. Use of the MOE is in line with what is proposed by EFSA and others for risk assessment of compounds in food that are both genotoxic and carcinogenic. ${ }^{[37,40,45]}$ Since in addition to methyleugenol in some samples also eugenol was detected a risk assessment for eugenol using the ADI of of $2.5 \mathrm{mg} / \mathrm{kg} /$ day established by JECFA (2006) $^{[27]}$ and the ADI of $1.0 \mathrm{mg} / \mathrm{kg}$ bw/ day established by EFSA (2012) ${ }^{[28]}$ was also performed.

Methyleugenol appeared to be the only alkenylbenzenes detected in 49 out of 114 samples of instant herbal beverages. The highest levels were measured in B91 a sample containing robusta coffee and ginger as ingredients. The high occurrence of methyleugenol in the herbal beverages is in line with the fact that most samples contain ginger as a major ingredient, since it was confirmed earlier that ginger (Zingiber officinale Rosc) naturally contains this alkenylbenzene. ${ }^{[46,47]}$ Furthermore Sigh et al. (2008) ${ }^{[48]}$ reported that methyleugenol was identified at levels amounting to $0.5 \%$ of the oleoresin derived from Z. officinale. Methyleugenol naturally occurs in other herbs, like nutmeg, cloves, lemongrass, betel pepper and basil[47] and the presence of these botanical ingredients in the herbal beverage samples B2, B32 and B104, therefore also likely contributed to the methyleugenol levels detected.

It is of interest to note that the difference in the methyleugenol levels between the different beverages might be more than 100 -fold. This relates to 1) the actual level 
of the methyleugenol containing herb in the sample, and 2) the level of methyleugenol in this botanical. This latter level is known to vary with the part of the plant used, the geographic variants, the growth conditions, physiological variations, evolution and genetic factors, growth stages of the plant, ${ }^{[49]}$ maturity of the plant at harvesting, the harvesting techniques, circumstance of storage, processing technologies, and measurement methods ${ }^{[50]}$. On the other hand, the methyleugenol level of 65 out of 114 was below the LOD. Although the results indicate that eugenol was detected in 4 out of 114 samples, the EDI resulting from use of these samples as herbal preparation appeared to be below the ADI of eugenol of $2.5 \mathrm{mg} / \mathrm{kg} \mathrm{bw} /$ day[27] indicating this does not raise a concern.

The level of eugenol detected in 4 out of the 114 samples analysed also varied more than 4-fold. The highest level of eugenol was detected in sample B5, sold as a traditional medicine (labelled BPOM RI TR). The relatively high level of eugenol in this sample may be due to the fact that extract of tamarind (Tamarindus indica L.) pulp contributed $14 \%$ to the ingredients, in addition to extract of betel (Piper betle L.) leaf $(5.6 \%)$ and honey $(2.8 \%)$. These 3 ingredients have been reported to contain eugenol.[20] Cinnamon and clove, also well known to contain eugenol,[20] likely contributed the eugenol levels in samples B83 and B109, sold as household herbal beverages (both labelled Depkes RI P-IRT). The highest EDI for eugenol registered in the present study of $46.9 \mu \mathrm{g} / \mathrm{kg} \mathrm{bw} /$ day $(2.5 \mathrm{mg} /$ day for a $54 \mathrm{~kg}$ person) resulting from intake of eugenol via herbal beverage sample B5 was lower than the maximum estimated intake in the EU from all sources previously reported to amount to 3 $\mathrm{mg} /$ day. ${ }^{[30]}$ Spices and essential oil are the major contribution to the intake of eugenol in the EU. Given that even this highest intake was below the ADI of 2.5 $\mathrm{mg} / \mathrm{kg} \mathrm{bw} /$ day ${ }^{[27]}$ and also below the ADI of $1.0 \mathrm{mg} / \mathrm{kg}$ bw/day established by EFSA $^{[28]}$ also exposure to eugenol via herbal drinks does not raise a concern.

The present study revealed an up to about 48 times difference in the EDI for methyleugenol resulting from consuming the different methyleugenol-containing herbal beverages, a difference that is caused by differences in their methyleugenol levels, but also by differences in the recommended daily use of the samples as indicated on the label, varying from 6 to $60 \mathrm{~g}$ per day. The highest EDI of 2,765.6 $\mu \mathrm{g}$ methyleugenol/person/day as calculated for B32 based on the EDI of $51.2 \mu \mathrm{g} / \mathrm{kg}$ bw/day and $54 \mathrm{~kg}$ bw for Indonesian people,[36] appears to be 34.4 fold higher than the estimated per capita intake of methyleugenol of $80.5 \mu \mathrm{g} /$ person/day from spices and oil for the USA population and 288.1 fold higher than the $9.6 \mu \mathrm{g} /$ person/day originating from nutmeg, mace and corresponding essential oils estimated for the EU population. ${ }^{[51]}$ 
Given that exposure to methyleugenol may occur also from other food sources it is of interest to also compare the EDI from herbal beverages estimated in the present study to the EDI for methyleugenol from all sources, estimated to amount to $190 \mu \mathrm{g} / \mathrm{kg} \mathrm{bw} /$ day ${ }^{[52]}$ or to $1-10 \mu \mathrm{g} / \mathrm{kg}$ bw/day[53]. This comparison reveals that intake from herbal drinks may contribute substantially to the dietary intake of methyleugenol. This is especially the case when it is considered that current intake of methyleugenol from the regular diet is likely substantially lower than what was estimated before, because at present addition of methyleugenol as a pure compound to flavour food is no longer allowed. ${ }^{[54]}$

Methyleugenol has been associated with carcinogenicity and genotoxicity, in animal studies, although epidemiological data to show the relevance of these effects for the human population are absent. In the absence of human data, risk assessment is based on animal data for tumor formation. In the present study the BMDL 10 derived from available data on dose-dependent induction of hepatocellular carcinoma in a 2 year rat study ${ }^{[19]}$ was used as a reference point to calculate the Margin of Exposure (MOE). Model averaging as an update on BMD modelling for toxicologically based risk assessment was applied to calculate the BMDL 10 used. Model averaging is preferred over selecting the lowest $\mathrm{BMDL}_{10}$ from results of fitting separate models. ${ }^{[38]}$ Model averaging estimates the $\mathrm{BMDL}_{10}$ as a weighted average of the outcomes of individual models in which the weight factor is determined by the Akaike Information Criterion (AIC). The AIC represents the goodness of fit of different mathematical models to a dose-response data set. ${ }^{[38]}$ The BMDL 10 value obtained for methyleugenol based on the male rat data by model averaging amounted to $22.2 \mathrm{mg} / \mathrm{kg}$ bw/ day and appeared to be lower than the value derived from the data for female rats that amounted to $66.5 \mathrm{mg} / \mathrm{kg}$ bw/day, reflecting the higher sensitivity of male rats. This value of $22.2 \mathrm{mg} / \mathrm{kg} \mathrm{bw} /$ day was used to calculate the MOE values. The value falls within the range of $\mathrm{BMDL}_{10}$ values of 15.3 - $34.0 \mathrm{mg} / \mathrm{kg} \mathrm{bw} /$ day reported before when analysing the rat male data by individual models, ${ }^{[35]}$ and is somewhat higher than the lowest $\mathrm{BMDL}_{10}$ of 15.3 $\mathrm{mg} / \mathrm{kg}$ bw used before in risk assessment of methyleugenol containing food supplements or samples of pesto. ${ }^{[35,55]}$

Given that an MOE value below 10,000 indicates a possible concern from a public health point of view and points at a priority for risk management actions, ${ }^{[40]}$ the results of the present study indicate that for 46 out of 114 herbal beverages there is a priority for risk management. This risk assessment is however based on lifetime daily consumption of the herbal beverages and one may question whether this is a realistic exposure scenario. 
In the absence of a generally established method to take less than lifetime exposure scenario's into account in risk assessment for genotoxic carcinogens by the MOE approach, an estimate of the risk associated to short term use of the herbal beverages was obtained using Haber's rule. Such a shorter period of consumption of the herbal beverages should be taken into account to better reflect the real life exposure scenario in which Indonesian people do not consume these preparations every day during their lifetime. Applying Haber's rule and assuming use for only 2 weeks every year of a lifetime the MOE values were 26 times higher than the MOE values for lifetime exposure, and were all $>10,000$ indicating a low priority of risk management. It is of importance to note that Haber's rule can be applied provided there is a linear relationship between tumour incidence and the dose of the carcinogen. ${ }^{[56]}$ This linearity is assumed and used more often in risk assessment of genotoxic carcinogens. It is used for example when correcting the dosing regimen in 2 year rodent carcinogenicity studies from 5 to 7 days exposure as done in the present and other studies ${ }^{[35,37]}$ for the data used for BMD modelling of the NTP carcinogenicity data for methyleugenol. However such linearity in the dose- and time- dependent response behaviour for tumour induction by methyleugenol is not available, although the existing evidence does support linearity in the dose- and time-dependent bioactivation of methyleugenol to its ultimate carcinogenic 1'sulfooxy metabolite, and for the DNA adduct formation in both cell models or experimental animals exposed to methyleugenol.[57, 58]

As depicted in Table 3.3, most of the herbal beverage samples, namely 31 out of the 43 samples included in the study $(72.1 \%)$, categorized as household food (labelled Depkes RI P-IRT), raise a concern when people would consume them every day during a lifetime. Also, a substantial number of herbal beverage samples registered as domestic processed food, or traditional medicine indicated a concern for human health. The limitation of producers' knowledge related to food safety and low-quality control processes for these products may cause the high content of methyleugenol containing herbs in these products. Putri (2018) ${ }^{[14]}$ reported that the house-hold industry in Indonesia can easily get a license to build independent businesses for their economy improvement, while at the same time the limitation of monitoring from NADFC causes their food products to fail to comply with the quality and safety standard. Regulation NADFC 12/2016 Article 6 on Criteria of Prossessed Food stipulates that to be registered every processed food should meet 3 criteria's: (1) safety parameters namely the maximum limit of microbial, physical and chemical contamination, (2) quality parameters, including fulfilment of quality requirements in accordance with the existed standards and requirements; and (3) nutritional parameters according to the established requirements. Beside these 3 
criteria's the processed food should comply the label requirement, good manufacturing practices and good distribution practices.[10] The results of the present study suggest that it would be of use that the process and regulation of manufacturing homemade herbal beverages is monitored more closely and may need to be updated in order to reduce the level of methyleugenol.

Currently, the National Agency for Drug and Food Control of Republic of Indonesia (BPOM RI) regulated estragole and safrole as natural food flavouring, with maximum permitted levels (MPLs) of $10 \mathrm{mg} / \mathrm{kg}$ for estragole and $0.1 \mathrm{mg} / \mathrm{kg}$ for safrole both in ready to drink beverages. The lower MPL for safrole than for estragole is due to consideration of the natural occurrence and use of estragole as a food flavouring. ${ }^{[10]}$ However, MPLs for methyleugenol in herbal beverages in Indonesia have not yet been established. The levels of methyleugenol of 2.6-443.7 $\mu \mathrm{g} / \mathrm{g}$ now encountered are higher than $0.1 \mathrm{mg} / \mathrm{kg}$ and for several samples even higher than $10 \mathrm{mg} / \mathrm{kg}$, so they would not be in compliance with the MPLs set in Indonesia for related alkenylbenzenes like safrole and estragole. It is of interest to note that, based on the risk assessment provided in the present study, an MPL value of $10 \mathrm{mg} / \mathrm{kg}$ would not be low enough to support safe daily consumption of these beverages during a lifetime, when recommended daily use would amount to the highest recommended daily consumption of 75 gram, resulting in an MOE of about 1,600. At an MPL of $0.1 \mathrm{mg} / \mathrm{kg}$ or $1 \mathrm{mg} / \mathrm{kg}$ the MOE would amount to 160,000 or 16,000 , and use of the herbal preparation would not be of concern. An MPL of 1 $\mathrm{mg} / \mathrm{g}$ would be in line with what is established by the European Union (EU), EC Regulation 1334/2008.[54] An MPL of $10 \mathrm{mg} / \mathrm{kg}$ would however support safe consumption when use would be limited to 2 weeks a year during a lifetime. On the other hand, reducing the recommended daily consumption of herbal beverages to $0.3 \mathrm{~g}$ per day during a lifetime will be safe to meet the MOE value of 10,000 using the highest methyleugenol level of $443.7 \mu \mathrm{g} / \mathrm{g}$. Obviously the approach to be taken is subject to a risk management decision.

Further evaluations of the present study revealed that with the levels of methyleugenol detected in the samples, their use would not raise a safety concern or priority for risk management if it would be limited to less than 144 weeks (about 2 weeks per year) during a lifetime. This result indicates that risk management of these herbal beverages may focus on providing information on the label for limitation of the consumption duration. Hermanu (2016) ${ }^{[59]}$ reported that the implementation of food safety aspects for many home industry food items in Indonesia is still limited, and the results of the present study provide an examples of how this could be improved. 
In conclusion, consumption of methyleugenol-containing herbal beverages can be considered safe when consumed for less than about 2 weeks a year during a lifetime. This conclusion holds for herbal beverages collected by targeted sampling on the Indonesian market. The study does support the establishment of an MPL for methyleugenol in foods and beverages in Indonesia, in line with what has been done for the related alkenylbenzenes estragole and safrole.

\section{Conflict of Interest}

The authors declare that there are no conflict of interest regarding this manuscript.

\section{Acknowledgements}

Financial support was received from the Indonesian Endowment Fund for Education, Ministry of Finance, Republic of Indonesia through a Beasiswa Pendidikan Indonesia Lembaga Pengelola Dana Pendidikan (BPI LPDP) doctoral scholarship for the first author [contract number: PRJ-365/LPDP/2016].

\section{Supplementary materials}

Supplementary materials of this article can be downloaded from https://doi.org/10.1016/j.fct.2019.02.001

\section{References}

[1] Muhammad, D. R. A., Dewettinck, K., Cinnamon and its derivatives as potential ingredient in functional food-A review. International Journal of Food Properties 2017, 20, 2237-2263.

[2] Bryer, E., A literature review of the effectiveness of ginger in alleviating mild-to-moderate nausea and vomiting of pregnancy. Journal of Midwifery $\mathcal{E}$ Women's Health 2005, 50, e1-e3.

[3] BPOM-RI, Laporan Tahunan 2016 Badan Pengawas Obat dan Makanan, Badan Pengawas Obat dan Makanan Republik Indonesia $2017 . \quad$ Available at: https://www.pom.go.id/new/admin/dat/20171127/laptah2016.pdf. Accessed 8 April 2018.

[4] Hassali, M. A., Khan, T. M., Shafie, A. A., Nazir, M., Public knowledge about herbal beverages in Penang, Malaysia. Australasian Medical Journal 2009, 1, 1-11.

[5] Butt, M. S., Sultan, M. T., Selected functional foods for potential in disease treatment and their regulatory issues. International Journal of Food Properties 2013, 16, 397-415.

[6] Low, T. Y., Wong, K. O., Yap, A. L. L., Haan, L. H. J., Rietjens, I. M. C. M., The regulatory framework across international jurisdictions for risks associated with consumption of botanical food supplements. Comprehensive Reviews in Food Science and Food Safety 2017, 16, 821-834.

[7] FDA, Dietary Supplement Products \& Ingredients, US Food and Drug Administration 2017. Available at: $\quad$ https://www.fda.gov/Food/DietarySupplements/ProductsIngredients/default.htm. Accessed 16 February 2018.

[8] Commission, E., Report from the Commission to the Council and the European Parliament on the use of substances other than vitamins and minerals in food supplements, Brussels 2008.1-12. Available at: https:/ /ec.europa.eu/food/sites/food/files/safety/docs/labelling_nutrition-supplementscomm_2008_0824_en.pdf. Accessed 25 June 2018.

[9] TGA, Advisory Committee on Complementary Medicines (ACCM), Therapeutic Goods Administration, Department of Health, Australia, Australia 2017, Available at: 
https://www.tga.gov.au/committee/advisory-committee-complementary-medicines-accm. Accessed 16 February 2017.

[10] BPOM-RI, Peraturan Kepala Badan Pengawas Obat Dan Makanan Republik Indonesia Nomor 12 Tahun 2016 Tentang Pendaftaran Pangan Olahan, Badan Pengawas Obat dan Makanan Republik Indonesia 2017. Available

http://jdih.pom.go.id/showpdf.php?u=giZCxzW6JpAGRcPnOwhBjW564tWbhWZSLziyNQ616o I=. Accessed 28 October 2018.

[11] Kemenkes-RI, Peraturan Menteri Kesehatan Republik Indonesia Nomor 007 Tahun 2012 tentang Registrasi Obat Tradisional, Menteri Kesehatan Republik Indonesia, Jakarta 2012. Available at: http:/ /jdih.pom.go.id/. Accessed 23 June 2017.

[12] Government-RI, Peraturan Pemerintah Republik Indonesia Nomor 28 Tahun 2004 tentang Keamanan, Mutu dan Gizi Pangan, Kementerian Hukum dan HAM RI 2004. Available at: http://peraturan.go.id/pp/nomor-28-tahun-2004-11e44c4ee74173f09491313231373239.html. Accessed 14 August 2017.

[13] Yulianti, M. D. M., R. , Tata cara registrasi untuk Pangan Olahan Industri Rumah Tangga (PIRT) dan Makanan Dalam Negeri (MD) dalam rangka peningkatan produk yang aman dan bermutu di Bandung Jawa Barat. Farmaka 2017, 15, 87-64.

[14] Putri, S. A., Challenge to enforce food safety law and regulation in Indonesia. IOP Conference Series: Earth and Environmental Science 2018, 175.

[15] Bertoli, A., Lucchesini, M., Mensuali-Sodi, A., Leonardi, M., Doveri, S., Magnabosco, A., Pistelli, L., Aroma characterisation and UV elicitation of purple basil from different plant tissue cultures. Food Chemistry 2013, 141, 776-787.

[16] EFSA, EFSA Compendium of botanicals that have been reported to contain toxic, addictive, psychotropic or other substances of concern. EFSA Supporting Publications 2009, 6, 281 R.

[17] Suparmi, S., Widiastuti, D., Wesseling, S., Rietjens, I. M. C. M., Natural occurrence of genotoxic and carcinogenic alkenylbenzenes in Indonesian jamu and evaluation of consumer risks. Food and Chemical Toxicology 2018, 118, 53-67.

[18] Herrmann, K., Schumacher, F., Engst, W., Appel, K. E., Klein, K., Zanger, U. M., Glatt, H., Abundance of DNA adducts of methyleugenol, a rodent hepatocarcinogen, in human liver samples. Carcinogenesis 2013, 34, 1025-1030.

[19] NTP, NTP Toxicology and Carcinogenesis Studies of Methyleugenol (CAS NO. 93-15-2) in F344/ N Rats and B6C3F1 Mice (Gavage Studies). National Toxicology Program technical report series 2000, 491, 1-412.

[20] Api, A. M., Belsito, D., Bhatia, S., Bruze, M., Calow, P., Dagli, M. L., Dekant, W., Fryer, A. D., Kromidas, L., La Cava, S., Lalko, J. F., Lapczynski, A., Liebler, D. C., Miyachi, Y., Politano, V. T., Ritacco, G., Salvito, D., Schultz, T. W., Shen, J., Sipes, I. G., RIFM fragrance ingredient safety assessment, Eugenol, CAS Registry Number 97-53-0. Food and Chemical Toxicology 2016, 97, S25-S37.

[21] Bakkali, F., Averbeck, S., Averbeck, D., Idaomar, M., Biological effects of essential oils - A review. Food and Chemical Toxicology 2008, 46, 446-475.

[22] NTP, Carcinogenesis studies of eugenol (CAS No. 97-53-0) in F344/N Rats and B6C3F1 Mice (Feed Studies). National Toxicology Program technical report series 1983, 223, 1-159.

[23] Rietjens, I. M., Cohen, S. M., Fukushima, S., Gooderham, N. J., Hecht, S., Marnett, L. J., Smith, R. L., Adams, T. B., Bastaki, M., Harman, C. G., Taylor, S. V., Impact of structural and metabolic variations on the toxicity and carcinogenicity of hydroxy- and alkoxy-substituted allyl- and propenylbenzenes. Chemical research in toxicology 2014, 27, 1092-1103.

[24] Miller, E. C., Swanson, A. B., Phillips, D. H., Fletcher, L., Liem, A., Miller, J. A., Structure-activity studies of the carcinogenicities in the mouse and rat of some naturally occurring and synthetic alkenylbenzene derivatives related to safrole and estragole. Cancer Research 1983, 43, 1124-1134.

[25] Maronpot, R. R., Haseman, J. K., Boorman, G. A., Eustis, S. E., Rao, G. N., Huff, J. E., Liver lesions in B6C3F1 mice: the National Toxicology Program, experience and position. Archives of toxicology. Supplement. $=$ Archiv fur Toxikologie. Supplement 1987, 10, 10-26.

[26] JECFA, Toxicological evaluation of certain veterinary drug residues in food, WHO Food Additives Series 17, WHO, Geneva, Switzerland 1982, Available at https:/ / apps.who.int/iris/bitstream/handle/10665/43506/9241660570_eng.pdf?sequence=1, Accessed 18 February 2018.

[27] JECFA, Safety evaluation of certain food additives, WHO Food Additives Series 56 2006, 155-161. 
[28] EFSA, Conclusion on the peer review of the pesticide risk assessment of the active substance eugenol. EFSA Journal 2012, 10, 2506.

[29] BPOM-RI, Statistik produk yang mendapat persetujuan izin edar, Badan Pengawas Obat dan Makanan Republik Indonesia, Jakarata 2018. Available at https://www.pom.go.id/new/\#. Accessed 12 February 2018.

[30] EFSA, Flavouring Group Evaluation 60 (FGE.60): Consideration of eugenol and related hydroxyallylbenzene derivatives evaluated by JECFA (65th meeting) structurally related to ringsubstituted phenolic substances evaluated by EFSA in FGE.22 (2006). EFSA Journal 2009, 7, 965.

[31] FDA, Food and Drug, Food and Drug Administration, USA 201821CFR184.1257. Available at: https:/ / www.accessdata.fda.gov/scripts/cdrh/cfdocs/cfcfr/CFRSearch.cfm?fr=184.1257. Accessed 3 January 2019.

[32] TGA, Substances that may be used in Listed medicines in Australia, Australia 2007. Available at: https://www.tga.gov.au/sites/default/files/cm-listed-substances_0.pdf. Accessed 3 January 2018.

[33] Gursale, A., Dighe, V., Parekh, G., Simultaneous quantitative determination of cinnamaldehyde and methyl eugenol from stem bark of Cinnamomum zeylanicum Blume using RP-HPLC. Journal of Chromatographic Science 2010, 48, 59-62.

[34] FDA, Bioanalytical Method Validation Guidance for Industry, Center for Drug Evaluation and Research, Food and Drug Administration USA 2017. Available at: https:/ / www.fda.gov/downloads/Drugs/Guidance/ucm070107.pdf. Accessed 26 October 2018.

[35] van Den Berg, S. J., Restani, P., Boersma, M. G., Delmulle, L., Rietjens, I., Levels of genotoxic and carcinogenic compounds in plant food supplements and associated risk assessment. Food and Nutrition Sciences 2011, 2, 989-1010.

[36] FAO, Body Weights and Heights by Countries, Agriculture and Consumer Protection 2017. Available at: http:/ / www.fao.org/docrep/meeting/004/M2846E/M2846E07.htm. Accessed 13 March 2018.

[37] Benford, D., DiNovi, M., Setzer, R. W., Application of the margin-of-exposure (MOE) approach to substances in food that are genotoxic and carcinogenic e.g.: Benzo[a]pyrene and polycyclic aromatic hydrocarbons. Food and Chemical Toxicology 2010, 48, S42-S48.

[38] EFSA-Scientific-Committee, Anthony, H., Diane, B., Thorhallur, H., John, J. M., Helle, K. K., Simon, M., Alicja, M., Hanspeter, N., Hubert, N., Colin, O., Antonia, R., Guido, R., Vittorio, S., Roland, S., Dominique, T., Marc, A., Laurent, B., Allen, D., Lutz, E., Update: use of the benchmark dose approach in risk assessment. EFSA Journal 2017, 15, e04658.

[39] EFSA, Manual for BMD Modeling, 2017. Available at: http://www.efsa.europa.eu/sites/default/files/170301-0-p6.pdf. Accessed 15 June 2018.

[40] EFSA, Opinion of the Scientific Committee on a request from EFSA related to A Harmonised approach for risk assessment of substances which are both genotoxic and carcinogenic. EFSA Journal 2005, 1-31.

[41] Doull, J., Rozman, K. K., Using Haber's Law to define the margin of exposure. Toxicology 2000, 149, $1-2$.

[42] Gaylor, D. W., The use of Haber's Law in standard setting and risk assessment. Toxicology 2000, 149, 17-19.

[43] Peña, E. A., Wensong, W., Walter, P., W., W. R., LingLing, A., Model selection and estimation with quantal-response data in benchmark risk assessment. Risk Analysis 2017, 37, 716-732.

[44] GEMS/Food-EURO, GEMS/Food-EURO second workshop on reliable evaluation of low-level contamination of food, WHO, Geneva (Switzerland) 1995, Available at ftp:/ ftp.ksph.kz/Chemistry_Food\%20Safety/TotalDietStudies/Reliable.pdf, Accessed 19 March 2018.

[45] Smith, B., Cadby, P., Leblanc, J.-C., Setzer, R. W., Application of the margin of exposure (MOE) approach to substances in food that are genotoxic and carcinogenic: Example: Methyleugenol, CASRN: 93-15-2. Food and Chemical Toxicology 2010, 48, S89-S97.

[46] EFSA, Compendium of botanicals reported to contain naturally occuring substances of possible concern for human health when used in food and food supplements. EFSA Journal 2012, 10: 2663. $1-100$.

[47] Tan, K. H., Nishida, R., Methyl eugenol: Its occurrence, distribution, and role in nature, especially in relation to insect behavior and pollination. Journal of Insect Science 2012, 12, 56-56. 
[48] Singh, G., Kapoor, I. P. S., Singh, P., de Heluani, C. S., de Lampasona, M. P., Catalan, C. A. N., Chemistry, antioxidant and antimicrobial investigations on essential oil and oleoresins of Zingiber officinale. Food and Chemical Toxicology 2008, 46, 3295-3302.

[49] Al-Kateb, H., Mottram, D. S., The relationship between growth stages and aroma composition of lemon basil Ocimum citriodorum Vis. Food Chemistry 2014, 152, 440-446.

[50] Speijers, G., Alink, G. M., Saeger, S. d., Hardy, A., Magan, N., Pilegaard, K., Battilani, P., Riemens, M. M., Evaluation of agronomic practices for mitigation of natural toxins, ILSI Europe, International Life Sciences Institute 2010.

[51] William, G. M., Mattia, A., Safety evaluation of certain food additives Prepared by the Sixty-ninth meeting of the Joint FAO/WHO Expert Committee on Food Additives (JECFA), World Health Organization, Geneva, India 2009, pp. 351-480.

[52] SCF, Opinion of the Scientific Committee on Food on Methyleugenol (4-Allyl-1,2-dimethoxybenzene), Scientific Committee on Food, Belgium 2001.

[53] Smith, R. L., Adams, T. B., Doull, J., Feron, V. J., Goodman, J. I., Marnett, L. J., Portoghese, P. S., Waddell, W. J., Wagner, B. M., Rogers, A. E., Caldwell, J., Sipes, I. G., Safety assessment of allylalkoxybenzene derivatives used as flavouring substances - methyleugenol and estragole. Food and Chemical Toxicology 2002, 40, 851-870.

[54] EC, Regulation (EC) No 1334/2008 of the European Parliament and of the Council of 16 December 2008 on flavourings and certain food ingredients with flavouring properties for use in and on foods and amending Council Regulation (EEC) No 1601/91, Regulations (EC) No 2232/96 and (EC) No 110/2008 and Directive 2000/13/EC (Text with EEA relevance), Official Journal of the European Union 2008. Available at: https:/ / eur-lex.europa.eu/legal-content/EN/TXT/PDF/?uri=CELEX:32008R1334\&from=EN. Accessed 26 June 2018.

[55] Al-Malahmeh, A. J., Al-ajlouni, A. M., Wesseling, S., Vervoort, J., Rietjens, I. M. C. M., Determination and risk assessment of naturally occurring genotoxic and carcinogenic alkenylbenzenes in basil-containing sauce of pesto. Toxicology Reports 2017, 4, 1-8.

[56] Crump, K. S., Hoel, D. G., Langley, C. H., Peto, R., Fundamental carcinogenic processes and their implications for low dose risk assessment. Cancer Research 1976, 36, 2973-2979.

[57] Al-Subeihi, A. A. A., Spenkelink, B., Punt, A., Boersma, M. G., van Bladeren, P. J., Rietjens, I. M. C. M., Physiologically based kinetic modeling of bioactivation and detoxification of the alkenylbenzene methyleugenol in human as compared with rat. Toxicology and Applied Pharmacology 2012, 260, 271-284.

[58] Gardner, I., Wakazono, H., Bergin, P., de Waziers, I., Beaune, P., Kenna, J. G., Caldwell, J., Cytochrome P450 mediated bioactivation of methyleugenol to 1'-hydroxymethyleugenol in Fischer 344 rat and human liver microsomes. Carcinogenesis 1997, 18, 1775-1783.

[59] Hermanu, B., Implementasi izin edar produk PIRT melalui model pengembangan sistem keamanan pangan terpadu. Proceeding SENDI_U 2016, Available at https:/ / media.neliti.com/media/publications/174678-ID-implementasi-izin-edar-produk-pirtmelal.pdf. Accessed 28 March 2018. 


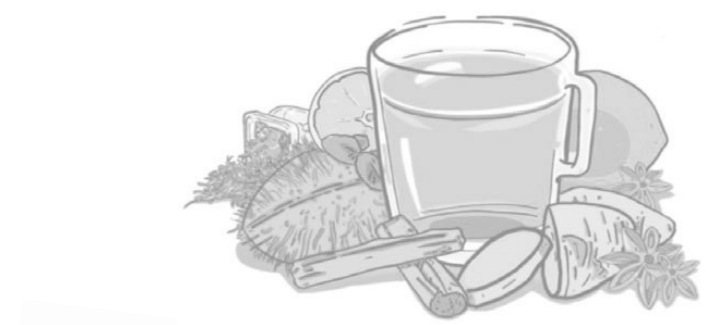

BENEFIT

RISK 


\section{Chapter 4}

\section{Detection of pyrrolizidine alkaloids in jamu}

available on the Indonesian market and accompanying safety assessment for human consumption

Suparmi Suparmi

Patrick P.J. Mulder

Ivonne M.C.M. Rietjens

Published in: Food and Chemical Toxicology 138 (2020): 111230 DOI: $10.1016 /$ j.fct.2020.111230

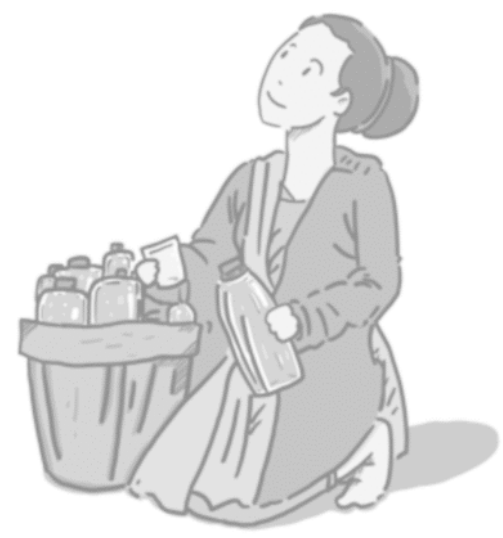




\section{Abstract}

The occurrence and accompanying risks of pyrrolizidine alkaloids (PAs) in Indonesian jamu were evaluated. PAs were detected in 34 out of 35 jamu containing PA-producing botanicals, in the range of $12.3-235,376 \mu \mathrm{g} / \mathrm{kg}$. A total PA level of 5.9$3,421 \mu \mathrm{g} / \mathrm{kg}$ was found in 17 out of 23 jamu made of non-PA-producing botanicals pointing to contamination with PA-producing plants. Short-time consumption of jamu is unlikely to result in acute toxic effects, although one sample would exceed an intake of $10 \mu \mathrm{g}$ PAs/ $\mathrm{kg}$ bw/day which may cause hepatic veno-occlusive disease (HVOD) in humans. The risk assessment for the genotoxic and carcinogenic potential of PAs, revealed Margin of Exposure (MOE) values below 10,000 for 27 out of all samples analysed (46.6\%), indicating a potential priority for risk management when assuming daily lifelong consumption. Assuming consumption for two weeks every year during a lifetime, and using Haber's rule, 13 out of 35 jamu samples containing PA-producing botanicals $(37 \%)$ still pose a priority, while the jamu consisting of non-PA-producing botanicals would be of no priority (MOE $>10,000$ ). This study provides data that can support risk management actions in Indonesia to minimize the potential health risk for jamu consumers due to the occurrence of toxic PAs in these products. 


\subsection{Introduction}

Indonesian jamu represents one of the traditional herbal medicine practices in Indonesia. Jamu products are available in the market mainly with BPOM RI TR labelling, referring to BPOM RI, the Badan Pengawas Obat dan Makanan Republik Indonesia being the regulatory body where the product is registered, while TR refers to the product category being obat tradisional produksi dalam negeri (Indonesian traditional medicine) ${ }^{[1]}$ Jamu is available in many forms, including powder, tablet, pill, caplet, capsule, liquid or simplicia (dried/fresh raw jamu botanicals). The jamu in powder form and simplicia are readily consumed by adding hot water and drinking the resulting preparation, while the other forms can be consumed directly as supplement. Considering the increasing demand for jamu in both local and international markets, BPOM RI is tightly monitoring the quality, safety and efficacy of the products. However, knowledge gaps regarding the possible adverse health effects of hazardous drugs and/or toxic constituents in the jamu currently hamper its monitoring activity. ${ }^{[2]}$ This issue may put consumers at risk especially when they are regular jamu users.

Botanical constituents of special concern are compounds known to be genotoxic and carcinogenic, which may be naturally occurring in the botanical ingredients of jamu and thus may pose a safety issue. In our previous work for example ${ }^{[3]}$ the alkenylbenzene $(\mathrm{AB})$ methyleugenol, appeared to be a major ingredient, detected in $91.3 \%$ of the jamu samples testing positive for ABs. Quantification of methyleugenol levels and exposure resulting from use of the respective jamu products resulted in Margin of Exposure (MOE) values generally $<10,000$, indicating a priority for risk management when assuming daily consumption during a lifetime. Another group of genotoxic compounds are the aristolochic acids (AAs) that can occur in plant food supplements (PFS) and herbal products at levels that raise a health concern for their consumers. A review of the literature showed that the levels of AA-1 and AA-II reported in selected PFS resulted in MOEs below 10,000 for 206 out of 573 (35.9\%) of the samples analysed[4], clearly indicating that herbal products containing AA1 and AAII were a priority for risk management. Recent data on PFS revealed that pyrrolizidine alkaloids (PAs) may represent a third category of botanical ingredients of concern. ${ }^{[5-7]}$ The aim of the present study was to investigate the potential presence of PAs in jamu and to perform a risk assessment. In humans, acute exposure to PAs can cause hepatic veno-occlusive disease (HVOD) with severe liver damage, in some cases with fatal outcome, ${ }^{[8-10]}$ whereas chronic exposure may lead to liver cirrhosis and pulmonary arterial hypertension[11, 12]. Furthermore, 1,2-unsaturated PAs, including lasiocarpine, monocrotaline and riddelliine, are considered genotoxic carcinogens 
due to their potency to be metabolized into reactive pyrroles. Therefore, the International Agency for Research on Cancer (IARC) classified these compounds as being possibly carcinogenic to humans (category 2B).[13]

PAs are naturally occurring heterocyclic phytotoxins that are widely distributed and present in more than 6,000 flowering plant species, particularly from the genera Senecio, Crotalaria, Heliotropium, Echium, Trichodesma, Symphytum, Petasites, Tussilago, Eupatorium and Gynura. $\left.{ }^{6,}, 10,14-17\right]$ Moreover in some botanical products including herbal teas, herbal medicines and food supplements, the detected PAs appeared to result from contamination of the non-PA-containing plant material, used to prepare the products, with PA-containing weeds during the cultivation or collection of these botanicals. In response, risk management actions were formulated by the European Medicines Agency (EMA) to reduce this level of contamination. In 2016 the Herbal Medicinal Products Committee (HMPC) of EMA has established a transitional limit of intake of $1.0 \mu \mathrm{g}$ PAs per day per person related to intake resulting from such contamination, for a 3 years period. ${ }^{[18]}$ Recently HMPC (2019) ${ }^{[19]}$ announced a consensus to extend the transitional period for a further 2 years.

In their assessment of the potential cancer risks resulting from chronic PA exposure, the EFSA Panel on Contaminants in the Food Chain (CONTAM Panel) established a lower confidence limit of the benchmark dose resulting in a 10\% extra cancer risk (BMDL $\mathrm{B}_{10}$ ) of $237 \mu \mathrm{g} / \mathrm{kg}$ body weight per day, derived from tumour data on riddelliine, as point of departure (POD) for calculating the MOE. ${ }^{[5]}$

The purpose of this current work is to investigate the occurrence of PAs in 58 Indonesian jamu products containing various mixed medicinal botanicals, including 35 samples containing PA-producing botanicals and 23 samples containing non-PAproducing botanicals. Based on the levels of PAs present and directions for use given by the producers, an exposure and safety assessment of consumption of these jamu was performed. The results of the study can support risk management in formulating regulatory actions to minimize the exposure to PAs via use of jamu.

\subsection{Materials and methods}

\subsubsection{Collection and preparation of samples}

A targeted sampling approach was applied to collect 58 samples of jamu from different brands. The samples were purchased from traditional markets or jamu stores in Indonesia as depicted in Figure 4.1, including sampling in Tangerang (4 stores, $n=4)$, Jakarta-Bekasi (12 stores, $n=16)$, Bogor ( 1 store, $n=1)$, Tegal (1 store, $n=4)$, Semarang-Bawen ( 3 stores, $n=7$ ), Temanggung ( 1 store, $n=1$ ), Magelang ( 1 store, $n=1)$, Surakarta-Sukoharjo (7 stores, $n=10)$, Trenggalek ( 1 store, $n=1$ ), 
Nganjuk-Kediri (4 stores, $n=9$ ), Malang ( 2 stores, $n=2$ ), and Jember ( 1 store, $n=2$ ). A total of 35 jamu samples (TR-1 - TR-35) were collected with the name of possible PA-containing botanicals on the label, including lithospermi radix (Lithospermum orientale (L.) L.), Gynura pseudochina (L.) DC., Gynura procumbens (Lour.) Merr., Gynura segetum (Lour.) Merr., Gynura divaricata (L.) DC., bandotan (Adenostemma lavenia (L.) Kuntze), Ageratum conyzoides (L.) L., flos farfarae (Tussilago farfara) and comfrey (Symphytum officinale L.). To monitor the possible contamination of jamu with PA-producing botanicals, a set of 23 samples that, according to the label, did not contain PA-producing botanicals, were included in the study (TR-36 - TR-58). Of these 23 samples, 21 were previously collected and analysed for $\mathrm{ABs}^{[3]}$, while 2 samples, collected during the targeted sampling exercise, were included because their label indicated the presence of aristolochic acid (AA) producing botanicals. Detailed information, including an overview of the respective botanicals of concern present in the samples, the health claims and recommended daily use written on the label, is summarised in Supplementary materials 1.

The 58 samples included in the study were marketed in different forms including caplet $(n=1)$, capsule $(n=27)$, liquid $(n=4)$, pill $(n=2)$ and powder $(n=$ $24)$. The homogeneity of each sample (except the liquid sample) was ensured by mixing the content from 10 packages manually in a ziplock plastic bag before taking samples for analysis. The powder samples were weighted and put into the plastic bag directly, the capsule samples were opened first and only the weighted content inside the capsule was put into the bag. The pill and caplet samples were weighted and ground with a mortar and the resulting powder was collected in the plastic bag.

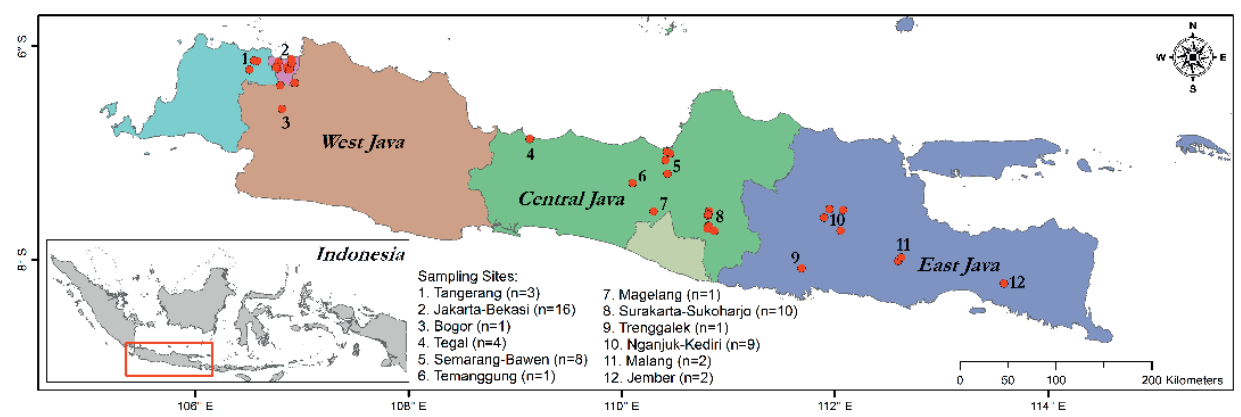

Figure 4.1. Sampling locations of jamu in Banten, Jakarta, West Java, Central Java, and East Java Provinces, Indonesia. The red dots represent the sampling locations of the products, including both PA- and nonPA-containing jamu and $\mathrm{n}$ is the number of collected samples in the respective city.

\subsubsection{Chemicals and reagents}

Water used was deionised MilliQ with a minimal resistance of $18.2 \mathrm{M}$. Acetonitrile (LC-MS grade) and methanol (LC-MS grade) were obtained from Actu- 
all (Oss, the Netherlands). Formic acid (analytical grade, 99-100\%) and ammonium carbonate (analytical grade) were obtained from Sigma-Aldrich (Zwijndrecht, the Netherlands). Fifty-nine PA analytical standards were sourced from Phytoplan (Heidelberg, Germany), except for: heliotrine and trichodesmine from Latoxan (Valence, France); usaramine from BOC Sciences (Shirley, NY, USA), florosenine from PRISNA (Leiden, the Netherlands), echimidine, indicine, indicine $\mathrm{N}$-oxide, intermedine, intermedine N-oxide, lycopsamine, lycopsamine N-oxide, monocrotaline, monocrotaline N-oxide and otosenine from Phytolab (Vestenbergsgreuth, Germany). Usaramine N-oxide, spartioidine N-oxide and trichodesmine N-oxide were in-house synthesized by the method of Chou et al. $(2003)^{[20]}$. A complete list of PA standards used in this study is presented in Supplementary materials 2 .

Stock solutions $(100 \mu \mathrm{g} / \mathrm{mL})$ of the individual PA standards were prepared in methanol, from these stock solutions a mixed solution $(1 \mu \mathrm{g} / \mathrm{mL}$ in methanol) containing all PA standards was prepared. This mixed standard solution was used to spike the jamu samples as described below.

\subsubsection{Extraction and purification}

The extraction procedure was based on an in-house validated method and performed as described by Chen et al. (2019) ${ }^{[21]}$, for the analysis of herbal teas and herbal medicines. Briefly, $20 \mathrm{~mL}$ of $0.2 \%$ formic acid solution was added to $1 \mathrm{~g}$ of jamu (1 $\mathrm{mL}$ for liquid samples) followed by agitation in a rotary tumbler for $30 \mathrm{~min}$. Before extraction one of the test portions was fortified with the mixed PA standard solution at $250 \mu \mathrm{g} / \mathrm{kg}(250 \mu \mathrm{L}$ of $1 \mu \mathrm{g} / \mathrm{mL}$ PA mix). Upon agitation the extract was centrifuged for $15 \mathrm{~min}$ at 3,500 g. After centrifugation, $5 \mathrm{~mL}$ of supernatant was transferred to a new tube and subsequently the supernatant was neutralized to $\mathrm{pH}$ 6-8 using approximately $350 \mu \mathrm{L}$ of $1 \mathrm{M}$ ammonium carbonate solution and the supernatant was centrifuged for another $15 \mathrm{~min}$ at 3,500 g.

The extracts were purified by solid phase extraction (SPE) using Strata-X Polymeric reversed phase $200 \mathrm{mg} / 6 \mathrm{ml}$ cartridges (Phenomenex, Palo Alto, CA, USA). Cartridges were conditioned with $6 \mathrm{~mL}$ methanol, followed by $6 \mathrm{~mL}$ water. The extract was passed through the cartridge, which was then washed with $6 \mathrm{~mL} 1 \%$ formic acid, followed by $6 \mathrm{~mL}$ water. The cartridges were dried for $10 \mathrm{~min}$ under reduced pressure using an SPE vacuum manifold. PAs were eluted with $6 \mathrm{~mL}$ of methanol and the eluates were dried under a stream of nitrogen at $50^{\circ} \mathrm{C}$ using a TurboVap (Biotage, Uppsala, Sweden). The residues were reconstituted in $500 \mu \mathrm{L}$ $10 \%$ methanol in water and filtered using $0.45 \mu \mathrm{m}$ PTFE filtervials (UniPrep, 
Whatman, Maidstone, UK). The vials were closed with help of a compressor. The purified extracts were stored at $-20^{\circ} \mathrm{C}$ until analysis.

\subsubsection{LC-MS/MS analysis}

The sample analysis was carried out in positive electrospray mode on an LCMS/MS system consisting of a Waters Acquity UPLC coupled to a Xevo TQ-S tandem mass spectrometer (Waters, Milford, MA, USA). Chromatographic separation was obtained on a $150 \times 2.1 \mathrm{~mm}, 1.7 \mu \mathrm{m}$ particle size, UPLC BEH C18 analytical column (Waters, Milford, MA, USA). The column and sample temperature were set at $50^{\circ} \mathrm{C}$ and $10^{\circ} \mathrm{C}$, respectively. The mobile phase used in LCMS/MS analysis consisted of water containing $10 \mathrm{mM}$ ammonium carbonate $\mathrm{pH} 9$ (as eluent A) and acetonitrile (as eluent $\mathrm{B}$ ) with a flow rate of $0.4 \mathrm{~mL} / \mathrm{min}$. A gradient elution was performed as follows: $0.0 \mathrm{~min} 100 \% \mathrm{~A} / 0 \% \mathrm{~B}, 0.1 \mathrm{~min} 95 \% \mathrm{~A} / 5 \% \mathrm{~B}$, $3.0 \mathrm{~min} 90 \% \mathrm{~A} / 10 \% \mathrm{~B}, 7.0 \mathrm{~min} 76 \% \mathrm{~A} / 24 \% \mathrm{~B}, 9.0 \mathrm{~min} 70 \% \mathrm{~A} / 30 \% \mathrm{~B}, 12.0 \mathrm{~min} 30 \%$ A/70\% B, 12.1-14.2 min 100\% A/0\% B. Of each sample extract, $2 \mu \mathrm{L}$ was injected.

Matrix matched standards (MMS) were used to assess the linearity of the LCMS/MS system and to confirm that the sample pre-treatment was done correctly. For MMS, 8 subsamples of $1 \mathrm{~g}$ of a blank plant food supplement, in which no PAs had been detected in a previous analysis (<LOD), were spiked with a mixture of the 59 PAs standards in a concentration range of $0-1000 \mu \mathrm{g} / \mathrm{kg}$. After waiting for $10 \mathrm{~min}$, the MMS samples were processed and analysed by the same procedure as described above. LOQs obtained were $5 \mu \mathrm{g} / \mathrm{kg}$ for individual PAs in dried plant material and $5 \mu \mathrm{g} / \mathrm{L}$ in liquids. Recovery and repeatability data were presented in Chen et al. (2019).[21]

Detection of PAs was done based on at least two MRM transitions measured per analyte. For detection and confirmation of PAs in the samples, retention times and ion ratios were compared to those of the calibration curves of the compounds prepared using the MMS. Besides the 59 PAs for which an analytical standard was available, the samples were screened for another 32 1,2-unsaturated PAs for which no standards were available. These PAs were included in the analytical method based on mass spectrometric data obtained from the analysis of selected extracts by running the LC-MS/MS in parent ion scanning mode. Fragment ions typically present in the fragmentation spectra of PAs were selected: ions with $m / z$ 94; 118; 120 and 138 for retronecine-type PAs and ions with $\mathrm{m} / z$ 122; 150 and 168 for otonecinetype PAs. When two or more fragment ions were produced from the same parent ion (the protonated molecular ion), the latter was marked as a potential PA and the corresponding transitions were included in the MRM method. See Supplementary 
materials 2 for an overview of the MS/MS transitions used for the complete set of PAs.

Quantification was performed by single level standard addition $(250 \mu \mathrm{g} / \mathrm{kg})$ to each sample. For those compounds for which no reference standard was available, a semi-quantitative concentration was obtained by comparison of the peak areas with that of the most closely related analogue (e.g. an isomer). For metabolites with tentative or unknown structures, no close related standard could be identified. In such cases the concentration was estimated by taking the sum of the two most intense MRM transitions and comparing this with the sum area of a selected reference standard, as indicated in Supplementary materials 2. Data processing was conducted with MassLynx 4.1 software (Waters Corporation, Milford, MA, USA).

Samples that contained PAs in a concentration exceeding $250 \mu \mathrm{g} / \mathrm{kg}$ were reanalysed. This was the case for 16 samples. Depending on the (range of) PA levels present in the samples, various dilutions of the purified extracts were made in triplicate. One of the 3 replicates was spiked with a mixed PA standard solution to obtain a concentration in the diluted extract of $50 \mathrm{ng} / \mathrm{mL}$, one was spiked at 200 $\mathrm{ng} / \mathrm{mL}$ and one extract was left unspiked. Samples TR-5, TR-6, TR-8, TR-15 and TR37 were diluted 40 -fold $(25 \mu \mathrm{L})$, TR-9, TR-10, TR-23, TR-26 and TR-32 were diluted 100 -fold $(10 \mu \mathrm{L})$, TR-24, TR-28 and TR-31 were diluted 40 -fold $(25 \mu \mathrm{L})$ as well as 200 fold (5 $\mu \mathrm{L})$, TR-12, TR-17 and TR-34 were diluted 40 -fold ( $25 \mu \mathrm{L})$ as well as 400 -fold $(2.5 \mu \mathrm{L})$. The final volume after dilution with water in all cases was $1 \mathrm{~mL}$.

\subsubsection{Exposure assessment resulting from the drinking of jamu based on PA levels detected}

In order to assess the potential exposure to PAs resulting from consuming the jamu, the estimated daily intake (EDI) was calculated according to Equation 4.1.

$E D I=\frac{W \times \text { total } P A s}{B W \times 1,000}$

(Equation 4.1)

where the EDI values are expressed in $\mu \mathrm{g} / \mathrm{kg}$ bw/day. $\mathrm{W}$ is the weight, expressed in $\mathrm{g}$ or $\mathrm{mL}$, of recommended daily use of these samples (Table 4.1) based on the information provided on the label (see Supplementary materials 1). For the liquid samples and when there was no information on the label regarding the weight of recommended daily use, this was estimated from the average weight of 3 replicate samples. Total PAs is the total amount of PAs detected in the sample by LC-MS/MS, expressed in $\mu \mathrm{g} / \mathrm{kg}$ for solid samples and in $\mu \mathrm{g} / \mathrm{L}$ for liquid samples. BW is body weight of $54 \mathrm{~kg}$, the average body weight for Indonesian male and female.[22] The factor 1,000 is added to convert $\mathrm{W}$ in $\mathrm{g}$ to $\mathrm{kg}$ or $\mathrm{mL}$ to $\mathrm{L}$. 


\subsubsection{Safety assessment based on PA levels detected in the jamu}

To assess the acute risks for consumers of jamu containing PAs, the EDI values calculated by Equation 4.1 were compared to the dose range of $1-3 \mathrm{mg} \mathrm{PA} / \mathrm{kg}$ bw/day at which acute/short-term adverse effects in humans were reported upon consumption for 4 days up to 2 weeks periods, as described by EFSA (2017) ${ }^{[5]}$. A daily intake of PAs of $10 \mu \mathrm{g} / \mathrm{kg}$ bw/ day established by WHO-IPCS (1998)[23] which may cause HVOD in humans, was used to evaluate the acute toxicity resulting from PAs intake via jamu consumption.

The MOE approach was applied to assess the chronic risk posed by the use of the PA-containing jamu, in line with the recommendations of EFSA for risk assessment of compounds that are both genotoxic and carcinogenic ${ }^{[24]}$. The MOE was calculated as described in Equation 4.2.

$M O E=\frac{B M D L_{10}}{E D I}$

(Equation 4.2)

where the MOE is dimensionless, the $\mathrm{BMDL}_{10}$ value used was $237 \mu \mathrm{g} / \mathrm{kg}$ bw/day established by EFSA (2017) ${ }^{[5]}$ for riddelliine and used as POD for evaluating the risks of PA exposure, and EDI values ( $\mu \mathrm{g} / \mathrm{kg} \mathrm{bw} /$ day) were calculated by Equation 4.1. $\mathrm{MOE}$ values were rounded to one significant figure.

The MOE values are based on chronic lifetime exposure, although realistic use of the jamu may be for shorter periods of time. As previously suggested Doull and Rozman (2000) ${ }^{[25]}$ Haber's rule was applied to correct the EDI and thus the MOE approach for shorter than lifetime exposure. Based on this rule the toxic outcome will be similar for situations where the product of the exposure time and the dose will be constant, $(k=C \times T ; C 1 \times T 1=C 2 \times T 2$, where $\mathrm{k}$ is the toxic outcome, $\mathrm{C}$ is the concentration (or dose) of the toxic chemical and $\mathrm{T}$ is the duration of exposure).[25-27] Using Haber's rule, the EDI of PAs can be expressed as follows:

$E D I(2 w k / y r$ during a lifetime $)=\frac{E D I}{26}$

(Equation 4.3)

where the EDI for 2 weeks every year during a lifetime is the EDI for daily lifetime exposure obtained by Equation 4.1 adapted to only 2 weeks yearly during a whole lifetime. To further illustrate how short term exposure would affect the MOE values, Haber's rule was also used to calculate the number of weeks (Equation 4.4) of daily consumption of the different samples that would result in an MOE value of 10,000: Number of weeks $=\frac{M O E \times 69 \times 52}{10,000}$

(Equation 4.4) where the MOE is the value for lifetime exposure calculated by Equation 4.2, 69 represents the life expectancy of Indonesian people in years, ${ }^{[28]} 52$ is the number of weeks within a year, and 10,000, the threshold for health concern[24]. 


\subsubsection{Safety assessment based on PA levels compared to the AB and AA levels detected in the jamu containing non-PA producing botanicals}

We compared for samples TR-36 to TR-56 the safety assessment on PA levels to the safety assessment of ABs. The MOE values for PA intake calculated from samples TR-36 to TR-56 were compared to previously reported MOE values for intake of $\mathrm{ABs}$ resulting from the $\mathrm{AB}$-producing botanicals in these jamu products. ${ }^{[3]}$ The MOE values were calculated using the $\mathrm{BMDL}_{10}$ of $15.3 \mathrm{mg} / \mathrm{kg}$ bw for the major alkenylbenzene in the mixture, methyleugenol,[29] and the EDI resulting from summing up the EDIs of the individual alkenylbenzenes assuming equal potency (See Supplementary materials 1). Samples TR-57 and TR-58 contained AAproducing botanicals, and for these samples the MOE values determined for PAs were compared to the MOE values calculated for the AA intake from these 2 jamu samples using the $\mathrm{BMDL}_{10}$ of $10 \mu \mathrm{g} / \mathrm{kg}$ bw/day ${ }^{[4]}$ estimated from reported data on kidney tumour formation by a mixture of AAs (71\% of AAI and $21 \%$ of AAII) upon oral exposure in rats ${ }^{[30]}$. The EDI values were calculated based on the AA levels determined using the UPLC method for quantification of AAs described previously.[4]

\subsection{Results}

\subsubsection{Levels of PAs in Indonesian jamu}

As shown in Table 4.1 (for a full set of results see Supplementary materials 3), PAs were detected in 34 out of 35 jamu samples containing PA-producing botanicals. The number of different PAs detected ranged from 2 to 40, and levels ranged from 12.3 to $235,376 \mu \mathrm{g} / \mathrm{kg}$. The highest PA level was found in sample TR-17 in which senecionine $\mathrm{N}$-oxide was present at the highest concentration, amounting to 114,071 $\mu \mathrm{g} / \mathrm{kg}$. Rinderine, senkirkine, and neosenkirkine were the top three most frequently found PAs, in 28, 26 and 23 samples, respectively, out of the 34 positive tested samples containing PA-producing botanicals. In one sample, TR-3, the levels of all PAs were below the LOQ.

According to the labelling, 29 of the 35 samples consisted of a Gynura species (mostly G. procumbens or G. segetum) or contained it as one of the ingredients. The 6 other samples contained Sympytum officinale (2 samples), and single samples of Adenostemma lavenia, Ageratum conyzoides, Lithospermum orientale and Tussilago farfara. Interestingly, 14 samples containing Gynura had high levels of PAs $(>12,000$ $\mu \mathrm{g} / \mathrm{kg}$ ), while in 15 samples containing Gynura only moderate or even low levels (between <LOQ and $1270 \mu \mathrm{g} / \mathrm{kg}$ ) of PAs were found. Most strikingly are jamu samples TR-7, TR-13, TR-16 and TR-11, that according to the label consisted solely 
of Gynura leaf or an extract prepared from Gynura, but analysis revealed only very low levels of PAs (between 12 and $73 \mu \mathrm{g} / \mathrm{kg}$ ).

Table 4.1. The level and EDI of PAs detected in Indonesian jamu containing PA-producing botanicals.

\begin{tabular}{|c|c|c|c|c|c|}
\hline $\begin{array}{l}\text { Sample } \\
\text { ID }\end{array}$ & $\begin{array}{l}\text { Number } \\
\text { of PAs } \\
\text { detected }\end{array}$ & $\begin{array}{l}\text { Total PAs } \\
\text { level } \\
(\mu \mathrm{g} / \mathrm{kg}) \text { a }\end{array}$ & $\begin{array}{l}\text { Recommended } \\
\text { daily use (g) }\end{array}$ & $\begin{array}{l}\text { EDI } \\
(\mu \mathrm{g} / \mathrm{kg} \\
\text { bw/day) }\end{array}$ & $\begin{array}{l}\text { Top three PAs and their } \\
\text { concentration }(\mu \mathrm{g} / \mathrm{kg})^{\mathrm{a}}\end{array}$ \\
\hline TR-1 & 2 & 13.1 & 1.9 & 0.0005 & Monoester 7.90 (7.7), rinderine (5.3) \\
\hline TR-2 & 3 & 135.3 & 14 & 0.035 & $\begin{array}{l}\text { Senkirkine (85.7), neosenkirkine (43.3), } \\
\text { rinderine (6.3) }\end{array}$ \\
\hline TR-3 & - & $<\mathrm{LOQ}$ & $200^{b}$ & $-c$ & - \\
\hline TR-4 & 3 & 31.8 & 3.4 & 0.002 & $\begin{array}{l}\text { Rinderine (16.8), echinatine (9.0), } \\
\text { rinderine N-ox (5.9) }\end{array}$ \\
\hline TR-5 & 37 & 35,066 & 1.1 & 0.691 & $\begin{array}{l}\text { Jacoline N-ox }(16,762) \text {, jacobine N-ox } \\
(4016) \text {, senkirkine }(3,042)\end{array}$ \\
\hline TR-6 & 26 & 17,435 & 5.6 & 1.808 & $\begin{array}{l}\text { Senkirkine }(5,807) \text {, senecionine }(4,918), \\
\text { neosenkirkine }(4,153)\end{array}$ \\
\hline TR-7 & 7 & 73.4 & 2.9 & 0.004 & $\begin{array}{l}\text { Lycopsamine (19.0), echinatine (15.0), } \\
\text { PA diester } 11.45(12.6)\end{array}$ \\
\hline TR-8 & 23 & 70,055 & 0.8 & 1.067 & $\begin{array}{l}\text { Neosenkirkine }(44,446), \text { senkirkine } \\
(15,674) \text {, integerrimine }(2,981)\end{array}$ \\
\hline TR-9 & 31 & 74,837 & 2.9 & 3.951 & $\begin{array}{l}\text { Jacoline N-ox }(30,507) \text {, onetine }(16,468) \text {, } \\
\text { jacoline }(8,342)\end{array}$ \\
\hline TR-10 & 27 & 39,632 & 3 & 2.229 & $\begin{array}{l}\text { Senkirkine }(15505) \text {, otonecine ester } 3.75 \\
(9,008) \text {, neosenkirkine }(7,065)\end{array}$ \\
\hline TR-11 & 2 & 12.3 & 3.7 & 0.001 & senkirkine (6.8), intermedine (5.5) \\
\hline TR-12 & 40 & 105,099 & 2.4 & 4.761 & $\begin{array}{l}\text { Senkirkine }(52,260), \text { neosenkirkine } \\
(19,495) \text {, otonecine ester } 3.75(17,460)\end{array}$ \\
\hline TR-13 & 4 & 65.7 & 3 & 0.004 & $\begin{array}{l}\text { Rinderine (38.0), intermedine (13.3), } \\
\text { senkirkine (8.0) }\end{array}$ \\
\hline TR-14 & 2 & 131.1 & $45^{\mathrm{b}}$ & 0.109 & Senkirkine (123.0), neosenkirkine (8.2) \\
\hline TR-15 & 27 & 21,516 & 0.5 & 0.202 & $\begin{array}{l}\text { Senecionine }(6,634) \text {, senkirkine }(6,588), \\
\text { neosenkirkine }(4,743)\end{array}$ \\
\hline TR-16 & 4 & 33.2 & 1.1 & 0.001 & $\begin{array}{l}\text { Rinderine (12.0), echinatine N-ox (8.8), } \\
\text { rinderine N-ox (7.6) }\end{array}$ \\
\hline TR-17 & 31 & 235,376 & 3 & 13.256 & $\begin{array}{l}\text { Senecionine N-ox }(114,071) \text {, senkirkine } \\
(66,713) \text {, integerrimine N-ox }(23,784)\end{array}$ \\
\hline TR-18 & 4 & 29.5 & 30 & 0.016 & $\begin{array}{l}\text { Echinatine N-ox (8.5), lycopsamine N- } \\
\text { ox }(8.1) \text {, rinderine }(6.9)\end{array}$ \\
\hline TR-19 & 8 & 453 & 2 & 0.017 & $\begin{array}{l}\text { Echinatine (187.4), rinderine (114.6), } \\
\text { lycopsamine }(58.0)\end{array}$ \\
\hline TR-20 & 9 & 276.6 & 2.9 & 0.015 & $\begin{array}{l}\text { Indicine N-ox (136.0), indicine (62.3), } \\
\text { rinderine (22.8) }\end{array}$ \\
\hline TR-21 & 8 & 270.2 & 6 & 0.030 & $\begin{array}{l}\text { PA diester } 11.45 \text { (91.2), lycopsamine N- } \\
\text { ox (56.2), Lycopsamine }(42.3)\end{array}$ \\
\hline TR-22 & 6 & 113.4 & 1.4 & 0.003 & $\begin{array}{l}\text { Echinatine (40.8), Rinderine (23.6), } \\
\text { lycopsamine (16.1) }\end{array}$ \\
\hline TR-23 & 23 & 51,425 & 1 & 0.933 & $\begin{array}{l}\text { Senkirkine }(23,234), \quad \text { neosenkirkine } \\
(15,662) \text {, otonecine ester } 3.75(7,749)\end{array}$ \\
\hline TR-24 & 37 & 63,877 & 0.9 & 1.065 & $\begin{array}{l}\text { Senkirkine }(28,452), \text { neosenkirkine } \\
(14,610) \text {, otonecine ester } 3.75(7,870)\end{array}$ \\
\hline TR-25 & 13 & 1,265 & 1.2 & 0.029 & $\begin{array}{l}\text { Neosenkirkine } \quad(699.3) \text {, senkirkine } \\
\text { (189.7), Otonecine ester } 3.75 \text { (93.5) }\end{array}$ \\
\hline TR-26 & 26 & 12,173 & 1.4 & 0.311 & $\begin{array}{l}\text { Senkirkine }(4,679), \quad \text { neosenkirkine } \\
(2,539) \text {, senecionine }(1,996)\end{array}$ \\
\hline
\end{tabular}




\begin{tabular}{|c|c|c|c|c|c|}
\hline $\begin{array}{l}\text { Sample } \\
\text { ID }\end{array}$ & $\begin{array}{l}\text { Number } \\
\text { of PAs } \\
\text { detected }\end{array}$ & $\begin{array}{l}\text { Total PAs } \\
\text { level } \\
(\mu \mathrm{g} / \mathrm{kg})^{a}\end{array}$ & $\begin{array}{l}\text { Recommended } \\
\text { daily use (g) }\end{array}$ & $\begin{array}{l}\text { EDI } \\
(\mu \mathrm{g} / \mathrm{kg} \\
\text { bw/day })\end{array}$ & $\begin{array}{l}\text { Top three PAs and their } \\
\text { concentration }(\mu \mathrm{g} / \mathrm{kg})^{\mathrm{a}}\end{array}$ \\
\hline TR-27 & 19 & 933.9 & 3.8 & 0.065 & $\begin{array}{l}\text { Senkirkine (237.2), senecionine N-ox } \\
(132.6) \text {, rinderine }(127.1)\end{array}$ \\
\hline TR-28 & 34 & 65,763 & 0.7 & 0.813 & $\begin{array}{l}\text { Senkirkine }(33,630), \quad \text { neosenkirkine } \\
(13,022) \text {, otonecine ester } 3.75(8,894)\end{array}$ \\
\hline TR-29 & 7 & 205.9 & 1.8 & 0.007 & $\begin{array}{l}\text { Echinatine }(103.5) \text {, lycopsamine (37.2), } \\
\text { rinderine }(21.4)\end{array}$ \\
\hline TR-30 & 4 & 42.5 & 1.5 & 0.001 & $\begin{array}{l}\text { Echinatine (15.9), rinderine (12.1), } \\
\text { lycopsamine (8.2) }\end{array}$ \\
\hline TR-31 & 36 & 104,842 & 3.4 & 6.556 & $\begin{array}{l}\text { Senkirkine }(48,296), \quad \text { neosenkirkine } \\
(16,787), \text { otonecine ester } 3.75(16,257)\end{array}$ \\
\hline TR-32 & 24 & 146,977 & 0.5 & 1.255 & $\begin{array}{l}\text { Echinatine }(33,713) \text {, echinatine N-ox } \\
(33,563) \text {, lycopsamine }(26,217)\end{array}$ \\
\hline TR-33 & 11 & 357.2 & 2.3 & 0.015 & $\begin{array}{l}\text { Rinderine N-ox (66.8), senkirkine } \\
(65.9), \text { neosenkirkine }(44.0)\end{array}$ \\
\hline TR-34 & 39 & 106,712 & 4.2 & 8.346 & $\begin{array}{l}\text { Senkirkine } \quad(49,156), \quad \text { neosenkirkine } \\
(18,997), \text { otonecine ester } 3.75(16,757)\end{array}$ \\
\hline TR-35 & 2 & 15.1 & $30^{\mathrm{b}}$ & 0.008 & Neosenkirkine (8.4), senkirkine (6.6) \\
\hline
\end{tabular}

${ }^{\mathrm{a}}$ Liquid samples are expressed in $\mu \mathrm{g} / \mathrm{L} .{ }^{\mathrm{b}}$ In $\mathrm{mL} .{ }^{\mathrm{c}}$ The EDI cannot be calculated because no PAs were detected above the LOQ.

PAs were also found in 17 out of 23 jamu samples containing non-PAproducing botanicals with levels ranging from 5.9 - 3,421 $\mu \mathrm{g} / \mathrm{kg}$ (Table 4.2), indicating there is a contamination with PA-producing plants. Senkirkine was the PA present at the highest level $(3,221 \mu \mathrm{g} / \mathrm{kg})$ in sample TR-58. The jamu made from non-PA-producing botanicals that tested positive for PAs contained between 1 and 14 different PAs, with rinderine being the PA most often found (14 out of 17 positive samples); albeit at relatively low levels (the highest concentration amounting to 43.5 $\mu \mathrm{g} / \mathrm{kg}$ ). Also its isomers intermedine, lycopsamine, echinatine and indicine, as well as the corresponding N-oxides were often present, in levels ranging from $5.2-135.5$ $\mu \mathrm{g} / \mathrm{kg}$. It should be noted that the levels of PAs present in jamu made from non-PAproducing botanicals were much lower than the PA levels found in many of the jamu made from PA-producing botanicals. The total PA level in sample TR- 58 was approximately 70 times lower than the level in TR-17, the sample with the highest PA content (Table 4.1).

Table 4.2. The level of PAs detected in Indonesian jamu containing non-PA-producing botanicals and the corresponding EDI

\begin{tabular}{|c|c|c|c|c|c|}
\hline $\begin{array}{l}\text { Sample } \\
\text { ID }\end{array}$ & $\begin{array}{l}\text { Number } \\
\text { of PAs } \\
\text { detected }\end{array}$ & $\begin{array}{l}\text { Total PAs } \\
\text { level } \\
(\mu \mathrm{g} / \mathrm{kg})^{a}\end{array}$ & $\begin{array}{l}\text { Recommended } \\
\text { daily use (g) }\end{array}$ & $\begin{array}{l}\text { EDI } \\
(\mu \mathrm{g} / \mathrm{kg} \\
\text { bw/day })\end{array}$ & $\begin{array}{l}\text { Top three PAs and their } \\
\text { concentration }(\mu \mathrm{g} / \mathrm{kg})^{\mathrm{a}}\end{array}$ \\
\hline TR-36 & - & $<\mathrm{LOQ}$ & 14 & $-c$ & - \\
\hline TR-37 & 10 & 127.8 & 14 & 0.033 & $\begin{array}{l}\text { Indicine N-ox (36.5), heliotrine N-ox } \\
\text { (19.9), echinatine N-ox (12.6) }\end{array}$ \\
\hline TR-38 & - & $<\mathrm{LOQ}$ & 14 & $-c$ & - \\
\hline TR-39 & 14 & 313.7 & 14 & 0.081 & $\begin{array}{l}\text { Indicine N-ox (91.9), heliotrine N-ox } \\
\text { (66.2), europine N-ox }(30.1)\end{array}$ \\
\hline TR-40 & - & $<\mathrm{LOQ}$ & 14 & $-c$ & - \\
\hline TR-41 & - & $<\mathrm{LOQ}$ & 14 & $-c$ & - \\
\hline
\end{tabular}




\begin{tabular}{|c|c|c|c|c|c|}
\hline $\begin{array}{l}\text { Sample } \\
\text { ID }\end{array}$ & $\begin{array}{l}\text { Number } \\
\text { of PAs } \\
\text { detected }\end{array}$ & $\begin{array}{l}\text { Total PAs } \\
\text { level } \\
(\mu \mathrm{g} / \mathrm{kg})^{\text {a }}\end{array}$ & $\begin{array}{l}\text { Recommended } \\
\text { daily use (g) }\end{array}$ & $\begin{array}{l}\text { EDI } \\
(\mu \mathrm{g} / \mathrm{kg} \\
\text { bw/day })\end{array}$ & $\begin{array}{l}\text { Top three PAs and their } \\
\text { concentration }(\mu \mathrm{g} / \mathrm{kg})^{\mathrm{a}}\end{array}$ \\
\hline TR-42 & 5 & 40.6 & 2.1 & 0.002 & $\begin{array}{l}\text { Rinderine }(14.7), \text { intermedine }(8.0) \text {, } \\
\text { rinderine N-ox (6.5) }\end{array}$ \\
\hline TR-43 & 10 & 144.8 & 14 & 0.038 & $\begin{array}{l}\text { Lycopsamine }(36.2) \text {, rinderine } \mathrm{N} \text {-ox } \\
(23.2) \text {, echimidine }(20.6)\end{array}$ \\
\hline TR-44 & - & $<\mathrm{LOQ}$ & 3 & $-c$ & - \\
\hline TR-45 & 8 & 253.2 & 14 & 0.066 & $\begin{array}{l}\text { Echinatine N-ox (70.8), rinderine (43.5), } \\
\text { echinatine (41.9) }\end{array}$ \\
\hline TR-46 & 3 & 60.2 & 7 & 0.008 & $\begin{array}{l}\text { Rinderine (33.3), rinderine N-ox (16.8), } \\
\text { intermedine (10.0) }\end{array}$ \\
\hline TR-47 & 7 & 149.8 & 14 & 0.039 & $\begin{array}{l}\text { Indicine N-ox (48.9), echinatine N-ox } \\
\text { (40.8), lycopsamine N-ox (15.6) }\end{array}$ \\
\hline TR-48 & 11 & 436.8 & 10 & 0.081 & $\begin{array}{l}\text { Indicine N-ox (135.5), indicine (86.8), } \\
\text { PA diester } 11.45(47.3)\end{array}$ \\
\hline TR-49 & 6 & 102.8 & 10 & 0.019 & $\begin{array}{l}\text { Rinderine (42.6), intermedine (16.9), } \\
\text { lycopsamine (14.4) }\end{array}$ \\
\hline TR-50 & 3 & 35.7 & 14 & 0.009 & $\begin{array}{l}\text { Rinderine (18.8), intermedine (10.8), } \\
\text { echinatine (6.2) }\end{array}$ \\
\hline TR-51 & 2 & 26.2 & 12 & 0.006 & $\begin{array}{l}\text { Monocrotaline }(17.7) \text {, heliotrine N-ox } \\
(8.4) \text {, europine N-ox (4.7) }\end{array}$ \\
\hline TR-52 & 3 & 49.5 & 1.7 & 0.002 & $\begin{array}{l}\text { Rinderine (20.4), lycopsamine (15.7), } \\
\text { intermedine (13.4) }\end{array}$ \\
\hline TR-53 & 6 & 125.2 & 2.1 & 0.005 & $\begin{array}{l}\text { Indicine N-ox (33.3), rinderine N-ox } \\
\text { (28.4), indicine (24.0) }\end{array}$ \\
\hline TR-54 & 4 & 86.7 & 10 & 0.016 & $\begin{array}{l}\text { Echinatine (43.9), echinatine N-ox } \\
\text { (19.8), lycopsamine (17.8) }\end{array}$ \\
\hline TR-55 & 1 & 5.9 & 14 & 0.002 & Rinderine (5.9) \\
\hline TR-56 & 7 & 70.1 & 14 & 0.018 & $\begin{array}{l}\text { Rinderine (17.7), echinatine N-ox } \\
\text { (13.0), echinatine (9.1) }\end{array}$ \\
\hline TR-57 & - & $<\mathrm{LOQ}$ & $5^{b}$ & $-c$ & - \\
\hline TR-58 & 4 & 3,421 & 3.6 & 0.228 & $\begin{array}{l}\text { Senkirkine }(3,221) \text {, otonecine ester } 3.75 \\
(121.5) \text {, senecionine }(52.3)\end{array}$ \\
\hline
\end{tabular}

a Liquid samples are expressed in $\mu \mathrm{g} / \mathrm{L} .{ }^{\mathrm{b}}$ In $\mathrm{mL} .{ }^{\mathrm{c}}$ The EDI cannot be calculated because no PAs were detected above the LOQ.

\subsubsection{The estimated daily intake (EDI) of PAs resulting from consumption of jamu}

Table 4.1 presents the EDI values of total PAs calculated for the consumption of positive samples of jamu containing PA-producing botanicals. The values range from 0.0005 to $13.3 \mu \mathrm{g} / \mathrm{kg}$ bw/day. The highest EDI of $13.3 \mu \mathrm{g} / \mathrm{kg}$ bw/day was calculated for consumption of jamu TR-17, which of all samples also had the highest level of PAs. As depicted in Table 4.2, the EDI values for intake of total PAs from jamu samples containing non-PA-producing botanicals ranged from 0.002 to 0.228 $\mu \mathrm{g} / \mathrm{kg} \mathrm{bw} /$ day. The highest EDI for this group of jamu products, calculated for TR58, was still almost 60 times lower compared to the highest EDI (TR-17) resulting from consumption of jamu containing PA-producing botanicals. 


\subsubsection{Risk assessment of jamu based on PA levels}

\subsubsection{Acute exposure scenario}

The EDI values for PAs resulting from the consumption of all jamu samples containing PA-producing botanicals (Figure 4.2a) and non-PA-producing botanicals are far below the dose range of 1-3 $\mathrm{mg}$ PA/ $\mathrm{kg}$ bw/day at which acute/short-term adverse effects in humans have been reported by (EFSA, 2017) ${ }^{[5]}$. This result indicates that jamu consumers are not at risk for acute toxicity of PAs when consuming those preparations for short periods of 4 days up to 2 weeks. However, in one jamu sample, TR-17, the EDI value is higher than $10 \mu \mathrm{g} / \mathrm{kg}$ bw/day, which has been linked to the prevalence of HVOD in humans. ${ }^{[23]}$ There are 11 (31\%) jamu samples containing PA-producing botanicals that would give rise to EDI values higher than $890 \mathrm{ng} / \mathrm{kg}$ bw per day, which is the highest estimated acute/short-term exposure level reported by EFSA (2016)[31], for consumption of an infusion of borage (Borago officinalis), a PA-producing plant consumed by a part of the European population (Figure 4.2a). On the other hand, the EDI of $13.3 \mu \mathrm{g} / \mathrm{kg} \mathrm{bw} /$ day, resulting from the consumption of 2 capsules of TR-17 three times a day, was in the same range as the estimated acute exposure of 11.55 or $25.82 \mu \mathrm{g} / \mathrm{kg}$ bw/day from consumption of one tablet/capsule of the PA-producing plants boneset (Eupatorium perfolatum) or hemp agrimony (Eupatorium cannabinum), respectively. ${ }^{[31]}$ Moreover, as can be seen in Figure 4.2b, out of 17 jamu samples tested positive for PAs while not containing PA-producing botanicals, the EDI of only one sample exceeded 170 $\mathrm{ng} / \mathrm{kg}$ bw/day. This value estimated by EFSA represents for mean adult consumers the upper end of the acute exposure range based on the reported contamination levels in the different food commodities combined. ${ }^{[5]}$ 


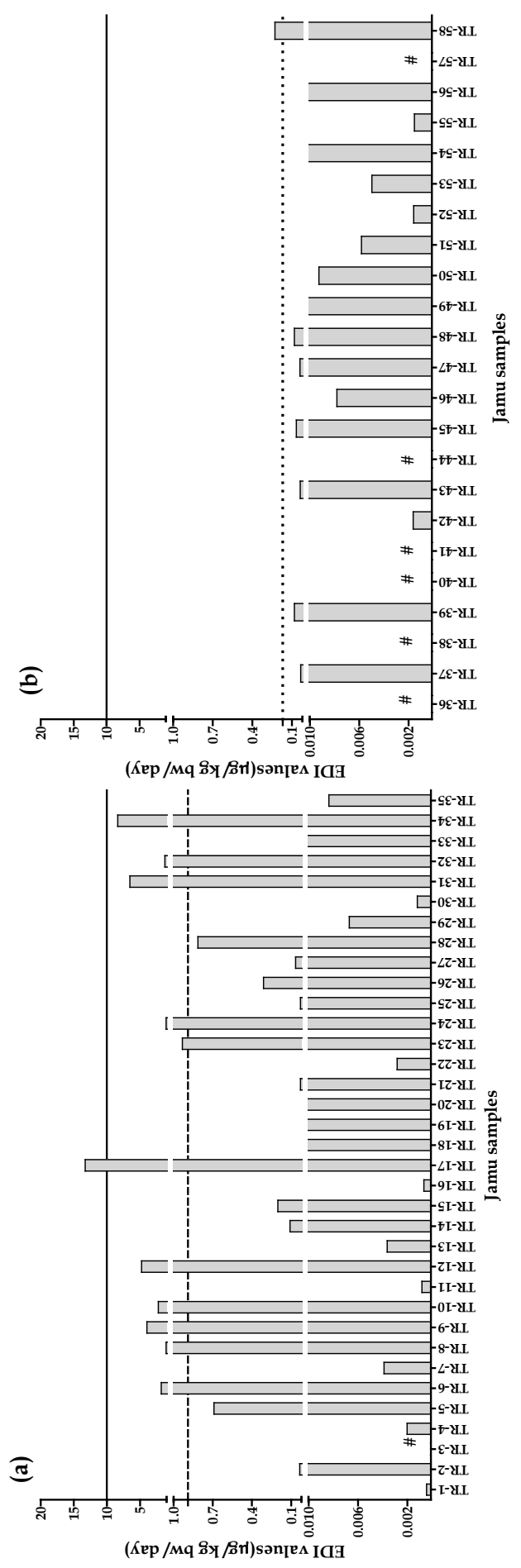

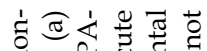

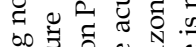

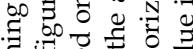

可 $\cong$ 㐘

ชั

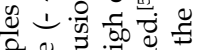

¿े.

क :

दे ซิ

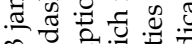

ते छ छ

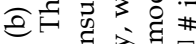

혁

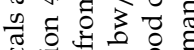

承 0.000

च્ّ

일

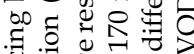

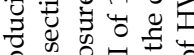

in 0

क्रे 중

吉吉导羊

$00 \sum^{0} \pm$

寻艺艺苋。

च $\frac{5}{5}$

ठ․

\& 氜焉

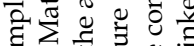

क ष

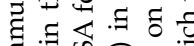

ฮ

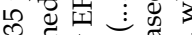

(들

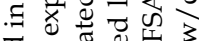

उ

记

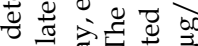

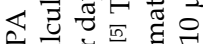

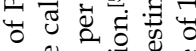

ธี

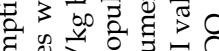

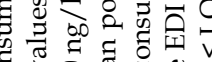

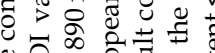

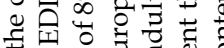

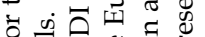

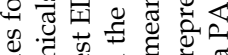

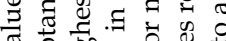

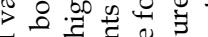

००

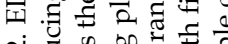

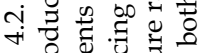

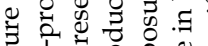

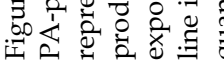




\subsubsection{Chronic exposure scenario}

The MOE values calculated for the jamu samples containing PA- and non-PAproducing botanicals, assuming daily lifetime consumption and 2 weeks of daily use every year during a lifetime, are depicted in Figure 4.3. The MOE values were calculated assuming equal potency for all PAs and using the $\mathrm{BMDL}_{10}$ of riddelliine of $237 \mu \mathrm{g} / \mathrm{kg} \mathrm{bw} /$ day as POD[5]. For 20 out of $35(57 \%)$ jamu containing PAproducing botanicals the MOE values were below 10,000, indicating there is a potential health concern (Figure 4.3a). Consumption of jamu TR-17 and TR-34 resulted in MOE values of only 20 and 30, pointing at intake levels that are approaching the dose levels that caused liver tumours in rodent studies. Correcting for shorter-than-life-time exposure resulted in MOE values below 10,000 for 13 out of 35 (37\%) jamu samples containing PA-producing botanicals (Figure 4.3a). MOE calculations for jamu samples containing non-PA-producing botanicals showed that 7 samples out of 23 would result in MOE values lower than 10,000 when assuming lifetime daily use, while there is no health concern (MOE $>10,000$ ) when these jamu would be consumed for a period of 2 weeks yearly during a lifetime (Figure $4.3 b$ ).

Figure 4.4 indicates the maximum number of weeks over a 69 -year lifetime during which the jamu could be consumed based on the PA levels detected in the samples. From Figure 4.4a it follows for example that jamu TR-1 could be consumed without raising a concern for up to 184,480 weeks, corresponding to far more than a lifetime, and thus would be of little concern. On the other hand consumption of jamu TR-17 and TR-34 would be of no concern only when consumed for 6-10 weeks during a lifetime, what corresponds to one day or less per year. For jamu containing non-PA-producing botanicals, the maximum number of weeks of use that would result in an acceptable exposure during a lifetime exceeded 2 weeks every year (Figure 4.4b). 

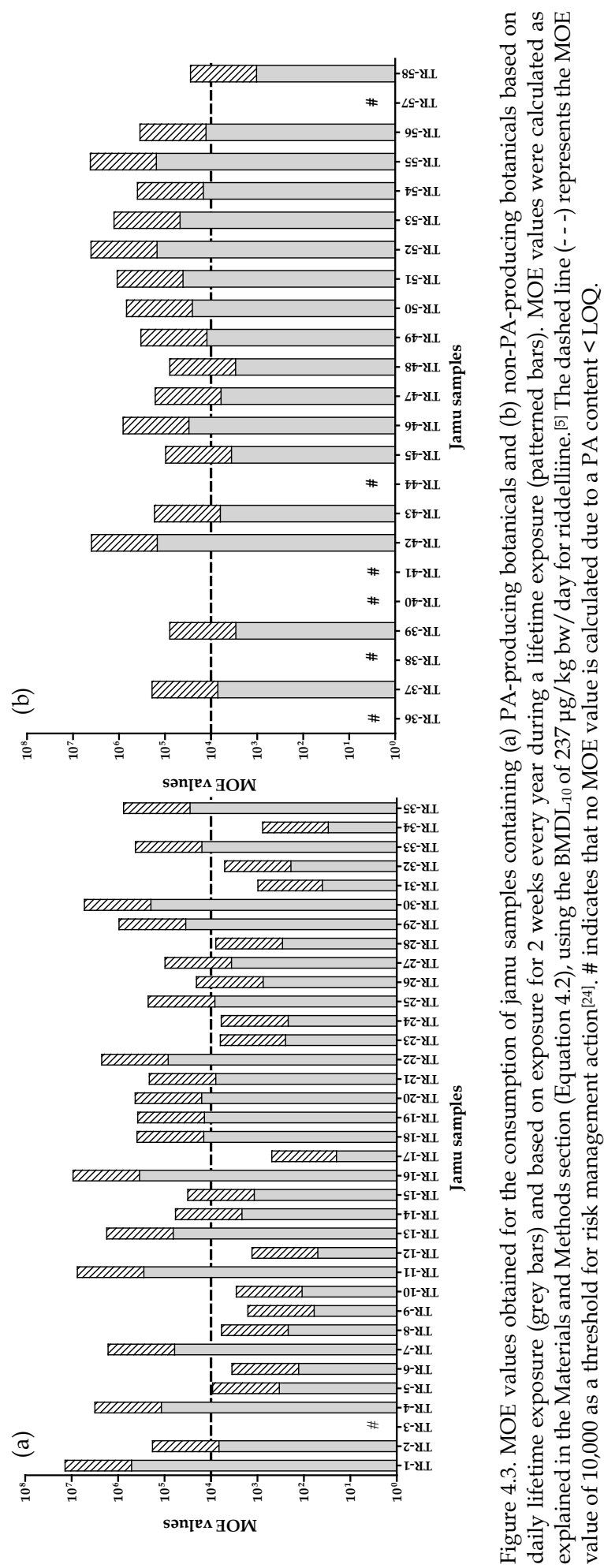


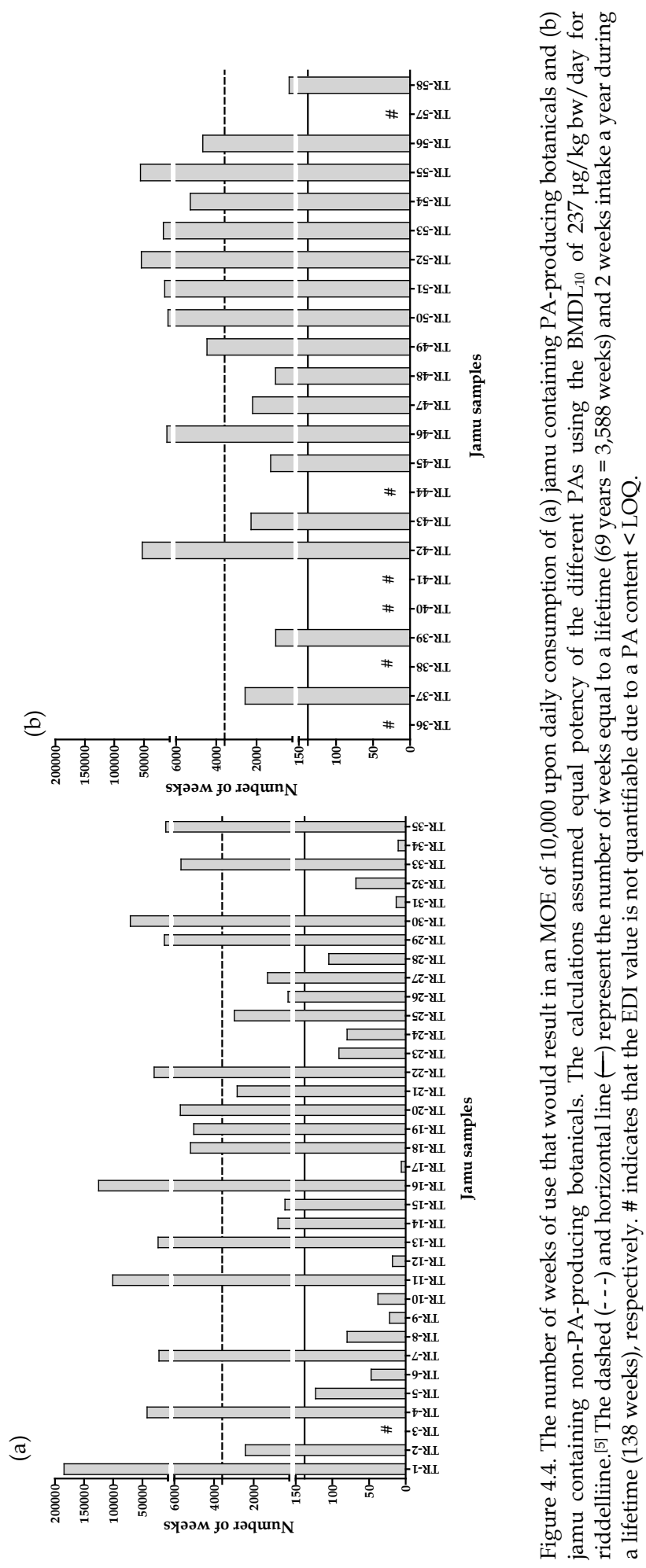




\subsubsection{Risk assessment of jamu containing non-PA-producing botanicals based on} PA, AB and AA levels

Figure 4.5 presents the MOE values obtained for the exposure to PAs combined with the MOE results of a risk assessment on ABs detected in samples TR36 to TR-56 and on AA levels detected in samples TR- 57 and TR-58. It can be seen in Figure 4.5a that in 5 samples, TR-36, TR-38, TR-40, TR-41, TR-44, no PAs were detected (thus no MOE could be calculated), but that two of these samples (TR-36 and TR-38) with respect to their $\mathrm{AB}$ concentrations could be considered a priority for risk management, even when consumption is 2 weeks every year during a lifetime (Figure 4.5b). Overall the data presented in Figure 4.5 reveal that for samples TR36-TR56 collected in a targeted sampling approach for jamu containing ABproducing botanicals, the health risk due to exposure to $A B s$ is substantially higher than the risk emerging from exposure to PAs from co-harvested PA-containing weeds.

Since the level of PAs in sample TR-57 was below the LOQ, it does not present a risk. However, since the list of botanical ingredients included Saussureae Radix and Magnoliae cortex, which are known to contain aristolochic acids, this sample was also analysed for the presence of AAs. The AAII level detected in this sample amounted to $10,500 \pm 1,900 \mu \mathrm{g} / \mathrm{kg}$, which resulted in MOE values for lifetime exposure and for 2 weeks exposure per year during a lifetime of 10.3 and 267.4, respectively, being both lower than 10,000 (insert in Figure 4.5), indicating a health concern. Jamu TR-58 consisted of Aristolochia debile as an AA producing botanical, and it contained AAI at 21,600 $\pm 6,000$ and AAII at 9,600 $\pm 1,400 \mu \mathrm{g} / \mathrm{kg}$. With a recommended use of $3.6 \mathrm{~g}$ per day this results in a MOE value for lifetime use of 4.8, and when consumed 2 weeks every year of 125, which are far below 10,000, indicating a health risk. This indicates that in TR-58 AAs present a larger concern than the PAs. 


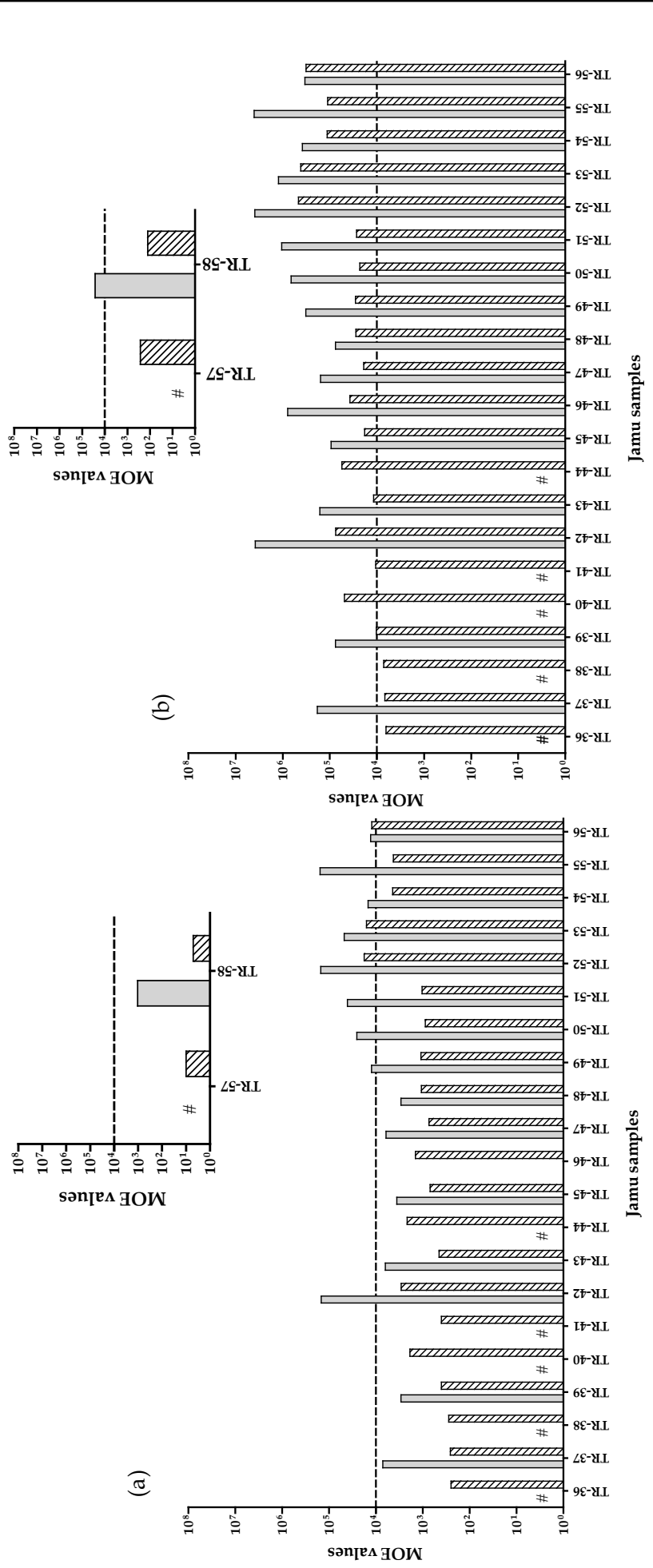

으옘ㄷㅇㅇㅛ 요

च

出

ज्ञ

ช

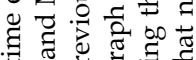

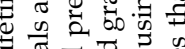

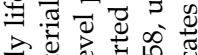

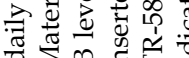

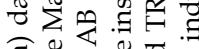

తิฐ

ธี .

उ

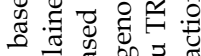

क )

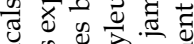

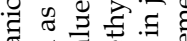

त्ञ

$00 \frac{\pi}{7}$ 됭 巳

긍 $\sum \frac{2}{x}$

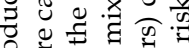

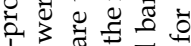

« क

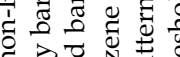

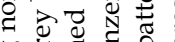

क. ప్

手焉交安

㐘艺氙《

워웡

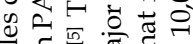

跣

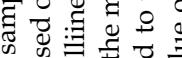

उ $\frac{0}{0}$

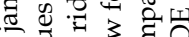

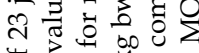

멍 중

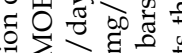

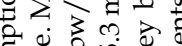

छ) छّ

की

证 $\approx \overrightarrow{1}$

छै

मे

이워

ช

むँ

융 की

0 व $\overline{0}$

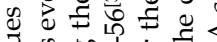

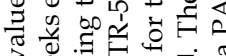

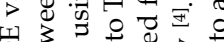

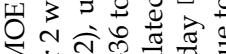

$\Sigma$ के भुष

เீ

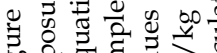

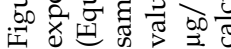




\subsection{Discussion}

This study investigated the presence of pyrrolizidine alkaloids in jamu containing PA-producing botanicals and in jamu containing non-PA-producing botanicals, with the aim to assess whether there is a potential health risk for consumers of these preparations. This assessment is of interest considering the increasing number of jamu consumers, and the fact that botanical ingredients in jamu may contain PAs which, due to their hepatotoxic, genotoxic, and carcinogenic properties, can pose a potential risk for consumers.

The analysis of jamu revealed high total PA levels of up to $235,376 \mu \mathrm{g} / \mathrm{kg}$ in the samples containing PA-producing botanicals. Twenty-nine of the 35 PA-plant containing jamu products contained a Gynura species. The genus Gynura belongs to the tribe Senecioneae of the Asteraceae family, and the genus contains PAs typical for this well-known and broad family of plant species. ${ }^{[32]}$ Interestingly, about half of these Gynura products contained high levels of PAs, while the other half contained relatively low levels. Many of the jamu samples made from Gynura that contain high PA levels show a specific profile in which otonecine-type PAs such as senkirkine, neosenkirkine, dehydrosenkirkine and various other otonecine-type analogues dominate. Senecionine and integerrimine are important PAs in these samples as well. This profile is very similar to that reported in a Chinese study for two closely related species, G. bicolor and G. divaricata. ${ }^{[33]}$ Senkirkine, senecionine, integerrimine, seneciphylline, spartioidine and retrorsine, together with several unidentified otonecine and cyclic ester analogues were reported for these two species. Senecionine and senkirkine were reported as important constituents of G. pseudochina. ${ }^{[34]}$ Senecionine, integerrimine, retrorsine, usaramine, spartioidine, seneciphylline and seneciphyllinine (acetylseneciphylline) have been reported as characteristic PAs for G. segetum (syn. G. japonica). ${ }^{[17,35,36]}$ These PAs are indeed present in the Gynura jamu samples high in PAs. However, 2 jamu samples, TR-5 (extract of G. segetum) and TR-9 (extract of G. procumbens), contain a rather different PA profile. Both contain high levels of jacobine, jacoline and jaconine and relatively low levels of the PAs mentioned above. Jacobine, jacoline and jaconine are (almost) absent in the other jamu samples containing Gynura.

Chen et al. (2017) ${ }^{[33]}$ reported for 8 herbal samples of G. bicolor and G. divaricata a total PA content of 1,400-39,690 $\mu \mathrm{g} / \mathrm{kg}$. These levels are somewhat lower than present in the group of 14 jamu samples with a high PA content (12,173-235,376 $\mu \mathrm{g} / \mathrm{kg}$ ). In contrast, Ji et al. (2019) ${ }^{[37]}$ reported very low PA levels in 12 herbal samples of G. procumbens $(15.6-848 \mu \mathrm{g} / \mathrm{kg})$, which would be in line with the results for the group of 15 samples of Gynura-containing jamu in which only low levels of PAs were found. The authors also investigated 8 commercial herbal products 
containing G. procumbens and found 7 samples to contain low levels (9.9-160.5 $\mu \mathrm{g} / \mathrm{kg}$ ) as well. However, one commercial sample contained a high amount of PAs $(33,900 \mu \mathrm{g} / \mathrm{kg})$, what is in the range of the levels found in the high PA-group. Aizhen et al. (2019) ${ }^{[35]}$ reported very high PA concentrations in batches of G. japonica (segetum) collected in China: in leaves the levels ranged from $460-2,860 \mathrm{mg} / \mathrm{kg}$ and in roots from $1,750-7,420 \mathrm{mg} / \mathrm{kg}$.

Jamu TR-32 consisted of Ageratum conyzoides, a plant of the Boraginaceae family. This sample contained a high amount of PAs, $146,977 \mu \mathrm{g} / \mathrm{kg}$, mainly composed of the monoesters echinatine, lycopsamine, intermedine, rinderine and their respective $\mathrm{N}$-oxides. The composition is in general agreement with literature ${ }^{[38,}$ 39] that report lycopsamine and echinatine as main constituents (together with acetyllycopsamine and dihydro analogues).

In 17 out of 23 jamu samples that had no PA-producing plants listed on their label, PAs were detected with the highest level amounting to $3,421 \mu \mathrm{g} / \mathrm{kg}$. This points at contamination with PA-producing plants that may be caused by the coharvesting of PA-containing weeds during cultivation or harvesting of the materials. Contamination with PA-producing plants has been reported for herbal teas $[6,40,41]$ and Chinese herbal medicines ${ }^{[21]}$. In the jamu samples mono-esters such as rinderine, indicine, lycopsamine and echinatine as well as their respective $\mathrm{N}$-oxides were the most frequently present. These mono-esters are typically found in species of the Boraginaceae family.[42]

The present study revealed a very wide variation in the EDI of PAs resulting from consuming the different jamu containing PA-producing herbs. This is due to the fact that there was a difference in their total PA levels, but also a wide range in the recommended daily use of the samples as indicated on the label, varying from 0.4 to $30 \mathrm{~g}$ per day for certain powders and up to $200 \mathrm{ml}$ per day for liquids. The highest EDI of $715.8 \mu \mathrm{g} /$ person/day was calculated for TR-17 based on the EDI of $13.3 \mu \mathrm{g} / \mathrm{kg}$ bw/day and a body weight of $54 \mathrm{~kg}$ for Indonesian people.[22] This EDI exceeded the transitional limit of intake of $1.0 \mu \mathrm{g}$ PAs per day per person, set by HMPC (2016) ${ }^{[18]}$ for herbal traditional medicinal products more than 700 -fold. Considering the high level of PAs detected in a large proportion of Gynura-based jamu, strict monitoring and quality control of these products may be necessary to reduce the related health risk for consumers.

The average EDI of $0.038 \mu \mathrm{g} / \mathrm{kg}$ bw/day resulting from use of jamu containing non-PA-producing botanicals was 37 times lower than the average EDI of $1.4 \mu \mathrm{g} / \mathrm{kg} \mathrm{bw} /$ day from use of the jamu containing PA-producing botanicals. Notwithstanding the much lower levels, exposure to PAs resulting from contamination of jamu products may contribute to the total dietary intake of PAs. 
Edgar et al. (2011)[43] reported that exposure to PAs via contamination of some widely consumed foods (e.g. grains, milk, meat, eggs, honey, pollen) can exceed the maximum tolerable daily intakes and/or maximum levels determined by a number of independent risk assessment authorities. The results of the present study underlines the importance of vigilance and the establishment of good manufacturing practises with respect to the harvesting and handling of plant materials used in jamu in Indonesia to reduce the contamination of jamu with PAsproducing weeds in order to protect their consumers.

The risk assessment based on acute exposure showed that use of jamu for short-term periods of, for example, 4 days up to 2 weeks does not raise a health concern for acute adverse effects in humans because the EDI based on PAs levels detected in all jamu samples were far below the value of $1-3 \mathrm{mg} / \mathrm{kg} \mathrm{bw} /$ day as reported by EFSA to result in acute human toxicity based on available case studies. ${ }^{[5]}$ However, the EDI value of TR-17 indicate that there is a concern for the prevalence of HVOD in humans because this EDI may exceed the daily intake associated with HVOD of $10 \mu \mathrm{g} / \mathrm{kg}$ bw/day and $15 \mu \mathrm{g} / \mathrm{kg}$ bw/ day reported by WHO-IPCS (1988) [23] and Ridker et al. (1985) ${ }^{[44]}$, respectively. Consumption of PA-containing G. segetum in the form of Chinese herbal products for 5 days up to 2 years reportedly caused PA-induced liver injury (PA-ILI) in 15 patients in China. ${ }^{45]}$ The herbs ingested by the patients contained seneciphylline, senecionine, and their N-oxides as predominant PAs at levels ranging from 274 to $13,645 \mathrm{mg} / \mathrm{kg}$. Wang et al. (2018) ${ }^{[46]}$ in a retrospective study reported that Gynura segetum-induced HVOD patients show 5 -year surrvival rates of $57 \%$, underlining the importance to prevent the potent toxicity of G. segetum. The mode of action behind the PA-ILI and Gynura segetuminduced HVOD is linked to pyrole-protein adduct formation resulting upon bioactivation of the PA to reactive pyrrole metabolites by cytochrome P450 enzymes. ${ }^{[45,47,48]}$ Although in most cases the PA levels in the Indonesian jamu are lower than the concentrations reported for Gynura in the Chinese studies, the risk of PA-ILI and HVOD due to exposure to PAs via Gynura-based jamu cannot be neglected, particularly for regular consumers. It clearly indicates that, in addition to concerns over the genotoxic carcinogenicity, some jamu also raise a concern with respect to PA-ILI and HVOD, further supporting the need for risk management actions.

When considering the chronic exposure, the MOE values for the PAs occurring in the jamu samples show that for 20 out of 35 (57\%) jamu products containing PA-producing botanicals this MOE was lower than 10,000 indicating there would be a concern for human health upon daily lifetime exposure. However, in real life jamu is likely to be used for medical purposes, so that Indonesian people 
tend to use the preparations for short intervals albeit on a regular basis. Therefore, an estimate of the risks accompanying this shorter-than-lifetime exposure (2 weeks every year during a lifetime) was made applying Haber's rule and resulted in MOE values that were 26 times higher than the MOE values for lifetime daily exposure. For this shorter-than-life-time exposure scenario MOE values $<10,000$ indicated that there is still a health concern for 13 out of the $35(37 \%)$ jamu samples containing PAsproducing botanicals. MOE values $<10000$ were also obtained for daily lifetime consumption of 7 out of the 17 positive jamu samples containing non-PA-producing herbs but found to be contaminated with PA-producing weeds. Their consumption for only 2 weeks a year during lifetime, however, did not raise a concern for human health.

It is important to note that the present risk assessment is based on the assumption of equal potency of all PAs detected in the samples and comparison to the $\mathrm{BMDL}_{10}$ of riddelliine, without taking into account differences in relative potency of the PAs present in the samples. Merz and Schrenk (2016) ${ }^{[9]}$ defined interim Relative Potency (REP) factors for the toxic and genotoxic potency of 1,2unsaturated PAs based on the available data on the genotoxic potency in Drosophila melanogaster, the cytotoxic potency in vitro in chicken hepatocellular carcinoma (CLR-2118) cells and their acute toxicity in adult rodents. Most recently Louisse et al. (2019) ${ }^{[50]}$ proposed REP factors based on results obtained in the $\gamma \mathrm{H} 2 \mathrm{AX}$ assay in HepaRG human liver cells for 37 PAs showing that open diester PAs (including lasiocarpine) and cyclic diester PAs (including riddelliine) display the highest potency. Taking into account the REP values in the evaluation of jamu can be useful to refine the risk assessment of these products and to facilitate a proper management action of these traditional medicines. However, given that the REP values for most of the major PAs detected in the jamu samples would be 0.3 or 1.0 it is expected that taking the REP values into account would not substantially change the outcomes of the risk assessment. This would be in line with the results from a previous risk assessment for PA-containing herbal teas and food supplements. ${ }^{[33]}$

Further evaluation of the results obtained in the present study revealed that for samples containing non-PA-producing botanicals, but collected in a targeted sampling for $\mathrm{AB}$-containing botanicals, the risk assessment based on $\mathrm{PA}, \mathrm{AB}$ and $\mathrm{AA}$ levels reveals that the presence of co-harvested PAs is in general of a lower concern than the levels of $\mathrm{ABs}$ and AAs present in these samples. This result indicates that risk management should focus on providing information to jamu producers regarding the genotoxic carcinogenic compounds that can naturally occur in specific botanicals, to minimize exposure to these compounds via consumption of jamu. In 
addition, regulations that control the use of Gynura plants in jamu need to be established.

In conclusion, consumption of Indonesian jamu that consist of PA-producing botanicals can be considered safe only when consumed for less than about 6 weeks during a lifetime. In addition, the results of the risk assessment highlight the need for monitoring actions and to update the process and regulation of manufacturing jamu, with the aim to reduce the level of PAs that occur in these products either naturally or via contamination. Applying Good Agricultural and Collection Practices (GACP) and the establishment of control measures may help to reduce potential PA contamination in jamu.

\section{Conflict of Interest}

The authors state no conflict of interest regarding this manuscript.

\section{Acknowledgements}

Financial support was received from the Indonesian Endowment Fund for Education, Ministry of Finance, Republic of Indonesia through a Beasiswa Pendidikan Indonesia Lembaga Pengelola Dana Pendidikan (BPI LPDP) doctoral scholarship for Suparmi [contract number: PRJ-365/LPDP/2016].

The authors want to thank Elena de Vries for her assistance in the analysis of the jamu samples.

\section{Supplementary materials}

Supplementary materials of this article can be downloaded from https:/ / doi.org/10.1016/j.fct.2020.111230

\section{References}

[1] BPOM-RI, Peraturan Kepala Badan Pengawas Obat Dan Makanan Republik Indonesia Nomor 12 Tahun 2016 Tentang Pendaftaran Pangan Olahan, Jakarta 201612. Available at: http://jdih.pom.go.id/showpdf.php?u=giZCxzW6JpAGRcPnOwhBjW564tWbhWZSLziyNQ616oI $=$. Accessed 28 October 2018 .

[2] BPOM-RI, Laporan Tahunan Badan POM 2018, Peraturan Kepala Badan Pengawas Obat Dan Makanan Republik Indonesia 2019. Available at: https://www.pom.go.id/new/admin/dat/20191212/LAPTAH-BPOM-2018.pdf. Accessed 12 December 2019.

[3] Suparmi, S., Widiastuti, D., Wesseling, S., Rietjens, I. M. C. M., Natural occurrence of genotoxic and carcinogenic alkenylbenzenes in Indonesian jamu and evaluation of consumer risks. Food and Chemical Toxicology 2018, 118, 53-67.

[4] Abdullah, R., Diaz, L. N., Wesseling, S., Rietjens, I. M. C. M., Risk assessment of plant food supplements and other herbal products containing aristolochic acids using the margin of exposure (MOE) approach. Food Additives \& Contaminants: Part A 2017, 34, 135-144.

[5] EFSA, Risks for human health related to the presence of pyrrolizidine alkaloids in honey, tea, herbal infusions and food supplements. EFSA Journal 2017, 15(7):4908, 1 - 34. 
[6] Bodi, D., Ronczka, S., Gottschalk, C., Behr, N., Skibba, A., Wagner, M., Lahrssen-Wiederholt, M., Preiss-Weigert, A., These, A., Determination of pyrrolizidine alkaloids in tea, herbal drugs and honey. Food Additives and Contaminants - Part A Chemistry, Analysis, Control, Exposure and Risk Assessment 2014, 31, 1886-1895.

[7] Chen, L., Mulder, P. P. J., Louisse, J., Peijnenburg, A., Wesseling, S., Rietjens, I. M. C. M., Risk assessment for pyrrolizidine alkaloids detected in (herbal) teas and plant food supplements. Regulatory Toxicology and Pharmacology 2017, 86, 292-302.

[8] Tandon, B. N., Tandon, H. D., Tandon, R. K., Narndranathan, M., Joshi, Y. K., An epidemic of venoocclusive disease of liver in Central India. The Lancet 1976, 308, 271-272.

[9] Mohabbat, O., Shafiq Younos, M., Merzad, A. A., Srivastava, R. N., Ghaos Sediq, G., Aram, G. N., An outbreak of hepatic veno-occlusive disease in North-Western Afghanistan. The Lancet 1976, 308, 269-271.

[10] Wiedenfeld, H., Plants containing pyrrolizidine alkaloids: toxicity and problems. Food Additives $\mathcal{E}$ Contaminants: Part A 2011, 28, 282-292.

[11] EFSA, Scientific opinion on pyrrolizidine alkaloids in food and feed. EFSA Journal 2011, 9(11):2406, $1-134$.

[12] Li, Y.-H., Tai, W. C.-S., Khan, I., Lu, C., Lu, Y., Wong, W.-Y., Chan, W.-Y., Wendy Hsiao, W.-L., Lin, G., Toxicoproteomic assessment of liver responses to acute pyrrolizidine alkaloid intoxication in rats. Journal of Environmental Science and Health, Part C 2018, 36, 65-83.

[13] IARC, IARC Monographs on he valuation of carcinogenic risks to humans, IARCPress Lyon France 2002.

[14] Fu, P. P., Xia, Q., Lin, G., Chou, M. W., Pyrrolizidine alkaloids-Genotoxicity, metabolism enzymes, metabolic activation, and mechanisms. Drug Metabolism Reviews 2004, 36, 1-55.

[15] EFSA, Opinion of the Panel on contaminants in the food chain [CONTAM] related to pyrrolizidine alkaloids as undesirable substances in animal feed. EFSA Journal 2007, 9(11):2406. 1-134.

[16] Liu, X., Klinkhamer, P. G. L., Vrieling, K., The effect of structurally related metabolites on insect herbivores: A case study on pyrrolizidine alkaloids and western flower thrips. Phytochemistry 2017, 138, 93-103.

[17] Qi, X., Wu, B., Cheng, Y., Qu, H., Simultaneous characterization of pyrrolizidine alkaloids and Noxides in Gynura segetum by liquid chromatography/ion trap mass spectrometry. Rapid Communications in Mass Spectrometry 2009, 23, 291-302.

[18] HMPC, Public statement on contamination of herbal medicinal products/traditional herbal medicinal products with pyrrolizidine alkaloids - Transitional recommendations for risk management and quality control (EMA/HMPC/328782/2016), 2016. Available at: https:/ / www.ema.europa.eu/en/documents/public-statement/public-statement-contaminationherbal-medicinal-products/traditional-herbal-medicinal-products-pyrrolizidine-alkaloids_en.pdf. Accessed 26 July 2019.

[19] HMPC, Call for scientific data for use in HMPC assessment work on 'Public statement on contamination of herbal medicinal products/traditional herbal medicinal products with pyrrolizidine alkaloids (EMA/HMPC/328782/2016), 2019. Available at: https:/ / www.ema.europa.eu/en/documents/herbal-call-data/call-scientific-data-use-hmpcassessment-work-public-statement-contamination-herbal-medicinal/traditional-herbal-medicinalproducts-pyrrolizidine-alkaloids-ema/hmpc/328782/2016_en.pdf. Accessed 29 July 2019.

[20] Chou, M. W., Wang, Y.-P., Yan, J., Yang, Y.-C., Beger, R. D., Williams, L. D., Doerge, D. R., Fu, P. P., Riddelliine $\mathrm{N}$-oxide is a phytochemical and mammalian metabolite with genotoxic activity that is comparable to the parent pyrrolizidine alkaloid riddelliine. Toxicology Letters 2003, 145, 239-247.

[21] Chen, L., Mulder, P. P. J., Peijnenburg, A., Rietjens, I. M. C. M., Risk assessment of intake of pyrrolizidine alkaloids from herbal teas and medicines following realistic exposure scenarios. Food and Chemical Toxicology 2019, 130, 142-153.

[22] FAO, Body Weights and Heights by Countries, Agriculture and Consumer Protection 2017 Available at: http:/ / www.fao.org/docrep/meeting/004/M2846E/M2846E07.htm. Accessed 19 May 2019.

[23] WHO-IPCS, Pyrrolizidine alkaloids/published under the joint sponsorship of the United Nations Environment Programme, the International Labour Organisation, and the World Health Organization. Environmental Health Criteria ; 801988,345 p.

[24] EFSA, Opinion of the Scientific Committee on a request from EFSA related to A Harmonised Approach for Risk Assessment of Substances Which are both Genotoxic and Carcinogenic. EFSA Journal 2005, 1-31. 
[25] Doull, J., Rozman, K. K., Using Haber's Law to define the margin of exposure. Toxicology 2000, 149, $1-2$.

[26] Felter, S. P., Conolly, R. B., Bercu, J. P., Bolger, P. M., Boobis, A. R., Bos, P. M. J., Carthew, P., Doerrer, N. G., Goodman, J. I., Harrouk, W. A., Kirkland, D. J., Lau, S. S., Llewellyn, G. C., Preston, R. J., Schoeny, R., Schnatter, A. R., Tritscher, A., van Velsen, F., Williams, G. M., A proposed framework for assessing risk from less-than-lifetime exposures to carcinogens. Critical Reviews in Toxicology 2011, 41, 507-544.

[27] Gaylor, D. W., The use of Haber's Law in standard setting and risk assessment. Toxicology 2000, 149, 17-19.

[28] WB, Indonesia, The World Bank Group 2017 Available at: https:/ / data.worldbank.org/country/indonesia?view=chart. Accessed 19 February 2018.

[29] van Den Berg, S. J., Restani, P., Boersma, M. G., Delmulle, L., Rietjens, I., Levels of genotoxic and carcinogenic compounds in plant food supplements and associated risk assessment. Food and Nutrition Sciences 2011, 2, 989-1010.

[30] Mengs, U., Lang, W., Poch, J.-A., The carcinogenic action of aristolochic acid in rats. Archives of Toxicology 1982, 51, 107-119.

[31] EFSA, Dietary exposure assessment to pyrrolizidine alkaloids in the European population. EFSA Journal 2016, 14, e04572.

[32] Langel, D., Ober, D., Pelser, P. B., The evolution of pyrrolizidine alkaloid biosynthesis and diversity in the Senecioneae. Phytochemistry Reviews 2011, 10, 3-74.

[33] Chen, J., Lü, H., Fang, L.-X., Li, W.-L., Verschaeve, L., Wang, Z.-T., De Kimpe, N., Mangelinckx, S., Detection and toxicity evaluation of pyrrolizidine alkaloids in medicinal plants Gynura bicolor and Gynura divaricata collected from different Chinese locations. Chemistry $\mathcal{E}$ Biodiversity 2017, 14, e1600221.

[34] Windono, T., Jenie, U. A., Kardono, L. B., Isolation and elucidation of pyrrolizidine alkaloids from tuber of Gynura pseudo-china (L.) DC. Journal of Applied Pharmaceutical Science 2012, 2, 5.

[35] Aizhen, X., Shao, Y., Fang, L., Yang, X., Zhang, S., Zheng, J., Ding, W., Yang, L., Wang, Z., Comparative analysis of toxic components in different medicinal parts of Gynura japonica and its toxicity assessment on mice. Phytomedicine 2019, 54, 77-88.

[36] Roeder, E., Medicinal plants in China containing pyrrolizidine alkaloids. Die Pharmazie 2000, 55, 711726.

[37] Ji, Y.-B., Wang, Y.-S., Fu, T.-T., Ma, S.-Q., Qi, Y.-D., Si, J.-Y., Sun, D.-A., Liao, Y.-H., Quantitative analysis of pyrrolizidine alkaloids in Gynura procumbens by liquid chromatography-tandem quadrupole mass spectrometry after enrichment by PCX solid-phase extraction. International Journal of Environmental Analytical Chemistry 2019, 99, 1090-1102.

[38] Wiedenfeld, H., Roder, E., Pyrrolizidine alkaloids from Ageratum conyzoides. Planta Medica 1991, 57, 578-579.

[39] Bosi, C. F., Rosa, D. W., Grougnet, R., Lemonakis, N., Halabalaki, M., Skaltsounis, A. L., Biavatti, M. W., Pyrrolizidine alkaloids in medicinal tea of Ageratum conyzoides. Revista Brasileira de Farmacognosia 2013, 23, 425-432.

[40] Mulder, P. P. J., López, P., Castelari, M., Bodi, D., Ronczka, S., Preiss-Weigert, A., These, A., Occurrence of pyrrolizidine alkaloids in animal- and plant-derived food: results of a survey across Europe. Food Additives E Contaminants: Part A 2018, 35, 118-133.

[41] Schulz, M., Meins, J., Diemert, S., Zagermann-Muncke, P., Goebel, R., Schrenk, D., SchubertZsilavecz, M., Abdel-Tawab, M., Detection of pyrrolizidine alkaloids in German licensed herbal medicinal teas. Phytomedicine 2015, 22, 648-656.

[42] El-Shazly, A., Wink, M., Diversity of pyrrolizidine alkaloids in the Boraginaceae Structures, distribution, and biological properties. Diversity 2014, 6, 188-282.

[43] Edgar, J. A., Colegate, S. M., Boppré, M., Molyneux, R. J., Pyrrolizidine alkaloids in food: a spectrum of potential health consequences. Food Additives E Contaminants: Part A 2011, 28, 308-324.

[44] Ridker, P. M., Ohkuma, S., McDermott, W. V., Trey, C., Huxtable, R. J., Hepatic venocclusive disease associated with the consumption of pyrrolizidine-containing dietary supplements. Gastroenterology $1985,88,1050-1054$.

[45] Ruan, J., Gao, H., Li, N., Xue, J., Chen, J., Ke, C., Ye, Y., Fu, P. P.-C., Zheng, J., Wang, J., Lin, G., Blood pyrrole-protein adducts - A biomarker of pyrrolizidine alkaloid-induced liver injury in humans. Journal of Environmental Science and Health, Part C 2015, 33, 404-421. 
[46] Wang, Y., Qiao, D., Li, Y., Xu, F., Risk factors for hepatic veno-occlusive disease caused by Gynura segetum: a retrospective study. BMC Gastroenterology 2018, 18, 156.

[47] Ma, J., Xia, Q., Fu, P. P., Lin, G., Pyrrole-protein adducts - A biomarker of pyrrolizidine alkaloidinduced hepatotoxicity. Journal of Food and Drug Analysis 2018, 26, 965-972.

[48] Lin, G., Wang, J. Y., Li, N., Li, M., Gao, H., Ji, Y., Zhang, F., Wang, H., Zhou, Y., Ye, Y., Xu, H. X., Zheng, J., Hepatic sinusoidal obstruction syndrome associated with consumption of Gynura segetum. Journal of Hepatology 2011, 54, 666-673.

[49] Merz, K.-H., Schrenk, D., Interim relative potency factors for the toxicological risk assessment of pyrrolizidine alkaloids in food and herbal medicines. Toxicology Letters 2016, 263, 44-57.

[50] Louisse, J., Rijkers, D., Stoopen, G., Holleboom, W. J., Delagrange, M., Molthof, E., Mulder, P. P. J., Hoogenboom, R. L. A. P., Audebert, M., Peijnenburg, A. A. C. M., Determination of genotoxic potencies of pyrrolizidine alkaloids in HepaRG cells using the $\mathrm{\gamma H} 2 \mathrm{AX}$ assay. Food and Chemical Toxicology 2019, 131, 110532. 


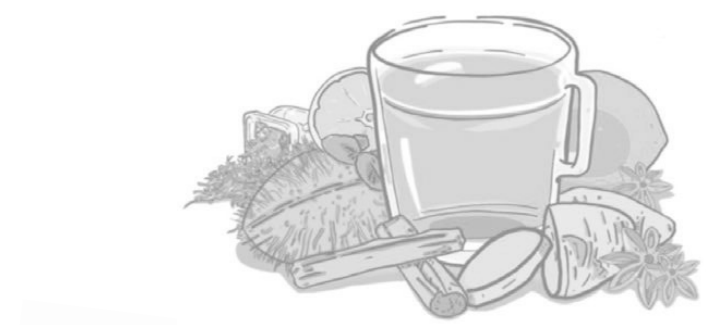

BENEFIT

RISK 


\section{Chapter 5}

Monocrotaline-induced liver toxicity in rat predicted by a combined in vitrophysiologically based kinetic modeling approach

Suparmi Suparmi

Sebastiaan Wesseling

Ivonne M.C.M. Rietjens

Submitted to: Archives of Toxicology (2019): Under review

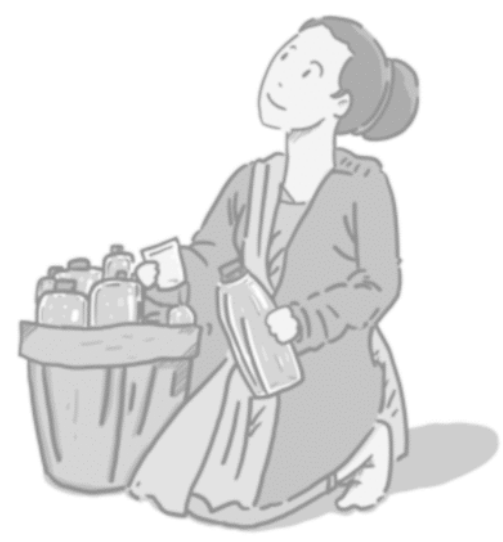




\section{Abstract}

The aim of the present study was to use an in vitro-in silico approach to predict the in vivo acute liver toxicity of monocrotaline and to characterize the influence of its metabolism on its relative toxic potency compared to lasiocarpine and riddelliine. In the absence of data on acute liver toxicity of monocrotaline upon oral exposure, the predicted dose-response curve for acute liver toxicity in rats and the resulting benchmark dose lower and upper confidence limits for $10 \%$ effect $\left(\mathrm{BMDL}_{10}\right.$ and $\mathrm{BMDU}_{10}$ ) were compared to data obtained in studies with intraperitoneal or subcutaneous dosing regimens. This indicated that the predicted $\mathrm{BMDL}_{10}$ value to be in line with No-observed-adverse-effect-levels (NOAELs) derived from availabe in vivo studies. The predicted $\mathrm{BMDL}_{10}-\mathrm{BMDU}_{10}$ of $1.7-6.3 \mathrm{mg} / \mathrm{kg}$ bw/day also matched the oral dose range of 1-3 $\mathrm{mg} \mathrm{PA} / \mathrm{kg}$ bw/day at which adverse effects in human are reported. A comparison to the oral toxicity of the related pyrrolizidine alkaloids (PAs) lasiocarpine and riddelline revealed that, although in the rat liver hepatocytes study monocrotaline was less toxic than lasocarpine and riddelliine, due to its relatively inefficient clearance its in vivo acute liver toxicity was predicted to be comparable. It is concluded that the combined in vitro-PBK modeling approach can provide insight in monocrotaline-induced acute liver toxicity in rats thereby filling existing gaps in the database on PA toxicity. Furthermore, the results reveal that the kinetic and metabolic properties of PAs can vary substantially and should be taken into account when considering differences in relative potency between different PAs. 


\subsection{Introduction}

Monocrotaline (Figure 5.1) is a secondary metabolite that belongs to a group of cyclic di-ester 1,2-unsaturated pyrrolizidine alkaloids (PAs). It is naturally present in Crotalaria species including Crotalaria spectabilis, C. sagittalis L., C. retusa L., and C. aegyptiaca Beth. ${ }^{[1,2]}$ High acute toxicity of monocrotaline towards animals and humans has been reported. ${ }^{[3-6]}$ Recently EFSA (2017)[7] listed monocrotaline as one of the 17 PAs to be monitored for their presence in food and feed because of possible concern for human health related to exposure to these PAs via food including consumption of tea and herbal infusions. PAs including monocrotaline are of concern because of their hepatotoxicity and the fact that they are genotoxic carcinogens. ${ }^{[7]}$ Monocrotaline is categorized as being possibly carcinogenic in humans (category 2B). ${ }^{[8]}$

Like all 1,2-unsaturated PAs monocrotaline is a pro-toxin (unreactive compound) requiring hepatic metabolic activation by cytochromes P450 to exert hepatic toxicity and carcinogenicity. $\left.{ }^{9,}, 10\right]$ CYP2A6 and CYP2E1 were found to be the major P450s active in metabolic activation of monocrotaline in rat liver.[11, 12] Metabolism of PAs is generally occurring via three pathways, namely hydrolysis, Noxidation, and hydroxylation followed by dehydrogenation (Figure 5.1).[13] Upon this dehydrogenation an unstable and highly reactive intermediate, named dehydromonocrotaline is formed. Dehydromonocrotaline can react with cellular macromolecules including proteins and DNA to form protein- and DNA-adducts, which are considered to be responsible for the toxicity including the genotoxicity of monocrotaline. ${ }^{[14-16]}$ Alternatively, dehydromonocrotaline can be detoxified through hydrolysis resulting in 6,7-dihydro-7-hydroxy-1-hydroxymethyl-5H-pyrrolizine (DHP) and via glutathione (GSH) conjugation resulting in formation of GSH-DHP and di-GSH-DHP (Figure 5.1). These molecules are considered less toxic and more stable, ${ }^{[13,17]}$ although they may still also react with proteins and DNA to form the same DNA adducts formed by dehydromonocrotaline and DHP.[18] 


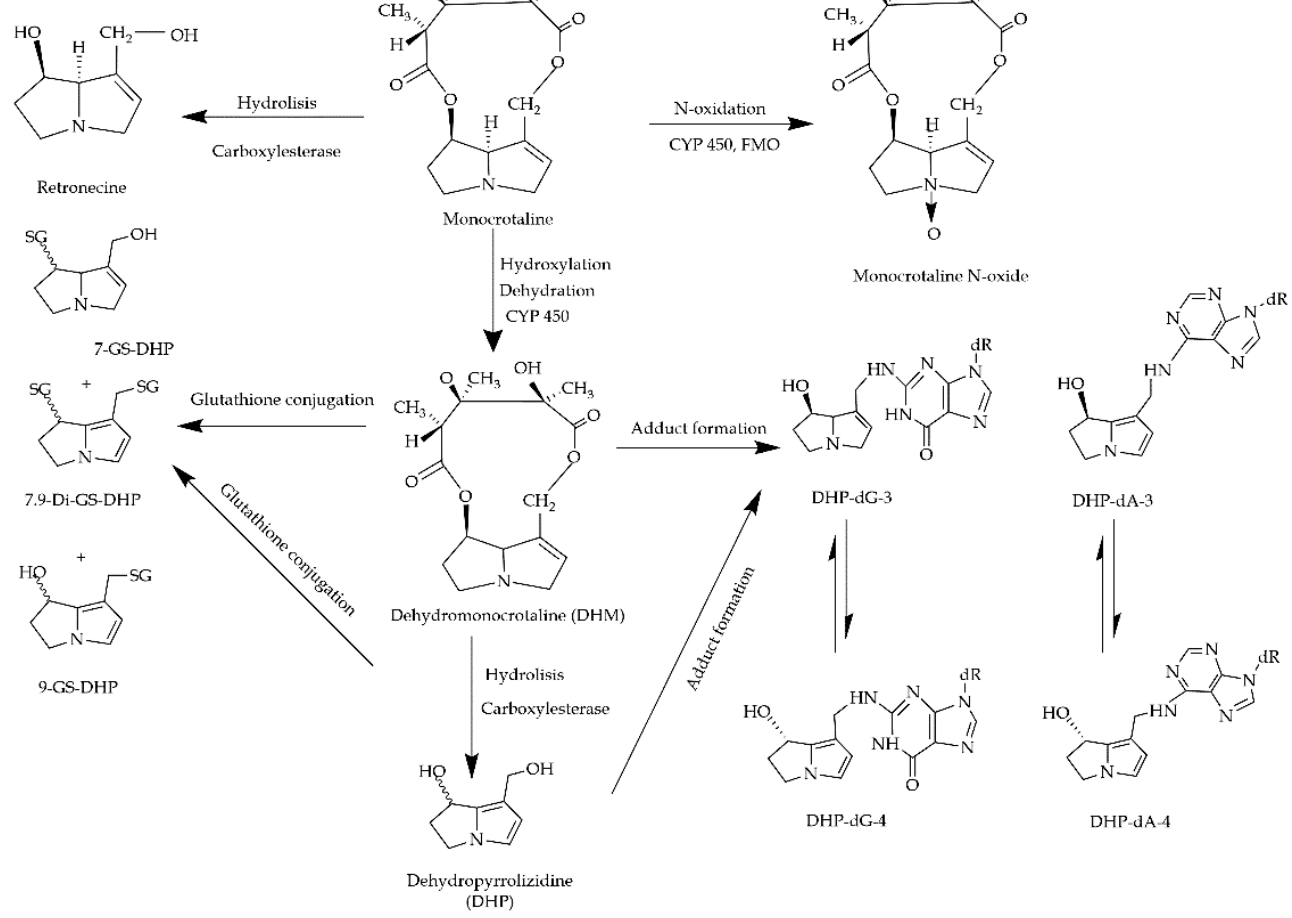

Figure 5.1. Schematic diagram of the metabolic pathways of monocrotaline and DNA adduct formation by monocrotaline metabolites relevant for rat and human. $\left.{ }^{[11}, 18-20\right]$ FMO = flavin-containing monooxygenase, CYP $450=$ cytochromes P450.

Upon bioactivation, monocrotaline causes a variety of toxic insults including pulmonary endothelial apoptosis, acute lung injury, pulmonary fibrosis, necrotizing pulmonary arteritis, myocarditis, hepatic veno-occlusive disease (HVOD), pulmonary hypertension, and right ventricular hypertrophy, ${ }^{[9,21-25]}$ in addition to an increased risk of developing liver carcinomas. ${ }^{[26]}$ In human, acute exposure to PAs can cause HVOD with severe liver damage with in some cases fatal outcomes, [27, 28] whereas chronic exposure is considered to increase the risk of developing cancer. ${ }^{[7]}$

However, only for a limited number of 1,2-unsaturated PAs in vivo toxicity data are available, and this implies that alternative testing strategies including readacross and in vitro to in vivo extrapolation (IVIVE) become important. In previous studies we reported the development and evaluation of physiologically-based kinetic (PBK) models for the PAs lasiocarpine and riddelliine for rat and human, and their use for conversion of in vitro data for toxicity in primary hepatocytes to quantitatively predict in vivo acute liver toxicity for both rat and human. ${ }^{29,}$, 30] Marked differences in toxicokinetics were observed between these two PAs influencing the predicted in vivo toxicity. This importance of toxicokinetics in the 
relative differences in toxic potency between different PAs was also noted in a recent study that characterized the intrinsic relative potency of a series of PAs showing a role for the rate and extent of their metabolism. ${ }^{[31]}$ The aim of the present study was to use the in vitro-PBK model facilitated reverse dosimetry approach to predict the in vivo acute liver toxicity of monocrotaline and to characterize the influence of its metabolism on its relative toxic potency compared to lasiocarpine and riddelliine. Monocrotaline was selected as the model compound because this is one of the few PAs in addition to lasiocarpne and riddelliine for which in vivo data on kinetics and liver toxicty are available thus enabling evaluations of the PBK model and predictions made.

\subsection{Material and Methods}

\subsubsection{Chemicals and biological materials}

Monocrotaline (>98\%) was purchased from MedChemExpress (Huissen, The Netherlands). The plateable cryopreserved male rat (Sprague-Dawley) hepatocytes (RTCP10 ${ }^{\mathrm{TM}}$ ), the thawing and plating supplement (serum-containing, CM 3000) pack, the cell maintenance supplement pack (serum free, CM4000), and Williams E Medium without phenol red (WEM, A1217601) were purchased from ThermoFisher (Naarden, The Netherlands). Pooled liver and intestinal microsomes from male Sprague-Dawley rats were purchased from Xenotech (Lenexa, USA). Dimethyl sulfoxide (DMSO) was obtained from Acros Organics (Geel, Belgium). Acetonitrile (UPLC/MS grade) was obtained from Biosolve (Valkenswaard, The Netherlands). Potassium hydrogen phosphate $\left(\mathrm{K}_{2} \mathrm{HPO}_{4}\right)$ and trifluoroacetic acid (TFA) were purchased from Merck (Darmstadt, Germany). Fetal calf serum (FCS) and the reduced form of $\beta$-nicotinamide adenine dinucleotidephosphate sodium salt hydrate (NADPH) were obtained from Sigma-Aldrich (Zwijndrecht, The Netherlands). WST-1 (4-[3-(4-iodophenyl)-2-(4-nitrophenyl)-2H-5-tetrazolio]-1,3benzene disulfonate) solution was purchased from Roche (Woerden, The Netherlands). Rapid equilibrium dialysis (RED) devices were purchased from Thermo Fisher Scientific (Bleiswijk, The Netherlands). Phosphate-buffered saline (PBS) was obtained from Invitrogen (Breda, The Netherlands).

\subsubsection{Outline of the PBK modeling-facilitated reverse dosimetry approach}

The prediction of in vivo monocrotaline induced liver toxicity in rat using a combined in vitro-PBK modeling approach consisted of the following steps: (1) establishment of in vitro concentration-response curves for the toxicity of monocrotaline in primary rat hepatocytes, (2) development of a PBK model describing in vivo kinetics of monocrotaline, using kinetic parameters defined based 
on in vitro assays using rat liver and intestinal samples, (3) evaluation of the PBK model predictions against available literature data on dose dependent blood levels of monocrotaline, (4) translation of the in vitro concentration-response curves for acute liver toxicity into in vivo dose-response curves for acute liver toxicity in rat using the PBK model taking into acount differences in protein binding of monocrotaline in the in vitro and in vivo situation, (5) benchmark dose (BMD) analysis on the predicted in vivo dose-response data to obtain a point of departure (POD), and (6) evaluation of the predicted POD for liver toxicity against available literature data.

\subsubsection{In vitro liver toxicity assay with primary rat hepatocytes}

The monocrotaline-induced liver toxicity was tested in vitro using the WST-1 assay which measures the formazan formation by the metabolically active cells from WST-1. Pooled cryopreserved plateable male rat (Sprague-Dawley) hepatocytes (RTCP10 ${ }^{\mathrm{TM}}$ ) were thawed and seeded in accordance with the manufacturer's protocol. Briefly, cells were seeded in 96-well plates (Greiner bio-one, Alphen aan den Rijn, The Netherlands) at a concentration of $5 \times 10^{5} \mathrm{cells} / \mathrm{ml}$ to give $1.25 \times 10^{4}$ cells/well and incubated at $37{ }^{\circ} \mathrm{C}, 5 \% \mathrm{CO}_{2}$ in a humidified atmosphere for $6 \mathrm{~h}$ to allow cell adherence. After incubation, medium was aspirated and then replaced by $100 \mu \mathrm{l} /$ well of exposure medium (serum free) containing the required concentration of monocrotaline. The cells were incubated for $24 \mathrm{~h}$ at increasing concentrations ( 0 $600 \mu \mathrm{M})$ of monocrotaline in exposure medium added from 200 times concentrated stock solutions in DMSO. The solvent DMSO $(0.5 \%(\mathrm{v} / \mathrm{v})$ final concentration in exposure medium) was used as a negative control and triton $\mathrm{X}$ (final concentration $1 \%(\mathrm{v} / \mathrm{v})$ in exposure medium) served as a positive control in all cytotoxicity assays. After exposure for $24 \mathrm{~h}, 5 \mu \mathrm{l}$ (1:20 dilution) WST-1 reagent were added to each well and plates were incubated for an additional $1 \mathrm{~h}$. Then, the plate was shaken at $1000 \mathrm{rpm}$ for $1 \mathrm{~min}$, and absorbance was measured at $440 \mathrm{~nm}$ (background absorbance at $620 \mathrm{~nm}$ was subtracted) using a SpectraMax M2 (Molecular Devices, Sunnyvale, USA).

Data are presented as mean values $\pm \mathrm{SE}$ from three independent experiments with 3 different batches of rat hepatocytes. The cell viability was expressed as percentage of the solvent control, with the solvent control set at $100 \%$. The obtained concentration-response curves for hepatoxicity were fitted with a symmetrical sigmoidal model (Hill slope) which was further used to derive $\mathrm{IC}_{50}$ values using log (inhibitor) vs. normalized response using GraphPad Prism software (version 5.00 for Windows, GraphPad software, San Diego, USA). 
5.2.4. In vitro incubations of monocrotaline with rat liver and intestinal microsomes to derive the kinetic parameters for the PBK model

The kinetic parameters for the PBK model of monocrotaline in rats were estimated by a substrate depletion approach using the protocol for microsomal incubations reported by Wang et al. (2009) ${ }^{[19]}$ with little modifications. The liver microsomal incubations were carried out in a total volume of $100 \mu$ l containing $0.1 \mathrm{M}$ $\mathrm{K}_{2} \mathrm{HPO}_{4}$ ( $\mathrm{pH} 7.4$ ), $0.5 \mathrm{mg}$ protein/ml of pooled rat liver/intestinal microsomes, and monocrotaline at final concentrations ranging from 0 to $500 \mu \mathrm{M}$ (added from 100 times concentrated stock solutions in $0.1 \mathrm{M} \mathrm{HCl}$, the latter in line with the protocol of Wang et al. (2009) ${ }^{[19]}$, and shown to have no effect on the incubation $\mathrm{pH}$ ). After 5 min of pre-incubation in a shaking water bath at $37^{\circ} \mathrm{C}$, the reactions were started by the addition of $1 \mathrm{mM}$ NADPH. The reactions were carried out for $1 \mathrm{~h}$ and $2 \mathrm{~h}$ for liver and intestinal microsomes, respectively. For each incubation, a corresponding control incubated in the absence of NADPH was included by adding buffer instead of NADPH. To stop the metabolic conversion, $100 \mu \mathrm{l}$ of ice-cold methanol were added and the sample was put on ice, then centrifuged at 5,000 $\times \mathrm{g}$ for $20 \mathrm{~min}$ at $4^{\circ} \mathrm{C}$ using a microcentrifuge (CT15RE, VWR, Leuven, Belgium). Supernatants were diluted 200 times in 90\% (v/v) acetonitrile and transferred to LC-MS vials. LC-MS analysis was performed using a Shimadzu Nexera XR LC-20AD SR UPLC system in tandem with a Shimadzu LCMS-8040 mass spectrometer (Shimadzu, Kyoto, Japan). From each incubation, $1 \mu \mathrm{l}$ of supernatant was loaded onto a Luna Omega polar C18 100A LC column $(1.6 \mu \mathrm{m} 100 \times 2.1 \mathrm{~mm}$, Phenomenex $)$ fitted with a FP polar precolumn (Phenomenex), using a flow rate of $0.3 \mathrm{ml} / \mathrm{min}$. The temperature was set at $40{ }^{\circ} \mathrm{C}$ and $5{ }^{\circ} \mathrm{C}$ for column and sample, respectively. The mobile phase consisted of ultrapure water (solvent $\mathrm{A}$ ) and acetonitrile (solvent $\mathrm{B}$ ) both containing $0.1 \%(\mathrm{v} / \mathrm{v}$ ) formic acid. The gradient began with $100 \%$ solvent A ( $0 \%$ B) for 1 min to wash away unwanted salts, followed by a linear gradient from 0 to $5 \% \mathrm{~B}$ till $8 \mathrm{~min}$ and a further increase to $100 \% \mathrm{~B}$ in $2 \mathrm{~min}$, keeping the elution at $100 \% \mathrm{~B}$ for $0.5 \mathrm{~min}$, then the column was set back to the starting conditions and equlibrated for $3.4 \mathrm{~min}$ before the next injection. The concentration of monocrotaline in the samples was quantified using a calibration curve prepared using a commercially available standard. For all incubations, three independent replicates were performed.

The time dependent decrease in the concentration of monocrotaline detected in NADPH containing reaction mixtures corrected for the time dependent decrease in the concentration of monocrotaline in the corresponding controls without the cofactor NADPH was used to determine the rate of monocrotaline depletion. The data for the monocrotaline concentration dependent rate of monocrotaline depletion 
thus obtained were fitted to the standard Michaelis-Menten equation (Equation 5.1) using GraphPad Prism, 5.0 software (San Diego, CA, USA).

$V=\frac{V_{\max } \times[S]}{\left(K_{m}+[S]\right)}$

(Equation 5.1)

with [S] representing the monocrotaline concentration, $\mathrm{V}_{\max }$ being the apparent maximum velocity ( $\mathrm{nmol} / \mathrm{min} / \mathrm{mg}$ microsomal protein), and $\mathrm{Km}$ being the apparent Michaelis-Menten constant $(\mu \mathrm{M})$. The ratio of $\mathrm{V}_{\max }$ and $\mathrm{K}_{\mathrm{m}}$ was calculated as the in vitro catalytic efficiency $\left(\mathrm{k}_{\text {cat }}\right)$ expressed in $\mathrm{nmol} / \mathrm{min} / \mathrm{g}$ tissue. The rat microsomal protein yield of $35 \mathrm{mg}$ microsomal protein/g tissue and $20.6 \mathrm{mg}$ microsomal protein/g tissue for liver and small intestine, respectively[32, 33] were used to scale $\mathrm{V}_{\max }$ and $\mathrm{k}_{\text {cat }}$ values obtained from the in vitro microsomal incubations to in vivo $V_{\max }$ and $k_{\text {cat }}$ values expressed in $\mathrm{nmol} / \mathrm{min} / \mathrm{g}$ tissue and $\mathrm{ml} / \mathrm{min} / \mathrm{g}$ tissue, respectively. The rat liver weight of $8.5 \mathrm{~g}$ and small intestine weight of $3.5 \mathrm{~g}$ (see Table 5.1) ${ }^{[34]}$ were used to scaled the in vivo $k_{\text {cat }}$ values to values expressed in $\mathrm{ml} / \mathrm{min} /$ tissue.

\subsubsection{Determination of fraction unbound $\left(f_{u b}\right)$ of monocrotaline in rat serum and correction for protein binding}

The monocrotaline-induced liver toxicity is assumed to be dependent on the concentration of unbound monocrotaline available for bioactivation. To correct for the difference in protein binding in the in vitro incubations and the in vivo situation the fraction unbound $\left(f_{u b}\right)$ of monocrotaline in the in vitro and in vivo situations was determined. Since the in vitro toxicity was determined in serum-free assay medium the concentrations of monocrotaline tested were considered to be equal to the

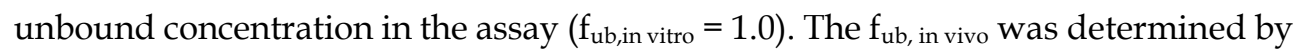
rapid equilibrium dialysis (RED). ${ }^{[35]}$ Briefly, $200 \mu \mathrm{l}$ of spiked rat serum containing $150 \mu \mathrm{M}$ monocrotaline (final concentration, $0.5 \% \mathrm{v} / \mathrm{v}$ DMSO) were added to the serum chambers of the RED device insert, while $350 \mu$ dialysis buffer (PBS) were added to the buffer chamber. The device was sealed with tape and incubated at $37^{\circ} \mathrm{C}$ on a shaker at $250 \mathrm{rpm}$. After incubation for $5 \mathrm{~h}$ when the system reached equilibrium ${ }^{[3]}, 50 \mu$ of post-dialysis samples were collected from the serum and buffer chambers into separate eppendorf tubes. Subsequently, $50 \mu \mathrm{l}$ of rat serum was added to the buffer samples and $50 \mu$ of PBS was added to the serum samples. To precipitate the protein, $300 \mu \mathrm{l}$ of ice-cold acetonitrile $(90 \% \mathrm{v} / \mathrm{v})$ was added to both tubes. After putting the mixtures on ice for $30 \mathrm{~min}$, the mixtures were centrifuged at $15,000 \mathrm{~g}$ for $30 \mathrm{~min}$ at $4{ }^{\circ} \mathrm{C}$, and the supernatants were diluted 5 times in $90 \%$ (v/v) acetonitrile and analyzed by LC-MS as described above. The measurements were performed in triplicate. 
The concentration of monocrotaline detected in each chamber was used to calculate $f_{\mathrm{ub}, \text { in vivo }}$ using Equation 5.2. ${ }^{[35,36]}$ The value of $f_{\mathrm{ub}}$, in vivo was used in the PBK modelling-based reverse dosimetry to calculate the total concentration of monocrotaline in rat liver blood according to the Equation 5.3.

$f_{\text {ub,in vivo }}=\frac{C_{b}}{C_{s}}$

(Equation 5.2)

$C_{\text {monocrotaline, rat blood }}=\frac{C_{u b, \text { in vitro }}}{f_{\text {ub,in vivo }}}$

(Equation 5.3)

where $f_{\mathrm{ub}}$, in vivo represents the fraction unbound of monocrotaline in rat serum, $\mathrm{C}_{\mathrm{b}}$ is the concentration of monocrotaline in the buffer chamber $(\mu \mathrm{M}), \mathrm{C}_{\mathrm{s}}$ is the concentration of monocrotaline detected in the serum chamber $(\mu \mathrm{M}), \mathrm{C}_{\text {monocrotaline, rat }}$ blood is the total concentration of monocrotaline in rat blood $(\mu \mathrm{M}), C_{u b}$, in vitro is the unbound concentration of monocrotaline in the in vitro culture medium which in the present study equals the concentration tested because $f_{u b, \text { in vitro }}$ equals 1.0.

\subsubsection{Development and evaluation of a PBK model for monocrotaline in rat}

A PBK model for monocrotaline in rat was developed based on the models for lasiocarpine and riddelliine in rats (Chen et al., 2018)[30]. Figure 5.2 depicts the conceptual PBK model, which consists of 7 separate compartments connected via the blood circulation. The physiological and anatomical parameters for rats were obtained from literature[34], while the blood/tissue partition coefficients for monocrotaline were estimated using the formula reported by DeJongh et al. (1997)[37] based on the water/octanol partition coefficient (log Kow) of monocrotaline of -0.65 predicted by ChemDraw 18.1 (Perkin-Elmer, USA) as presented in Table 5.1.

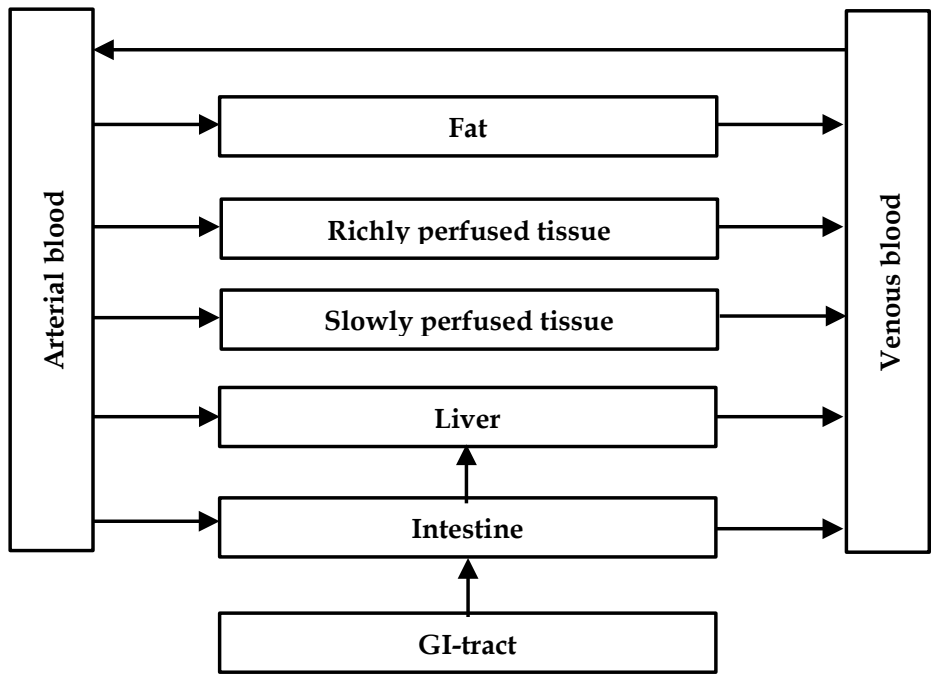

Figure 5.2. Schematic diagram of the PBK model for monocrotaline in rat, based on the model previously developed for lasiocarpine and riddelliine.[30] 
Table 5.1. Physiological and physicochemical parameters for rats applied in the PBK model for monocrotaline.

\begin{tabular}{lll}
\hline Parameters & Symbol & Value \\
\hline Physiological parameters[34] & & 0.25 \\
Body weight (kg) & BW & 0.07 \\
Tissue volume (fraction of body weight) & & 0.034 \\
Fat & VFc & 0.014 \\
Liver & VLc & 0.074 \\
Small intestine & VSic & 0.042 \\
Blood & VBc & 0.75 \\
Richly perfused tissue & VRc & 15 \\
Slowly perfused tissue & VSc & \\
Cardiac output (L/h/kg-.74) & QC & 0.07 \\
Blood flow to tissue (fraction of cardiac output) & & 0.132 \\
Fat & QFc & 0.118 \\
Liver & QLc & 0.51 \\
Small intestine & QSic & 0.17 \\
Richly perfused tissue & QRc & \\
Slowly perfused tissue & QSc & \\
Physicochemical parameters ${ }^{[37]}$ & & 0.46 \\
Tissue/blood partition coefficients & & 0.77 \\
Fat & PF & 0.77 \\
Liver & PL & 0.77 \\
Small intestine & PI & 0.42 \\
Richly perfused tissue & PR & PS \\
Slowly perfused tissue & &
\end{tabular}

The absorption rate constants $\left(\mathrm{K}_{\mathrm{a}}\right)$ for the uptake of monocrotaline from the intestinal compartment into the liver was estimated based on the reported $K_{a}$ for adonifoline, using the correlation of Caco-2 permeation and molecular properties described in literature[38], as follows:

$\log P_{a p p}=-5.469+0.236 \log P$

(Equation 5.4)

$\frac{\log P_{\text {app monocrotaline }}}{K a_{\text {monocrotaline }}}=\frac{\log P_{\text {app }} \text { adonifoline }}{K a_{\text {adonifoline }}}$

(Equation 5.5)

where $\log \mathrm{P}_{\text {app }}$ is the $\log$ value of the permeability coefficient $\left(\mathrm{P}_{\text {app }}\right), \log \mathrm{P}$ is the water/octanol partition coefficient predicted by ChemDraw 18.1 (Perkin-Elmer, USA) being -0.65 and -1.49 for monocrotaline and adonifoline, respectively. The

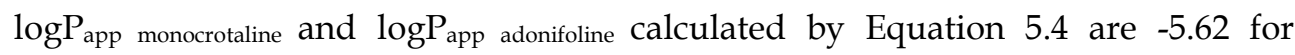
monocrotaline and -5.82 for adonifoline. Using the the reported $\mathrm{K}_{\mathrm{a}}$ for adonifoline of $0.6 / \mathrm{h}$, the value of Ka monocrotaline derived from Equation 5.5 is 0.58 , which was used in the PBK modeling. This Ka value was assumed to reflect efficient uptake of monocrotaline and thus to also include the potential contribution of the organic cation transporter 1 (OCT1) reported by Tu et al. (2013) ${ }^{[39]}$ to play a role in active transport of monocrotaline into the liver.

The model code in Berkeley Madonna (version 9.1.14, UC Berkeley, CA, USA) using Rosenbrock's algorithms for stiff systems for the developed PBK models of monocrotaline in rats is presented in Supplementary materials 1. In the PBK model 
the excretion of monocrotaline into urine was not included due to the fact that the excretion of monocrotaline as a parent compound in urine is negligible. ${ }^{[40]}$

\subsubsection{Evaluation of the PBK model}

To evaluate the PBK model performance, predicted monocrotaline concentrations in blood were compared to reported concentrations of monocrotaline equivalents in rat blood upon intravenous (iv) injection of $60 \mathrm{mg} / \mathrm{kg}$ bw $(10 \mu \mathrm{Ci} / \mathrm{kg})$ of $\left[{ }^{14} \mathrm{C}\right]$ monocrotaline. ${ }^{[41]}$ To this end the predicted time dependent monocrotaline concentration in blood was compared to the time dependent monocrotaline equivalent concentration curve reported by Estep et al. (1991)[41] which was derived from the published curve of monocrotaline equivalents (in nmol/g) against time (in h) using webPlotDigitizer (https://automeris.io/WebPlotDigitizer/) under the assumption that the weight of blood plasma $(\mathrm{g})$ is equal to the volume of blood $(\mathrm{mL})$. The final concentration of monocrotaline equivalents $(\mu \mathrm{M})$ in whole blood was obtained by added up the concentration values in plasma and in red blood cells (Supplementary materials 2, Figure S1 and Table S1).[41]

In addition a sensitivity analysis was performed to identify the key parameters which contribute most to the predicted maximum concentrations in liver blood at an oral dose of 1 and $3 \mathrm{mg} / \mathrm{kg}$ bw which representing the lowest and highest dose in the range for the estimated daily human intake of PAs reported by EFSA (2017) ${ }^{[7]}$ that might result in adverse health effects if consumed for 4 days up to a 2 weeks periods.

The sensitivity analysis was performed as described previously[42] calculating normalized sensitivity coefficients (SCs):

$S C=\frac{\left(C^{\prime}-C\right)}{P^{\prime}-P} \times\left(\frac{P}{C}\right)$

(Equation 5.6)

where $C$ is the initial value of the model output, $C^{\prime}$ is the modified value of the model output resulting from an increase in parameter value, $\mathrm{P}$ is the initial parameter value and $\mathrm{P}^{\prime}$ is the modified parameter value. Each parameter was analyzed individually by changing one parameter at a time ( $5 \%$ increase) and keeping the other parameters the same.[42]

\subsubsection{Translation of in vitro liver toxicity to in vivo liver toxicity}

The in vitro concentration-response curve for monocrotaline-induced cytotoxicity in primary rat hepatocytes was translated into a predicted in vivo doseresponse curve for acute liver toxicity using PBK modeling-facilitated reverse dosimetry. Within this translation a correction was made to take the difference in protein binding between the in vitro incubations $\left(f_{u b}\right.$, in vitro $\left.=1.00\right)$ and the in vivo 


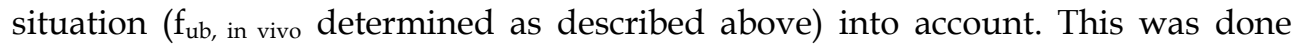
because it was assumed that only the free fraction of monocrotaline will be available to be bioactivated and exert the effects. Each concentration tested in the cytotoxicity assay, corrected by Equation 5.3 to calculate the corresponding total blood concentration, taking differences in in vitro and in vivo protein binding into acount, was set equal to the maximum concentration of monocrotaline in the liver blood and the developed PBK model was used to determine the coresponding oral dose. The dose response curve for monocrotaline-induced liver toxicity resulting from this translation was compared to the previous predicted dose-response curves for lasiocarpine and riddelliine. ${ }^{[30]}$

\subsubsection{BMD analysis of in vitro concentration-response data and of predicted in vivo dose-response data}

To define the benchmark dose resulting in a 10\% increase in liver toxicity over the background level $\left(\mathrm{BMD}_{10}\right)$ the predicted in vivo dose-response data for monocrotaline-induced acute liver toxicity in rats were used for BMD modeling. To compare the toxic potency of monocrotaline with that of lasiocarpine and riddelliine, the predicted dose response curves reported previously for these PAs ${ }^{[30]}$ was also used for BMD modeling. Dose-response modeling and BMD analysis were performed using the EFSA BMD modeling webtool (PROAST version 66.38, https://shiny-efsa.openanalytics.eu/app/bmd).[43] The lowest Akaike Information Criterion (AIC) value among the available models were used to judge the the goodness of fit application of the models.

\subsubsection{Evaluation of the predicted PoD for liver toxicity against available literature data}

The predicted $\mathrm{BMDL}_{10}-\mathrm{BMDU}_{10}$ values of monocrotaline in this study were compared to the PODs derived from in vivo rat acute liver toxicity data on monocrotaline reported in the literature. ${ }^{[3,4,6,44]}$ When the data from these in vivo studies were not suitable for BMD analysis due to the limited number of data points and/or insufficient distribution of the data points over the dose-response curves, the no observed adverse effect level (NOAEL) was used for the comparison. When only a lowest observed adverse effect level (LOAEL) was available, the NOAEL was calculated using the LOAEL divided by a factor of 10.[45] 


\subsection{Results}

\subsubsection{Monocrotaline-induced liver toxicity in vitro}

Monocrotaline induced liver toxicity in primary rat hepatocytes with an $\mathrm{IC}_{50}$ value of $225 \mu \mathrm{M}$ as shown in Figure 5.3. The highest concentration of $600 \mu \mathrm{M}$ decreased cell viability by over $60 \%$ while limited solubility prevented testing of higher concentrations and reaching $100 \%$ cytotoxicity. The $\mathrm{EC}_{50}$ obtained for monocrotaline is 20.7- and 35.7-fold higher than the $\mathrm{EC}_{50}$ values previously obtained in the same model system for lasicarpine $\left(\mathrm{EC}_{50} 10.9 \mu \mathrm{M}\right)$ and riddelliine $\left(\mathrm{EC}_{50} 6.3 \mu \mathrm{M}\right)$ respectively.[30]

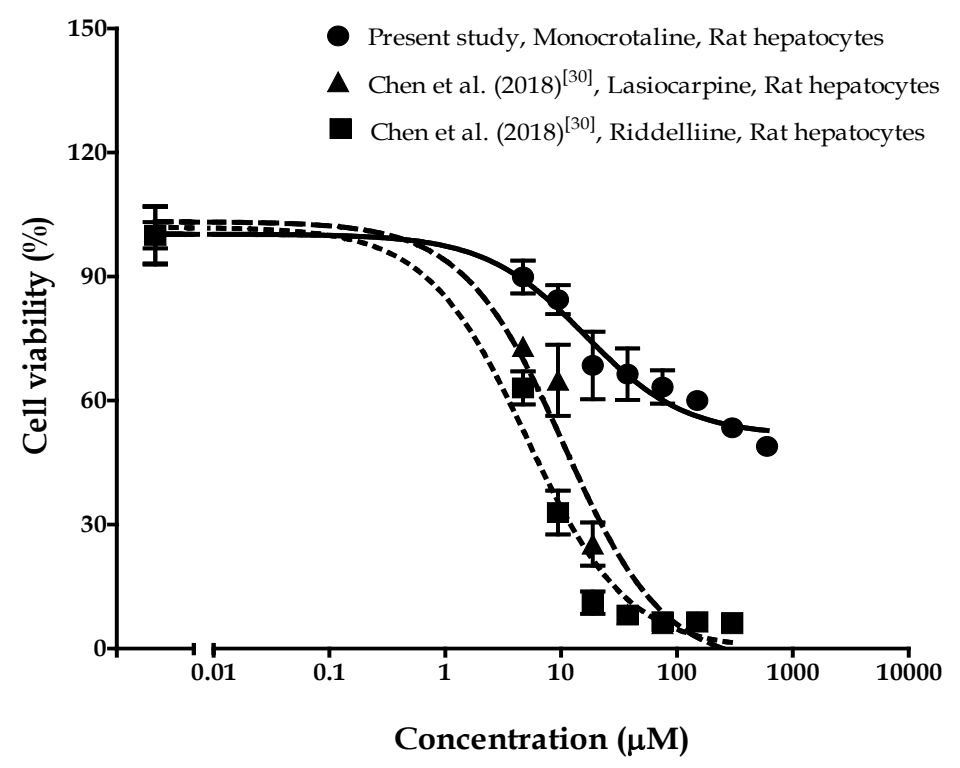

Figure 5.3. Concentration-response curves for effects of monocrotaline (circles with solid line) on cell viability of primary rat hepatocytes exposed for $24 \mathrm{~h}$ (means $\pm \mathrm{SE}$ ) and, for comparison, for effects of lasiocarpine (triangles with dashed line) and riddelliine (squares with dotted line) as reported by Chen et al. $(2018)^{[30]}$.

\subsubsection{Metabolic clearance of monocrotaline by rat liver and intestine microsomes}

Figure 5.4 shows the monocrotaline concentration dependent rate of conversion of the compound in incubations with rat intestinal and liver microsomes. Table 5.2 presents the $V_{\max }$ and $K_{m}$ values derived from these curves and also the catalytic effciency $\left(k_{c a t}\right)$ for clearance of monocrotaline calculated as $V_{\max } / K_{m}$. For comparison Table 5.2 also presents the kinetic parameters for depletion of lasiocarpine and riddelliine previously reported ${ }^{[30]}$. It appears that monocrotaline is converted by the liver microsomes with an in vivo scaled $\mathrm{k}_{\text {cat }}(\mathrm{ml} / \mathrm{min}$ tissue) that is 18 times higher than the conversion rate by intestinal microsomes (Figure 5.4 and Table 5.2). Lasiocarpine and riddeliine showed the same trend where the scaled 
catalytic efficiency for conversion expressed per intestinal tissue was 15.4 and 253 times, respectively, lower than that for the liver indicating the intestinal contribution to PA clearance to be minor (Table 5.2). The scaled $\mathrm{k}_{\text {cat }}$ for conversion of monocrotaline in the liver was 41.8 and 4.3 times lower compared to the scaled liver $\mathrm{k}_{\mathrm{cat}}$ of lasiocarpine and riddelliine, respectively, indicating that the metabolism of monocrotaline was the lowest among the three PAs. The total scaled in vivo $\mathrm{k}_{\text {cat }}$ sum of liver and intestine) for depletion of monocrotaline was 42.1 and 4.1 fold, respectively lower than that for lasiocarpine and riddelline.
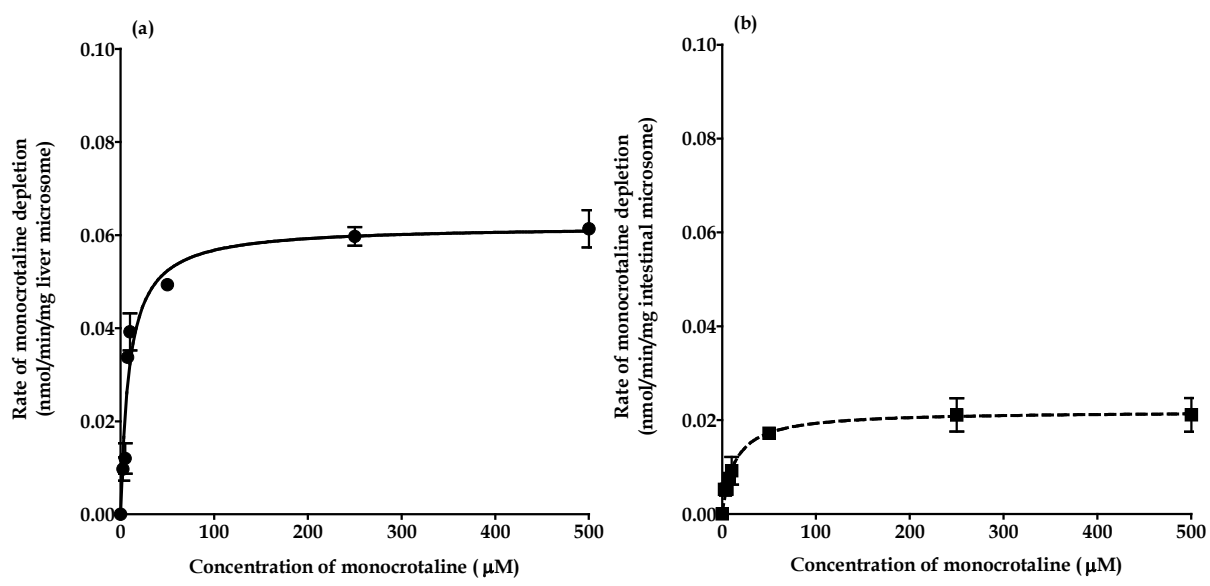

Figure 5.4. Concentration-dependent rate of monocrotaline depletion in incubations with: (a) rat liver microsomes and (b) intestinal microsomes. Values are presented as means \pm SE derived from 3 independent experiments.

Table 5.2. Kinetic parameters for metabolic conversion of monocrotaline (present study), lasiocarpine and riddelliine ${ }^{[30]}$ in incubations with pooled rat liver and instestine microsomes.

\begin{tabular}{|c|c|c|c|c|c|c|}
\hline $\begin{array}{l}\text { Compound } \\
\text { Organ }\end{array}$ & $\begin{array}{l}\mathrm{V}_{\max } \\
(\mathrm{nmol} / \mathrm{min} / \mathrm{m} \\
\text { g microsomal } \\
\text { protein) }\end{array}$ & $\begin{array}{l}\mathrm{Km} \\
(\mu \mathrm{M})\end{array}$ & $\begin{array}{l}\mathrm{K}_{\mathrm{cat}} \\
(\mathrm{ml} / \mathrm{min} / \mathrm{mg} \\
\text { microsomal } \\
\text { protein) }\end{array}$ & $\begin{array}{l}\text { Scaled } V_{\max } \\
(\mathrm{nmol} / \mathrm{min} \\
/ \mathrm{g} \text { tissue })^{\mathrm{a}}\end{array}$ & $\begin{array}{l}\text { Scaled } K_{\text {cat }} \\
(\mathrm{ml} / \mathrm{min} / \mathrm{g} \\
\text { tissue })^{\mathrm{a}}\end{array}$ & $\begin{array}{l}\text { Scaled } \mathrm{K}_{\text {cat }} \\
(\mathrm{ml} / \mathrm{min} / \\
\text { tissue })^{\mathrm{b}}\end{array}$ \\
\hline \multicolumn{7}{|c|}{ Monocrotaline (present study) } \\
\hline Liver & 0.06 & 9.2 & 0.01 & 2.1 & 0.2 & 1.9 \\
\hline Intestine & 0.02 & 13.4 & 0.001 & 0.4 & 0.03 & 0.1 \\
\hline \multicolumn{7}{|c|}{ Lasiocarpine ${ }^{[30]}$} \\
\hline Liver & 5.3 & 19.5 & 0.27 & 186 & 9.5 & 80.9 \\
\hline Intestine & 1.7 & 23.4 & 0.07 & 35.0 & 1.50 & 5.2 \\
\hline \multicolumn{7}{|c|}{ Riddelliine [30] } \\
\hline Liver & 2.1 & 75.7 & 0.03 & 73.5 & 0.97 & 8.2 \\
\hline Intestine & 0.1 & 221 & 0.0005 & 2.06 & 0.009 & 0.03 \\
\hline
\end{tabular}

aScaled $\mathrm{V}_{\max }$ and $\mathrm{k}_{\text {cat }}$ calculated from the in vitro $\mathrm{V}_{\max }$ and $\mathrm{k}_{\text {cat }}$ based on a microsome protein yield of 35 $\mathrm{mg}$ microsomal protein/(g liver) or $20.6 \mathrm{mg}$ microsomal/ (g small intestine) ${ }^{[32,33]}$.

bScaled in vivo $\mathrm{k}_{\text {cat }}\left(\mathrm{mL} / \mathrm{min} /\right.$ tissue) derived from the in vivo $\mathrm{k}_{\text {cat }}(\mathrm{ml} / \mathrm{min} / \mathrm{g}$ tissue) based on the liver weight of $8.5 \mathrm{~g}$ or small intestine weight of $3.5 \mathrm{~g}^{[34]}$ 


\subsubsection{PBK model predictions and evaluation}

Due to unavailability of in vivo kinetic data for monocrotaline upon oral administration in rat, the blood concentration-time curves of monocrotaline as predicted by the developed PBK model upon iv administration were evaluated against the available concentration of monocrotaline equivalents in rat blood upon the iv administration of $60 \mathrm{mg} / \mathrm{kg}$ of $\left[{ }^{14} \mathrm{C}\right]$ monocrotaline ${ }^{[41]}$. The predicted blood concentrations were on average 1.6- to 3.4-fold higher than the blood concentrations observed in vivo (see Table S1 Supplementary materials 2). Given this limited deviation it was concluded that the PBK model could be used for the in vitro to in vivo extrapolations.

\subsubsection{Sensitivity analysis}

The performance of the developed PBK model was further evaluated by a sensitivity analysis to determine the parameters which affect the prediction of the maximum concentration of monocrotaline in liver blood. The parameters that result in a normalized sensitivity coefficient higher than an absolute value of 0.1 are shown in Figure 5.5. At an oral dose level of of 1 and $3 \mathrm{mg} / \mathrm{kg}$ bw, representing the lowest and highest dose in the range for the estimated daily human intake of PAs that might result in adverse health effects if consumed for 4 days up to a 2 weeks periods $[7]$, the predicted maximum concentration of monocrotaline in liver blood was affected by the fraction of liver volume $\left(\mathrm{VL}_{\mathrm{C}}\right)$, the partition coefficient of monocrotaline into liver tissue (PL), the partition coefficient into slowly perfused tissue (PS), the absorption rate from the intestinal compartment into the liver (Ka), the liver microsomal protein yield, and the kinetic parameters $\left(\mathrm{V}_{\max }\right.$ and $\left.\mathrm{K}_{\mathrm{m}}\right)$ for monocrotaline depletion in the liver. The predicted monocrotaline concentration in liver blood was not sensitive to the kinetic parameters for monocrotaline depletion in the small intestine-related parameters in line with the earlier observation that monocrotaline metabolism is this organ is substantially less efficient (Figure 5.4). 


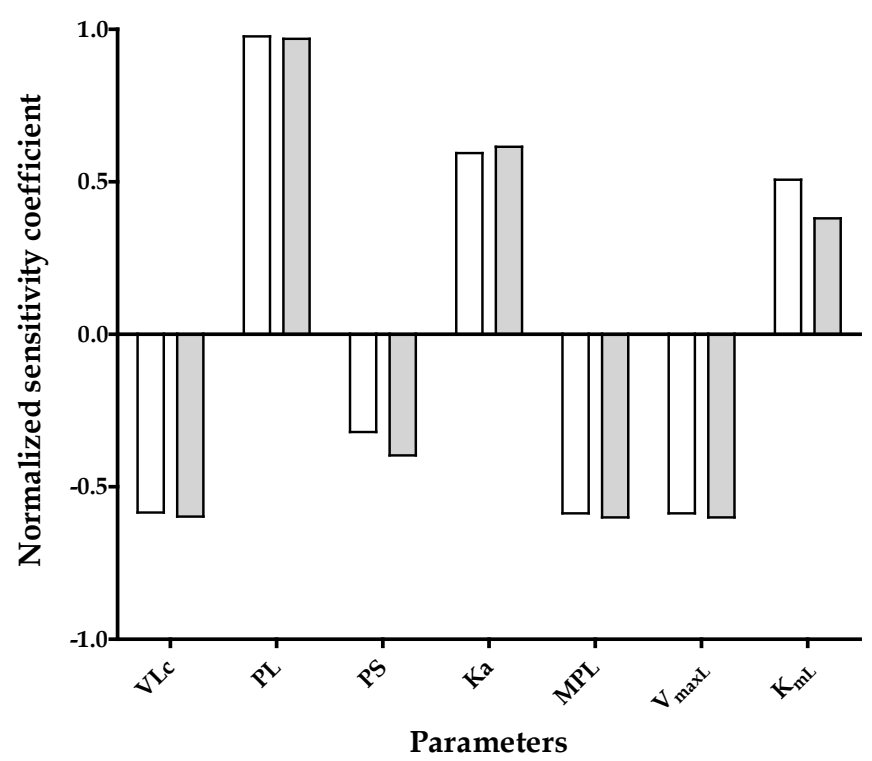

Figure 5.5. Normalized sensitivity coefficients for the parameters of the rat PBK model for monocrotaline of influence on the predicted maximum concentration in liver blood at a single oral dose of monocrotaline of $1 \mathrm{mg} / \mathrm{kg}$ bw (white bars), or $3 \mathrm{mg} / \mathrm{kg}$ bw/day (grey bars) PAs. VLc $=$ fraction of liver volume, $\mathrm{PL}=$ liver/blood partition coeffient, PS = slowly perfused tissue/blood partition coefficient, $\mathrm{Ka}=$ uptake rate constant, MPL = liver microsomal protein yield, $\mathrm{V}_{\operatorname{maxL}}$ and $\mathrm{K}_{\mathrm{mL}}=$ the maximum rate of depletion and the Michaelis-Menten constant for depletion of monocrotaline in liver

\subsubsection{Predicted hepatotoxicity of monocrotaline in rats and application of PROAST modeling on predicted dose-response data to derive PODs}

The RED assay resulted in an $f_{u b, \text { in vivo }}$ of monocrotaline in rat serum of $0.53 \pm 0.12$, a value used to correct for the differences in protein binding between the in vivo and in vitro situation. With this $\mathrm{f}_{\mathrm{ub}, \text { in vivo }}$ the concentrations tested in the cytotoxicity assay were converted to in vivo total blood concentrations by equation 5.3 and then converted to the corresponding dose levels using the PBK model. The dose levels thus obtained were used to create the corresponding dose response curve for acute liver toxicity.

The predicted in vivo dose-response curve thus obtained is shown in Figure 5.6. For comparison also the dose-response curves previously predicted for lasicarpine and riddelliine by the same approach ${ }^{[30]}$ are included in the figure. From the results obtained it can be concluded that monocrotaline is predicted to be somewhat less toxic than riddelliine and somewhat more toxic than lasiocarpine. A BMD analysis was performed on the predicted dose-response data resulting in a predicted $\mathrm{BMD}_{10}$ and range of $\mathrm{BMDL}_{10}-\mathrm{BMDU}_{10}$ values for monocrotaline, lasiocarpine, and riddelliine as presented in Table 5.3. The predicted $\mathrm{BMD}_{10}$ for 
monocrotaline appeared to be 1.5 fold higher than that obtained from the predicted dose-response curve for riddelliine ${ }^{[30]}$, while the value was 8.6 fold lower than that predicted for lasiocarpine.

Comparison of these predicted differences in in vivo toxicity to the relative differences observed in vitro (Figure 5.3) shows that the differences in in vitro toxicity between monocrotaline, lasiocarpine and riddelliine were subtantially different from the differences observed in vitro where lasiocarpine and riddelliine were 35.7 and 20.7, respectively more toxic than monocrotaline. This shift towards relatively higher toxicity for monocrotaline in the in vivo situation is due to the differences in kinetics where monocrotaline appeared to be metabolised with a catalytic efficiency that was 4.1- and 42.1-fold lower than that for lasiocarpine and riddelliine, respectively. This implies that at similar dose levels the accompanying blood concentrations and thus toxicity will be relatively higher for monocrotaline. This result corroborates that differences in kinetics substantialy influence the relative in vivo potencies of PAs, and should not be ignored when defining relative potency factors.

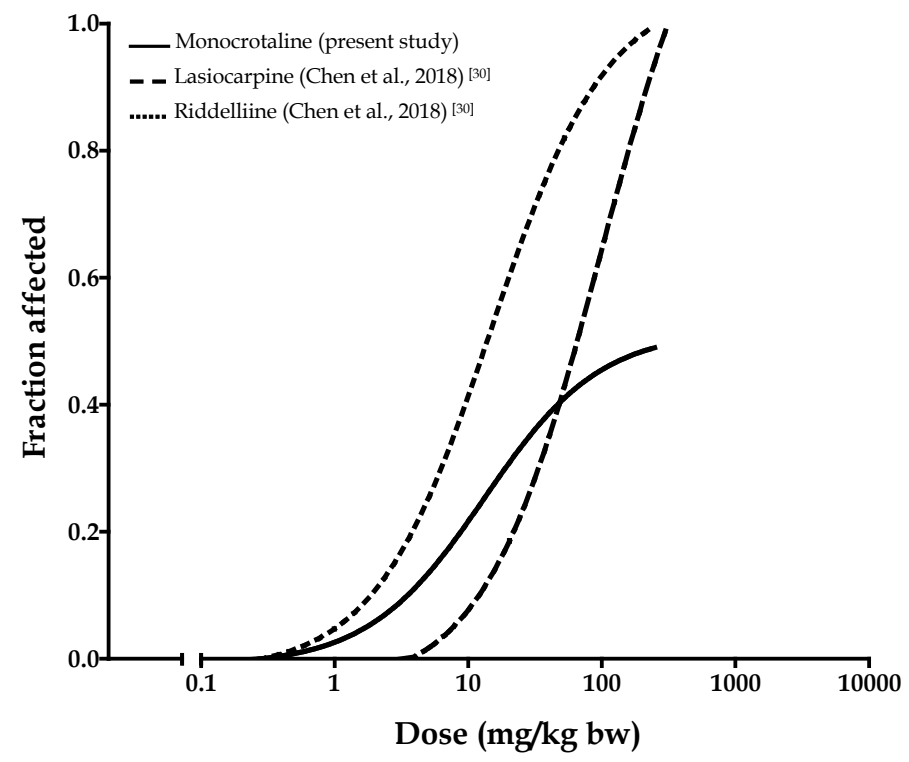

Figure 5.6. Predicted in vivo dose-response curves for acute liver toxicity in rats obtained by combining in vitro data in primary rat hepatocytes and PBK modeling-based reverse dosimetry for monocrotaline (black line). For comparison the predicted dose response curves for liver toxicity of lasiocarpine (dashed line) and riddelliine (dotted line) reported by Chen et al. (2018) ${ }^{[30]}$ are also presented. 
Table 5.3. Predicted BMDL $10-B_{M D U}$ values derived from the dose-response curves presented in Figure 5.6 predicted by PBK modeling-facilitated reverse dosimetry.

\begin{tabular}{llll}
\hline Compound & $\begin{array}{l}\text { Predicted BMDL } 10-B_{M D U} \\
(\mathrm{mg} / \mathrm{kg} \text { bw/day })\end{array}$ & $\begin{array}{l}\text { Predicted BMD } 10 \\
(\mathrm{mg} / \mathrm{kg} \text { bw/day })\end{array}$ & $\begin{array}{l}\text { Source of the predicted dose } \\
\text { response-curve }\end{array}$ \\
\hline Monocrotaline & $1.7-6.3$ & 3.8 & Present study \\
Riddelline & $1.3-3.7$ & 2.6 & Chen et al. $(2018)^{[30]}$ \\
Lasiocarpine & $17.6-55.8$ & 32.5 & Chen et al. $(2018)^{[30]}$ \\
\hline
\end{tabular}

\subsubsection{Comparison of the predicted PODs to PODs derived from the reported data for liver toxicity in rats}

To further evaluate the in vitro-PBK modeling facilitated reverse dosimetry approach for prediction of monocrotaline-induced acute liver toxicity, the predicted $\mathrm{BMDL}_{10}$ for monoctotaline induced liver toxicity was compared to the corresponding PODs (NOAEL values) derived from available in vivo studies for liver toxicity of monocrotaline in rats. Table 5.4 provides the overview of reported data on monocrotaline-induced acute liver toxicity in rats based on the endpoints of increased level of bound pyrrolic metabolites, increased alanine aminotransferase (ALT) activity, apoptosis of hepatic parencymal cells (HPC) and hepatic congestion $[3,4,6,44]$. Since results from oral toxicity studies were not avalable, studies included in this comparison were studies with ip or sc dosing regimens. Given that the data of none of these studies enabled BMD modeling, the PODs from the available studies were based on the NOAEL or, when a NOAEL was not available, derived from the LOAEL value by assuming the NOAEL would amount to the LOAEL divided by 10[45] (Table 5.4). 


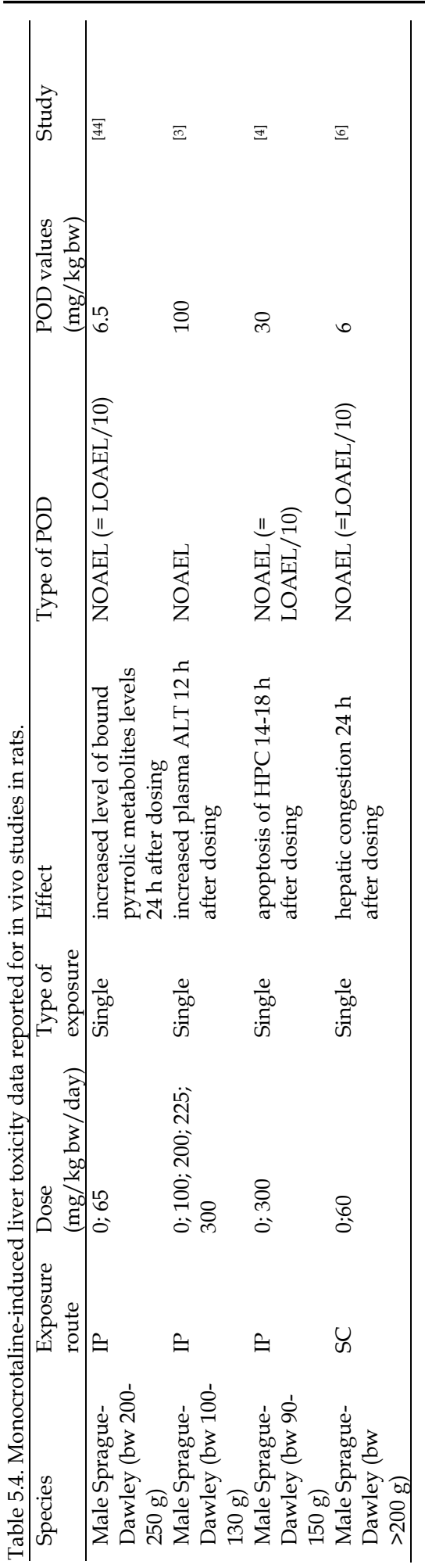


Figure 5.7 presents a comparison of the predicted $\mathrm{BMDL}_{10}-\mathrm{BMDU}_{10}$ value of monocrotaline to the PODs data of Table 5.4. This comparison reveals that the reported toxicity data upon ip exposure vary substantially, and that the predicted BMDL $_{10}$ value is in line with especially the NOAEL derived from the study with ip dosing reported by Yan and Huxtable (1996) ${ }^{[44]}$ and sc dosing reported by Lachant et al. (2018) ${ }^{[6]}$. The $\mathrm{BMDL}_{10}-\mathrm{BMDU}_{10}$ of $1.7-6.3 \mathrm{mg} / \mathrm{kg} \mathrm{bw} /$ day predicted by the in vitro-in silico approach of the present study is in line with this estimated toxic oral dose range of 1-3 $\mathrm{mg} \mathrm{PA} / \mathrm{kg}$ bw/ day[7].

\section{Oral, predicted}

BMDL $_{10}-$ BMDU $_{10}$ (present study)

IP, NOAEL (= LOAEL/10)

(Yan and Huxtable, 1996) ${ }^{[44]}$

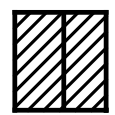

IP, NOAEL

(Copple et al, 2002) ${ }^{[3]}$

IP, NOAEL (=LOAEL/10)

(Copple et al, 2004) $^{[4]}$

SC, NOAEL (=LOAEL/10)

(Lachtnant et al., 2018) $^{[6]}$

Oral, EDI of PAs (EFSA, 2017) ${ }^{[7]}$

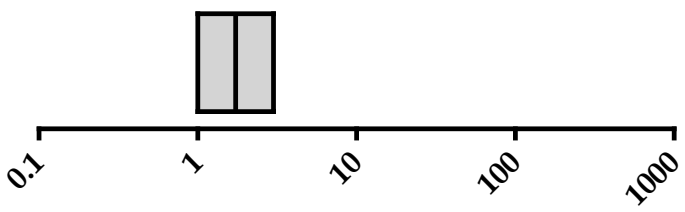

\section{Dose $(\mathrm{mg} / \mathrm{kg} \mathrm{bw})$}

Figure 5.7. $\mathrm{BMDL}_{10}-\mathrm{BMDU}_{10}$ values for liver toxicity in rats predicted by the PBK modeling-facilitated reverse dosimetry approach using data for toxicity of monocrotaline in rat hepatocytes (patterned bar), compared to PODs derived from literature data on in vivo liver toxicity of monocrotaline in rats from studies with sc or ip dosing presented in Table 5.4 (vertical black bars). The grey bar below the line represents an oral dose range of $1-3 \mathrm{mg} \mathrm{PA} / \mathrm{kg}$ bw/day at which acute/short-term adverse effect in humans may occur. ${ }^{[7]}$

\subsection{Discussion}

The aim of the present study was to use an in vitro-in silico approach to predict the in vivo acute liver toxicity of monocrotaline and to characterize the influence of its metabolism on its relative in vivo toxic potency compared to lasiocarpine and riddelliine. This in vitro-in silico approach was recently shown able to predict the acute liver toxicity of lasiocarpine and riddelliine.[30] The results now 
obtained for monocrotaline further validate the approach as a possible method to fill existing gaps in the database on PAs relevant in food. Furthermore, comparison of the results to those previously obtained for lasiocarpine and riddelliine[30] corroborated the influence of metabolism on the relative toxic potency of these three PAs.

The in vitro concentration-response data for monocrotaline-induced toxicity were obtained using primary rat hepatocytes. Primary rat hepatocytes from pooled male Sprague-Dawley rats were used because male rats were previously reported to be more sensitive towards monocrotaline toxicity than female rats[ ${ }^{[6]}$ and also because most in vivo data available for the liver toxicity of monocrotaline were obtained in male rats (Table 5.4). Comparison of the in vitro toxicity data to the in vitro study of Louisse et al. (2019)[47] which showed that monocrotaline did not exhibit cytotoxicity in HepaRG cells upon $24 \mathrm{~h}$ exposure, indicates that rat hepatocytes are more sensitive to the toxicity induced by monocrotaline. This result is in line with data from Ning et al. (2019) ${ }^{[29]}$ who reported that rat hepatocytes are more sensitive towards lasiocarpine and riddelliine induced liver toxicity than HepaRG cells. Primary rat hepatocytes likely contain higher levels of the cytochrome P450 enzymes required for metabolism including the bioactivation of parent PAs.[11, ${ }^{12]}$ In the in vitro assay with rat primary hepatocytes the $\mathrm{IC}_{50}$ value of monocroaline was 20.7- and 35.7- fold higher than the $\mathrm{IC}_{50}$ values previoulsy reported in the same model system for lasiocarpine and riddelliine, respectively. ${ }^{[30]}$ The lower toxicity of monocrotaline in in vitro liver model systems is also in line with what has been observed in other studies using HepG2 or HepaRG cells. ${ }^{[47,48]}$

Since in the in vitro models used the liver toxicity of monocrotaline is quantified depending on the concentration of the parent compound, which is metabolised to its toxic metabolites within the cells of the in vitro model system, the PBK model developed in the present study describes the kinetics of monocrotaline and not of its metabolites and also the reverse dosimetry is based on concentrations of the parent compound. The subtrate depletion analysis indicated that monocrotaline was slowly metabolized in the incubations with rat liver and intestinal microsomes. The kinetic eficiency for monocrotaline conversion appeared to be 42.1- and 4.1- fold lower compared to that previously obtained for lasiocarpine and riddelliine, respectively using the same approach as Chen et al. (2018)[30]. This indicates that the metabolism of monocrotaline was the lowest among these three PAs. This result is line with the study performed by Lester et al. (2019)[31] who reported that monocrotaline is metabolically stable in the rat sandwich culture hepatocyte cell system. Marked differences in metabolic degradation among PAs was also reported recently by Geburek et al. (2019) ${ }^{[49]}$ using in vitro incubations with 
rat liver microsomes indicating as well that conversion of monocrotaline was lower than that of riddelliine. In the present study these kinetic differences were taken into account when translating the concentration-response curves for in vitro toxicity to the predicted dose-response curves for acute liver toxicity using PBK modelfacilitated reverse dosimetry approach.

Evaluation of the developed PBK model for monocrotaline showed that the predicted concentrations of monocrotaline in blood were in line with the kinetic data available for monocrotaline in rats.[41] The PBK model used was also similar to that previously developed and evaluated for the PAs lasiocarpne and riddelliine. ${ }^{[30]}$ Chen et al. (2018) ${ }^{[30]}$ demonstrated that the developed PBK model could adequately predict blood concentrations of riddelliine and also adequately translate the in vitro liver toxicity induced by lasiocarpine to a predicted in vivo dose-reponse curve for liver toxicity. The results of the present study reveal that the same approach can quantitatively predict the reported in vivo acute liver toxicity of monocrotaline. The predicted $\mathrm{BMDL}_{10}$ value appeared to be in line with the NOAELs derived from availabe in vivo studies, although the comparison also revealed that especially the NOAELs derived from the reported toxicity data upon ip exposure vary substantially, in part due to the fact that the NOAELs or LOAELs were the lowest dose levels tested, leaving room for the actual LOAEL and NOAEL being lower than what has now been derived from the data. The predicted BMDL 10 was in line with the NOAEL derived from the study with sc dosing reported by Lachant et al. $(2018)^{[6]}$. The differences observed may in part also be ascribed to the difference in dosing regimen with the predicted values refering to oral exposure while the in vivo were from studies with ip or sc dosing. Due to the lack of data for monocrotaline induced acute toxicity via oral intake in rats, the predicted $B M D L_{10}-B_{M D U}$ value was also compared to the oral dose range of $1-3 \mathrm{mg} \mathrm{PA} / \mathrm{kg} \mathrm{bw} /$ day at which acute/short-term adverse effects in human are reported to occur when consuming a combination of PAs via teas or herbal infusions ${ }^{[7]}$. The BMDL ${ }_{10}-B^{-} D_{10}$ of 1.7-6.3 $\mathrm{mg} / \mathrm{kg}$ bw/day predicted by the in vitro-in silico approach of the present study is in line with this estimated toxic oral dose level, indicating that the toxicity of monocrotaline would match the overall toxicity estimated for PAs.

The result of the present study also indicated that taking the kinetics into account the predicted in vivo differences in toxicity between monocrotaline and lasiocarpine and riddelliine appeared to be smaller than what would be predicted based on the vitro data obtained in primary hepatocytes. The predicted BMDL $\mathrm{L}_{10}$ value for acute liver toxicity of monocrotaline obtained in the present study supports the classification of monocrotaline as a toxic PA, with a potency for acute liver toxicty that seems comparable to that of lasiocarpine and riddelliine. To what extent 
this conclusions also holds for the carcinogenicity of these PAs remains to be estabished. The conclusion of similar potency is in line with the provisional relative potency factors (pRPF) derived by Merz and Schrenk (2016) ${ }^{[50]}$ indicating that monocrotaline, as well as riddelliine are categorized as the most potent congeners with a pRPF similar to that of lasiocarpine of 1.0. This result is in contrast to the ranking presented by Xia et al. (2013) ${ }^{[51]}$ based on the formation of DNA adducts, who ranked monocrotaline as group II with moderate tumour formation. Louisse et al. (2019) ${ }^{[47]}$ classified monocrotaline into group 3 with an pRPF of 0.06 based on its in vitro $\gamma \mathrm{H} 2 \mathrm{AX}$ induction potency in the human liver cell line HepaRG, while lasiocarpine and ridddelliine were categorized as group 1 with a pRPF of 1.08 and 1 , respectively. However these in vitro studies are based on different endpoint and also do not take potential differences in in vivo toxicokinetics into account, while the result of the present study clearly indicate that this will hamper the translation of in vitro RPFs to the in vivo situation. The lower metabolic clearance of monocrotaline than of lasiocarpine and riddelliine observed in the present study is in line with the results from Lester et al. (2019) ${ }^{[31]}$ and Geburek et al. (2019) ${ }^{[49]}$, and will result in higher relative in vivo concentrations and potential toxicity than predicted based on in vitro concentration-response curves.

In conclusion, the results of the present study illustrate that a combined in vitro-in silico approach can be used to obtain insights in monocrotaline-induced acute liver toxicity in rats. Furthermore, the comparison of its relative toxic potency to lasiocarpine and riddelliine indicates that the kinetic and metabolic properties of these PAs should be taken into account when defining relative differences in in vivo toxic potency. This insight can be used to obtain a promising alternative testing strategy in risk and safety evaluation of PAs.

\section{Conflict of interest}

The authors state no conflicts of interest.

\section{Acknowledgments}

This research was supported by a grant from the Indonesian Endowment Fund for Education, Ministry of Finance, Republic of Indonesia through a Beasiswa Pendidikan Indonesia Lembaga Pengelola Dana Pendidikan (BPI LPDP) doctoral scholarship [grant number: PRJ-365/LPDP/2016] awarded to Suparmi.

\section{Supplementary materials}

Supplementary materials 1 and 2 can be downloaded from https://drive.google.com/open?id=1vXdSIdgp58Bs0Vr053HoZY86875wEPrK. 


\section{References}

[1] EFSA, Scientific opinion on pyrrolizidine alkaloids in food and feed. EFSA Journal 2011, 9(11):2406, $1-134$.

[2] Adams, R., Rogers, E. F., The structure of monocrotaline, the alkaloid in Crotalaria spectabilis and Crotalaria retusa L.. Journal of the American Chemical Society 1939, 61, 2815-2819.

[3] Copple, B. L., Banes, A., Ganey, P. E., Roth, R. A., Endothelial cell injury and fibrin deposition in rat liver after monocrotaline exposure. Toxicological Sciences 2002, 65, 309-318.

[4] Copple, B. L., Rondelli, C. M., Maddox, J. F., Hoglen, N. C., Ganey, P. E., Roth, R. A., Modes of cell death in rat liver after monocrotaline exposure. Toxicological Sciences 2004, 77, 172-182.

[5] Yan, C. C., Huxtable, R. J., The relationship between the concentration of the pyrrolizidine alkaloid monocrotaline and the pattern of metabolites released from the isolated liver. Toxicology and Applied Pharmacology 1995, 130, 1-8.

[6] Lachant, D. J., Meoli, D. F., Haight, D., Lyons, J. A., Swarthout, R. F., White, R. J., Low dose monocrotaline causes a selective pulmonary vascular lesion in male and female pneumonectomized rats. Experimental Lung Research 2018, 44, 51-61.

[7] EFSA, Risks for human health related to the presence of pyrrolizidine alkaloids in honey, tea, herbal infusions and food supplements. EFSA Journal 2017, 15(7): 4908, 1-34.

[8] IARC, IARC monographs on the evaluation of carcinogenic risk of chemicals to humans, International Agency for Research on Cancer 2019.

[9] Shumaker, R. C., Robertson, K. A., Hsu, I. C., Allen, J. R., Neoplastic transformation in tissues of rats exposed to monocrotaline or dehydroretronecine. JNCI: Journal of the National Cancer Institute 1976, $56,787-790$.

[10] Mattocks, A. R., Toxicity of pyrrolizidine alkaloids. Nature 1968, 217, 723-728.

[11] Yao, J., Li, C.-g., Gong, L.-k., Feng, C.-c., Li, C.-z., Gao, M., Luan, Y., Qi, X.-m., Ren, J., Hepatic cytochrome P450s play a major role in monocrotaline-induced renal toxicity in mice. Acta Pharmacologica Sinica 2014, 35, 292-300.

[12] Ruan, J., Yang, M., Fu, P., Ye, Y., Lin, G., Metabolic activation of pyrrolizidine alkaloids: insights into the structural and enzymatic basis. Chemical Research in Toxicology 2014, 27, 1030-1039.

[13] Fu, P. P., Xia, Q., Lin, G., Chou, M. W., Pyrrolizidine alkaloids-Genotoxicity, metabolism enzymes, metabolic activation, and mechanisms. Drug Metabolism Reviews 2004, 36, 1-55.

[14] Butler, W. H., Mattocks, A. R., Barnes, A. J. M., Lesions in the liver and lungs of rats given pyrrole derivatives of pyrrolizidine alkaloids. The Journal of Pathology 1970, 100, 169-175.

[15] Lafranconi, M. W., Huxtable, R. J., Hepatic metabolism and pulmonary toxicity of monocrotaline using isolated perfused liver and lung. Biochemical Pharmacology 1984, 33, 2479-2484.

[16] Reid, M. J., Lamé, M. W., Morin, D., Wilson, D. W., Segall, H. J., Involvement of cytochrome P450 3A in the metabolism and covalent binding of 14C-monocrotaline in rat liver microsomes. Journal of Biochemical and Molecular Toxicology 1998, 12, 157-166.

[17] Li, W., Wang, K., Lin, G., Peng, Y., Zheng, J., Lysine Adduction by Reactive Metabolite(s) of Monocrotaline. Chemical Research in Toxicology 2016, 29, 333-341.

[18] Xia, Q., He, X., Ma, L., Chen, S., Fu, P. P., Pyrrolizidine alkaloid secondary pyrrolic metabolites construct multiple activation pathways leading to DNA adduct formation and potential liver tumor initiation. Chemical Research in Toxicology 2018, 31, 619-628.

[19] Wang, J., Yang, L., Wang, C., Wang, Z., The action of cytochrome p450 enzymes and flavincontaining monooxygenases on the N-oxide of pyrrolizidine alkaloid monocrotaline. Asian Journal of Traditional Medicines 2009, 4, 41-50.

[20] Yang, X., Li, W., Sun, Y., Guo, X., Huang, W., Peng, Y., Zheng, J., Comparative study of hepatotoxicity of pyrrolizidine alkaloids retrorsine and monocrotaline. Chemical Research in Toxicology 2017, 30, 532-539.

[21] Gomez-Arroyo, J. G., Farkas, L., Alhussaini, A. A., Farkas, D., Kraskauskas, D., Voelkel, N. F., Bogaard, H. J., The monocrotaline model of pulmonary hypertension in perspective. American Journal of Physiology-Lung Cellular and Molecular Physiology 2012, 302, L363-L369.

[22] Schultze, A. E., Roth, R. A., Chronic pulmonary hypertension-the monocrotaline model and involvement of the hemostatic system. Journal of Toxicology and Environmental Health, Part B 1998, 1, 271-346.

[23] Li, N., Xia, Q., Ruan, J., Fu, P. P., Lin, G., Hepatotoxicity and tumorigenicity induced by metabolic activation of pyrrolizidine alkaloids in herbs. Current drug metabolism 2011, 12, 823-834. 
[24] Lu, Y., Ma, J., Song, Z., Ye, Y., Fu, P. P., Lin, G., The role of formation of pyrrole-ATP synthase subunit beta adduct in pyrrolizidine alkaloid-induced hepatotoxicity. Archives of Toxicology 2018, 92, 3403-3414.

[25] Fu, P. P., Pyrrolizidine alkaloids: Metabolic activation pathways leading to liver tumor initiation. Chemical Research in Toxicology 2017, 30, 81-93.

[26] Newberne, P. M., Rogers, A. E., Nutrition, monocrotaline, and aflatoxin B1 in liver carcinogenesis. Plant Foods for Man 1973, 1, 23-31.

[27] Tandon, B. N., Tandon, H. D., Tandon, R. K., Narndranathan, M., Joshi, Y. K., An epidemic of venoocclusive disease of liver in Central India. The Lancet 1976, 308, 271-272.

[28] Mohabbat, O., Shafiq Younos, M., Merzad, A. A., Srivastava, R. N., Ghaos Sediq, G., Aram, G. N., An outbreak of hepatic veno-occlusive disease in North-Western Afghanistan. The Lancet 1976, 308, 269-271.

[29] Ning, J., Chen, L., Strikwold, M., Louisse, J., Wesseling, S., Rietjens, I. M. C. M., Use of an in vitro-in silico testing strategy to predict inter-species and inter-ethnic human differences in liver toxicity of the pyrrolizidine alkaloids lasiocarpine and riddelliine. Archives of Toxicology 2019.

[30] Chen, L., Ning, J., Louisse, J., Wesseling, S., Rietjens, I. M. C. M., Use of physiologically based kinetic modelling-facilitated reverse dosimetry to convert in vitro cytotoxicity data to predicted in vivo liver toxicity of lasiocarpine and riddelliine in rat. Food and Chemical Toxicology 2018, 116, 216-226.

[31] Lester, C., Troutman, J., Obringer, C., Wehmeyer, K., Stoffolano, P., Karb, M., Xu, Y., Roe, A., Carr, G., Blackburn, K., Mahony, C., Intrinsic relative potency of a series of pyrrolizidine alkaloids characterized by rate and extent of metabolism. Food and Chemical Toxicology 2019, 131, 110523.

[32] Medinsky, M. A., Leavens, T. L., Csanády, G. A., Gargas, M. L., Bond, J. A., In vivo metabolism of butadiene by mice and rats: a comparison of physiological model predictions and experimental data. Carcinogenesis 1994, 15, 1329-1340.

[33] Cubitt, H. E., Houston, J. B., Galetin, A., Relative importance of intestinal and hepatic glucuronidation -impact on the prediction of drug clearance. Pharmaceutical Research 2009, 26, 1073.

[34] Brown, R. P., Delp, M. D., Lindstedt, S. L., Rhomberg, L.R. et al.,, Physiological parameter values for physiologically based pharmacokinetic models. 1997, 13.

[35] Waters, N. J., Jones, R., Williams, G., Sohal, B., Validation of a rapid equilibrium dialysis approach for the measurement of plasma protein binding. Journal of Pharmaceutical Sciences 2008, 97, 4586-4595.

[36] van Liempd, S., Morrison, D., Sysmans, L., Nelis, P., Mortishire-Smith, R., Development and validation of a higher-throughput equilibrium dialysis assay for plasma protein binding. JALA: Journal of the Association for Laboratory Automation 2011, 16, 56-67.

[37] DeJongh, J., Verhaar, H. J. M., Hermens, J. L. M., A quantitative property-property relationship (QPPR) approach to estimate in vitro tissue-blood partition coefficients of organic chemicals in rats and humans. Archives of Toxicology 1997, 72, 17-25.

[38] Hou, T. J., Zhang, W., Xia, K., Qiao, X. B., Xu, X. J., ADME evaluation in drug discovery. 5. Correlation of Caco-2 permeation with simple molecular properties. Journal of Chemical Information and Computer Sciences 2004, 44, 1585-1600.

[39] Tu, M., Sun, S., Wang, K., Peng, X., Wang, R., Li, L., Zeng, S., Zhou, H., Jiang, H., Organic cation transporter 1 mediates the uptake of monocrotaline and plays an important role in its hepatotoxicity. Toxicology 2013, 311, 225-230.

[40] Bull, L. B., Culvenor, C. t., Dick, A., The pyrrolizidine alkaloids: their chemistry, pathogenicity and other biological properties. New Biological Books Reviews and Brief Notices 1968, 9, 293.

[41] Estep, J. E., Lame, M. W., Morin, D., Jones, A. D., Wilson, D. W., Segall, H. J., [1 $\left.{ }^{4} C\right]$ monocrotaline kinetics and metabolism in the rat. Drug metabolism and disposition: the biological fate of chemicals 1991, $19,135-139$.

[42] Evans, M. V., Andersen, M. E., Sensitivity analysis of a physiological model for 2,3,7,8tetrachlorodibenzo-p-dioxin (TCDD): Assessing the impact of specific model parameters on sequestration in liver and fat in the rat. Toxicological Sciences 2000, 54, 71-80.

[43] EFSA-Scientific-Committee, Anthony, H., Diane, B., Thorhallur, H., John, J. M., Helle, K. K., Simon, M., Alicja, M., Hanspeter, N., Hubert, N., Colin, O., Antonia, R., Guido, R., Vittorio, S., Roland, S., Dominique, T., Marc, A., Laurent, B., Allen, D., Lutz, E., Update: use of the benchmark dose approach in risk assessment. EFSA Journal 2017, 15, e04658, 1-41.

[44] Yan, C. C., Huxtable, R. J., Effects of monocrotaline, a pyrrolizidine alkaloid, on glutathione metabolism in the rat. Biochemical Pharmacology 1996, 51, 375-379. 
[45] Barnes, D. G., Dourson, M., Dourson, M., Preuss, P., Barnes, D. G., Bellin, J., Derosa, C., Engler, R., Erdreich, L., Farber, T., Fenner-Crisp, P., Francis, E., Ghali, G., Hill, R., Irene, S., Marcus, W., Patrick, D., Perlin, S., Revesz, A., Rubenstein, R., Reference dose (RfD): Description and use in health risk assessments. Regulatory Toxicology and Pharmacology 1988, 8, 471-486.

[46] Mattocks, A. R., Acute hepatotoxicity and pyrrolic metabolites in rats dosed with pyrrolizidine alkaloids. Chemico-Biological Interactions 1972, 5, 227-242.

[47] Louisse, J., Rijkers, D., Stoopen, G., Holleboom, W. J., Delagrange, M., Molthof, E., Mulder, P. P. J., Hoogenboom, R. L. A. P., Audebert, M., Peijnenburg, A. A. C. M., Determination of genotoxic potencies of pyrrolizidine alkaloids in HepaRG cells using the $\gamma \mathrm{H} 2 \mathrm{AX}$ assay. Food and Chemical Toxicology 2019, 131, 110532.

[48] Kusuma, S. S., Tanneeru, K., Didla, S., Devendra, B. N., Kiranmayi, P., Antineoplastic activity of monocrotaline against hepatocellular carcinoma. Anti-cancer Agents in Medicinal Chemistry 2014, 14, 1237-1248.

[49] Geburek, I., Preiss-Weigert, A., Lahrssen-Wiederholt, M., Schrenk, D., These, A., In vitro metabolism of pyrrolizidine alkaloids - Metabolic degradation and GSH conjugate formation of different structure types. Food and Chemical Toxicology 2019, 110868.

[50] Merz, K.-H., Schrenk, D., Interim relative potency factors for the toxicological risk assessment of pyrrolizidine alkaloids in food and herbal medicines. Toxicology Letters 2016, 263, 44-57.

[51] Xia, Q., Zhao, Y., Von Tungeln, L. S., Doerge, D. R., Lin, G., Cai, L., Fu, P. P., Pyrrolizidine alkaloidderived DNA adducts as a common biological biomarker of pyrrolizidine alkaloid-induced tumorigenicity. Chemical Research in Toxicology 2013, 26, 1384-1396. 


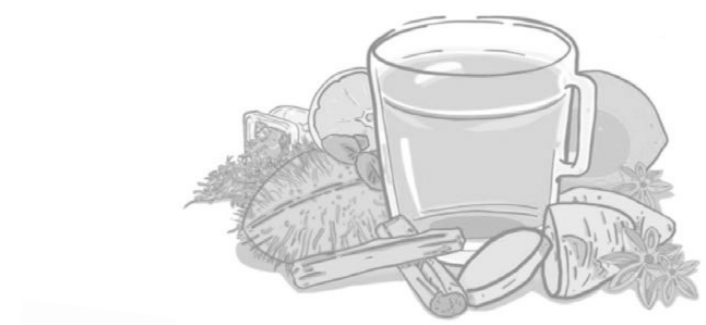

BENEFIT

RISK 


\section{Chapter 6}

\section{Combining in vitro data and physiologically}

based kinetic modeling facilitated reverse dosimetry to define in vivo dose-response curves for bixin- and crocetin-induced activation of PPARy in humans

Suparmi Suparmi

Laura de Haan

Albertus Spenkelink

Jochem Louisse

Karsten Beekmann

Ivonne M.C.M. Rietjens

Published in: Molecular Nurition and Food

Research (2019) 1900880:1-9

DOI: 10.1002/mnfr.20190088

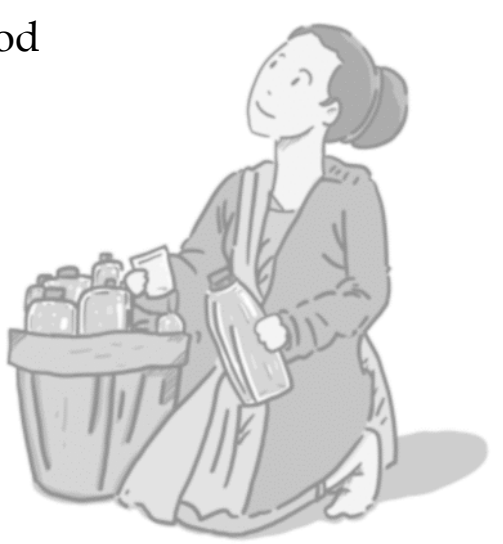




\section{Abstract}

Scope: It is investigated whether at realistic dietary intake bixin and crocetin could induce peroxisome proliferator-activated receptor $\gamma$ (PPAR $\gamma)$-mediated gene expression in humans using a combined in vitro-in silico approach.

Methods and results: Concentration-response curves obtained from in vitro PPARYreporter gene assays are converted to in vivo dose-response curves using physiologically based kinetic modeling-facilitated reverse dosimetry, from which the benchmark dose levels resulting in a 50\% effect above background level (BMD $\left.{ }_{50}\right)$ are predicted and subsequently compared to dietary exposure levels. Bixin and crocetin activated PPARY-mediated gene transcription in a concentrationdependent manner with similar potencies. Due to differences in kinetics, the predicted $\mathrm{BMD}_{50}$ values for in vivo PPAR $\gamma$ activation are about 30 -fold different, amounting to 115 and 3,505 mg/ kg bw for crocetin and bixin, respectively. Human dietary and/or supplemental estimated daily intakes may reach these $\mathrm{BMD}_{50}$ values for crocetin but not for bixin, pointing at better possibilities for in vivo PPARY activation by crocetin.

Conclusion: Based on a combined in vitro-in silico approach, it is estimated whether at realistic dietary intakes plasma concentrations of bixin and crocetin are likely to reach concentrations that activate PPAR $\gamma$-mediated gene expression, without the need for a human intervention study. 


\subsection{Introduction}

Bixin (methyl hydrogen 9'-cis-6,6'-diapocarotene-6,6'-dioate and crocetin (8,8'-diapocarotene-8,8'-dioic acid) (Figure 6.1) are food-borne carotenoids. ${ }^{[1,2]}$ Bixin is present in the extract prepared from the seed coat of annatto (Bixa orellana $\mathrm{L}$ ). Annato extracts containing bixin are an approved food color additive (E160b), for which the European Food Safety Authority (EFSA) established an acceptable daily intake (ADI) of $6 \mathrm{mg} / \mathrm{kg}$ bw/day. ${ }^{[3-5]}$ Crocetin occurs naturally in the fruits of gardenia (Gardenia jasminoides Ellis) and in the stigma of saffron (Crocus sativus L.) frequently consumed due to its use as food colorant and flavouring. ${ }^{[6]}$ Saffron containing crocetin is recognized as food additive in the USA, while JECFA recognized saffron as a food ingredient rather than a food additive. ${ }^{7]}$ In addition to use as food additives, bixin and crocetin have been considered as potential functional food ingredients with beneficial effects in various diseases, including type 2 diabetes mellitus (T2DM). ${ }^{[8,9]}$

(a)

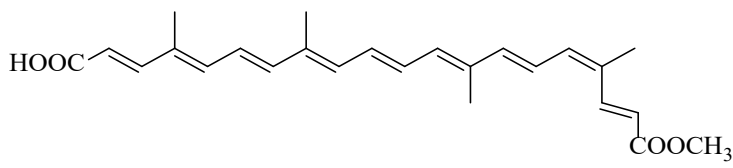

(b)

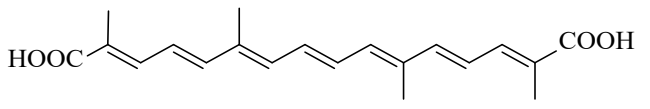

Figure 6.1. Chemical structures of bixin (a) and crocetin (b).

Studies in experimental animals revealed that bixin shows hypoglycemic activity in streptozotocin-induced diabetic rats, ${ }^{[10]}$ and that crocetin enhances insulin sensitivity in insulin resistant rats, ${ }^{[11-13]}$ suggesting their potential beneficial roles in T2DM. The interest to explore the carotenoids as potential functional food ingredients is increasing, due to the growing reports about side-effects associated with current T2DM medication. Thiazolidinediones (TZDs), which once were the most widely used drugs for treatment of T2DM,[14] have been reported to cause body weight gain and increased risks for myocardial infarction, peripheral edema and bone fracture. ${ }^{[15]}$ TZDs are believed to exert their therapeutic effects via activation of peroxisome proliferator-activated receptor $\gamma($ PPAR $\gamma)$, which is also suggested as mode of action underlying the potential beneficial effects of bixin and crocetin.

PPARY activation has been reported to increase insulin sensitivity, ${ }^{[16]}$ decrease free fatty acid levels in plasma and increase lipid storage in adipose tissue.[17] Several carotenoids, including bixin and also norbixin, $\beta$-carotene, lutein, neoxanthin, phytoene, lycopene, $\beta$-carotene, astaxanthin, $\beta$-cryptoxanthin, zeaxanthin, $\gamma$ carotene, $\delta$-carotene have been shown able to activate PPAR $\gamma$-mediated gene expression in vitro.[18-21] It remains to be established however, whether the reported 
PPAR $\gamma$ activating characteristics can also be expected at realistic human dietary intake levels.

Therefore the aim of the present study was to investigate whether the reported PPAR $\gamma$ activating characteristics of bixin and crocetin may be expected at realistic human daily intake levels. To this end, concentration-response curves for bixin- and crocetin-dependent activation of PPAR $\gamma$-mediated gene expression in a stably transfected U2OS PPAR $\gamma$ reporter gene cell line were converted to predicted in vivo dose response curves using so-called physiologically based kinetic (PBK) modeling facilitated reverse dosimetry. This approach facilitates evaluation of whether PPAR $\gamma$ activating characteristics of bixin and crocetin may be expected at realistic human dietary intake levels without the need for a human intervention study.

A PBK model can predict the concentration of a compound and its relevant metabolites in any tissue at any point in time and for any dose level, within its applicability domain. ${ }^{[22]}$ After the PBK model is validated with the available in vivo data, it can be used to convert in vitro concentrations, set equal to internal concentrations in blood or a tissue of choice, to corresponding in vivo dose levels, by so-called reverse dosimetry.[23, 24] In PBK modeling facilitated reverse dosimetry, the PBK model is used in the reverse order compared to the forward dosimetry that is generally applied in pharmacokinetics. Forward dosimetry is applied to calculate the internal concentration of a compound or its metabolite that can be expected in blood or a relevant tissue upon a given dose level. In the reverse dosimetry approach, in vitro concentrations are set equal to blood or tissue levels of the respective compound in the PBK model, following which the PBK model is used to calculate the corresponding in vivo dose level for any given route of administration. Subsequent benchmark dose (BMD) modeling can be applied on the predicted in vivo dose-response data, to determine effective exposure levels for humans, like a BMD value defining the dose levels inducing a limited but measurable response above background level and the BMDL values, the lower confidence limits of the BMD. [23]

\subsection{Experimental Section}

\subsubsection{In vitro PPARY CALUX assay of bixin and crocetin}

Bixin (96.5\% purity by HPLC) was purchased from International Laboratory (San Fransisco, USA). Norbixin was extracted from annatto seeds using extraction with $8 \%$ ethanol in dichloromethane $\left(\mathrm{CH}_{2} \mathrm{Cl}_{2}\right)$. Norbixin was purified from this extract by preparative thin layer chromatography (TLC). Crocetin (98\% purity by HPLC) was purchased from Carotenature (Lupsingen, Switzerland). The 
cytotoxicity of bixin, norbixin and crocetin was tested in vitro as previously decribed using the cytotox CALUX cell line to ascertain that the test compounds did not affect the luciferase activity themselves under the conditions tested.[25] PPAR $\gamma$-mediated gene expression was tested using the PPAR $\gamma 2$-reporter gene assay in PPAR- $\gamma 2$ CALUX cells provided by BioDetection Systems BV (Amsterdam, The Netherlands).[26] To analyse the effects of bixin, norbixin and crocetin on PPARYmediated gene expression, the cells were incubated for $24 \mathrm{~h}$ at increasing concentrations (0.01-100 $\mu \mathrm{M})$ of the compounds in culture medium added from 200 times concentrated stock solutions in THF. The final concentration of THF in exposure medium was $0.5 \%(\mathrm{v} / \mathrm{v}) .1 \mu \mathrm{M}$ rosiglitazone, a well-known PPARY agonist, ${ }^{[27]}$ was included in every plate as positive control (added from a 200 times concentrated stock solution in DMSO). Luciferase activity of the lysate was quantified at room temperature using a luminometer (Glowmax Multi Detection System, Promega Madison USA).

Data are presented as mean values \pm SD from three independent experiments with six replicates per plate. The PPAR $\gamma$ responses were expressed relative to the response of the rosiglitazone positive control set at $100 \%$. The obtained concentration-response curves were fitted with a symmetrical sigmoidal model (Hill slope) using GraphPad Prism software (version 5.00 for Windows, GraphPad software, San Diego, USA) which was further used to derive $\mathrm{EC}_{50}$ values.

\subsubsection{Determination of model parameter values for hepatic clearance}

Pooled human cryopreserved hepatocytes (HEP10) for suspension were purchased from Life Technologies (Bleiswijk, The Netherlands). The cells were thawed and assessed for metabolic stability in accordance with the manufacturer's protocol (Supporting information 1). The intrinsic clearance ( $\left.\mathrm{CL}_{\text {int }}\right)$ values of bixin and crocetin were estimated by a substrate depletion approach using the protocol provided by the supplier for in vitro assessment of metabolic stability in suspensions with cryopreserved pooled mixed gender human hepatocytes (HEP10) with little modifications. The rate of disappearance of the parent compounds at a single, low substrate concentration (i.e. $3 \mu \mathrm{M}$ ) were scaled to in vivo clearance values to describe the hepatic clearance of the parent compounds in the PBK model. After incubation at time points $0,7.5,15,30$, and $60 \mathrm{~min}$, the residual parent compounds were analysed using a Waters UPLC-DAD-System. For all incubations, three independent replicates were performed.

The slope of the linear curve for the time dependent percent residual parent compound from the HEP10 containing reaction mixtures corrected for the percent residual parent compound in the corresponding blancs without cells was used to 
determine the in vitro $t_{1 / 2}$ (expressed in min) of the parent compound. Using the elimination rate constant $\mathrm{k}=0.693 / \mathrm{t}_{1 / 2}, \mathrm{CL}_{\text {int, in vitro }}$ expressed in $\mu \mathrm{L} / \mathrm{min} / 10^{6}$ cells can be described as Equation 6.1.

$C L_{\text {int, in vitro }}=\frac{0.693}{t_{1 / 2}} \times \frac{\mathrm{V}}{\mathrm{N}}$

(Equation 6.1)

where $\mathrm{V}$ is the volume of the incubation (expressed in $\mu \mathrm{L}$ ) and $\mathrm{N}$ is number of hepatocytes per well (expressed in $10^{6}$ cells). ${ }^{[28]}$ The human physiological parameters reported by Soars et al.[${ }^{[29]}$ were used to scale the in vitro $C L_{\text {int }}$ values to in vivo $C L_{\text {int }}$ values which were applied in the PBK models (Equation 6.2).

$C L_{\text {int, in vivo }}=W L \times b w \times H e p \times C L_{\text {int, in vitro }} \times 60 \times 10^{-6}$

(Equation 6.2)

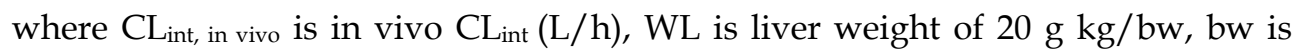
human body weight of $70 \mathrm{~kg}$ used in the PBK models, Hep is hepatocellularity of

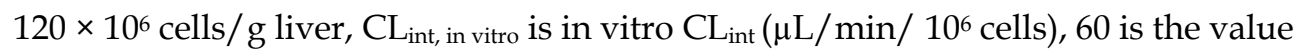
of $60 \mathrm{~min}$ within $1 \mathrm{~h}, 10^{-6}$ to convert from $\mu \mathrm{L}$ to $\mathrm{L}$.

As norbixin, which is a likely metabolite of bixin, was unable to induce PPAR $\gamma$-mediated gene transcription even at the highest concentration tested, and in line with literature ${ }^{[18]}$, it was not considered in the clearance studies and subsequent PBK modeling.

\subsubsection{Development and evaluation of a PBK model for bixin and crocetin}

A PBK model is a set of mathematical equations which describe the absorption, distribution, metabolism and excretion (ADME) characteristics of a compound within an organism based on three types of parameters, i.e: i) physiological and anatomical (e.g. cardiac output, tissue volumes and tissue blood flows), (ii) physico-chemical (blood/tissue partition coefficients) and (iii) kinetic parameters (e.g. kinetic constants for metabolic reactions). ${ }^{[23]}$ Figure 6.2 depicts the conceptual PBK model, which consists of separate compartments for the gastrointestinal (GI) tract, liver, slowly perfused tissues (e.g. skin, muscle, bone), rapidly perfused tissues (e.g. heart, lung, brain), fat and blood. 


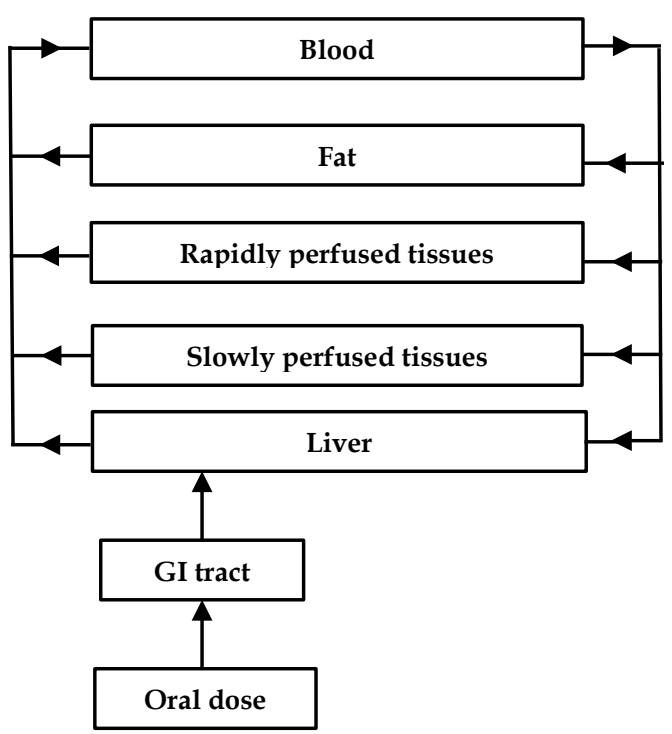

Figure 6.2. Schematic representation of the conceptual PBK model for bixin and crocetin in human.

The values of human physiological and anatomical parameters were obtained from literature, ${ }^{[30]}$ while the blood/ tissue partition coefficients were estimated using the formula using Log P values of olive oil, pKa and fraction unbound in serum as input, ${ }^{[31]}$ and as shown in the supporting information 2 (Table S1 and Table S2). Log Kow values were estimated using ChemBio-Draw Ultra 14.0 (Cambridge-Soft, USA). Kinetic parameters for hepatic clearance of bixin and crocetin were determined using HEP10 incubations performed as described above. Berkeley Madonna 8.3.18 (Macey and Oster, UC Berkeley, CA) was used to code and numerically integrate the PBK models applying Rosenbrock's algorithm for stiff systems. Compared to other algorithms in Berkeley Madonna (BM), the Rosenbrock's algorithm serves better for stiff systems[32-34] and was shown to provide adequate results in previous studies providing proofs of principle for the PBK model based reverse dosimetry.[35-42]

The model code for the developed PBK models of bixin is presented in Supplementary information 3.

To evaluate the PBK model performance, predicted maximum bixin and crocetin concentrations in the blood were compared to reported maximum blood concentrations in humans as reported in the literature.[43, 44] Maximum concentrations of bixin and crocetin in blood were predicted by PBK modeling using a ka value of $1 \mathrm{~h}^{-1}$ for each compound assuming fast and complete uptake.[45]

In addition a sensitivity analysis was performed to identify the key parameters which contribute most to the predicted maximum blood concentrations 
$\left(\mathrm{C}_{\max }\right)$ at an oral dose of $0.23 \mathrm{mg} / \mathrm{kg}$ bw for bixin and $0.25 \mathrm{mg} / \mathrm{kg}$ bw for crocetin. This sensitivity analysis was performed as described previously|[6] calculating normalized sensitivity coefficients (SCs) by Equation 6.3.

$S C=\frac{\left(C^{\prime}-C\right)}{P^{\prime}-P} \times\left(\frac{P}{C}\right)$

(Equation 6.3)

where $C$ is the initial value of the model output, $C^{\prime}$ is the modified value of the model output resulting from an increase in parameter value, $\mathrm{P}$ is the initial parameter value and $\mathrm{P}^{\prime}$ is the modified parameter value. Each parameter was analyzed individually by changing one parameter at a time ( $5 \%$ increase) and keeping the other parameters the same.

\subsubsection{Translation of in vitro PPAR $\gamma$ concentration respon curves to in vivo PPAR $\gamma$ dose response curves}

The in vitro concentration-response curves for bixin- and crocetin-induced activation of PPAR $\gamma$ mediated gene transcription were translated into predicted in vivo dose-response curves using PBK modeling-facilitated reverse dosimetry. This reverse dosimetry was based on the concentration of the parent compound, which was assumed to represent the form of the carotenoids activating PPAR $\gamma$-mediated gene expression.

Furthermore, within this translation a correction was made to take the differences in albumin and lipid concentrations between in vitro and in vivo conditions into account. This was done because it was assumed that only the free fraction of the carotenoid will be available to exert the effects. Extracellular instead of intracellular concentrations were used because unbound concentrations in blood were considered to best match the in vitro model where cells were exposed to the carotenoids dissolved in the medium on top of the cell layer. The unbound fraction $\left(f_{u b}\right.$, in vitro $)$ was estimated to determine the fraction bound ( $\left.f_{b \text {, in vitro }}\right)$ to lipid and protein in culture medium. ${ }^{[47]}$ Each nominal concentration applied in the in vitro PPAR $\gamma$-mediated gene expression assay ( $\mathrm{EC}_{\text {in vitro }}$ ) of bixin and crocetin was extrapolated to an in vivo effect concentration ( $E C_{\text {in vivo }}$ ) according to the extrapolation rule of Gülden and Seibert (2003) $)^{[47]}$ as described in supporting information 4 . Each in vivo concentration ( $\mathrm{EC}_{\text {in vivo }}$ ), thus obtained was set equal to the blood $\mathrm{C}_{\max }$ of bixin and crocetin in the PBK model. The PBK model was subsequently used to calculate the corresponding oral dose levels in humans to derive the in vivo dose-response curves.

To define the benchmark dose resulting in a $50 \%$ increase over the background level of PPARY activation $\left(\mathrm{BMD}_{50}\right)$ the predicted in vivo dose-response data for bixin- and crocetin-induced PPAR $\gamma$-mediated gene expression in human 
were used for BMD modeling. Dose-response modeling and BMD analysis were performed using the EFSA BMD modeling webtool (PROAST version 66.38, https://shiny-efsa.openanalytics.eu/app/bmd).[48] Data were analysed using the exponential model for continuous data because this model appeared to provide the best (goodness of) fit with the lowest Akaike Information Criterion (AIC) value among the available models. In the visualization result of PROAST, a CES (critical effect size), CED (critical effect dose), CEDL (lower bound of the CED), CEDU (upper bound of the CED) correspond to the BMR, BMD $\mathrm{B}_{50}, \mathrm{BMDL}_{50}$ (lower bound of the $\mathrm{BMD}_{50} 95 \%$-confidence interval), and $\mathrm{BMDU}_{50}$ (upper bound of the $\mathrm{BMD}_{50} 95 \%$ confidence interval), respectively.

\subsection{Results}

\subsubsection{Bixin- and crocetin-induced activation of PPAR $\gamma$-mediated gene expresssion}

Bixin and crocetin increased PPAR $\gamma$-mediated gene expression in a concentration-dependent manner, while norbixin appeared unable to induce PPAR $\gamma$-mediated gene expression up to the highest concentration tested of $100 \mu \mathrm{M}$ (Figure 6.3). Bixin and crocetin were of similar potency and had an $\mathrm{EC}_{50}$ of 23.5 and $17.7 \mu \mathrm{M}$, respectively. Using the cytotox CALUX cell line it was confirmed that at the concentrations tested there was no cytotoxicity and the test compounds did not affect the luciferase activity (data not shown).
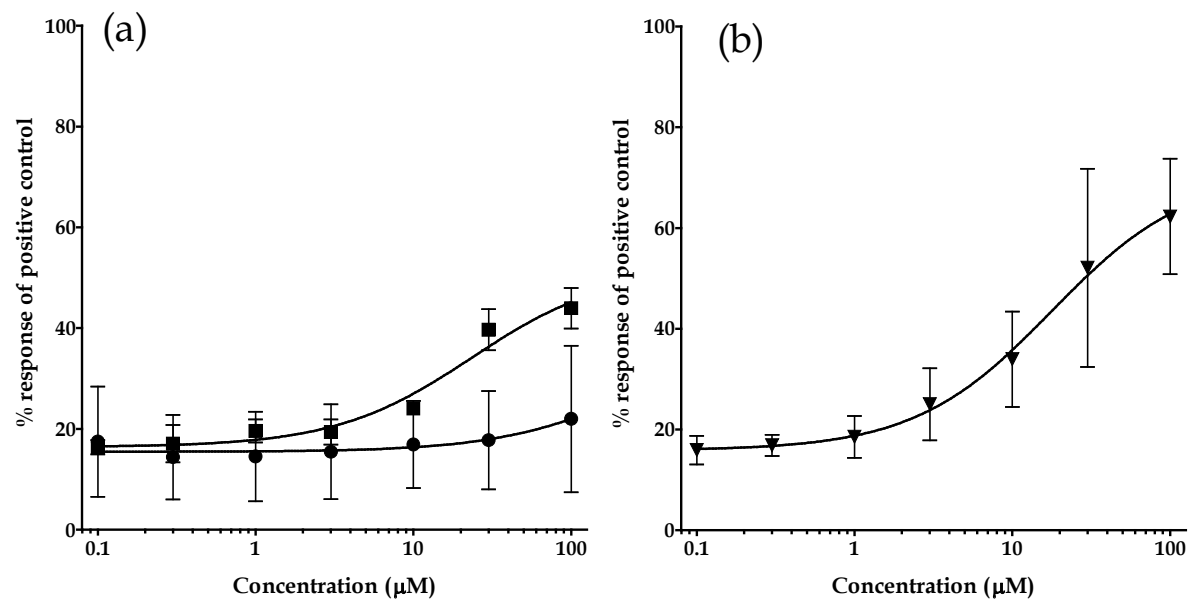

Figure 6.3. Concentration-dependent induction of PPAR $\gamma$-mediated gene expression by (a) bixin (squares) and norbixin (circles), and (b) crocetin (triangles) expressed as percentage of the response induced by the positive control $1 \mu \mathrm{M}$ rosiglitazone set at $100 \%$. The induction by roziglitazone was between 7 - and 8 -fold. Values are presented as means \pm standard deviations derived from 3 independent experiments. 


\subsubsection{Hepatic clearance of bixin and crocetin}

The hepatic clearance of bixin and crocetin was determined for subsequent PBK modeling using incubations with primary human hepatocytes. Figure 6.4 shows that bixin concentrations decreased during the incubation, resulting in an in vitro clearance $\left(\mathrm{Cl}_{\text {int in vitro }}\right)$ of $36.13 \mu \mathrm{L} / \mathrm{min} / 10^{6}$ cells, and a scaled in vivo clearance $\left(\mathrm{CL}_{\text {int in vivo }}\right.$ of $364.16 \mathrm{~L} / \mathrm{h}$. Crocetin concentrations were not clearly affected along the 60 minutes incubation with human hepatocytes and therefore, for subsequent PBK modeling, hepatic clearance was assumed to be negligible $\left(\mathrm{CL}_{\mathrm{int}}\right.$ in vivo $\left.=0\right)$.

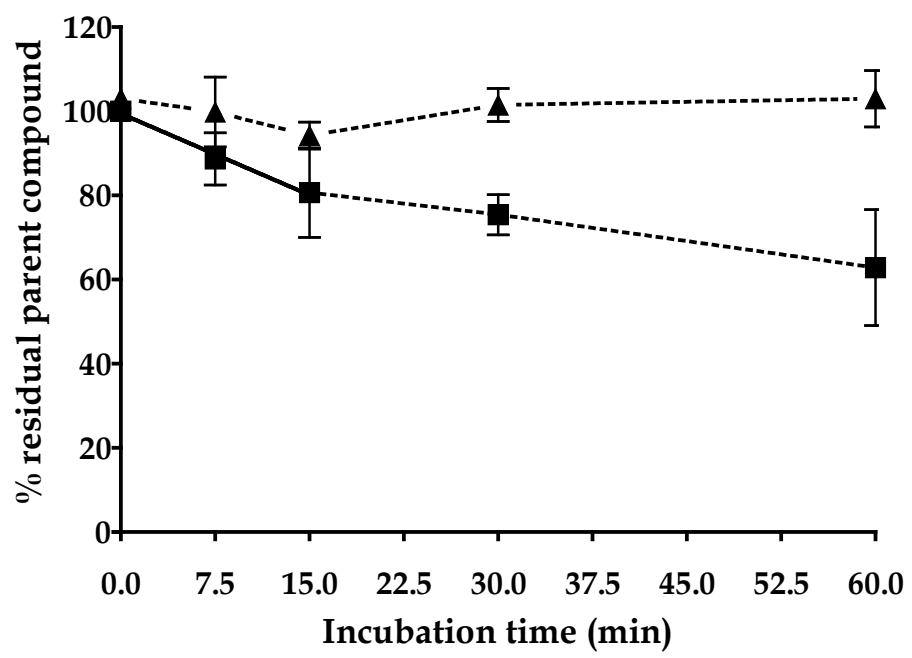

Figure 6.4. Hepatic clearance of bixin (square) and crocetin (triangle) during the incubations with primary human hepatocytes for $60 \mathrm{~min}$. The slope for linear regression until $15 \mathrm{~min}$ (straight line) was used to determine the in vitro half-life $\left(\mathrm{t}_{1 / 2}\right)$ of bixin.

\subsubsection{Evaluation of the PBK models for bixin and crocetin}

To evaluate the PBK models, the dose-dependent blood concentrations of bixin and crocetin in humans were predicted and compared to blood concentrations resulting from oral intake of bixin and crocetin reported in literature. For bixin, the one study available reported a maximum blood concentration $\left(\mathrm{C}_{\max }\right)$ of $0.029 \mu \mathrm{M}$ after an oral dose of $0.23 \mathrm{mg} / \mathrm{kg} \mathrm{bw} .{ }^{[43]}$ This predicted $\mathrm{C}_{\max }$ value accurately matched the PBK model based predicted $\mathrm{C}_{\max }$ value of $0.027 \mu \mathrm{M}$. For crocetin, also a single human study was available reporting $\mathrm{C}_{\max }$ values after oral intake at three different dose levels of $0.125,0.25$, and $0.374 \mathrm{mg} / \mathrm{kg}$ bw..$^{[4]}$ The PBK model based predicted $\mathrm{C}_{\max }$ values at these dose levels amounted to $0.12,0.25$, and $0.37 \mu \mathrm{M}$ which were 2.5, 2.5-, and 2.3-fold lower than the reported values of $0.31,0.61$ and $0.85 \mu \mathrm{M}$, respectively. Thus, comparison of the predicted and reported blood levels of bixin and crocetin reveals that the PBK models adequately predicted the $\mathrm{C}_{\max }$ values. 
Furthermore, comparison of the $C_{\max }$ values of bixin and crocetin reveals that the $\mathrm{C}_{\max }$ values for bixin are about 5-14 times lower than those of crocetin.

The performance of the developed models was further evaluated by a sensitivity analysis to assess the parameters that affect the prediction of the $C_{\max }$ of bixin and crocetin in blood to the largest extent. The sensitivity analysis was performed at an oral dose of $0.23 \mathrm{mg} / \mathrm{kg}$ bw for bixin and $0.25 \mathrm{mg} / \mathrm{kg}$ bw for crocetin, which are dose levels applied in the available in vivo kinetic studies. Only the parameters that resulted in a normalized sensitivity coefficient higher than 0.1 (in absolute value) are shown in Figure 6.5. The results obtained reveal that the prediction of $\mathrm{C}_{\max }$ in the PBK model is most sensitive to the parameters related to the liver including the hepatic clearance $\left(\mathrm{CL}_{\mathrm{int}}\right)$, the absorption rate constant for uptake from the GI tract into the liver (ka) and hepatocellularity (Hep).

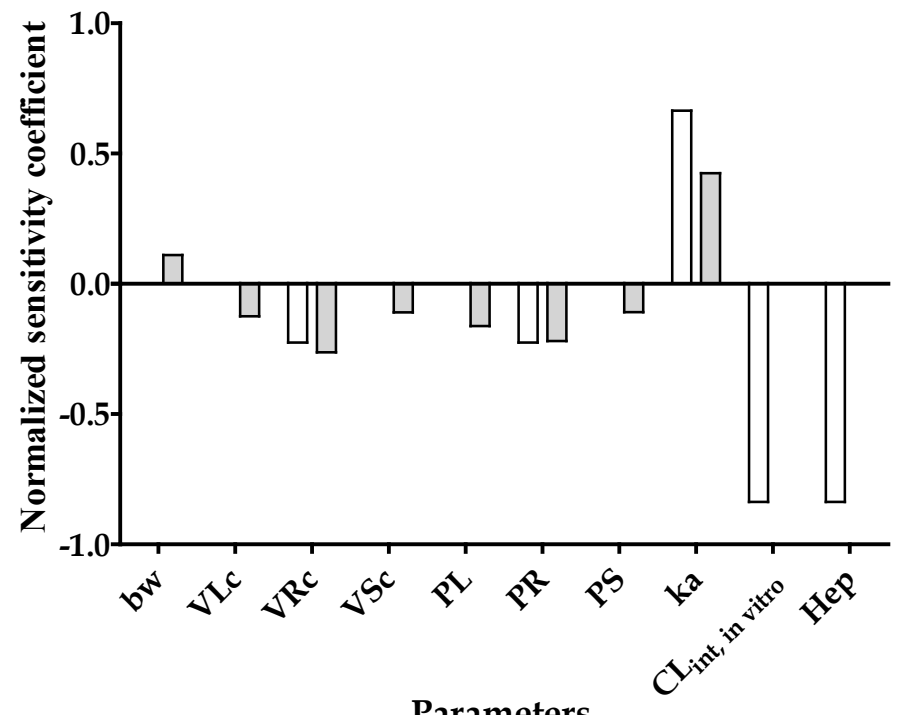

Figure 6.5. Normalized sensitivity coefficients for the parameters of the PBK model for bixin and crocetin on predicted $\mathrm{C}_{\max }$ in blood at a single oral dose of $0.23 \mathrm{mg} / \mathrm{kg}$ for bixin (white bars) and $0.25 \mathrm{mg} / \mathrm{kg}$ (grey bars) for crocetin. $\mathrm{bw}=$ body weight, $\mathrm{VLc}=$ fraction of liver volume, $\mathrm{VRc}=$ fraction of rapidly perfused tissues volume, $\mathrm{VSc}=$ fraction of slowly perfused tissues volume, $\mathrm{PL}=$ liver/blood partition coefficient, $\mathrm{PS}=$ slowly perfused tissue/blood partition coefficient, $\mathrm{PR}=$ rapidly perfused tissue/blood partition coefficient, $\mathrm{ka}=$ uptake rate constant, $\mathrm{C}_{\text {int, in vitro }}=$ in vitro intrinsic clearance of bixin/crocetin, Hep $=$ hepatocellularity.

Figure 6.6 presents the in vivo dose reponse curves obtained for bixin and crocetin when, upon correction for the differences in unbound fraction, the in vitro concentrations were converted to corresponding in vivo dose levels. BMD modeling of these data (for details see supporting information 5 Figure S1), resulted in the 
$\mathrm{BMD}_{50}, \mathrm{BMDL}_{50}$ and $\mathrm{BMDU}_{50}$ values presented in Table 6.1. From these data it follows that the $\mathrm{BMD}_{50}$ of bixin is about 30 times higher than that of crocetin.

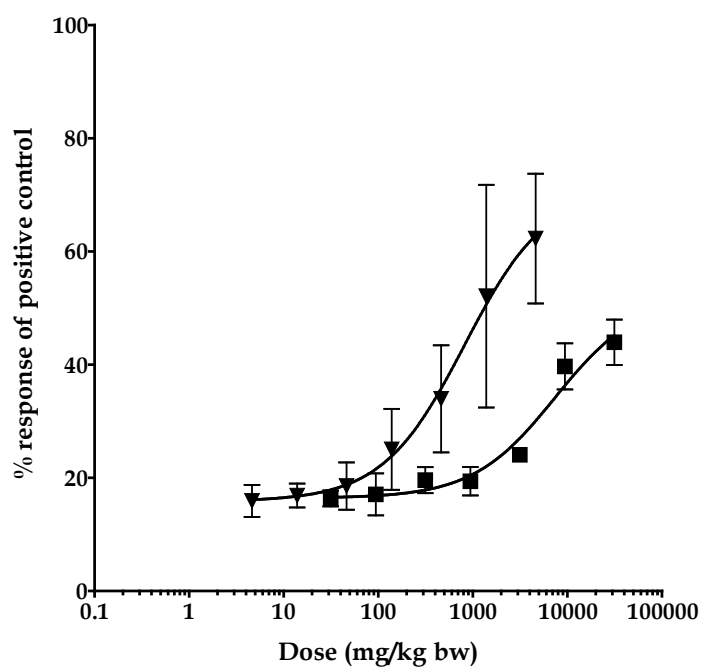

Figure 6.6. Predicted in vivo dose-response curves for PPAR $\gamma$-mediated gene expression of bixin (square) and crocetin (triangle) in human. Predicted dose-response data were obtained using PBK modelingfacilitated reverse dosimetry for conversion of in vitro concentration-response data obtained in the PPARY CALUX reporter gene assay (Figure 6.3).

Table 6.1. BMD 50 and BMDL50-BMDU ${ }_{50}$ values derived from the dose-response curves predicted using PBK modeling-facilitated reverse dosimetry to convert the in vitro concentration-response curves as obtained in the present study to in vivo dose-response curves.

\begin{tabular}{ccc}
\hline Compound & BMD $_{\mathbf{5 0}}(\mathbf{m g} / \mathbf{k g}$ bw) & Predicted BMDL $\left._{50}-\mathbf{B M D U}_{\mathbf{5 0}} \mathbf{( m g} / \mathbf{k g ~ b w}\right)$ \\
\hline Bixin & 3,505 & $1,710-5,220$ \\
Crocetin & 115 & $0.32-374$ \\
\hline
\end{tabular}

\subsubsection{Comparison to human dietary intake levels}

The predicted $\mathrm{BMD}_{50}$ values including the $\mathrm{BMDL}_{50}$ and $\mathrm{BMDU}_{50}$ values thus obtained were compared to the reported dose levels of bixin and crocetin resulting from daily intake in humans as taken from the literature. Figure 6.7 shows a comparison of the predicted $\mathrm{BMD}_{50}$ values (presenting also the $\mathrm{BMDL} \mathrm{L}_{50}-\mathrm{BMDU}_{50}$ range) for bixin- and crocetin-mediated induction of PPAR $\gamma$ activity in vivo and the estimated dietary intake levels, resulting from use of the compounds as food additives and/or as functional food ingredients in food supplements. 


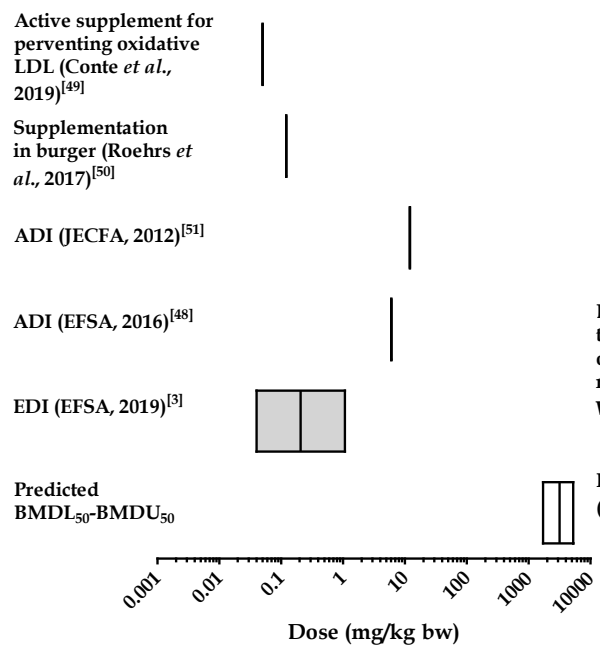

(a)

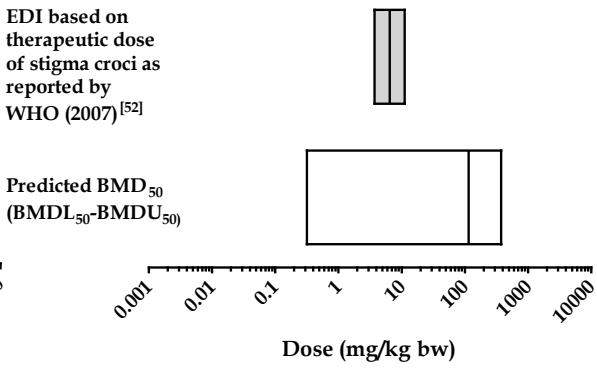

(b)

Figure 6.7. Comparison of the predicted in vivo $\mathrm{BMD}_{50}, \mathrm{BMDL}_{50}-\mathrm{BMDU}_{50}$ for PPAR $\gamma$ activation with available EDI values for a) bixin and b) crocetin in human. For comparison also the available ADI values are included.

The recent exposure assessment performed by EFSA ${ }^{[3]}$ reported the estimated maximum level of dietary exposure to bixin-based annatto extracts (E 160b) from its use as food additive to amount to $0.04-1.07 \mathrm{mg} / \mathrm{kg}$ bw/day (95 $5^{\text {th }}$ percentile). This value is 3 to 5 orders of magnitude lower than the predicted $\mathrm{BMD}_{50}$ for PPAR $\gamma$ acivation, which reveals that normal dietary intake of bixin is expected to not result in activation of PPAR $\gamma$-mediated gene expression. Also bixin supplementation at a level of $0.05 \mathrm{mg} / \mathrm{kg}$ bw in healty human subjects which was reported to be an active dose to prevent early oxidative modifications in LDL as key event of atherosclerosis ${ }^{[49]}$ is several orders of magnitude below the predicted $\mathrm{BMD}_{50}$ for inducing the PPAR $\gamma$-mediated gene expression. This result is in line with results reported before concluding that bixin supplementation amounting to $1.2 \mathrm{mg} / \mathrm{kg} \mathrm{bw}$ ( $10 \%$ of the ADI) had no effect on the postprandial oxidative LDL levels and thus seemed inactive in preventing the risk of cardiovascular disease and insulin resistance. ${ }^{[50]}$ Furthermore comparison of the predicted $\mathrm{BMD}_{50}$ values to the ADI values for bixin of $6 \mathrm{mg} / \mathrm{kg}$ bw/ day and $0-12 \mathrm{mg} / \mathrm{kg}$ bw/ day established by EFSA [3] and JECFA[51] reveals that these ADI values are also 2 to 3 orders of magnitude lower than the $\mathrm{BMD}_{50}$ indicating that they will prevent effective PPAR $\gamma$-mediated gene expression.

For crocetin there are no existing values for the EDI resulting from its use as a food ingredient. However, the WHO (2007) ${ }^{[52]}$ based on the Pharmacopoeia of the 
People's Republic of China reported that the recommended therapeutic daily dose of stigma croci (saffron stigma) is 3-9 g. Considering the level of crocin of 25.95 $\mathrm{mg} / 100 \mathrm{mg}$ dry saffron [53] and the mass ratio of crocetin to crocin, this dose of stigma croci is estimated to be equivalent to an intake of crocetin of $3.74-11.2 \mathrm{mg} / \mathrm{kg}$ bw/day for a $70 \mathrm{~kg}$ person (see supporting information 6 for the detailed calculation). Comparison of this EDI to the predicted $\mathrm{BMD}_{50}$ and $\mathrm{BMDL}_{50}-\mathrm{BMDU}_{50}$ range for crocetin reveals that the recommended therapeutic dose as reported by the WHO (2007) ${ }^{[52]}$ is predicted to represent a dose levels where PPAR $\gamma$ activation in human might be expected, although it must be noted that the confindence intervals in the predicted dose-response data for crocetin are large.

\subsection{Discussion}

PPAR $\gamma$ has been identified as a ligand-regulated nuclear receptor reported to increase insulin sensitivity in the treatment of T2DM. This made PPAR $\gamma$ a target for drug development and also resulted in reports on various natural dietary ingredients able to activate PPAR $\gamma$-mediated gene expression. This includes reports on activation of PPAR $\gamma$ by various carotenoids as detected in in vitro reporter gene assays. ${ }^{[18-21]}$ Some carotenoids, including the model compounds of the present study bixin and crocetin have also been proposed for use as functional food ingredients and/or are used in traditional medicine to treat T2DM-related symptoms. ${ }^{[54]}$ For crocetin, the therapeutic use of crocetin-containing stigma croci has been proposed at dose levels amounts to 3-9 g per person, estimated in the present study to be equivalent to $3.74-11.2 \mathrm{mg}$ crocetin/ $\mathrm{kg}$ bw for a $70 \mathrm{~kg}$ person. ${ }^{[52]}$ The aim of the present study was to investigate at what dose levels bixin and crocetin would be expected to induce PPAR $\gamma$-mediated gene expression in humans in vivo by using a combined in vitro-in silico based testing strategy without the need for a human intervention study. Thus, the present study especially investigated whether doseresponse curve for in vivo PPAR $\gamma$ activation in human by bixin and crocetin can be quantitatively predicted by PBK modeling-facilitated reverse dosimetry of PPAR $\gamma$ activation data obtained in an in vitro PPAR $\gamma$ reporter gene assay.

The results of the in vitro study indicate that both bixin and crocetin can activate PPAR $\gamma$-mediated gene expression in U2OS PPAR 2 cells (Figure 6.3). This observation is in line with earlier reports on PPAR $\gamma$ activation by related carotenoids.[18-21] The results also match the results which reported that branched fatty compounds represent a group of natural PPAR $\gamma$ agonists able to enhance insulin sensitivity of adipocytes.[18] The $\mathrm{EC}_{50}$ values for bixin- and crocetindependent induction of PPAR $\gamma$-mediated gene expression in the U2OS PPAR $\gamma 2$ cells 
were similar indicating a similar intrinsic potency of the carotenoids to induce PPAR $\gamma$ activity. The absence of PPAR $\gamma$ induction by norbixin, the metabolite resulting from hydrolysis of bixin, as observed in the present study is in line with results previously reported by Takahashi et al. $2009{ }^{[18]}$ who reported that the activity of norbixin for PPAR $\gamma$ activation was substantially lower than that of bixin when tested in the luciferase assay using a chimera protein of PPAR $\gamma$ and the PPAR fulllength system, respectively. Moreover Roehrs et al. (2014) ${ }^{[10]}$ found the opposite effect of bixin and norbixin on potentially PPAR $\gamma$ related effects in vivo; where the highest dose of norbixin increased dyslipidaemia and oxidative stress in streptozotocin-induced diabetes rats, bixin showed an antihyperglycemic effect, improving lipid profiles, and protecting against damage induced by oxidative stress in the diabetic state.

To enable the translation of the in vitro concentration-response curves to in vivo dose-response curves for PPAR $\gamma$ activation by bixin and crocetin, PBK models for bixin and crocetin were developed. Characterisation of the model parameters for hepatic clearance revealed that hepatic clearance of crocetin was limited as compared to that observed for bixin. This result explains the observed differences in reported and also in the PBK modeling-based predicted $C_{\max }$ levels for crocetin and bixin in blood at comparable dose levels. The $C_{\max }$ values for crocetin were about 1020 fold higher than those for bixin at comparable dose levels. Furthermore, comparison of the predicted $C_{\max }$ values to $C_{\max }$ values actually observed in available in vivo kinetic studies in human ${ }^{[43,44]}$ revealed that for both bixin and crocetin these differences were limited. The predicted $\mathrm{C}_{\max }$ of bixin of $0.027 \mu \mathrm{M}$ was similar to the reported value of $0.029 \mu \mathrm{M} .{ }^{[43]}$ For crocetin there was only a 2-fold difference between the PBK model predictions and the reported $C_{\max }$ values ${ }^{[44]}$, the predicted values being somewhat too low.

Upon evaluation of the PBK models the available in vitro concentrationresponse curves for bixin- and crocetin-mediated PPAR $\gamma$ activation were converted to in vivo dose-response curves using PBK modeling-facilitated reverse dosimetry. The $\mathrm{BMD}_{50}$ and $\mathrm{BMDL}_{50}-\mathrm{BMDU}_{50}$ values derived from the dose-response curves thus obtained were compared to estimated daily intakes for bixin and crocetin resulting from realistic exposure scenarios. These comparisons revealed that EDI values for bixin resulting from its use as a food additive ${ }^{[3]}$ or as food supplement ${ }^{[49,50]}$ are unlikely to result in PPAR $\gamma$-mediated gene expression in humans. In contrast, use of crocetin-containing stigma croci at dose levels amounting to 3-9 g per person, estimated to be equivalent to $3.74-11.2 \mathrm{mg}$ crocetin $/ \mathrm{kg}$ bw for a $70 \mathrm{~kg}$ person[52], were predicted to more likely result in substantial induction of PPAR $\gamma$-mediated gene 
expression in human. However, it must be noted that the confindence intervals in the predicted dose-response data for crocetin are large and that the $\mathrm{BMD}_{50}$ of the predicted dose-response data is about 10 times higher than the intake at therapeutic dose levels. On the other hand, since clearance of crocetin was measured to be negligible in our in vitro studies, crocetin clearance in vivo is expected to be limited as well so that internal concentrations may increase upon daily repeated crocetin intake, resulting in lower predicted effective dose levels.

It is of interest to note that in spite of the intrinsic similar potency of bixin and crocetin to induce PPAR $\gamma$-mediated gene expression, as reflected by similar $\mathrm{EC}_{50}$ values in the PPAR $\gamma$ reporter gene assay, the predicted in vivo $\mathrm{BMD}_{50}$ values differed 30 -fold with the value for crocetin being lower. This can be ascribed to the more efficient clearance of bixin than of crocetin, resulting in lower dose levels required to reach effective in vivo $C_{\max }$ levels for crocetin than for bixin. This difference in clearance was observed in the in vitro incubations with the primary hepatocytes used in the present study. The few articles reporting on the pharmacokinetics of crocetin in human confirm the inefficient, albeit not negligible, clearance of crocetin. ${ }^{[44,55-57]}$

The present study used PBK modeling-based reverse dosimetry converting in vitro data to predicted in vivo dose-reponse curves enabling definition of effective in vivo dose levels. In previous studies this combined in vitro-in silico approach appeared already valid for other endpoints including for example genistein-induced estogenicity[36], hesperitin-induced effects on inhibition of protein kinase A activity[35], azole-[37], phenol-[38], retinoic acid-[39] and glycol ether-mediated developmental toxicity ${ }^{[40]}$, and lasiocarpine- and riddelliine-induced liver toxicity ${ }^{[41}$, 42]. The results of the present study illustrate that this combined in vitro-in silico approach can also be used to obtain insights in human responses to potential functional food ingredients. This insight can be used to select the promising compounds for subsequent human intervention studies and can help in the selection of doses in such studies.

\section{Conflict of interest}

The authors state no conflicts of interest.

\section{Acknowledgments}

This research was supported by a grant from the Indonesian Endowment Fund for Education (LPDP), Ministry of Finance, Republic of Indonesia [grant number: PRJ-365/LPDP/2016] awarded to Suparmi. 


\section{Supporting information}

Supporting information to this article can be downloaded from: https://doi.org/10.1002/mnfr.201900880.

\section{References}

[1] Rao, A. V., Rao, L. G., Carotenoids and human health. Pharmacological Research 2007, 55, $207-216$.

[2] Milani, A., Basirnejad, M., Shahbazi, S., Bolhassani, A., Carotenoids: biochemistry, pharmacology and treatment. British Journal of Pharmacology 2017, 174, 1290-1324.

[3] EFSA, Safety of annatto E and the exposure to the annatto colouring principles bixin and norbixin (E 160b) when used as a food additive. EFSA Journal 2019, 17, e05626.

[4] Mercadante, A. Z., Steck, A., Pfander, H., Isolation and identification of new apocarotenoids from annatto (Bixa orellana) seeds. Journal of Agricultural and Food Chemistry. 1997, 45, 1050-1054.

[5] Scotter, M. J., Thorpe, S. A., Reynolds, S. L., Wilson, L. A., Strutt, P. R., Characterization of the principal colouring components of annatto using high performance liquid chromatography with photodiode-array detection. Food Additives \& Contaminants 1994, 11, 301-315.

[6] Pfister, S. M., P.; Steck, A.; Pfander, H, Isolation and structure elucidation of carotenoid-glycosyl esters in Gardenia fruits (Gardenia jasminoides Ellis) and saffron (Crocus sativus L.). Journal of Agricultural and Food Chemistry 1996, 44, 2612-2615.

[7] IACM, The International Association of Color Manufacturers (IACM), Washington DC 2017.

[8] Hosseinzadeh, H., Nassiri-Asl, M., Avicenna's (Ibn Sina) the Canon of Medicine and Saffron (Crocus sativus): A Review. Phytotherapy Research 2013, 27, 475-483.

[9] Vilar, D. d. A., Vilar, M. S. d. A., de Lima e Moura, T. F. A., Raffin, F. N., et al., Traditional uses, chemical constituents, and biological activities of Bixa orellana L.: a review. The Scientific World Journal 2014, 2014, 857292-857292.

[10] Roehrs, M., Figueiredo, C. G., Zanchi, M. M., Bochi, G. V., et al., Bixin and norbixin have opposite effects on glycemia, lipidemia, and oxidative stress in streptozotocin-induced diabetic rats. International Journal of Endocrinology 2014, 2014.

[11] Xi, L., Qian, Z., Shen, X., Wen, N., Zhang, Y., Crocetin prevents dexamethasone-induced insulin resistance in rats. Planta Medica 2005, 71, 917-922.

[12] Xi, L., Qian, Z., Xu, G., Zheng, S., et al., Beneficial impact of crocetin, a carotenoid from saffron, on insulin sensitivity in fructose-fed rats. Journal of Nutritional Biochemistry 2007, 18, 64-72.

[13] Sheng, L., Qian, Z., Shi, Y., Yang, L., et al., Crocetin improves the insulin resistance induced by highfat diet in rats. British Journal of Pharmacology 2008, 154, 1016-1024.

[14] Nathan, D. M., Buse, J. B., Davidson, M. B., Ferrannini, E., et al., Medical management of hyperglycemia in type 2 diabetes: A consensus algorithm for the initiation and adjustment of therapy. A consensus statement of the American Diabetes Association and the European Association for the Study of Diabetes 2009, 32, 193-203.

[15] Nesto, R. W., Bell, D., Bonow, R. O., Fonseca, V., et al., Thiazolidinedione use, fluid retention, and congestive heart failure: A Consensus Statement from the American Heart Association and American Diabetes Association. Circulation 2003, 108, 2941-2948.

[16] Kintscher, U., Law, R. E., PPAR $\gamma$-mediated insulin sensitization: the importance of fat versus muscle. American Journal of Physiology - Endocrinology and Metabolism 2005, 288, E287-E291.

[17] Grygiel-Górniak, B., Peroxisome proliferator-activated receptors and their ligands: Nutritional and clinical implications - A review. Nutrition Journal 2014, 13.

[18] Takahashi, N., Goto, T., Taimatsu, A., Egawa, K., et al., Bixin regulates mRNA expression involved in adipogenesis and enhances insulin sensitivity in 3T3-L1 adipocytes through PPARY activation. Biochemical and Biophysical Research Communications 2009, 390, 1372-1376.

[19] García-Rojas, P., Antaramian, A., González-Dávalos, L., Villarroya, F., et al., Induction of peroxisomal proliferator-activated receptor $\gamma$ and peroxisomal proliferator-activated receptor $\gamma$ coactivator 1 by unsaturated fatty acids, retinoic acid, and carotenoids in preadipocytes obtained from bovine white adipose tissue1,2. Journal of Animal Science 2010, 88, 1801-1808.

[20] Gijsbers, L., van Eekelen, H. D. L. M., de Haan, L. H. J., Swier, J. M., et al., Induction of peroxisome proliferator-activated receptor $\gamma$ (PPAR $\gamma$ )-mediated gene expression by tomato (Solanum lycopersicum L.) Extracts. Journal of Agricultural and Food Chemistry. 2013, 61, 3419-3427. 
[21] Takahashi, N., Kawada, T., Goto, T., Yamamoto, T., et al., Dual action of isoprenols from herbal medicines on both PPARY and PPARa in 3T3-L1 adipocytes and HepG2 hepatocytes. FEBS Letters 2002, 514, 315-322.

[22] Rietjens, I. M. C. M., Louisse, J., Punt, A., Tutorial on physiologically based kinetic modeling in molecular nutrition and food research. Molecular Nutrition and Food Research 2011, 55, 941-956.

[23] Louisse, J., Beekmann, K., Rietjens, I. M., Use of physiologically based kinetic modeling-based reverse dosimetry to predict in vivo toxicity from in vitro data. Chemical Research in Toxicology 2017, 30, 114-125.

[24] Louisse, J., Verwei, M., Woutersen, R. A., Blaauboer, B. J., Rietjens, I. M. C. M., Toward in vitro biomarkers for developmental toxicity and their extrapolation to the in vivo situation. Expert Opinion on Drug Metabolism E Toxicology 2012, 8, 11-27.

[25] Van der Linden, S. C., von Bergh, A. R. M., van Vught-Lussenburg, B. M. A., Jonker, L. R. A., et al., Development of a panel of high-throughput reporter-gene assays to detect genotoxicity and oxidative stress. Mutation Research - Genetic Toxicology and Environmental Mutagenesis 2014, 760, 2332.

[26] Gijsbers, L., Man, H. Y., Kloet, S. K., De Haan, L. H. J., et al., Stable reporter cell lines for peroxisome proliferator-activated receptor $\gamma($ PPAR $\gamma)$-mediated modulation of gene expression. Analytical Biochemistry 2011, 414, 77-83.

[27] Willson, T. M., Cobb, J. E., Cowan, D. J., Wiethe, R. W., et al., The structure - Activity relationship between peroxisome proliferator-activated receptor $\gamma$ agonism and the antihyperglycemic activity of thiazolidinediones. Journal of Medicinal Chemistry 1996, 39, 665-668.

[28] McGinnity, D. F., Soars, M. G., Urbanowicz, R. A., Riley, R. J., Evaluation of fresh and cryopreserved hepatocytes as in vitro drug metabolism tools for the prediction of metabolic clearance. Drug Metabolism and Disposition 2004, 32, 1247-1253.

[29] Soars, M. G., Burchell, B., Riley, R. J., In vitro analysis of human drug glucuronidation and prediction of in vivo metabolic clearance. Journal of Pharmacology and Experimental Therapeutics 2002, 301, 382390.

[30] Brown, R. P., Delp, M. D., Lindstedt, S. L., Rhomberg, L.R. et al.,, Physiological parameter values for physiologically based pharmacokinetic models, Toxicol. Ind. Health 1997.

[31] Berezhkovskiy, L. M., Determination of volume of distribution at steady state with complete consideration of the kinetics of protein and tissue binding in linear pharmacokinetics. Journal of Pharmaceutical Sciences 2004, 93, 364-374.

[32] Rosenbrock, H. H., Some general implicit processes for the numerical solution of differential equations. The Computer Journal 1963, 5, 329-330.

[33] Krause, A., Lowe, P. J., Visualization and communication of pharmacometric models with berkeley madonna. CPT Pharmacometrics Syst Pharmacol 2014, 3, e116-e116.

[34] Macey, R., Oster, G., Zahnley, T., Berkeley Madonna user's guide. Berkely, CA: University of California 2009.

[35] Boonpawa, R., Spenkelink, A., Punt, A., Rietjens, I. M. C. M., Physiologically based kinetic modeling of hesperidin metabolism and its use to predict in vivo effective doses in humans. Molecular Nutrition and Food Research. 2017, 1600894.

[36] Boonpawa, R., Spenkelink, A., Punt, A., Rietjens, I. M. C. M., In vitro-in silico-based analysis of the dose-dependent in vivo oestrogenicity of the soy phytoestrogen genistein in humans. British Journal of Pharmacology 2017b, 174, 2739-2757.

[37] Li, H., Zhang, M., Vervoort, J., Rietjens, I. M. C. M., et al., Use of physiologically based kinetic modeling-facilitated reverse dosimetry of in vitro toxicity data for prediction of in vivo developmental toxicity of tebuconazole in rats. Toxicology Letters 2017, 266, 85-93.

[38] Strikwold, M., Spenkelink, B., de Haan, L. H. J., Woutersen, R. A., et al., Integrating in vitro data and physiologically based kinetic (PBK) modelling to assess the in vivo potential developmental toxicity of a series of phenols. Archives of Toxicology 2017, 91, 2119-2133.

[39] Louisse, J., Bosgra, S., Blaauboer, B. J., Rietjens, I. M. C. M., Verwei, M., Prediction of in vivo developmental toxicity of all-trans-retinoic acid based on in vitro toxicity data and in silico physiologically based kinetic modeling. Archives of Toxicology 2015, 89, 1135-1148.

[40] Louisse, J., de Jong, E., van de Sandt, J. J. M., Blaauboer, B. J., et al., The use of in vitro toxicity data and physiologically based kinetic modeling to predict dose-response curves for in vivo developmental toxicity of glycol ethers in rat and man. Toxicological Sciences 2010, 118, 470-484. 
[41] Ning, J., Chen, L., Strikwold, M., Louisse, J., et al., Use of an in vitro-in silico testing strategy to predict inter-species and inter-ethnic human differences in liver toxicity of the pyrrolizidine alkaloids lasiocarpine and riddelliine. Archives of Toxicology 2019.

[42] Chen, L., Ning, J., Louisse, J., Wesseling, S., Rietjens, I. M. C. M., Use of physiologically based kinetic modelling-facilitated reverse dosimetry to convert in vitro cytotoxicity data to predicted in vivo liver toxicity of lasiocarpine and riddelliine in rat. Food and Chemical Toxicology 2018, 116, 216-226.

[43] Levy, L. W., Regalado, E., Navarrete, S., Watkins, R. H., Bixin and norbixin in human plasma: Determination and study of the absorption of a single-dose of annatto food color. Analyst 1997, 122, 977-980.

[44] Umigai, N., Murakami, K., Ulit, M. V., Antonio, L. S., et al., The pharmacokinetic profile of crocetin in healthy adult human volunteers after a single oral administration. Phytomedicine 2011, 18, 575-578.

[45] Punt, A., Freidig, A. P., Delatour, T., Scholz, G., et al., A physiologically based biokinetic (PBBK) model for estragole bioactivation and detoxification in rat. Toxicology and Applied Pharmacology 2008, 231, 248-259.

[46] Evans, M. V., Andersen, M. E., Sensitivity analysis of a physiological model for 2,3,7,8tetrachlorodibenzo-p-dioxin (TCDD): assessing the impact of specific model parameters on sequestration in liver and fat in the rat. Toxicological Sciences 2000, 54, 71-80.

[47] Gülden, M., Seibert, H., In vitro-in vivo extrapolation: estimation of human serum concentrations of chemicals equivalent to cytotoxic concentrations in vitro. Toxicology 2003, 189, 211-222.

[48] EFSA and Tard, A., Exposure assessment of annatto colouring principles bixin and norbixin (E 160b) when used as food additives. EFSA Journal 2017, 15, e04966.

[49] Conte, L., Somacal, S., Nichelle, S. M., Rampelotto, C., et al., Short-term bixin supplementation of healthy subjects decreases the susceptibility of LDL to $\mathrm{Cu}^{2+}$-induced oxidation ex vivo. Journal of Nutrition and Metabolism 2019, 2019, 13.

[50] Roehrs, M., Conte, L., da Silva, D. T., Duarte, T., et al., Annatto carotenoids attenuate oxidative stress and inflammatory response after high-calorie meal in healthy subjects. Food Research International 2017, 100, 771-779.

[51] JECFA, Joint, FAO WHO Expert Committee on Food Additives World Health Organization 2012.

[52] WHO, Ottawa 2007. WHO Monographs on Selected Medicinal Plants, Volume 3, Available at https://apps.who.int/medicinedocs/documents/s14213e/s14213e.pdf. Accessed 28 June 2018.

[53] Anastasaki, E. G., Kanakis, C. D., Pappas, C., Maggi, L., et al., Quantification of Crocetin Esters in Saffron (Crocus sativus L.) Using Raman Spectroscopy and Chemometrics. Journal of Agricultural and Food Chemistry. 2010, 58, 6011-6017.

[54] Sluijs, I., Cadier, E., Beulens, J. W. J., van der A, D. L., et al., Dietary intake of carotenoids and risk of type 2 diabetes. Nutrition, Metabolism and Cardiovascular Diseases 2015, 25, 376-381.

[55] Lautenschläger, M., Sendker, J., Hüwel, S., Galla, H. J., et al., Intestinal formation of trans-crocetin from saffron extract (Crocus sativus L.) and in vitro permeation through intestinal and blood brain barrier. Phytomedicine 2015, 22, 36-44.

[56] Mizuma, H., Tanaka, M., Nozaki, S., Mizuno, K., et al., Daily oral administration of crocetin attenuates physical fatigue in human subjects. Nutrition Research 2009, 29, 145-150.

[57] Chryssanthi, D. G., Lamari, F. N., Georgakopoulos, C. D., Cordopatis, P., A new validated SPEHPLC method for monitoring crocetin in human plasma-Application after saffron tea consumption. Journal of Pharmaceutical and Biomedical Analysis 2011, 55, 563-568. 


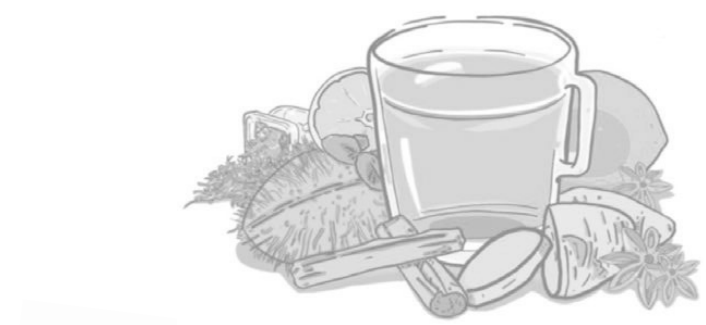

BENEFIT

RISK 
Chapter 7

General discussion

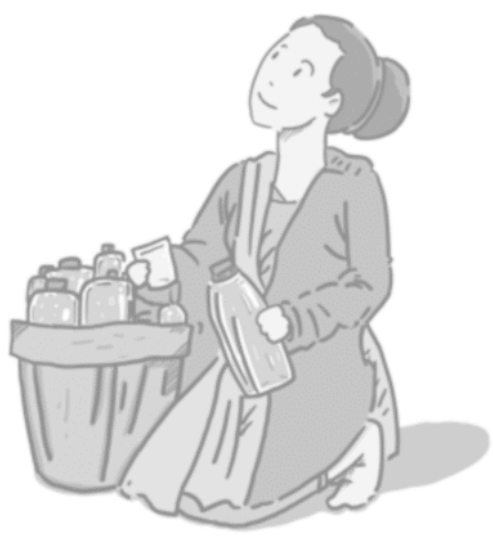




\subsection{Overview and general discussion of main findings}

The high consumer demand for beneficial alternative medicines provokes a notorious production of herbal products in Indonesia. Based on the research on medicinal botanicals and jamu in 2017, Indonesia has 2,848 species of medicinal botanicals from which 32,014 efficacious formulae of herbal products have been developed. ${ }^{[1]}$ The preference of Indonesian people for use of traditional medicine increased by $44.3 \%$ during 2010-2018. [2] While the consumers perceive that herbal products are "safe" and "natural" and thus "healthy", a risk and benefit assessment is crucial to support the safe and effective use of herbal products. ${ }^{[3-5]}$

The aim of this thesis was to analyze potential health risks due to the presence of constituents that are genotoxic and carcinogenic in botanicals and botanical products on the Indonesian market. The constituents of concern were alkenylbenzenes (ABs), pyrrolizidine alkaloids (PAs) and aristolochic acids (AAs). Their levels were determined in botanical preparations collected by a targeted sampling approach on the Indonesian market, followed by an exposure and risk assessment using the so-called Margin of Exposure (MOE) approach. In addition, a novel testing strategy for quantitative in vitro to in vivo extrapolation (QIVIVE) was applied to investigate if this novel testing strategy can help to fill data gaps in the currently available data base on the toxicity of PAs. The approach was used to predict acute liver toxicity in rats of the PA monocrotaline as the model compound. In addition, the same novel testing strategy was applied to provide a proof of principle to predict potential beneficial effects of botanical constituents in humans. To this end, the in vitro activity for activation of peroxisome proliferator receptor gamma (PPAR $\gamma$ ) mediated gene expression by the model carotenoids bixin and crocetin was translated to an in vivo dose response curve for PPAR $\gamma$ activation in humans. This allowed comparison of supplemental dose levels of bixin and crocetin to predicted dose levels for in vivo activity to evaluate whether these supplemental dose levels would be potentially active in vivo, activating PPAR $\gamma$ and potentially contributing to improvement of insulin sensitivity. Figure 7.1 summarizes the main findings of the thesis, which are discussed in some more detail in this chapter. 


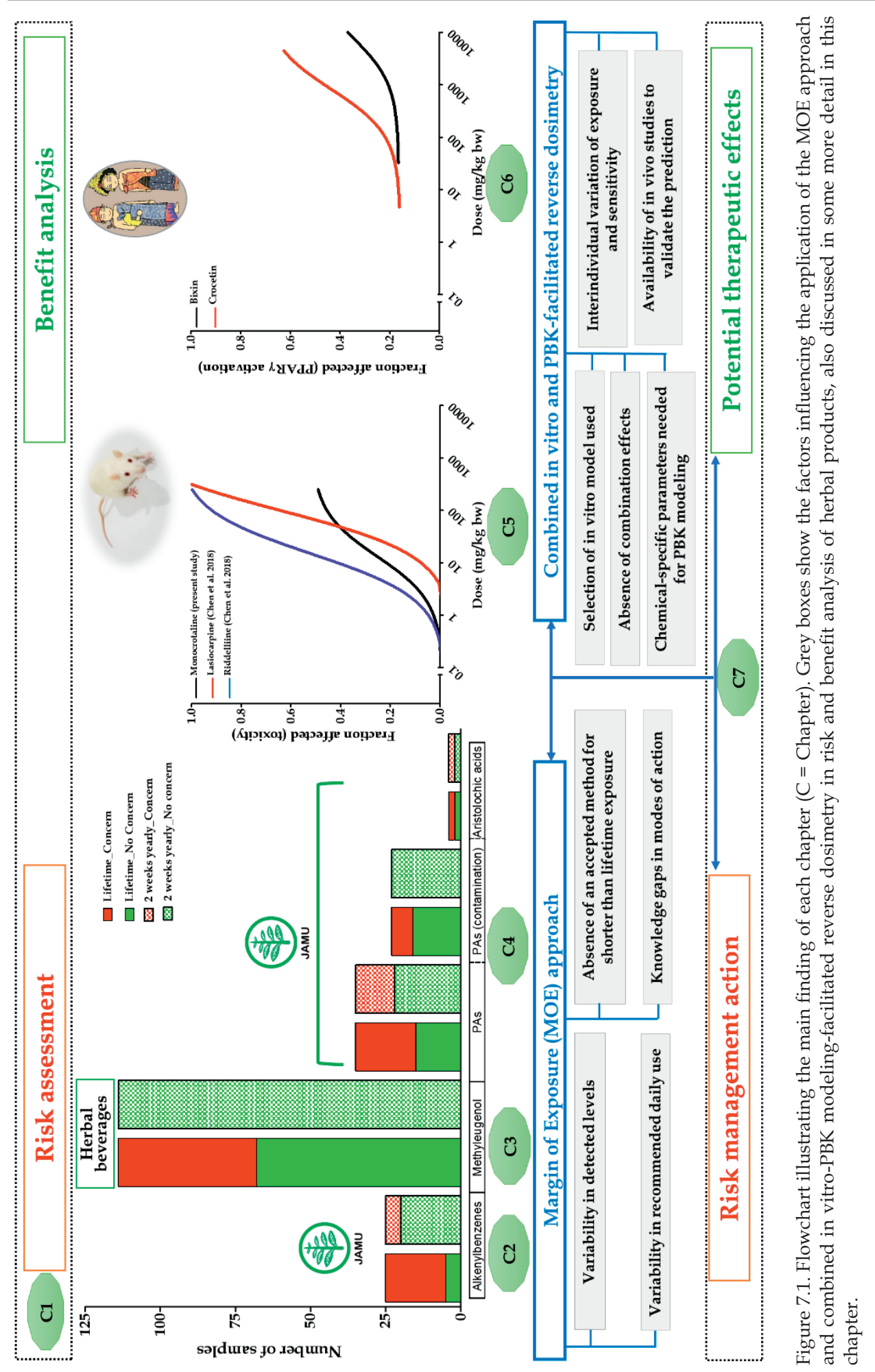


Chapter 1 presented an overview of the importance of the herbal market in Indonesia and the available regulatory framework. In addition, the methods for risk and benefit assessment of herbal products used in the thesis, including the alternative testing strategy applied, were presented in some more detail, and the selected compounds ABs, PAs including monocrotaline, AAs, bixin and crocetin were introduced. In Chapter 2, 3 and $\mathbf{4}$ series of botanical preparations collected by targeted sampling on the Indonesian market were analyzed for the presence of constituents of concern because they are genotoxic and carcinogenic. This enabled a risk assessment using the MOE approach. Overall, the MOE values obtained were generally $<10,000$, indicating a priority for risk management when assuming daily life-long consumption of AB-containing jamu (Chapter 2), methyleugenolcontaining herbal beverages (Chapter 3), and jamu containing PA-producing botanicals and non-PA-producing botanicals (Chapter 4). It was also considered that risk assessment using the MOE is generally based on the assumption that estimated exposures are relevant every day during a whole lifetime.

For use of botanicals and botanical preparations, which are rather expected to be used during shorter periods of illness, this shorter-than-lifetime exposure was also considered. Although a formally accepted method to take this shorter-thanlifetime-exposure into account is currently not available, some studies suggest using Haber's rule to correct in a linear way for the duration of exposure. Using Haber's rule, it was estimated that exposure to ABs, including methyleugenol, and to PAs, via the majority of products analyzed, would be of low concern when the herbal preparations would be consumed for less than 2 weeks per year during a lifetime, although some samples still raised a concern.

Furthermore, combining in vitro bioassays with physiologically based kinetic (PBK) modeling-facilitated reverse dosimetry was shown to enable quantitative prediction of the acute liver toxicity of monocrotaline in rats (Chapter 5), while the method was also able to estimate whether at realistic dietary intake the carotenoids bixin and crocetin could be expected to induce PPAR $\gamma$-mediated gene expression in humans (Chapter 6). Factors influencing the results presented in this thesis are discussed in this chapter (Chapter 7). The chapter also proposes some future perspectives related to the findings, indicating topics to consider in continued work in the field of risks and benefits of botanicals and botanical preparations.

In the risk assessment performed in Chapter 2, $\mathbf{3}$ and 4, MOE values were calculated by dividing relevant $\mathrm{BMDL}_{10}$ values (lower confidence limit of the benchmark dose resulting in a 10\% extra cancer incidence) by the estimated daily intakes (EDI) of the targeted compounds. The EDI values were based on experiments in which the levels of the ABs, PAs and AAs were quantified in jamu and herbal 
beverages obtained on the Indonesian market via targeted sampling. Using the results of these chemical analyses and the dose of the product recommended by the respective manufacturers, intake was estimated and compared with $\mathrm{BMDL}_{10}$ values to calculate MOE values. When studying the risk assessments using the MOE approach, there are many factors that may need further consideration in future studies. These aspects include: variability in detected levels of the targeted compounds, variability in recommended daily use mentioned on the label that can influence the risk assessment. Other bottlenecks to be considered to a further extent are absence of a generally accepted method to take shorter-than-lifetime exposure into account, and knowledge gaps in modes of action. When applying a QIVIVE approach for the risk and benefit analysis as done in the present study, selection of the in vitro model used, the absence of combination effects, the chemical-specific parameters needed for PBK modeling, interindividual variation of exposure and sensitivity among Indonesian people, and the availability of in vivo studies to validate the predictions are issues for further consideration and future research. In the following sections, these additional considerations are discussed in more detail.

\subsubsection{Variability in detected levels of the targeted compounds}

Variety in occurrence of the targeted compounds is one of the challenges in risk assessment of herbal products. The profile and level of detected compounds are known to vary widely in different types of herbal products (Chapter 2 and 3) and may vary even within the product brand. Table 7.1 shows that using the same sampling strategy and analytical procedure the profile of detected ABs showed substantial variation among four types of herbal products, including jamu (Chapter 2), herbal beverages (Chapter 3), herbal teas (unpublished results) and botanical food spices (unpublished results). None of the samples contained apiol, because parsley (Petroselinum crispum) and dill (Anethum graveolens), main apiol-producing plants ${ }^{[6,7]}$ were not used as botanicals materials in the Indonesian herbal products investigated. Methyleugenol appeared to be a major $A B$ detected in all the types of samples, while for this $\mathrm{AB}$ a maximum residue level has not been established in Indonesia. 
Table 7.1. Overview of $\mathrm{AB}$ occurrence in the different types of samples analyzed in the present thesis.

\begin{tabular}{|c|c|c|c|c|c|c|c|c|c|}
\hline \multirow[t]{2}{*}{$\begin{array}{l}\text { Type of } \\
\text { samples }\end{array}$} & \multirow[t]{2}{*}{$\mathrm{n}^{\mathrm{a}}$} & \multirow{2}{*}{$\begin{array}{c}\mathrm{n} \\
\text { positive } \\
(\%)^{\mathrm{b}}\end{array}$} & \multicolumn{7}{|c|}{$\begin{array}{c}\text { Number of samples containing each individual } \mathrm{AB} \text { (\% of positive } \\
\text { samples containing the compound) }\end{array}$} \\
\hline & & & $\begin{array}{l}\text { Methyl- } \\
\text { eugenol }\end{array}$ & Myristicin & Safrole & Estragole & Elimicin & Apiol & Eugenol \\
\hline Jamu & 25 & $23(92)$ & $21(91.2)$ & $13(56.5)$ & $4(17.4)$ & $2(8.7)$ & $-c$ & - & - \\
\hline Herbal & 11 & 49 (43) & 49 (100) & - & - & - & - & - & $4(3.5)^{d}$ \\
\hline beverages & 4 & & & & & & & & \\
\hline Herbal teas & 9 & $8(88.9)^{e}$ & 7 (87.5) & $6(75)$ & - & - & 1 (11.1) & - & - \\
\hline $\begin{array}{l}\text { Botanical } \\
\text { food spices }\end{array}$ & 25 & $24(96)$ & $10(41.7)$ & $7(29.2)$ & $16(66.7)$ & 8 (33.3) & $1(4.2)$ & - & - \\
\hline
\end{tabular}

a Number of samples analyzed

b Number of samples that were found to contain ABs (level > LOD) out of the total number of samples detected

c Not detected

d Additional $\mathrm{AB}$ detected in the samples (\% out of the total sample analyzed): eugenol is not a genotoxic and carcinogenic $\mathrm{AB}$.

e ABs for these samples were detected in methanol extracts

This variety of occurrence for ABs but also for PAs and AAs (Chapter 4), relates to the raw materials, sample preparation, extraction and analytical methods applied to prepare the botanical preparations. Crews et al. (2010) reported that extracting, separating, identifying, and measuring a wide variety of PAs in very different matrices including plants, seeds, honey, pollen, body fluids, and insects is challenging for the analyst. ${ }^{[8]}$ The variability of the $\mathrm{AB}, \mathrm{PA}$ and AA levels may be due to differences in extraction efficiency ${ }^{[9-11]}$, but also to ecological factors[12, 13], harvesting time, harvesting techniques, storage circumstances, processing technologies, and measurement methods ${ }^{[14-16]}$. Therefore, a standardized production procedure is essential to minimalize the variability in the levels of these important toxins in food and botanicals samples $[8,17]$, while better characterisation of batch to batch variability will also be of use for adequate future risk assessment and risk management.

Furthermore, the sample strategy chosen and thus how well the sample analysed represents the whole batch, plays an important role in the reliability of any conclusions drawn from the sample analysis. In the present thesis (Chapter 2-4) samples were collected in retail packages, ten consumer packages were selected from the same batch, then pooled by mixing the contents before analysis as recommended by WHO[17]. In addition, storage of the samples collected should be optimized to prevent the degradation of targeted compounds to ascertain that storage will not have a significant influence on the compound profiles.[18, 19]

The variability in composition of botanical materials affects the variability of detected levels of the compounds of interest. AB-producing botanicals appeared to be present in many herbal products sold by the sellers in the sampling locations. 
Ginger (Zingiber officinale Rosc) rhizome, fennel (Foeniculum vulgarei Mill.) fruit, and cinnamon (Cinnamomum burmannii Blume) bark, lemongrass (Cymbopogon nardus L. Rendle) leaf, betel (Piper betle L.) leaf, nutmeg (Myristica fragrans Houtt.) seed, clove (Syzygium aromaticum (L.) flower, basil (Ocimum basilicum) leaves, all well-known AB-producing botanicals[20-22], were present in many of the collected samples. For example, ginger, fennel, and cinnamon were found in respectively 26, 23 and 22 of the 55 jamu samples (registered as BPOM RI-TR) analysed in Chapter 2 and 3. According to the label, the content of these AB-producing botanicals contributed around 0.1 to $90 \%$ to the weight of the sample. In contrast, occurrence of PA- and AA-producing botanicals appeared to be less common in jamu, in part because the use of (some) PA- and AA-producing botanicals has been restricted in Indonesia. For example comfrey (Symphytum officinale) as a PA-containing botanical has been listed as a banned ingredient in Indonesian traditional medicines based on regulation BPOM RI No 7:2018.[23] In Chapter 3 comfrey was only found in 2 out of 35 jamu samples containing other PA-producing botanicals, including Lithospermum orientale, Gynura pseudochina, Gynura sp., Gynura procumbens, Gynura segetum and Adenostemma lavenia. Botanical Aristolochia spp, Stephania tetrandra S.Moore, Magnolia officinalis Rehder \& E.H.Wilson, and their preparations, have been banned as ingredients in traditional medicines in Indonesia based on Regulation BPOM RI No. 7, 2018.[23] Only 1 out of 15 jamu collected in the targeted approach for AA containing plants appeared to contain Aristolochia spp. The other 14 samples targeted for AA containing plants contained Saussurea lappa, Clematis chinensis, Stephania tetrandra, Asarum sieboldii, and Aucklandii lappa as AA-producing botanicals. ${ }^{[24]}$

In case of PA occurrence due to the contamination of jamu samples by PAproducing botanicals (Chapter 4), Schulz et al. (2015) ${ }^{[25]}$ reported that properties of the contaminating botanicals or of part of the botanicals in the samples caused the variation in the PA content within different samples of the same batch. To reduce the impact of unhomogenized composition during sample analysis, it might be useful to reduce the sample size, but increase the number of samples from a specific batch while keeping the same sample/extraction volume ratio. One could even consider use of statistical approaches to define optimal sampling strategies, as is current practice when for example sampling mycotoxins. ${ }^{[26,27]}$

\subsubsection{Variability in recommended daily use mentioned on the label}

The potential exposure to carcinogenic genotoxic compounds resulting from consuming the herbal products analysed in the present thesis (Chapter 2-4) was estimated using the direction for their use as indicated on the labels. For some products the recommended daily use is clearly indicated on the label, but for others 
there appeared to be no information on recommended use on the label. Based on Regulation BPOM RI No 31: 2018, the label of food should indicate product name, ingredients, net weight, name and address of producer/importer, halal information if relevant, date and production code, information on expiring date, marketing authorization number and source of certain ingredients.[28] The regulation does not prescribe the presence on the label of information on directions for use and use levels.

Based on the information available on the labels of the samples analysed in the present thesis, the recommended daily consumption appeared to vary substantially among the types of herbal products, and this obviously influenced the risk assessment (Table 7.2). Jamu, registered as BPOM RI TR, appeared to show a high variability of the weight of recommended daily use (0.5 - $200 \mathrm{~g})$, with especially the high use levels resulting in a high number of samples (23.6\% out of 246 samples) raising a health concern and indicating a priority for risk management action. The recommended daily intake also varied among herbal beverages produced by household industry (Depkes RI P-IRT) with also high use level preparations showing the highest number of samples which raise concern for human health. In contrast, the products registered as domestic processed food (BPOM RI MD) indicated the lowest variability in the range of recommended daily uses (1 - $30 \mathrm{~g})$. The high variability of use and use level recommendations for the consumers on the labels of jamu and their variable quality in terms of absence of constituents of concern, may relate to the large number of jamu producers and to what extent each of them complies with the regulation on jamu production. Clearly harmonisation of use levels and quality control provide important issues for future risk management actions.

Table 7.2. Overview of recommended daily intake in the different types of samples analyzed in the present thesis and the percentage raising health concerns upon use over a lifetime.

\begin{tabular}{|c|c|c|c|c|c|}
\hline \multirow{2}{*}{$\begin{array}{l}\text { Registration } \\
\text { code } \\
\text { marketing } \\
\text { authorization }\end{array}$} & \multirow[t]{2}{*}{ Type of product } & \multirow{2}{*}{$\begin{array}{l}\text { Total } \\
\text { samples } \\
\text { analysed }\end{array}$} & \multicolumn{2}{|c|}{$\begin{array}{l}\text { Recommended } \\
\text { intake }(\mathrm{g})\end{array}$} & \multirow{2}{*}{$\begin{array}{l}\text { Total } \\
\text { samples } \\
\text { which } \\
\text { raise } \\
\text { concern } \\
(\%)^{\mathrm{a}}\end{array}$} \\
\hline & & & Range & $\begin{array}{l}\text { Average } \pm \\
\text { SD }\end{array}$ & \\
\hline BPOM RI TR & Traditional medicine & 131 & $0.15-200.0$ & $12.2 \pm 19.3$ & $58(23.6)$ \\
\hline BPOM RI MD & Domestic Processed Food & 54 & $1.0-30.0$ & $12.2 \pm 10.1$ & $20(8.1)$ \\
\hline BPOM RI SD & Domestic supplement & 9 & $4.0-21.0$ & $12.2 \pm 6.0$ & $0(0.0)$ \\
\hline BPOM RI ML & Foreign Processed Food & 1 & 18.0 & - & $1(0.4)$ \\
\hline Depkes RI P-IRT & Food Household Industry & 51 & $1.0-75.0$ & $18.8 \pm 12.3$ & $33(24.6)$ \\
\hline Total & & 246 & & & 112 \\
\hline
\end{tabular}

a Percentage of total samples analysed 


\subsubsection{Absence of a generally accepted method to take shorter-than-lifetime exposure into account}

The fact that the duration of herbal product consumption is unlikely to extend over a whole lifetime as assumed in the MOE approach for risk assessment is another factor that needs future attention. People tend to consume these preparations during periods of illness, and therefore in this thesis the MOE approach was combined with Haber's rule to take shorter-than-lifetime, i.e. more realistic, exposure scenarios into account. This approach was previously proposed by Felter et al. (2011) ${ }^{[29]}$ as a framework for assessing the risk from shorter-than-lifetime exposures to potential human carcinogens. The application of Haber's rule, however, is not a generally accepted approach when using the MOE for risk assessment of exposure to genotoxic carcinogens. Under this rule, the toxic outcome is assumed to be similar for situations where the product of the exposure time and the dose will be constant, $(\mathrm{k}=\mathrm{C} \times \mathrm{T} ; \mathrm{C} 1 \times \mathrm{T} 1=\mathrm{C} 2 \times \mathrm{T} 2$, where $\mathrm{k}$ is the toxic outcome, $\mathrm{C}$ is the concentration (or dose) of the toxic chemical and $\mathrm{T}$ is the time of exposure). This implies a linear relationship between the response and the dose as well as the exposure time.[29]

The question of whether the rule also holds for nonlinear dose-response relationships has been debated by various authors. [30] The use of Haber's rule in risk assessment should be critically evaluated when the response is nonlinear, considering the mode of action (MOA) and toxicokinetics/toxicodynamics of the compound(s) of interest. Several approaches could be considered for use of Haber's rule for nonlinear responses, ${ }^{[29]}$, including its use with the application of a dose-rate correction factor (DRCF) [31], and/or assigning "default" adjustment factors. ${ }^{[32]}$

Felter et al. (2011) ${ }^{[29]}$ indicated that use of Haber's rule assumes that chemicalspecific carcinogenicity data are available, and that the data support a linear doseresponse relationship. To what extent such a linearity relationship holds for the induction of liver tumors by ABs, PAs, and AAs remains to be established and may depend on the MOA underlying the carcinogenicity. It is important to note that at the present state-of-the-art evidence supporting such linear behaviour of the adverse effects of ABs consists of PBK-based studies showing dose dependent linearity in the bioactivation to the ultimate carcinogenic 1 '-sulfoxymetabolites and in DNA adduct formation, increasing in a linear way from realistic dietary exposure levels up to dose levels causing significant tumor formation. ${ }^{[33-36]}$ However, the linearity of the subsequent mutagenic and carcinogenic effects of the $1^{\prime}$-sulfoxy AB DNA adducts, has not been quantified so far. For AAs and PAs such information is also presently not available. Thus, it can be concluded that providing such information on dose-dependent linearity of the adverse response, and definition of a generally accepted approach to deal with shorter than lifetime exposure in risk assessment of 
genotoxic and carcinogenic botanical constituents is an important topic for the future risk assessment of botanicals and botanical preparations.

\subsubsection{Knowledge gaps in the mode of action (MOA)}

Other challenges remaining in the risk assessment of AB-, PA- and AAcontaining botanicals and botanical preparations relate to the MOA underlying the carcinogenic and genotoxic effects. For ABs, for example, knowledge on the level of DNA adduct formation required to raise risks on tumor formation in humans above background levels remains to be elucidated. The 1'-sulfoxymetabolite and the subsequently formed DNA adducts play an important role in the AB-induced carcinogenicity, and knowledge on the levels of DNA adduct formation in human livers at relevant dietary intake levels would be of use to facilitate human risk assessment. This is especially of interest because previously, DNA adduct formation induced by dietary intake of methyleugenol was detected in 29 out of 30 human liver samples at levels that amounted for the maximal and median levels to 37 and 13 adducts per $10^{8}$ nucleosides respectively. ${ }^{[37]}$ Given the use of jamu containing the AB methyleugenol, it would be of interest to study whether such DNA adducts can also be detected in Indonesian human liver samples, and to develop methods that would allow estimation of the corresponding risks, in order to evaluate whether these risks would substantially increase background tumor incidences.

Such a method enabling estimation of the risks resulting from DNA adduct formation in human liver upon realistic daily exposure to ABs could be based on combining PBK models predicting dose dependent DNA adduct formation in the liver with data on DNA adduct formation at dose levels causing liver tumors in experimental animals. In this approach the PBK models will facilitate rat to human and high to low dose extrapolations. In addition, further studies on repair of DNA adducts resulting from $\mathrm{AB}, \mathrm{PA}$ and $\mathrm{AA}$ exposure might help to clarify the risks of consumption of botanicals and botanical preparations containing these constituents at realistic low dose levels. Primary hepatocytes could likely be used to study possible repair and stability of the DNA adducts and would thus provide insight in whether formation of adducts, even during a short period, could have irreversible effects and thus be deleterious, or whether they are likely to be efficiently repaired, thereby decreasing the risk. For PAs, DNA adduct formation can be considered a surrogate measure of the reactive pyrrolic ester intermediate that forms intracellularly.[38] DNA adducts, DHP-dG-3, DHP-dG-4, DHP-dA-3, and DHP-dA4 , are a common biological biomarker of PA-induced liver tumor formation [39, 40], so to better link their formation to a MOA based risk assessment for PA exposure seems an important topic for future research. 


\subsubsection{Selection of the in vitro model used for QIVIVE}

The quality of in the vitro studies used to define the concentration response curves that from the basis of the PBK model based QIVIVE, also need some further consideration. The in vitro assay, end points and readout parameters selected should cover the relevant MOAs of targeted compounds and are crucial for reliable predictions of the in vivo situation made by PBK-modeling facilitated reverse dosimetry.

For the analysis of beneficial effects of bixin and crocetin in PPAR $\gamma$ activation (Chapter 6), the PPAR- 22 CALUX cells appeared to provide an adequate in vitro cell model to quantify PPARY-mediated gene expression. Gijsbers et al. (2011) ${ }^{[41]}$ demonstrated that the PPAR 1 CALUX and PPAR 2 CALUX cells, U2OS cells transfected by an expression vector for PPAR 1 or PPARY2 and a pGL3-3xPPREtata-luc or pGL4-3xPPRE-tata-luc reporter, provide in vitro tools to test (mixtures of) chemicals, endogenous ligands, and (food) compounds for their ability to activate PPAR 1 1-mediated and PPAR $\gamma 2$-mediated gene expression. These cell lines express the complete human PPARY receptor, ${ }^{[41]}$ potentially allowing more faithful translation to effects in humans than the systems based on a chimeric PPAR $\gamma-G A L 4$ receptor ${ }^{[42,43]}$.

When studying the liver toxicity of PAs, as done in the present thesis, maintaining metabolic activity within the cell model used determines the quality of the in vitro studies. Lauschke et al. (2016) ${ }^{[44]}$ reported that ideally, in vitro systems for studies on drug metabolism and toxicity, should accurately correspond to the phenotypes observed in vivo, including the expression of P450 and phase II enzymes, transporters, and nuclear receptors. Furthermore, viability, functionality, and phenotypes of cells should be stable for multiple weeks in culture to allow repeated dose toxicity studies. Primary hepatocytes in suspension or in monolayer culture are currently considered the most appropriate model for the evaluation of integrated drug metabolism, toxicity/metabolism correlations, mechanisms of hepatotoxicity, and the interactions (inhibition and induction) of xenobiotics with drug-metabolising enzymes.[45, 46] However, at the present state-of-the-art stability of this in vitro model is somewhat limited, hardly enabling studies beyond 24-72 hours duration.

Monolayer cultures of primary hepatocytes have been the gold standard for in vitro hepatotoxicity testing for acute effects. ${ }^{[47]}$ In Chapter 5, the cryopreserved monolayer culture of primary rat hepatocytes was used to assess monocrotalineinduced acute liver toxicity. Although the cryopreservation was reported to slightly reduce cell viability compared to fresh isolated hepatocytes, ${ }^{[48,49]}$ the cell viability used in the present study was more than $90 \%$ after thawing. This indicates that 
cryopreserved primary rat hepatocytes can be used as an adequate cell model to quantify in vitro liver toxicity of PAs.

Chapter 6 used pooled human cryopreserved hepatocytes (HEP10) in suspension to define the kinetic parameters for clearance in the PBK models for bixin and crocetin. The use of this cell model for clearance studies is supported by results reported by Griffin and Houston (2005)[50] showing that hepatocyte monolayer cultures offer the potential for extending measurements for predicting in vivo clearance to the lower end of the clearance range (below $0.1 \mu \mathrm{mol} / \mathrm{min} / 10^{6}$ cells). An important limitation of these primary cell models is the donor-to-donor variability in terms of the activity of phase I (CYP) and phase II (UGT and SULT) enzymes. To prevent the donor-to-donor variability, human induced-pluripotent stem cells (iPSCs) may provide a limitless supply of hepatocytes for highthroughput screening with minor batch-to-batch variability.[45]

Thus, selection of the appropriate cell model is essential to ascertain that the in vitro data reflect the relevant kinetics and toxicity. To further illustrate this argument, as an example, Figure 7.2 shows the in vitro concentration-response data for monocrotaline-induced toxicity in rat hepatocytes, HepG2 cells, and HepaRG cells, indicating that the rat hepatocytes are more sensitive to the toxicity induced by monocrotaline. This indicates that when biotransformation is an essential condition for toxicity, it is important to select an in vitro system that is metabolically competent. The fact that monocrotaline does not induce toxicity towards HepG2 and HepaRG cells reflects that the expression level of the relevant CYPs in HepaRG cells is generally lower than that in rat or human primary hepatocytes.[51] Finding ways to extend this model to a model that allows repeated dose toxicity studies would be of use to obtain insight in repeated dose toxicity and facilitate prediction of also chronic liver toxicity of PAs by the novel in vitro-PBK model based testing strategy. Currently, sandwich-cultured hepatocytes $(\mathrm{SCH})$ may provide an interesting model to achieve this goal, since they are recognized as a powerful in vitro tool that can be utilized to study drug-drug interactions at the transport level, hepatotoxicity and drug-induced liver injury (DILI) for longer exposure time.[52, 53] 


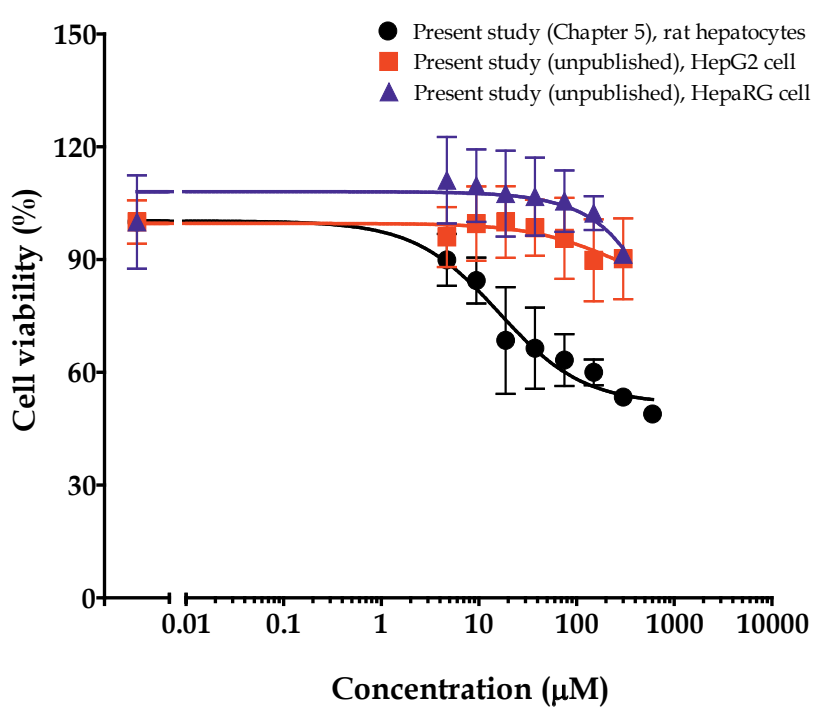

Figure 7.2. Concentration-response curves for effects of monocrotaline on cell viability of primary rat hepatocytes (black), HepG2 cells (red) and HepaRG cells (blue) exposed for $24 \mathrm{~h}$ (means \pm SE).

\subsubsection{Absence of combination effects}

It should also be pointed out that the toxicity of monocrotaline (Chapter 5) has been mainly studied in this thesis using the parent compound monocrotaline in isolation. In the risk assessment (Chapter 4) combined exposure to PAs has been taken into account assuming similar potency of all PAs detected. In the real scenario, consuming a herbal product may result in simultaneous exposure to more than one PA give the occurrence of PAs in the botanical preparations, while these PAs may have different potency. In addition, some herbal products appeared to contain more than one class of genotoxic and carcinogenic ingredients, so to contain ABs and/or AAs in addition to PAs. Synergistic and antagonistic actions of the various ingredients in herbal product may fortify or weaken the toxicity of individual constituents when taken in the form of a herbal preparation. Chou and $\mathrm{Fu}(2006)^{[40]}$ reported that toxic DNA adducts were not only detected in the liver DNA of rats treated with riddelliine but also following the administration of PA containing comfrey root extract, coltsfoot root extract, flos farfara extract, coltsfoot tussilage, and comfrey compound oil. An additive effect was demonstrated by $\mathrm{Li}$ et al. (2013) ${ }^{[54]}$ for senecionine and seneciphylline in which the extract of Gynura segetum, a senecionine and seneciphylline-containing herb, exhibited cytotoxicity to HepG2 cells compared to the toxicity caused by the sum of these two PAs tested individually. Taking into consideration the profiles of PAs detected in samples of jamu in the present thesis (Chapter 4) in which samples contained from 2 up to 40 
types of PAs, in vitro assays testing the potential combination toxicity of the PAs present in the herbal preparations in primary rat/human hepatocytes seems of interest for future studies. Also, the definition of relative potency (REP) factors to take different potency of the different PAs into account in the risk assessment appears to be an important topic for further research. ${ }^{[55,56]}$

Merz and Schrenk (2016) ${ }^{[56]}$ defined interim REP factors for the relative potency of 1,2-unsaturated PAs based on the available data on the genotoxic potency in Drosophila melanogaster, the cytotoxic potency in vitro in chicken hepatocellular carcinoma (CLR-2118) cells and their acute toxicity in adult rodents $\left(\mathrm{LD}_{50}\right)$. EFSA however indicated that the REP factors for PAs should be further refined before taking them into account in risk assessment. ${ }^{[55]}$ It is of importance to note that due to the limitation of carcinogenicity data for PAs, the interim REP values did not (yet) take the relative potency of PAs for tumor formation into account.

In the present thesis REP factors were used in Chapter 3 to estimate the combined exposure of different ABs in the same sample using a toxic equivalency (TEQ) approach in which methyleugenol was used as the reference compound (REP value $=1.00$ ). Comparison of the outcomes obtained taking these REP factors into account to those obtained assuming equal potency of the ABs, did not substantially influence the outcomes, mainly because methyleugenol was the major $\mathrm{AB}$ detected and the REP values for the other ABs were not substantially different from that for methyleugenol. As discussed in Chapter 4, incorporating the REP in the evaluation of jamu will refine the risk assessment of these traditional medicines.

Human dietary exposure to ABs, PAs and AAs occurs in a complex of other herbal ingredients, where, interactions in a complex food matrix can occur that can affect the bioavailability and toxicity of these compounds. ${ }^{[4,57]}$ In case of for example estragole, Jeurissen et al. (2007) ${ }^{58]}$ reported that bioactivation and subsequent adverse effects of estragole might be lower in a matrix of other basil ingredients than what would be expected on the basis of experiments using estragole as a single compound. Furthermore, co-exposure to estragole and (mixtures of) different basil derived flavonoids, especially nevadensin, resulted in substantial inhibition of the SULT-mediated bioactivation of estragole and subsequent DNA adduct formation in liver cells both in vitro and in vivo. ${ }^{[59,60]}$ Such matrix effects should be taken into account in the risk and safety assessment of botanicals and botanical preparations on a case-by-case basis also considering the underlying mode of action.

\subsubsection{Chemical-specific parameters needed for PBK modeling}

The MOE approach needs carcinogenicity data to define the $\mathrm{BMDL}_{10}$. However, not for all ABs, PAs, and AAs tumor data that would enable the definition 
of a $\mathrm{BMDL}_{10}$ for risk assessment are available. Therefore, novel strategies including PBK model based QIVIVE and read across could be applied to obtain the BMDL 10 of compounds of interest. Such an approach has already been applied to predict the $\mathrm{BMDL}_{10}$ for tumor formation forelemicin by PBK model based read across from estragole and methyleugenol[61], or the $\mathrm{BMDL}_{10}$ for tumor formation by myristicin and apiol via PBK model based read across from safrole ${ }^{[62,63]}$. The approach could also be applied for read across from lasiocarpine and riddelliine to other PAs. ${ }^{[64,65]}$ Since many $\mathrm{BMDL}_{10}$ values needed for risk assessment of botanical ingredients that are genotoxic and carcinogenic are unavailable, this QIVIVE approach seems a promising strategy for the future.

Given this conclusion it is also of interest to note that the development of PBK modeling based applications are time and effort consuming, because PBK models need chemical-specific parameters describing the absorption, distribution, metabolism and excretion (ADME) processes.[66] This indicates a need for further development of generic PBK models that can be based on parameters obtained by in silico and efficient in vitro methodologies. An efficient PBK modeling based read across would enable selection of the chemicals that could be prioritized for further risk assessment and/or in vivo testing facilitating an efficient and time-and-costsaving risk assessment of genotoxic carcinogens for which rodent tumor data are not available.[67] The use of in silico modeling, such as quantitative structure activity relationship (QSAR) modeling should be considered for the prediction of model parameter values as was done also for several of the parameters required for the PBK models of the present thesis (Chapter $\mathbf{5}$ and $\mathbf{6}$ ) in which tissue:blood partition coefficients were predicted by the LogP value of the chemical.[68, 69] However, the potential of in silico modeling for estimating values for kinetic model parameters remains to be further developed and evaluated.

Another aspect that needs to be incorporated in future PBK models is the effect of repeated dosing on the in vivo kinetic characteristics. In Chapters $\mathbf{5}$ and $\mathbf{6}$, the prediction was made for single oral exposure, while in real situations rats/humans are exposed to chemicals repeatedly. The repeated exposure may influence expression levels of metabolizing enzymes. This should be incorporated in the PBK models used, preferably based on adequate in vitro models that must be further optimized and validated to make them suitable for making quantitative predictions on enzyme induction in the in vivo situation.

\subsubsection{Interindividual variation of exposure and sensitivity}

The intensity, frequency, route and duration of herbal product consumption varies among Indonesian population. For example, Kemenkes-RI (2010) reported 
that $59.12 \%$ of the total Indonesian population above 15 years of age consume jamu as traditional medicines, with the frequency of consumption being every day $(4.36 \%$ ), seldom (once a week/month, $45.03 \%$ ), and never $(9.73 \%) .[70]$ This consumption behavior may cause interindividual variation in the exposure to the $\mathrm{ABs}, \mathrm{PAs}$, and AAs via drinking the preparations. However, the risk and benefit analysis via consumption of herbal products was estimated in the present thesis for the average Indonesian population, without taking interindividual differences into account. In Chapter 2, 3, 4 the exposure was assessed by an approach using the detected levels of $\mathrm{ABs} / \mathrm{PAs} / \mathrm{AAs}$ in the samples and recommended daily intake mentioned on the label. For the future it may be of interest to consider the use of biomonitoring strategies, enabling personal monitoring, ${ }^{[71,72]}$ since these strategies are expected to provide a more reliable insight into actual levels of exposure and will enable to take intraindividual aspects of variability in types and dose of toxic compounds consumed into account in the exposure and risk characterization.

Slob (2006) ${ }^{[73]}$ reported that probabilistic dietary exposure assessments based on Monte Carlo sampling may facilitate this analysis of the interindividual variation in exposure. In addition, exposure from different consumer products can be considered simultaneously in assessing the exposure. In addition, a risk assessment may take into account interindividual differences in sensitivity by defining compound specific adjustment factors instead of default uncertainty factors as discussed later in this chapter (Section 7.2.6.).

\subsubsection{Availability of in vivo studies to validate the prediction}

An important aspect of novel QIVIVE approaches is the fact that in vivo data are still needed to evaluate the PBK model predictions on both kinetics and toxicity. Comparing model predictions with experimental data, such as area under the curve (AUC), peak plasma concentration $\left(\mathrm{C}_{\max }\right)$, time to peak concentration $\left(\mathrm{t}_{\max }\right)$, and plasma half-life is often used to evaluate the PBK models. Setting deviation thresholds of 0.5 to 2-fold, is often used to examine the performance of the model. Sensitivity analysis can be used to evaluate the impact of variations in model parameters on model outputs. ${ }^{[4]}$ Ideally, the in vivo data used in an evaluation step should be representing the same situation as what has been targeted, including type of compound, administration route and species. However, due to the limitation in the amount, nature or even quality of reported in vivo data, the evaluation and validation of the predictions may sometimes be difficult, as discussed in Chapter 5 and 6.

Defining PBK models taking insights in the MOA into account will increase the model's capability to predict and extrapolate to the in vivo situation. To enhance 
the acceptance of PBK models at an international level, currently a good modelingpractice (GMP) is established to guide the use of the in vitro and in silico methodologies in developing PBK models without the need of in vivo data. In the GMP, assuming there is no possibility of generating in vivo animal data for the model calibration, the model can be built when there are: (1) in vitro and in silico alternatives available to generate ADME parameters (including prediction of metabolism) of sufficient quality and (2) modeling platforms available and accessible. ${ }^{[75]}$ The available in vitro and in silico methods can be obtained from in silico metabolic simulation tools for microbial and human metabolism ${ }^{[76]}$ taking into account the guideline to choose QSAR models for ADME endpoints.[77] Several modelingplatforms, such as PK-Sim (www.systems-biology.com), GastroPlus (www.simulations-plus.com) and SimCyp (https://www.certara.com) are available and accessible to generate GMP. ${ }^{[75]}$ Use of these available commercial platforms may prove a way forward that will facilitate use and acceptance of PBK model-based strategies by larger groups of scientists including regulators and risk managers.

\subsection{Future perspectives}

A collaboration between farmers, health professionals (physicians, pharmacists and nurses), consumers, academia, industry, and government is needed to promote the safety of Indonesian herbal products. Figure 7.3 shows the summary of alternative solution for factors which currently hamper the risk and benefit analysis discussed above, followed by some action plans for risk management action including all stakeholders involved.

Based on this scheme seven future actions are proposed in order to further improve safety and efficacy of herbal preparations on the Indonesian market. These actions include, (1) improvement of the quality of botanicals by applying Good Agricultural and Collection Practices (GACP) for the farmers, (2) increasing the safety of herbal products by applying good manufacturing practice (GMP) of herbal product and food safety training for the manufacturers/producers, (3) development of a toxicity database of medicinal botanicals used in Indonesia, (4) restriction of the exposure to genotoxic carcinogenic compounds by establishing MPLs and refining the label requirements for botanicals and botanical preparations, (5) use of human biomonitoring (HBM) and PBK modeling for a more refined exposure and risk and benefit analysis of Indonesian herbal products, (6) incorporation of Chemical Specific Adjustment Factors (CSAFs) for interspecies and interindividual variation in kinetics within the human population, and finally (7) exploring the beneficial effects of botanicals and botanical preparations. 


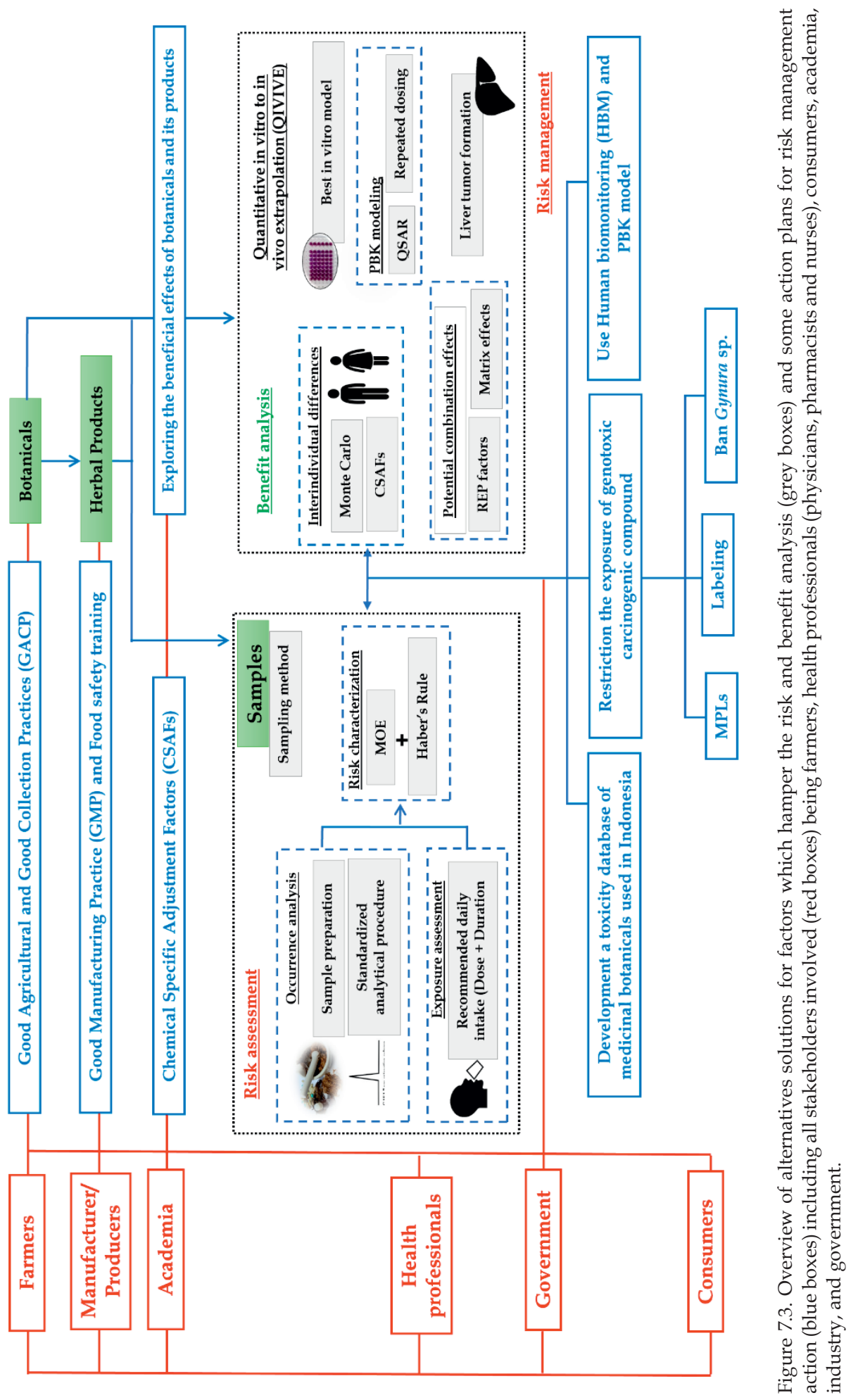




\subsubsection{Improvement of the quality of botanicals by applying Good Agricultural and Collection Practices (GACP) for the farmers}

Farmers have an important role as a supplier for the botanical materials of herbal products. The contamination of jamu products made from non-PA producing plants by especially PA-producing botanicals presents an issue raising concern for these products (Chapter 4). The contamination may occur during the cultivation, or the harvesting of the jamu materials, resulting in compounds of concern ending up in intermediate or finished products. Many PA-producing botanicals like daun dewa (Gynura segetum) are weeds that may accidentally contaminate medicinal botanicals. For this reason, applying Good Agricultural and Collection Practices (GACP) ${ }^{[78] \text {, }}$ may help to reduce potential PA contamination in jamu. In addition the quality of botanicals that are selected for herbal products can be controlled by an appropriate procedure in plant identification (plant part) and adequate control of factors influencing the presence of constituents of concern during plant production, harvesting and post-harvesting procedures. ${ }^{[79]}$ It may also be reconsidered whether it is prudent to use PA-containing botanicals in herbal products at the levels currently in use.

\subsubsection{Increase the safety of herbal products by applying Good Manufacturing Practice (GMP) of herbal product and food safety training for the manufacturers/producers}

Table 7.3 shows the number of samples which appeared of concern for human health pointing at a need for risk management actions and reveals that this number varied among the registration code for their market. Herbal products registered as domestic processed food (BPOM RI MD) presented only $8 \%$ of samples of concern because of the presence of genotoxic and carcinogenic constituents. This relatively lower number of samples raising a concern may be related to the fact that the herbal products marketed as domestic processed food have to meet the requirements of Good Manufacturing Practice (GMP) and are considered to be of higher quality than herbal products marketed as jamu. This result of the present thesis indicates that risk management actions for Indonesian herbal products may be prioritized for jamu, one of the traditional medicines used by Indonesians. This priority is of interest considering the high number of jamu consumers and the fact that ABs, PAs and AAs were detected in the products (Chapter 2-4). 
Table 7.3. Overview of the risk characterization using the MOE approach for the different Indonesian herbal products.

\begin{tabular}{|c|c|c|c|c|}
\hline \multirow[t]{2}{*}{ Registration code per chapter in this thesis } & \multirow[t]{2}{*}{ Targeted compound } & \multirow[t]{2}{*}{$\begin{array}{l}\text { Total } \\
\text { samples }\end{array}$} & \multicolumn{2}{|c|}{$\begin{array}{l}\text { Concern for risk } \\
\text { management }\end{array}$} \\
\hline & & & Yes & No \\
\hline Chapter 2 (Jamu) & Alkenylbenzenes & & & \\
\hline BPOM RI TR & & 25 & 20 & 5 \\
\hline Chapter 3 (Herbal beverages) & Methyleugenol & & & \\
\hline Depkes RI P-IRT & & 43 & 31 & 12 \\
\hline BPOM RI MD & & 31 & 7 & 24 \\
\hline BPOM RI TR & & 30 & 7 & 23 \\
\hline BPOM RI SD & & 9 & 0 & 9 \\
\hline BPOM RI ML & & 1 & 1 & 0 \\
\hline Chapter 4 (Jamu) & Pyrrolizidine alkaloids & & & \\
\hline BPOM RI TR & & 35 & 20 & 15 \\
\hline BPOM RI TR & & $23^{a}$ & 7 & 16 \\
\hline Unpublished result (Jamu) & & & & \\
\hline BPOM RI TR & Aristolochic acid & 15 & 2 & 13 \\
\hline Unpublished result (Botanical food spices) & Alkenylbenzenes & & & \\
\hline Depkes RI P-IRT & & 5 & 2 & 3 \\
\hline BPOM RI MD & & 20 & 13 & 7 \\
\hline Unpublished result (Herbal teas) ${ }^{b}$ & Alkenylbenzenes & & & \\
\hline Depkes RI P-IRT & & 3 & 0 & 3 \\
\hline BPOM RI MD & & 3 & 0 & 3 \\
\hline BPOM RI TR & & 3 & 2 & 1 \\
\hline
\end{tabular}

a Samples containing non-PA-producing botanicals to assess the contamination of PAs

${ }^{\mathrm{b}}$ MOE values based on the level of ABs extracted using hot water and 1 cup of tea a day

Based on regulation BPOM (246/MENKES/Per/V/90 and HK.00.05.41.1384, 2005), the production and distribution of traditional medicines should comply with the GMP of traditional medicines (Cara Pembuatan Obat Tradisional yang Baik = СРОТВ). Until now, in Indonesia there are 1,247 herbal medicine manufacturers consisting of 129 traditional medicine industries (industri obat tradisional = IOT), with the remaining ones consisting of middle (Usaha Menengah Obat Tradisional=UMOT) and small business enterprises of traditional medicines (Usaha Kecil Obat Tradisional = UKOT). However, until 2018 only 111 facilities for the production of traditional medicines received the certificate of $\mathrm{CPOTB}^{[80]}$, indicating that the risks of consumption of the respective herbal products produced may not be adequately evaluated and/or regulated or guaranteed.

Providing a training or workshops on food safety and registration procedures for producers of herbal products can be a first step in overcoming the limitations of producer awareness and knowledge. This can be achieved not only by supporting IOT and UKOT to get СРOTB certificates which has been done by BPOM-RI (2018)[80], but also through detailed training on the assessment of the adverse health effects potentially arising from incorrect formulations which use botanicals of concern because of constituents that are genotoxic and carcinogenic. As seen in Table 7.3 and discussed in Chapter 3, the high number of samples of herbal beverages 
(Depkes RI-PIRT) which raise concern for human health indicating a priority for risk management may be due to the limited awareness and knowledge of the producers on the food safety and registration procedure.[18, 82] A study on jamu sellers in Semarang reported that the sellers formulate jamu based on their knowledge and experiences on the main types of compounds in botanical materials and health effects. The sellers use traditional equipment to produce the jamu. ${ }^{[33]}$ Limyati and Juniar (1998) ${ }^{[84]}$ reported the contamination of raw material and products of jamu gendong with bacteria, yeasts and molds, indicating the low application of food safety among sellers. Another example is the detection of carcinogenic aflatoxin B1, B2 and G2 in 14 jamu preparations. ${ }^{[85]}$ Thus, it can be concluded that improving awareness among producers and implementing GMP within the field of jamu production will improve the safety of these products.

\subsubsection{Development a toxicity database of medicinal botanicals used in Indonesia}

The toxicity data and knowledge on the occurrence of adverse reactions as a result of use of Indonesian herbal products are still limited. The result of a monitoring program on adverse health effects resulting from the consumption of traditional medicine and food supplements showed that there were 19 and 37 electronic reports related to adverse effects of consumption of traditional herbal and health supplements in 2018. [80] From January - until September 2019, there were 149 reports on adverse health effects due to consumption of traditional medicines in Indonesia. ${ }^{[86]}$ Although the report did not mention the compounds involved in causing the reported adverse effects, it seems likely that these reports relate to cases of acute toxicity, while the results of the MOE approach-based risk assessment in this thesis provide evidence that also chronic toxicity such as the toxicity resulting from the exposure to carcinogenic genotoxic compounds in the products, should be taken into consideration.

Analysing the side effects of herbal products is reported to be much more complex than analysing side effects of conventional pharmaceuticals, especially in the case of chronic toxicity, where causality can be very difficult to establish. ${ }^{[87]}$ Only a few reports on adverse effects of jamu have been reported in the peer reviewed literature so far. Paul et al. (2005)[88] reported a case on agranulocytosis and citrobacterial infection in a 75-year-old woman with osteoarthritis after consuming jamu adulterated by phenylbutazone (to enhance the analgetic and antiinflammatory effect). Besides adulteration, the jamu was also contaminated with Klebsiella pneumoniae, Enterobacter sakazakii and Clostridium species. Recently, a study on costs of illness due to consumption of drug-adulterated herbal medicines resulting in kidney failure showed that adulterated jamu contributed $0.02-2.69 \%$ to 
the costs of kidney failure in Indonesia. ${ }^{[89]}$ The examples provided by these 2 case studies, could form the basis for a toxicity database of toxic compounds in botanicals and botanical preparations specific for the Indonesian market.

Afendi et al. (2012) ${ }^{[00]}$ already built the KNApSAcK Family database (http://www.knapsackfamily.com/jamu/top.jsp) that contains the formula names and botanical ingredients of 5,310 formulae out of more than 7,000 commercial jamu registered at BPOM RI. The database encompasses 550 medicinal plants and 12 morphological segments. However, a database of jamu toxicity and constituents of potential concern has not been established yet. Such information on adverse effects, toxicity or constituents of concern in jamu formulations could be included in the KNApSAcK Family database. However, it may also be of use if the toxicity database will be built in a different online platform to cover botanical constituents of concern for all Indonesian herbal products, and not be restricted to only jamu.

The databases should cover the toxic compound, toxicity data (in vitro and/or in vivo), as well as data on toxicokinetics, toxicogenomics, and mode of action. The EFSA Compendium of Botanicals (https://www.efsa.europa.eu/en/data/compendium-botanicals) can be used as an example of a database on botanicals that are reported to contain naturally occurring substances of possible concern for human health when present in food.[91] Such an online toxicity database may be a first step towards prioritization amongst issues related to the adverse reactions that have been associated with different herbal products. Using the database, toxicants can be identified easier and earlier and potentially be removed or modified during the production process, ${ }^{[92]}$ for example by reducing the proposed use and use levels, and/or via removal of the constituent of concern for example by using other botanicals or varieties with lower levels of the respective constituent. ${ }^{[19]}$

Furthermore, the database can be used to counterbalance the perception of consumers, and sometimes even medical practitioners, that herbal products are harmless. Numerous examples of herb-drug, herb-herb interactions and herbinduced side effects with serious clinical consequences have been documented in other regions/countries ${ }^{[33-96]}$, indicating the importance of similar research to further document what is clinically relevant to the situation in Indonesia. Users, prescribers and producers of jamu should be aware of this. More and continuous control is needed on traditional medicines such as jamu to guarantee safety for the consumer. This should preferably be regulated on a national level and implemented in the manufacturing process to ensure the safety in use of products on the market.[97] 
7.2.4. Restriction the exposure to genotoxic carcinogenic compound by establishing MPLs, refining the labels and regulation for botanicals and botanical preparations

The exposure to ABs and PAs via consumption of herbal products can also be restricted by establishing maximum permitted levels (MPLs). BPOM RI (2016) ${ }^{[98]}$ has stipulated an MPL of $10 \mathrm{mg} / \mathrm{kg}$ for estragole and of $0.1 \mathrm{mg} / \mathrm{kg}$ for safrole based on Regulation of Head BPOM RI No. 22, while MPLs for methyleugenol and PAs have not (yet) been established. As discussed in Chapter 3, an MPL value of $0.1-1 \mathrm{mg} / \mathrm{kg}$ can be considered to reduce the exposure to methyleugenol via consuming the herbal products to a level that would raise less concern.

In addition, to reducing the exposure to PAs via reducing the consumption of jamu an MPL for PAs also can be set based on the result of Chapter 4. Assuming an average recommended daily use of jamu containing PA-producing botanicals of 10.8 $\mathrm{g}$ and a $\mathrm{BMDL}_{10}$ value of $237 \mu \mathrm{g} / \mathrm{kg} \mathrm{bw} /$ day for riddelliine,,[55] an MPL of $0.1 \mathrm{mg}$ $\mathrm{PAs} / \mathrm{kg}$ jamu will result in an MOE of 10,000 and thus would not be of concern for human health. Furthermore, the high level of PAs detected in a large proportion of especially the Gynura-based jamu, indicates that banning the use of Gynura sp. as botanical constituent in herbal products will increase consumer safety. The highest PA level of 114,071 $\mu \mathrm{g} / \mathrm{kg}$ detected in sample TR-17 was 93.3-fold higher than the level of PAs in dried comfrey (Symphytum officinale) leaves of 2,523.1 $\mu \mathrm{g} / \mathrm{kg}$ (analysed using the same method as described in Chapter 4), a constituent already banned from use in herbal preparations including jamu. ${ }^{[99]}$ The level of Gynurabased jamu (TR-17) was 3 times higher than the level of PAs detected in dried farfara (Tussilago farfara) flos of $84,585.9 \mu \mathrm{g} / \mathrm{kg}$, which was also relatively high. Based on these results, the regulation HK.00.05.23.3644[100] can be refined by adding Gynura sp. and Tussilago farfara to the list of banned ingredients in Indonesian traditional medicines. BPOM RI can consider warning or paying more attention to the inclusion of Gynura sp. and Tussilago farfara in herbal products marketed in Indonesia.

To reduce the exposure to $\mathrm{ABs}$ and PAs, also the labelling regulation can be refined by adding restrictions on the recommended daily dose, the duration of consumption, and the adverse effects upon prolonged consumption on the label of herbal products to further support consumer safety. The labelling is useful not only for consumers and risk assessors, but also for general practitioners, so they can prescribe the product in the appropriate dose for an appropriate duration. So far, on the label of Indonesian herbal products there is no information about the limitation of consumption duration or use levels.

Chapter 2-4 indicated that short-term consumption can reduce the risk of exposure to the carcinogenic genotoxic herbal constituents. This recommendation 
would be comparable to Stevinson et al. (2002) ${ }^{[101]}$ who reported that when taken as a short-term monotherapy at recommended doses, kava (Piper methysticum) extracts appear to be well tolerated by most consumers. However, long-term use can cause dermatological reactions, neurological complications and, of greatest concern, liver damage. Another example is ginger (Zingiberis officinalle), which is mostly used as an ingredient in Indonesian herbal products, which can cause heartburn and act as a gastric irritant in doses exceeding $6 \mathrm{~g}$ of dried ginger. ${ }^{[102]}$ In Chapter 4, it is concluded that consumption of Indonesian jamu that contain PA-producing botanicals can be considered safe when consumed for less than about 6 weeks during a lifetime. This limitation of consumption duration is also recommended by European Medicine Agency (EMA) ${ }^{[103]}$ for PA exposure via drinking bitter fennelbased herbal preparations. The same recommendation to consume the PAcontaining herbal preparations for a short-time only (defined as 6 weeks) at dose levels not exceeding $1 \mu \mathrm{g}$ PAs/day is also regulated by Germany and The Netherlands. $[104,105]$

\subsubsection{Use of human biomonitoring (HBM) and PBK modeling for improved exposure and risk and benefit analysis of Indonesian herbal products}

The risks resulting from exposure to natural toxins via consumption of herbal products have not yet been assessed by the Indonesia Risk Assessment Center (INARAC), a body under the BPOM RI. So far INARAC finalized the Microbiology Risk Assessment (MRA) of chicken Salmonella and a risk assessment on Aflatoxin B1 (AFB1) levels in peanuts and their processed products.[106] Currently, the body is working on the risk assessment of 3-monochloro-propane-1,2-diol (3-MCPD) esters and glycidol esters (GE) present as contamination in palm oil, and acrylamide in coffee [107]. Based on the results of risk assessment of ABs, PAs, and AAs present in botanicals and botanical preparations on the Indonesian market reported in the present thesis, a further risk assessment, as well as a risk management action and related risk communication actions could be considered by the Indonesian authorities.

Further actions could also include a further study in Indonesia on the exposure to and effects of the compounds of concern due to frequent and prolonged consumption of herbal products. The study will be useful to inform the risk managers on the importance of actions to monitor the safety of herbal products. In case of the effect of exposure to ABs, PAs, and AAs via consuming herbal products on the incidence of liver cancer in Indonesia, epidemiological data would be needed and, if possible, further analysis of liver samples from the patients to quantify levels of relevant DNA adducts. Also, a more refined dietary exposure assessment of ABs, 
PAs and AAs including both acute and chronic exposure should be conducted in the Indonesian population. The data on occurrence resulting from the present thesis can be used as a basis to perform an exposure assessment by combining them with the consumption data of Indonesian herbal products, as was done for the European population by EFSA (2016) ${ }^{[108]}$. Furthermore, a more refined exposure assessment for these compounds could be done by human bio-monitoring (HBM) for example by measuring specific metabolites and/or haemoglobin adducts as biomarkers of exposure.[109]

Biomarkers of exposure may involve measurements of the parent compound, metabolites or DNA- or protein adducts and reflect internal doses, the biologically effective doses or target organ doses. ${ }^{[109]}$ Biomarkers in blood and urine are most commonly used as biomarkers of exposure and cells in blood may provide surrogate endpoints for effects in internal organs. Occurrence of persistent DNA-adducts would be ideal parameters for HBM to evaluate the mutagenicity of ABs, PAs or AAs and potentially related elevated cancer risks. ${ }^{72]}$ Furthermore, when liver samples from patients with liver cancer who consumed herbal products would become available, this HBM approach can be further refined for use in risk assessment.

HBM data can be of use in both forward and backward methods. Forward methods analyse the measured intake doses to predict body burden and related biomarker levels, while backward (reverse) analysis uses urinary/blood HBM data to reconstruct past exposure. For the reverse dosimetry methods, the fractional urinary excretion (FUE), defining the fraction of the dose that ends up as a defined biomarker in a relevant matrix is needed to convert the urinary level of a biomarker into an oral dose level [110]. When applying the reverse dosimetry methods PBKmodeling also will prove to be a way forward to translate the biomarker levels to oral dose levels.

Recently, PBK modeling has already been accepted as a tool for risk assessment or for use as supporting information in some of the chemical-specific dossiers evaluated by the Scientific Committee on Consumer Safety (SCCS), EFSA, the US Environmental Protection Agency (EPA), the US Food and Drug Administration (FDA) and the EMA[75], and this approach could also become of use to tackle the lack of epidemiological data in exposure and safety assessment of Indonesian herbal products. As reported by Paini et al. (2019) [75] application of new generation-PBK models would be extremely valuable in the generation of virtual population/patient libraries for exposure assessment, studies on the effect of enzyme polymorphisms and of drug-drug interactions and interindividual variability in relation to chemical exposures and toxicological outcomes. 
7.2.6. Incorporation of Chemical Specific Adjustment Factors (CSAFs) for interspecies and interindividual variation in kinetics within the human population

In the MOE approach a factor 10 for interindividual variability is included in the default cutoff value of 10,000 to evaluate whether there is a concern or not. The factor 10 is consisting of a default value of 3.16 for kinetics and 3.16 for dynamics. ${ }^{[30]}$ Integrating PBK modeling with Monte Carlo simulations using human in vitro data can be used as a strategy to quantify inter-individual variations in kinetics and take these into account in risk assessment in a chemical specific way defining so-called chemical specific adjustment factors (CSAFs) that can replace the default factor of 10 for interindividual differences. This approach has been used to predict inter-individual and inter-ethnic variation in bioactivation and liver toxicity of the PA lasiocarpine ${ }^{[111]}$, the $\mathrm{AB}$ estragole ${ }^{[112]}$, phenol[113], and trans-2-hexenal[114]. This approach can be extended to other ABs, PAs and AAs and to the individual Indonesian people. Quantifying inter-individual variations will enable a more refined risk assessment for the Indonesian population.

\subsubsection{Exploring the beneficial effects of botanicals and its products}

The health claims of Indonesian herbal products mentioned on the label or advertised via various media are provoking the increasing consumption trends of the products (Chapter 1). Figure 7.4 depicts an overview of the classes of diseases which are targeted and/or claimed to be cured by the 197 samples analysed in Chapter 2, 3 and 4. The health claims mentioned on the label were used to classify the diseases based on the International Classification of Diseases (ICD)-10 ver. 2016.[115] Beneficial effects were not mentioned on the label of $24.4 \%(48 / 197)$ of the total samples (NA). 


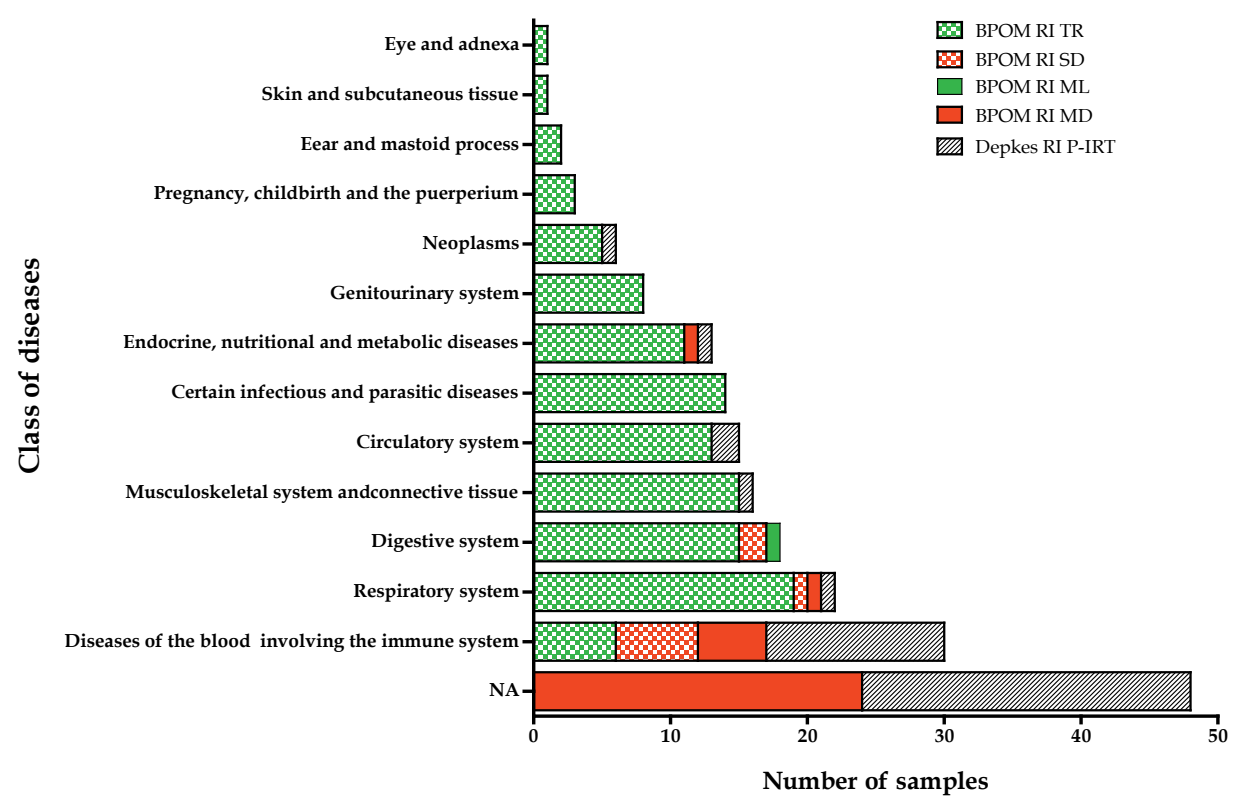

Figure 7.4. Overview of type of diseases which are targeted and/or claimed to be cured by the Indonesian herbal product samples analysed in Chapter 2, 3 and 4. The detail of actual health claims mentioned on the labels has been described in the respective chapters. NA refers to No available information on health claims mentioned on the label of the sample.

As depicted in the figure, health claims targeting the blood and blood-forming organs and certain disorders involving the immune system are linked to the highest number of samples (24.4\% out of the total samples), while only a few samples target eye, ear, and skin-related diseases. Interestingly 6 samples claim that after consuming the products consumers can cure their neoplasm-related diseases. The respective labels indicate that the products help to maintain the health condition of tumour and cancer patients, and to prevent and treat cancer (cervix, breast, liver, brain, lung, leukaemia, and other diseases related with cancers, cysts and tumours). Diseases of the respiratory system such as cough, cough with phlegm, asthma, and sore throat are claimed to be treated after consuming 19 of the samples of jamu (registered as BPOM RI TR).

These claimed beneficial effects of the products are considered to be related to the biological activity of constituents of the botanical(s) inside the products. For example, in jamu claimed to have an effect on ailments related to the respiratory system, fennel (Foeniculum vulgare Mill.) bark is the active botanical ingredient in the preparations. The use of fennel as traditional medicine for a wide range of effects has been reviewed.[116, 117] Spasmolytic effects on contracted smooth muscles is reported as the mode of action underlying the anti-asthma effects of fennel.[118, 119] 
Another example is ginger (Zingiberis officinale) of which the rhizome is present in many samples analysed in this thesis linked with beneficial effects on digestive system-related illness. Gingerols and shogaols and their activity on cholinergic M receptors and serotonergic 5-HT and 5-HT receptors are reported as the MOA of the effect of ginger to cure nausea and vomiting. ${ }^{[120]}$ However, since the jamu ingredients consist of mixed medicinal plants to get the desired efficacy, the beneficial effects of the preparation can be explored further to support the efficacy of jamu.

As discussed in Chapter 1, the therapeutic effects of jamu are mainly based on empirical data, inherited across generations ${ }^{[121,122]}$, and thus generation of science based evidence for the beneficial effects of the Indonesian botanicals and their products remains to be performed. The efforts can support the program saintifikasi jamu established by the Indonesian government. This program is aiming to collect data on jamu efficacy based on a scientific basis understanding the clinical practice, context of usage, safety of usage, effectiveness, elucidation of active compounds related to the therapeutic effect, and elucidation of the underlying therapeutic mechanism. [123] QIVIVE using the combination of in vitro assay and PBK modelingfacilitated reverse dosimetry, as also applied in Chapter 6 of the present thesis, can be a solution to prove the efficacy of jamu and other Indonesian herbal products. The method can be used to obtain insights in human responses to potential functional food ingredients. This insight can be used to select the promising botanicals for subsequent human intervention studies and can help in the selection of doses to be applied in such studies.

\section{Conclusion}

The research presented in this thesis supports risk management aimed at prioritizing regulatory actions to reduce potential risks connected to the exposure to genotoxic carcinogens, ABs, PAs an AAs via consumption of Indonesian herbal products. In addition, a novel testing strategy, combining in vitro and PBK modeling-facilitated reverse dosimetry, was found to facilitate risk and benefit assessment of botanical compounds without the need for animal experiments and/or human intervention studies. Many aspects, including variability in detected levels of the targeted compounds, variability in recommended daily use mentioned on the label, interindividual variation of exposure among Indonesian people, absence of a generally accepted method to take shorter-than-lifetime exposure into account, the knowledge gaps in modes of action, selection of the best in vitro model for QIVIVE, potential combination effects, the chemical-specific parameters needed for PBK modeling and availability of in vivo studies to validate the predictions 
should be considered for future research. Seven actions including (1) applying Good Agricultural and Collection Practices (GACP) for farmers, (2) applying good manufacturing practice (GMP) of herbal product and food safety training for manufacturers and producers, (3) development of a toxicity database of medicinal botanicals used in Indonesia, (4) restriction of the exposure to genotoxic carcinogenic compounds by establishing MPLs and refining the label requirements for botanicals and botanical preparations, (5) use of human biomonitoring (HBM) and PBK modeling for a more refined exposure, risk and benefit analysis of Indonesian herbal products, (6) incorporation of Chemical Specific Adjustment Factors (CSAFs) for interspecies and interindividual variation in kinetics within the human population in the risk assessment, and (7) exploring the beneficial effects of botanicals and botanical preparations, were proposed to improve safety and efficacy of botanicals and botanical preparations on the Indonesian market.

\section{References}

[1] Kemenkes-RI, Kemenkes Dorong Pengembangan Industri Obat Tradisional, 2019 Available at: https:/ / www.kemkes.go.id/article/view/19082100002/kemenkes-dorong-pengembanganindustri-obat-tradisional.html. Accessed 8 December 2019.

[2] Kemenkes-RI, Hasil Utama RISKESDAS 2018, Jakarta 2018. Available at: http:/ / www.kesmas.kemkes.go.id/assets/upload/dir_519d41d8cd98f00/files/Hasil-riskesdas2018_1274.pdf. Accessed 1 January 2020.

[3] Hasler, C. M., Functional foods: Benefits, concerns and challenges-A position paper from the american council on science and health. The Journal of Nutrition 2002, 132, 3772-3781.

[4] Rietjens, I. M. C. M., Slob, W., Galli, C., Silano, V., Risk assessment of botanicals and botanical preparations intended for use in food and food supplements: Emerging issues. Toxicology Letters 2008, 180, 131-136.

[5] Vargas-Murga, L., Garcia-Alvarez, A., Roman-Viñas, B., Ngo, J., Ribas-Barba, L., van den Berg, S. J. P. L., Williamson, G., Serra-Majem, L., Plant food supplement (PFS) market structure in EC Member States, methods and techniques for the assessment of individual PFS intake. Food $\mathcal{E}$ Function 2011, 2, 731-739.

[6] Simon, J. E., Quinn, J., Characterization of essential oil of parsley. Journal of Agricultural and Food chemistry 1988, 36, 467-472.

[7] Saleh-E-In, M. M., Sultana, N., Hossain, M. N., Hasan, S., Islam, M. R., Pharmacological effects of the phytochemicals of Anethum sowa L. root extracts. BMC Complementary and Alternative Medicine 2016, 16, 464-464.

[8] Crews, C., Berthiller, F., Krska, R., Update on analytical methods for toxic pyrrolizidine alkaloids. Analytical and Bioanalytical Chemistry 2010, 396, 327-338.

[9] Alajlouni, A. M., Al-Malahmeh, A. J., Isnaeni, F. N., Wesseling, S., Vervoort, J., Rietjens, I. M., Level of alkenylbenzenes in parsley and dill based teas and associated risk assessment using the Margin of Exposure approach. Journal of agricultural and food chemistry 2016, 64, 8640-8646.

[10] van den Berg, S. J. P. L., Alhusainy, W., Restani, P., Rietjens, I. M. C. M., Chemical analysis of estragole in fennel based teas and associated safety assessment using the Margin of Exposure (MOE) approach. Food and Chemical Toxicology 2014, 65, 147-154.

[11] Chen, L., Mulder, P. P. J., Louisse, J., Peijnenburg, A., Wesseling, S., Rietjens, I. M. C. M., Risk assessment for pyrrolizidine alkaloids detected in (herbal) teas and plant food supplements. Regulatory Toxicology and Pharmacology 2017, 86, 292-302.

[12] Liu, W., Liu, J., Yin, D., Zhao, X., Influence of ecological factors on the production of active substances in the anti-cancer plant Sinopodophyllum hexandrum (Royle) T.S. Ying. PloS one 2015, 10, e0122981. 
[13] Al-Kateb, H., Mottram, D. S., The relationship between growth stages and aroma composition of lemon basil Ocimum citriodorum Vis. Food Chemistry 2014, 152, 440-446.

[14] Smith, R. L., Adams, T. B., Doull, J., Feron, V. J., Goodman, J. I., Marnett, L. J., Portoghese, P. S., Waddell, W. J., Wagner, B. M., Rogers, A. E., Caldwell, J., Sipes, I. G., Safety assessment of allylalkoxybenzene derivatives used as flavouring substances - methyleugenol and estragole. Food and Chemical Toxicology 2002, 40, 851-870.

[15] Di Cesare, L. F., Forni, E., Viscardi, D., Nani, R. C., Changes in the chemical composition of basil caused by different drying procedures. Journal of Agricultural and Food Chemistry 2003, 51, 3575-3581.

[16] Speijers, G., Alink, G. M., Saeger, S. d., Hardy, A., Magan, N., Pilegaard, K., Battilani, P., Riemens, M. M., Evaluation of Agronomic Practices for Mitigation of Natural Toxins, ILSI Europe, International Life Sciences Institute 2010.

[17] WHO, Quality Control Methods for Herbal Materials, World Health Organization, Geneva 2011. Available at: https:// apps.who.int/iris/handle/10665/44479. Accessed 13 December 2019.

[18] Berkhout, D. J. C., Benninga, M. A., van Stein, R. M., Brinkman, P., Niemarkt, H. J., de Boer, N. K. H., de Meij, T. G. J., Effects of sampling conditions and environmental factors on fecal volatile organic compound analysis by an electronic nose device. Sensors (Basel, Switzerland) 2016, $16,1967$.

[19] Ifeoma, O., Oluwakanyinsola, S., New insights into toxicity and drug testing, IntechOpen 2013.

[20] Woehrlin, F., Fry, H., Abraham, K., Preiss-Weigert, A., Quantification of flavoring constituents in cinnamon: high variation of coumarin in cassia bark from the German retail market and in authentic samples from Indonesia. Journal of Agricultural and Food Chemistry 2010, 58, 10568-10575.

[21] Rietjens, I. M., Cohen, S. M., Fukushima, S., Gooderham, N. J., Hecht, S., Marnett, L. J., Smith, R. L., Adams, T. B., Bastaki, M., Harman, C. G., Taylor, S. V., Impact of structural and metabolic variations on the toxicity and carcinogenicity of hydroxy- and alkoxy-substituted allyl- and propenylbenzenes. Chemical Research in Toxicology 2014, 27, 1092-1103.

[22] Mimica-Dukić, N., Kujundžić, S., Soković, M., Couladis, M., Essential oil composition and antifungal activity of Foeniculum vulgare Mill. obtained by different distillation conditions. Phytotherapy Research. 2003, 17, 368-371.

[23] BPOM-RI, Peraturan Badan Pengawas Obat dan Makanan Nomor 7 Tahun 2018 Tentang Bahan Baku yang Dilarang dalam Pangan Olahan, Kementerian Hukum dan Hak Asasi Manusia Republik Indonesia, Jakarata 20187. Available at: https:/ /jdih.pom.go.id/. Accessed 12 October 2019.

[24] Martena, M. J., van der Wielen, J. C. A., van de Laak, L. F. J., Konings, E. J. M., de Groot, H. N., Rietjens, I. M. C. M., Enforcement of the ban on aristolochic acids in Chinese traditional herbal preparations on the Dutch market. Analytical and Bioanalytical Chemistry 2007, 389, 263-275.

[25] Schulz, M., Meins, J., Diemert, S., Zagermann-Muncke, P., Goebel, R., Schrenk, D., SchubertZsilavecz, M., Abdel-Tawab, M., Detection of pyrrolizidine alkaloids in German licensed herbal medicinal teas. Phytomedicine 2015, 22, 648-656.

[26] IARC, Sampling and sample preparation methods for determining concentrations of mycotoxins in foods and feeds. IARC scientific publications 2012, 39-51.

[27] Whitaker, T. B., Sampling foods for mycotoxins. Food Additives and Contaminants 2006, $23,50-61$.

[28] BPOM-RI, Peraturan Badan Pengawas Obat dan Makanan Nomor 31 Tahun 2018 Tentang Label Pangan Olahan, Kepala Badan Pengawas Obat dan Makanan Republik Indonesia 2018. Available at: http://standarpangan.pom.go.id/dokumen/peraturan/2018/0.PerBPOM_31_Tahun_2018_Lab el_Pangan_Olahan_31_Jan_2019_Join.pdf. Accessed 23 December 2019.

[29] Felter, S. P., Conolly, R. B., Bercu, J. P., Bolger, P. M., Boobis, A. R., Bos, P. M. J., Carthew, P., Doerrer, N. G., Goodman, J. I., Harrouk, W. A., Kirkland, D. J., Lau, S. S., Llewellyn, G. C., Preston, R. J., Schoeny, R., Schnatter, A. R., Tritscher, A., van Velsen, F., Williams, G. M., A proposed framework for assessing risk from less-than-lifetime exposures to carcinogens. Critical Reviews in Toxicology $2011,41,507-544$

[30] EFSA, Opinion of the Scientific Committee on a request from EFSA related to A Harmonised Approach for Risk Assessment of Substances Which are both Genotoxic and Carcinogenic. EFSA Journal 2005, 282, 1-31.

[31] Bos, P. M. J., Baars, B.-J., van Raaij, M. T. M., Risk assessment of peak exposure to genotoxic carcinogens: a pragmatic approach. Toxicology Letters 2004, 151, 43-50.

[32] Callis, C. M., Bercu, J. P., DeVries, K. M., Dow, L. K., Robbins, D. K., Varie, D. L., Risk assessment of genotoxic impurities in marketed compounds administered over a short-term duration: Applications to oncology products and implications for impurity control limits. Organic Process Research \& Development 2010, 14, 986-992. 
[33] Al-Subeihi, A. A. A., Spenkelink, B., Punt, A., Boersma, M. G., van Bladeren, P. J., Rietjens, I. M. C. M., Physiologically based kinetic modeling of bioactivation and detoxification of the alkenylbenzene methyleugenol in human as compared with rat. Toxicology and Applied Pharmacology 2012, 260, 271-284.

[34] Martati, E., Boersma, M. G., Spenkelink, A., Khadka, D. B., van Bladeren, P. J., Rietjens, I. M. C. M., Punt, A., Physiologically Based Biokinetic (PBBK) modeling of safrole bioactivation and detoxification in humans as compared with rats. Toxicological Sciences 2012, 128, 301-316.

[35] Punt, A., Paini, A., Boersma, M. G., Freidig, A. P., Delatour, T., Scholz, G., Schilter, B., Bladeren, P. J. v., Rietjens, I. M. C. M., Use of Physiologically Based Biokinetic (PBBK) modeling to study estragole bioactivation and detoxification in humans as compared with male rats. Toxicological Sciences 2009, 110, 255-269.

[36] Rietjens, I. M. C. M., Punt, A., Schilter, B., Scholz, G., Delatour, T., van Bladeren, P. J., In silico methods for physiologically based biokinetic models describing bioactivation and detoxification of coumarin and estragole: Implications for risk assessment. Molecular Nutrition and Food Research 2010, 54, 195-207.

[37] Herrmann, K., Schumacher, F., Engst, W., Appel, K. E., Klein, K., Zanger, U. M., Glatt, H., Abundance of DNA adducts of methyleugenol, a rodent hepatocarcinogen, in human liver samples. Carcinogenesis 2013, 34, 1025-1030.

[38] Lester, C., Troutman, J., Obringer, C., Wehmeyer, K., Stoffolano, P., Karb, M., Xu, Y., Roe, A., Carr, G., Blackburn, K., Mahony, C., Intrinsic relative potency of a series of pyrrolizidine alkaloids characterized by rate and extent of metabolism. Food and Chemical Toxicology 2019, 131, 110523.

[39] Xia, Q., Zhao, Y., Von Tungeln, L. S., Doerge, D. R., Lin, G., Cai, L., Fu, P. P., Pyrrolizidine alkaloidderived DNA adducts as a common biological biomarker of pyrrolizidine alkaloid-induced tumorigenicity. Chemical Research in Toxicology 2013, 26, 1384-1396.

[40] Chou, M. W., Fu, P. P., Formation of DHP-derived DNA adducts in vivo from dietary supplements and Chinese herbal plant extracts containing carcinogenic pyrrolizidine alkaloids. Toxicology and Industrial Health 2006, 22, 321-327.

[41] Gijsbers, L., Man, H. Y., Kloet, S. K., De Haan, L. H. J., Keijer, J., Rietjens, I. M. C. M., Van Der Burg, B., Aarts, J. M. M. J. G., Stable reporter cell lines for peroxisome proliferator-activated receptor $\gamma$ (PPARY)-mediated modulation of gene expression. Analytical Biochemistry 2011, 414, 77-83.

[42] Takahashi, N., Goto, T., Taimatsu, A., Egawa, K., Katoh, S., Kusudo, T., Sakamoto, T., Ohyane, C., Lee, J. Y., Kim, Y. i., Uemura, T., Hirai, S., Kawada, T., Bixin regulates mRNA expression involved in adipogenesis and enhances insulin sensitivity in 3T3-L1 adipocytes through PPARY activation. Biochemical and Biophysical Research Communications 2009, 390, 1372-1376.

[43] Schupp, M., Lee, L. D., Frost, N., Umbreen, S., Schmidt, B., Unger, T., Kintscher, U., Regulation of peroxisome proliferator-activated receptor gamma activity by losartan metabolites. Hypertension $2006,47,586-589$.

[44] Lauschke, V. M., Hendriks, D. F. G., Bell, C. C., Andersson, T. B., Ingelman-Sundberg, M., Novel 3D culture systems for studies of human liver function and assessments of the hepatotoxicity of drugs and drug candidates. Chemical Research in Toxicology 2016, 29, 1936-1955.

[45] Gómez-Lechón, M. J., Tolosa, L., Conde, I., Donato, M. T., Competency of different cell models to predict human hepatotoxic drugs. Expert Opinion on Drug Metabolism E Toxicology 2014, 10, 15531568.

[46] Gomez-Lechon, M. J., Donato, M. T., Castell, J. V., Jover, R., Human hepatocytes as a tool for studying toxicity and drug metabolism. Current Drug Metabolism 2003, 4, 292-312.

[47] Soldatow, V. Y., Lecluyse, E. L., Griffith, L. G., Rusyn, I., In vitro models for liver toxicity testing. Toxicology Research 2013, 2, 23-39.

[48] Donato, M. T., Lahoz, A., Montero, S., Bonora, A., Pareja, E., Mir, J., Castell, J. V., Gómez-Lechón, M. J., Functional assessment of the quality of human hepatocyte preparations for cell transplantation. Cell Transplantation 2008, 17, 1211-1219.

[49] McGinnity, D. F., Soars, M. G., Urbanowicz, R. A., Riley, R. J., Evaluation of fresh and cryopreserved hepatocytes as in vitro drug metabolism tools for the prediction of metabolic clearance. Drug Metabolism and Disposition 2004, 32, 1247-1253.

[50] Griffin, S. J., Houston, J. B., Prediction of in vitro intrinsic clearance from hepatocytes: comparison of suspensions and monolayer cultures. Drug Metabolism and Disposition: The Biological Fate of Chemicals 2005, 33, 115-120. 
[51] Kanebratt, K. P., Andersson, T. B., Evaluation of HepaRG cells as an in vitro model for human drug metabolism studies. Drug Metabolism and Disposition 2008, 36, 1444-1452.

[52] Swift, B., Pfeifer, N. D., Brouwer, K. L. R., Sandwich-cultured hepatocytes: an in vitro model to evaluate hepatobiliary transporter-based drug interactions and hepatotoxicity. Drug metabolism Reviews 2010, 42, 446-471.

[53] Yang, K., Guo, C., Woodhead, J. L., St Claire, R. L., 3rd, Watkins, P. B., Siler, S. Q., Howell, B. A., Brouwer, K. L. R., Sandwich-cultured hepatocytes as a tool to study drug disposition and druginduced liver injury. Journal of Pharmaceutical Sciences 2016, 105, 443-459.

[54] Li, Y. H., Kan, W. L. T., Li, N., Lin, G., Assessment of pyrrolizidine alkaloid-induced toxicity in an in vitro screening model. Journal of Ethnopharmacology 2013, 150, 560-567.

[55] EFSA, Risks for human health related to the presence of pyrrolizidine alkaloids in honey, tea, herbal infusions and food supplements. EFSA Journal 2017, 15, e04908.

[56] Merz, K.-H., Schrenk, D., Interim relative potency factors for the toxicological risk assessment of pyrrolizidine alkaloids in food and herbal medicines. Toxicology Letters 2016, 263, 44-57.

[57] Schilter, B., Andersson, C., Anton, R., Constable, A., Kleiner, J., O'Brien, J., Renwick, A. G., Korver, O., Smit, F., Walker, R., Guidance for the safety assessment of botanicals and botanical preparations for use in food and food supplements. Food and Chemical Toxicology 2003, 41, 1625-1649.

[58] Jeurissen, S. M. F., Punt, A., Delatour, T., Rietjens, I. M. C. M., Basil extract inhibits the sulfotransferase mediated formation of DNA adducts of the procarcinogen 1'-hydroxyestragole by rat and human liver S9 homogenates and in HepG2 human hepatoma cells. Food and Chemical Toxicology 2008, 46, 2296-2302.

[59] Alhusainy, W., van den Berg, S. J. P. L., Paini, A., Campana, A., Asselman, M., Spenkelink, A., Punt, A., Scholz, G., Schilter, B., Adams, T. B., van Bladeren, P. J., Rietjens, I. M. C. M., Matrix modulation of the bioactivation of estragole by constituents of different alkenylbenzene-containing herbs and spices and physiologically based biokinetic modeling of possible in vivo effects. Toxicological Sciences 2012, 129, 174-187.

[60] Alhusainy, W., Paini, A., van den Berg, J. H. J., Punt, A., Scholz, G., Schilter, B., van Bladeren, P. J., Taylor, S., Adams, T. B., Rietjens, I. M. C. M., In vivo validation and physiologically based biokinetic modeling of the inhibition of SULT-mediated estragole DNA adduct formation in the liver of male Sprague-Dawley rats by the basil flavonoid nevadensin. Molecular Nutrition and Food Research 2013, 57, 1969-1978.

[61] van den Berg, S. J., Punt, A., Soffers, A. E., Vervoort, J., Ngeleja, S., Spenkelink, B., Rietjens, I. M., Physiologically based kinetic models for the alkenylbenzene elemicin in rat and human and possible implications for risk assessment. Chemical Research in Toxicology 2012, 25, 2352-2367.

[62] Alajlouni, A. M., Al_Malahmeh, A. J., Kiwamoto, R., Wesseling, S., Soffers, A. E. M. F., Al-Subeihi, A. A. A., Vervoort, J., Rietjens, I. M. C. M., Mode of action based risk assessment of the botanical food-borne alkenylbenzene apiol from parsley using physiologically based kinetic (PBK) modelling and read-across from safrole. Food and Chemical Toxicology 2016, 89, 138-150.

[63] Al-Malahmeh, A. J., Al-Ajlouni, A., Wesseling, S., Soffers, A. E. M. F., Al-Subeihi, A., Kiwamoto, R., Vervoort, J., Rietjens, I. M. C. M., Physiologically based kinetic modeling of the bioactivation of myristicin. Archives of Toxicology 2017, 91, 713-734.

[64] Chen, L., Ning, J., Louisse, J., Wesseling, S., Rietjens, I. M. C. M., Use of physiologically based kinetic modelling-facilitated reverse dosimetry to convert in vitro cytotoxicity data to predicted in vivo liver toxicity of lasiocarpine and riddelliine in rat. Food and Chemical Toxicology 2018, 116, 216-226.

[65] Ning, J., Chen, L., Strikwold, M., Louisse, J., Wesseling, S., Rietjens, I. M. C. M., Use of an in vitroin silico testing strategy to predict inter-species and inter-ethnic human differences in liver toxicity of the pyrrolizidine alkaloids lasiocarpine and riddelliine. Archives of Toxicology 2019 93, 801-818.

[66] Rietjens, I. M. C. M., Louisse, J., Punt, A., Tutorial on physiologically based kinetic modeling in molecular nutrition and food research. Molecular Nutrition and Food Research 2011, 55, 941-956.

[67] Bessems, J. G., Loizou, G., Krishnan, K., Clewell, H. J., Bernasconi, C., Bois, F., Coecke, S., Collnot, E.-M., Diembeck, W., Farcal, L. R., Geraets, L., Gundert-Remy, U., Kramer, N., Küsters, G., Leite, S. B., Pelkonen, O. R., Schröder, K., Testai, E., Wilk-Zasadna, I., Zaldívar-Comenges, J.-M., PBTK modelling platforms and parameter estimation tools to enable animal-free risk assessment: Recommendations from a joint EPAA - EURL ECVAM ADME workshop. Regulatory Toxicology and Pharmacology 2014, 68, 119-139. 
[68] DeJongh, J., Verhaar, H. J. M., Hermens, J. L. M., A quantitative property-property relationship (QPPR) approach to estimate in vitro tissue-blood partition coefficients of organic chemicals in rats and humans. Archives of Toxicology 1997, 72, 17-25.

[69] Berezhkovskiy, L. M., Determination of volume of distribution at steady state with complete consideration of the kinetics of protein and tissue binding in linear pharmacokinetics. Journal of Pharmaceutical Sciences 2004, 93, 364-374.

[70] Kemenkes-RI, Riset Kesehatan Dasar (RISKESDAS) 2010, Jakarta 2010. Available at: http://kesga.kemkes.go.id/images/pedoman/Riskesdas\%202010\%20Nasional.pdf. Accessed 1 January 2020.

[71] Calafat, A. M., Ye, X., Silva, M. J., Kuklenyik, Z., Needham, L. L., Human exposure assessment to environmental chemicals using biomonitoring. International Journal of Andrology 2006, 29, 166-171.

[72] Angerer, J., Ewers, U., Wilhelm, M., Human biomonitoring: State of the art. International Journal of Hygiene and Environmental Health 2007, 210, 201-228.

[73] Slob, W., Probabilistic dietary exposure assessment taking into account variability in both amount and frequency of consumption. Food and Chemical Toxicology 2006, 44, 933-951.

[74] Paini, A., Leonard, J. A., Kliment, T., Tan, Y.-M., Worth, A., Investigating the state of physiologically based kinetic modelling practices and challenges associated with gaining regulatory acceptance of model applications. Regulatory Toxicology and Pharmacology 2017, 90, 104-115.

[75] Paini, A., Leonard, J. A., Joossens, E., Bessems, J. G. M., Desalegn, A., Dorne, J. L., Gosling, J. P., Heringa, M. B., Klaric, M., Kliment, T., Kramer, N. I., Loizou, G., Louisse, J., Lumen, A., Madden, J. C., Patterson, E. A., Proença, S., Punt, A., Setzer, R. W., Suciu, N., Next generation physiologically based kinetic (NG-PBK) models in support of regulatory decision making. Computational Toxicology 2019, 9, 61-72.

[76] Mostrag-Szlichtyng, A., Worth, A., In silico modelling of microbial and human metabolism: a case study with the fungicide carbendazim. JRC Scientific and Technical Report EUR 24523 EN 2010.

[77] Patel, M., Chilton, M. L., Sartini, A., Gibson, L., Barber, C., Covey-Crump, L., Przybylak, K. R., Cronin, M. T. D., Madden, J. C., Assessment and Reproducibility of Quantitative Structure-Activity Relationship Models by the Nonexpert. Journal of Chemical Information and Modeling 2018, 58, 673682.

[78] WHO, WHO guidelines on good agricultural and collection practices (GACP) for medicinal plants, Geneva 2003. Available at: https://apps.who.int/medicinedocs/pdf/s4928e/s4928e.pdf. Accessed 3 January 2020.

[79] Franz, C., Chizzola, R., Novak, J., Sponza, S., Botanical species being used for manufacturing plant food supplements (PFS) and related products in the EU member states and selected third countries. Food E Function 2011, 2, 720-730.

[80] BPOM-RI, Laporan Tahunan Badan POM 2018, 2019.1-303. Available at: https://www.pom.go.id/new/admin/dat/20191212/LAPTAH-BPOM-2018.pdf. Accessed 12 December 2019.

[81] Yulianti, M. D. M., R. , Tata Cara Registrasi untuk Pangan Olahan Industri Rumah Tangga (PIRT) dan Makanan Dalam Negeri (MD) dalam Rangka Peningkatan Produk yang Aman dan Bermutu di Bandung Jawa Barat. Farmaka 2017, 15, 87-64.

[82] Putri, S. A., Challenge to enforce food safety law and regulation in Indonesia. IOP Conference Series: Earth and Environmental Science 2018, 175.

[83] Sumarni, W., Sudarmin, S., Sumarti, S. S., The scientification of jamu: a study of Indonesian's traditional medicine. Journal of Physics: Conference Series 2019, 1321, 032057.

[84] Limyati, D. A., Juniar, B. L. L., Jamu Gendong, a kind of traditional medicine in Indonesia: the microbial contamination of its raw materials and endproduct. Journal of Ethnopharmacology 1998, 63, 201-208.

[85] Ali, N., Hashim, N. H., Saad, B., Safan, K., Nakajima, M., Yoshizawa, T., Evaluation of a method to determine the natural occurrence of aflatoxins in commercial traditional herbal medicines from Malaysia and Indonesia. Food and Chemical Toxicology 2005, 43, 1763-1772.

[86] BPOM-RI, Kinerja BPOM Dalam Rangka Triwulan II tahun 2019, 2019 Available at: https://www.pom.go.id/new/admin/dat/20191212/RTN-TW-2-2019.pdf. Accessed 24 December 2019.

[87] Kristanc, L., Kreft, S., European medicinal and edible plants associated with subacute and chronic toxicity part I: Plants with carcinogenic, teratogenic and endocrine-disrupting effects. Food and Chemical Toxicology 2016, 92, 150-164. 
[88] Paul, J., Duncan, J. R., Sharp, P., Norris, A., Siddiq, M. A., Bacon, C., Weighill, J., Agranulocytosis and citrobacter infection associated with jamu, a herbal remedy containing phenylbutazone. Clinical Infectious Diseases 2005, 40, 1859-1860.

[89] Puspandari, D. A., Rizal, M. F., Cost of illness konsumsi jamu berbahan kimia obat yang potensial menyebabkan gagal ginjal Badan Pengawas Obat dan Makanan Reublik Indonesia, Jakarta 2019 Available at: https://www.pom.go.id/new/view/more/berita/17422/Forum-Diseminasi-HasilRiset-Dan-Kajian-Obat-Dan-Makanan-Badan-POM-tahun-2019-.html. Accessed 2 January 2020.

[90] Afendi, F. M., Okada, T., Yamazaki, M., Hirai-Morita, A., Nakamura, Y., Nakamura, K., Ikeda, S., Takahashi, H., Altaf-Ul-Amin, M., Darusman, L. K., Saito, K., Kanaya, S., KNApSAcK Family Databases: Integrated Metabolite-Plant Species Databases for Multifaceted Plant Research. Plant and Cell Physiology 2012, 53, e1-e1.

[91] EFSA, Compendium of Botanicals, European Food Safety Authority 2017 Available at: https:/ / www.efsa.europa.eu/en/data/compendium-botanicals. Accessed 6 January 2020.

[92] Gamaniel, K., Toxicity from medicinal plants and their products. Nigerian Journal of Natural Products and Medicine 2000, 4, 4-8.

[93] Na, D. H., Ji, H. Y., Park, E. J., Kim, M. S., Liu, K.-H., Lee, H. S., Evaluation of metabolism-mediated herb-drug interactions. Archives of Pharmacal Research 2011, 34, 1829-1842.

[94] Izzo, A. A., Ernst, E., Interactions between herbal medicines and prescribed drugs. Drugs 2009, 69, 1777-1798.

[95] Kennedy, D. A., Seely, D., Clinically based evidence of drug-herb interactions: a systematic review. Expert Opinion on Drug Safety 2010, 9, 79-124.

[96] Tarirai, C., Viljoen, A. M., Hamman, J. H., Herb-drug pharmacokinetic interactions reviewed. Expert Opinion on Drug Metabolism E Toxicology 2010, 6, 1515-1538.

[97] Woerdenbag, H. J., Nguyen, T. M., Vu, D. V., Tran, H., Nguyen, D. T., Tran, T. V., De Smet, P. A. G. M., Brouwers, J. R. B. J., Vietnamese traditional medicine from a pharmacist's perspective. Expert Review of Clinical Pharmacology 2012, 5, 459-477.

[98] BPOM-RI, Peraturan Kepala Badan Pengawas obat dan Makanan Republik Indonesia Nomor 22 Tahun 2016 tentang Penggunaan Bahan Tambahan Perisa, Menteri Hukum dan Hak Asasi Manusia Republik Indonesia, Jakarta 2016.1. Available at. Accessed 22 October 2017.

[99] BPOM-RI, Keputusan Kepala Badan Pengawas Obat dan Makanan Nomor HK.00.05.4.03960 Tentang Larangan Produksi dan Distribusi Obat Tradisional dan Suplemen Makanan yang Mengandung Tanaman Aristolochia Sp, Kementerian Hukum dan HAM 2001. Available at: http:/ /jdih.pom.go.id/ showpdf.php?u=4zv\%2BedyC7OYxwobMtDH1N\%2FovpzK1QwV\%2Bd5 6Ij5sY\%2BLg\%3D. Accessed 26 December 2019.

[100] BPOM-RI, Keputusan Kepala Badan Pengawas Obat dan Makanan Nomor Nomor HK.00.05.23.3644 Tentang Ketentuan Pokok Pengawasan Suplemen Makanan, Kementerian Hukum dan HAM 2004. Available https://jdih.pom.go.id/showpdf.php?u=d4VArDdZs6oSoP4DOJbSbz3qbNY4ceqRp1jFcPWkbcA \%3D. Accessed 26 December 2019.

[101] Stevinson, C., Huntley, A., Ernst, E., A systematic review of the safety of kava extract in the treatment of anxiety. Drug Safety 2002, 25, 251-261.

[102] Chrubasik, S., Pittler, M. H., Roufogalis, B. D., Zingiberis rhizoma: A comprehensive review on the ginger effect and efficacy profiles. Phytomedicine 2005, 12, 684-701.

[103] EMA, Committee on herbal medicinal products (HMPC) assessment report on Foeniculum vulgare Miller, 2008.EMA/HMPC/411665/2008.

Available

at:

https:/ / www.ema.europa.eu/en/documents/herbal-summary/foeniculum-vulgare-miller-

subsp-vulgare-var-dulce-miller-thellung-fructus-fennel-fruit-sweet-hmpc_en.pdf. Accessed 7 December 2017.

[104] BfR, Pyrrolizidine alkaloids in herbal teas and teas, 2013 Available at: https://mobil.bfr.bund.de/cm/349/pyrrolizidine-alkaloids-in-herbal-teas-and-teas.pdf. Accessed 25 October 2017.

[105] WKB, Warenwetbesluit kruidenpreparaten besluit van 19 januari 2001, houdende vaststelling van het warenwetbesluit kruidenpreparaten, 2001 Available at: https:/ / wetten.overheid.nl/BWBR0012174/2014-12-13. Accessed 13 December 2019.

[106] BPOM RI, Laporan Tahunan 2016 Badan Pengawas Obat dan Makanan, Indonesia, Badan Pengawas Obat dan Makanan, Jakarta 2017. Available at: http://www.pom.go.id/new/admin/dat/20171127/laptah2016.pdf. Accessed 3 January 2018. 
[107] INARAC, Indonesia Risk Assessment Center (INARAC) dalam Forum Diseminasi Hasil Riset Dan Kajian Obat Dan Makanan Badan POM tahun 2019 Indonesia Risk Assessment Center (INARAC), Jakarta 2019 Available at: https://www.pom.go.id/new/view/more/berita/17422/Forum-DiseminasiHasil-Riset-Dan-Kajian-Obat-Dan-Makanan-Badan-POM-tahun-2019-.html. Accessed 3 January 2020.

[108] EFSA, Dietary exposure assessment to pyrrolizidine alkaloids in the European population. EFSA Journal 2016, 14, e04572.

[109] Silins, I., Högberg, J., Combined toxic exposures and human health: biomarkers of exposure and effect. International Journal of Environmental Research and Public Health 2011, 8, 629-647.

[110] Gurusankar, R., Yenugadhati, N., Krishnan, K., Hays, S., Haines, D., Zidek, A., Kuchta, S., Kinniburgh, D., Gabos, S., Mattison, D., Krewski, D., The role of human biological monitoring in health risk assessment. International Journal of Risk Assessment and Management 2017, 20, 136-197.

[111] Ning, J., Rietjens, I. M. C. M., Strikwold, M., Integrating physiologically based kinetic (PBK) and Monte Carlo modelling to predict inter-individual and inter-ethnic variation in bioactivation and liver toxicity of lasiocarpine. Archives of Toxicology 2019, 93, 2943-2960.

[112] Punt, A., Paini, A., Spenkelink, A., Scholz, G., Schilter, B., van Bladeren, P. J., Rietjens, I. M. C. M., Evaluation of interindividual human variation in bioactivation and dna adduct formation of estragole in liver predicted by physiologically based kinetic/dynamic and monte carlo modeling. Chemical Research in Toxicology 2016, 29, 659-668.

[113] Strikwold, M., Spenkelink, B., Woutersen, R. A., Rietjens, I. M. C. M., Punt, A., Development of a combined in vitro physiologically based kinetic (PBK) and monte carlo modelling approach to predict interindividual human variation in phenol-induced developmental toxicity. Toxicological Sciences 2017, 157, 365-376.

[114] Kiwamoto, R., Spenkelink, A., Rietjens, I. M. C. M., Punt, A., A physiologically based in silico model for trans-2-hexenal detoxification and DNA adduct formation in human including interindividual variation indicates efficient detoxification and a negligible genotoxicity risk. Archives of Toxicology 2013, 87, 1725-1737.

[115] WHO, International Classification of Diseases (ICD) 10 Version:2016, 2018 Available at: https://icd.who.int/browse10/2016/en. Accessed 3 December 2019.

[116] Badgujar, S. B., Patel, V. V., Bandivdekar, A. H., Foeniculum vulgare Mill: a review of its botany, phytochemistry, pharmacology, contemporary application, and toxicology. BioMed Research International 2014, 2014, 842674-842674.

[117] Rather, M. A., Dar, B. A., Sofi, S. N., Bhat, B. A., Qurishi, M. A., Foeniculum vulgare: A comprehensive review of its traditional use, phytochemistry, pharmacology, and safety. Arabian Journal of Chemistry 2016, 9, S1574-S1583.

[118] Boskabady, M. H., Khatami, A., Relaxant effect of Foeniculum vulgare on isolated Guinea Pig tracheal chains. Pharmaceutical Biology 2003, 41, 211-215.

[119] Ostad, S. N., Soodi, M., Shariffzadeh, M., Khorshidi, N., Marzban, H., The effect of fennel essential oil on uterine contraction as a model for dysmenorrhea, pharmacology and toxicology study. Journal of Ethnopharmacology 2001, 76, 299-304.

[120] Giacosa, A., Morazzoni, P., Bombardelli, E., Riva, A., Bianchi Porro, G., Rondanelli, M., Can nausea and vomiting be treated with ginger extract? European Review for Medical and Pharmacological Sciences 2015, 19, 1291-1296.

[121] Riswan, S., Sangat-Roemantyo, H., Jamu as traditional medicine in Java, Indonesia. South Pacific Study 2002, 23, 1-10.

[122] BPOM-RI, Keputusan Kepala Badan Pengawas Obat dan Makanan Republik Indonesia Nomor HK. 00.05.4.2411 tentang Ketentuan Pokok Pengelompokan dan Penandaan Obat Bahan Alam Indonesia, Kepala Badan Pengawas Obat dan Makanan Republik Indonesia 2004. Available at: https://jdih.pom.go.id/. Accessed 24 December 2019.

[123] Ragamustari, S. K., Leveraging jamu heritage using science and technology, The Jakarta Post, Jakarta 2019 Available at: https://www.thejakartapost.com/academia/2019/04/08/leveraging-jamuheritage-using-science-and-technology.html. Accessed 12 December 2019. 


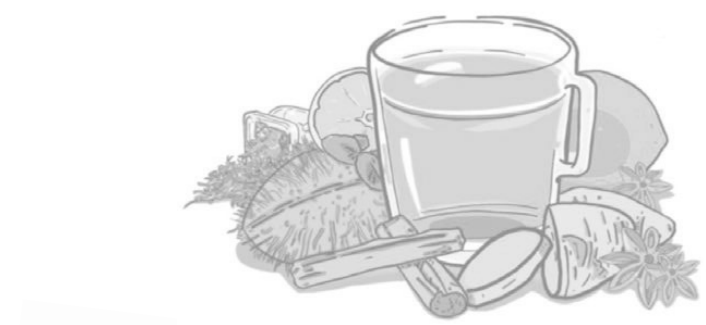

BENEFIT

RISK 
Chapter 8

Summary

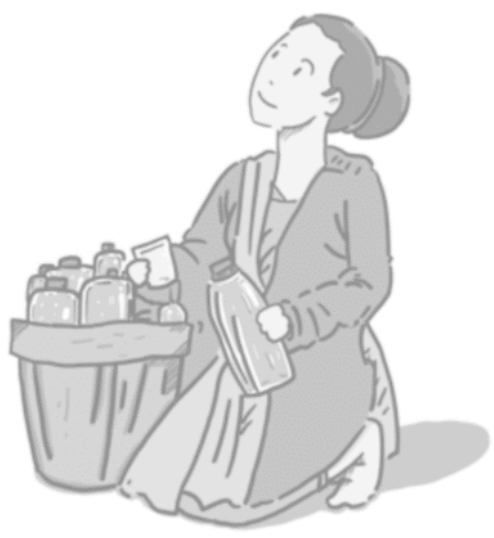




\section{Summary}

In Indonesia, the market demand for herbal products keeps growing, and as a result, herbal products increasingly provide economic and perceived clinical benefits. A risk and benefit assessment are crucial to be performed to support the safe use of herbal products although the consumers perceive herbal product as "safe" and "natural" and thus "healthy" (Chapter 1). The aim of the present thesis was to perform an assessment of potential risks and some benefits of herbal products available in the Indonesian market. The model compounds chosen included especially naturally occurring genotoxic and carcinogenic botanical constituents including alkenylbenzenes (ABs) and pyrrolizidine alkaloids (PAs). Beneficial effects focussed on potential PPAR $\gamma$ activation by the carotenoids bixin and crocetin. Existing but also novel testing strategies were used to evaluate the relevance of effects at estimated human intake levels.

The consumer risks of jamu, Indonesian traditional herbal medicines, was assessed focussing on the presence of AB-containing botanical ingredients (Chapter 2). Methyleugenol, appeared to be a major $A B$ present, being detected in $91.3 \%$ of the collected jamu samples. Quantification of $\mathrm{AB}$ levels and exposure resulting from use of the respective jamu products resulted in Margin of Exposure (MOE) values generally $<10,000$, indicating a priority for risk management when assuming daily consumption during a lifetime. Using Haber's rule, it was estimated that two weeks consumption of these jamu only once would not raise a concern (MOE $>10,000$ ). However, when considering use for two weeks every year during a lifetime, 5 samples still raised a concern. It is concluded that the consumption of AB-containing jamu can be of concern especially when consumed daily for longer periods of time.

Based on these results it was anticipated that methyleugenol may also be present and pose a risk in Indonesian instant herbal beverages. Chapter 3 analysed methyleugenol in many instant herbal beverages containing various mixed herbs collected on the Indonesian market by a targeted sampling strategy. Interestingly, eugenol was detected in a few samples at a level that resulted in an estimated daily intake (EDI) lower than the acceptable daily intake (ADI) of $2.5 \mathrm{mg} / \mathrm{kg}$ bw thus not raising a concern for human health. The MOE for methyleugenol intake by targeted consumers, including both adults and children, revealed that several of the herbal products targeted at adults would require a risk management action, while only a few samples targeted at children pointed at a priority for risk management, when the respective herbal beverages would be used every day during a lifetime. However, when assuming the consumption for 2 weeks, every year during a lifetime and using Haber's rule then all MOE values were estimated to be $>10,000$ indicating no priority for risk management. An overview of the current product registration 
type of these samples indicated that herbal beverages registered as household food (labelled as 'Depkes RI P-IRT'), would raise a concern when people would consume them every day during a lifetime. The study provided data that can support establishment of a maximum permitted level (MPL) for methyleugenol in herbal beverages in Indonesia.

Another group of genotoxic compounds potentially present in botanicals and botanical preparations and raising a health concern are PAs. In Chapter 4, the occurrence and accompanying risks of PAs in Indonesian jamu were evaluated. PAs were detected in $97.1 \%$ of the jamu containing PA-producing botanicals and in $74 \%$ of the jamu samples that had no PA-producing botanicals listed on their label. This latter point shows contamination with PA-producing plants due to co-harvesting of PA-containing weeds during cultivation or harvesting of the materials. Short-time, 4 days up to 2 weeks, consumption of jamu, is unlikely to result in acute toxic effects, although one sample would exceed an intake of $10 \mu \mathrm{g}$ PAs/kg bw/day which may cause hepatic veno-occlusive disease (HVOD) and PA-induced liver injury (PA-ILI) in humans. When evaluating the potential risk for genotoxicity and carcinogenicity via the MOE approach, MOE values below 10,000 were obtained for $46.6 \%$ of the samples, indicating a priority for risk management when assuming daily lifelong consumption. Assuming consumption for two weeks every year during a lifetime, and using Haber's rule, 37\% of the jamu samples containing PA-producing botanicals still raised a concern, while the jamu consisting of non-PA-producing botanicals would be of low concern. This study provided data that can support risk management actions in Indonesia to minimize the potential health risk for jamu consumers due to the occurrence of toxic PAs in these products.

Exposure to these PAs, including monocrotaline via herbal product consumption is of concern because of their hepatotoxicity and the fact that they are genotoxic carcinogens. Considering that only for a limited number of 1,2unsaturated PAs in vivo toxicity data are available, hampering risk assessment where differences in relative potency between different PAs are considered, alternative testing strategies including read-across and quantitative in vitro to in vivo extrapolation (QIVIVE) become important for risk analysis. In Chapter 5, a combination of in vitro-physiologically based kinetic (PBK) modeling-facilitated reverse dosimetry was used to predict the in vivo acute liver toxicity of the PA monocrotaline and to characterize the influence of its metabolism on its relative toxic potency compared to lasiocarpine and riddelliine. In the absence of data on acute liver toxicity of monocrotaline upon oral exposure, the predicted dose-response curve for acute liver toxicity in rats and the resulting benchmark dose lower and upper confidence limits for $10 \%$ effect $\left(\mathrm{BMDL}_{10}\right.$ and $\mathrm{BMDU}_{10}$ ) were compared to 
data obtained in studies with intraperitoneal or subcutaneous dosing regimens. This indicated the predicted $\mathrm{BMDL}_{10}$ value to be in line with no-observed-adverse-effectlevels (NOAELs) derived from available in vivo studies. The predicted BMDL $\mathrm{B}_{10^{-}}$ $\mathrm{BMDU}_{10}$ of $1.7-6.3 \mathrm{mg} / \mathrm{kg}$ bw/day also matched the oral dose range of 1-3 mg $\mathrm{PA} / \mathrm{kg}$ bw/day at which adverse effects in human are reported. A comparison to the oral toxicity of the related pyrrolizidine alkaloids (PAs) lasiocarpine and riddelline revealed that, although in the rat liver hepatocytes study monocrotaline was less toxic than lasocarpine and riddelliine, due to its relatively inefficient clearance the in vivo acute liver toxicity was predicted to be comparable. It was concluded that the combined in vitro-PBK modeling approach can provide insight in monocrotaline-induced acute liver toxicity in rats thereby filling existing gaps in the database on PA toxicity. Furthermore, the results reveal that the kinetic and metabolic properties of PAs can vary substantially and should be considered when considering differences in relative potency between different PAs.

The combined in vitro-PBK modeling approach was also applied for benefit analysis of the therapeutic effect of bixin and crocetin in type 2 diabetes mellitus suggested to occur via PPAR $\gamma$ activation. Chapter 6 investigated whether at realistic dietary intake from botanical preparations bixin and crocetin could induce PPAR $\gamma$ mediated gene expression in humans. Concentration-response curves obtained from in vitro PPAR $\gamma$-reporter gene assays were converted to in vivo dose-response curves using PBK modeling-facilitated reverse dosimetry, from which the benchmark dose resulting in a $50 \%$ effect above background level $\left(B \mathrm{DD}_{50}\right)$ values were predicted and subsequently compared to dietary exposure levels. In the PPAR $\gamma$ reporter gene assay bixin and crocetin activated PPARY-mediated gene transcription in a concentrationdependent manner with similar potencies. Due to differences in kinetics, the predicted $\mathrm{BMD}_{50}$ values for in vivo PPAR $\gamma$ activation was about 30-fold different, amounting to 115 and $3,505 \mathrm{mg} / \mathrm{kg}$ bw for crocetin and bixin, respectively. Human dietary and/or supplemental estimated daily intakes may reach these $\mathrm{BMD}_{50}$ values for crocetin but not for bixin, pointing at better possibilities for in vivo PPAR $\gamma$ activation by crocetin. The results presented further show that based on a combined in vitro-in silico approach, it could be estimated whether at realistic dietary intakes plasma concentrations of bixin and crocetin are likely to reach concentrations that activate PPARY-mediated gene expression, without the need for a human intervention study.

The results obtained in the present thesis support the conclusion that there is a need for risk management formulating regulatory actions to minimize the potential health risks for consumers in Indonesia due to the occurrence of toxic ABs, PAs and AAs in herbal products (Chapter 7). It is important to note that this 
conclusion holds for herbal products collected by targeted sampling, and not for all herbal products on the Indonesian market. Several methodological considerations are formulated that need to be considered when performing the risk and benefit analysis to avoid over-/under-estimation of risks or benefits. Furthermore, the relevance of risk assessment to support risk management action is highlighted, and considerations regarding the potential for the application of PBK model based QIVIVE for predicting beneficial as well as adverse effects, without the need for animal experiments and/or human intervention studies are formulated.

Altogether, it can be concluded that the risk assessment using the MOE approach combined with Haber's rule can be used to prioritize risk management actions to prevent the adverse health effects of consuming Indonesian herbal products containing genotoxic carcinogens. In addition, a novel testing strategy, combining in vitro and PBK modeling-facilitated reverse dosimetry was found to facilitate risk and benefit assessment of botanical compounds without the need for animal experiments and/or human intervention studies. 


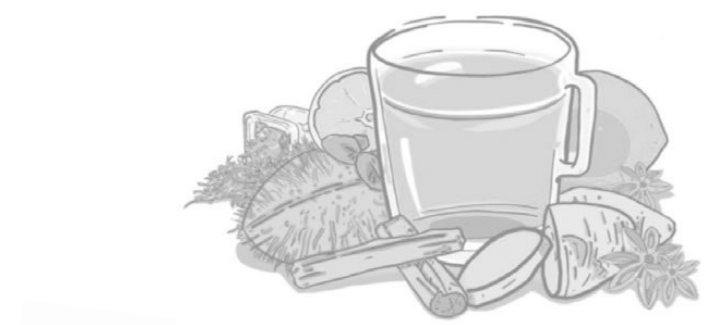

BENEFIT

RISK 


\section{Appendices}

Acknowledgements

About the author

List of publications

Overview of completed training activities

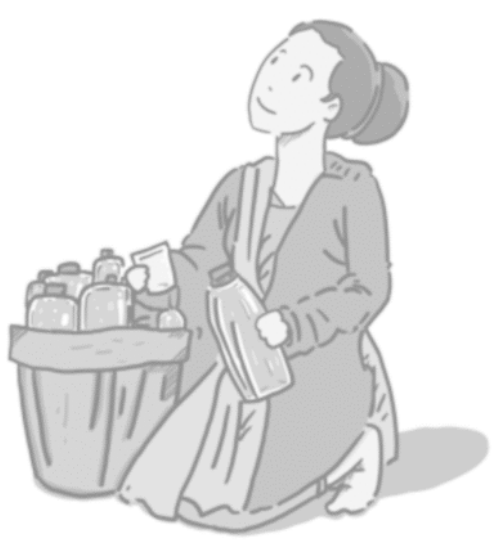




\section{Acknowledgements}

In this opportunity I would like to acknowledge my sincere gratitude to many people for helping me to finish my PhD as presented in this thesis.

First and foremost, I would like to thank my promotor Prof. Dr I.M.C.M. Rietjens who made the biggest difference in my life. Thanks for your Letter of Acceptance which brings me to this wonderful department with the new facilities in Helix. Since then, she has been there for last four years, motivating and inspiring every bit of me towards new possibilities in life. Not only in the research, I found her as an excellent supervisor and my role model to become a good teacher. Her intelligent ideas, thought provoking discussions and comprehensive understanding, when I was struggling to synthesize my research outcomes were much appreciated.

I would like to extend my gratitude to my previous daily supervisors Dr. Karsten Beekmann and Dr. Jochem Louisse for the involvement in my early stages of the PhD life. Although it was quite a challenge in my first year, without your valuable guidance, the bixin and crocetin paper would not have been possible to publish. Karsten, your critical scientific views have inspired me to thrive for excellence. Jochem, thanks for teaching me the PBK modeling.

I would like to acknowledge other co-authors of my publications. Dr. Sebas Wesseling who extended his supports and acted as my unofficial daily supervisor and provided technical help in LC-MS and UPLC. Special thanks to Laura for answering all technical questions regarding cell cultures and providing valuable suggestions for balancing between job and family. Bert, it was a great pleasure to work in UPLC labs with your joke and storytelling on raising children. My sincere thanks to Dr. Patrick Mulder from Wageningen Food Safety Research who provided valuable suggestions on my targeted sampling for PA-containing jamu and writing the PA paper. Furthermore, I would like to extend my gratitude to Elena, who helped and taught me during performing solid phase extraction in your lab.

I would like to thank the current and former staff members at Toxicology for the nice times and the comradery atmosphere. My special thanks to Lidy for the arrangement of administrative matters I needed even before arrived in Wageningen until finalized my thesis. I will miss your voice to sing lang zal ze leven in de gloria during my birthday. Letty, thank you for your help with administrative matters of PET course and the fun talking during the coffee breaks and lab trip. Carla and Gerda, thanks for always opening your door for any administrative help. Carla, thanks for arranging ticket and hotel for my opponents, I enjoy our discussion about Indonesia with you. Hans, thank you for always opening your door for me for any sort of technical help, especially when my technician buddies were absent. Wouter thanks for some nice talks during coffee break. My sincere thanks to Dr. Nico van den Brink and Dr. Hans Bouwmeester for the constructive comments during my research in progress presentations. 
The friendship amongst the PhD-candidates is very crucial for my $\mathrm{PhD}$ journey. Room 4033 is my second home with a nice environment, many thanks for my former (Jia, Lu, Gogo) and current officemates (Ixchel, Nina, Jingxuan and Tessa) who allowed me to pray and even cry in our office, also to share the happiness. The former PhD students at TOX Jonathan, Nacho, Rozaini, Rung, Sunday, Myrtho, Marcia, Samantha, Amer, Abdul, Leny, Mebrahtom, Martha, and Aziza thank you for all the good time when doing activities together. Current Intoxicated PhDs Diana, Mengying, Annelies, Katja, Shengsheng, Dora, Mengying, Shuo, Felicia, Isaac, Danlei, Menno, Bohan, Myoying, Biyao, Weija, Jing, Pim, Chen, Artem and Asraf, thank you for sharing during the experiments in the lab, the discussion during the lunch or coffee break, and the good times outside of work especially during our $\mathrm{PhD}$ trip in Japan, PET course and lab trips. New Intoxicated PhDs Jin, Merel, Yi Ming, Veronique, Edith, Maartje, Akansha, Aafke, Frances, Ren and Orsi, thanks for nice conversations and friendship. Thanks to my $\mathrm{PhD}$ friends from my husband group, MAE: Chris (for the monthly Donald Duck magazine), Celia (for the aquarium), Park, Erik, Misha and Diede (thanks for nice friendship and the dinner).

I would also like to thank my former MSc students Imron, Yizhi, Diana, Alex, Siti, Chodijah, Charlotte, Wenting and Yogi for the efforts to contribute in my project.

I would also like to express my gratitude to the committee members Prof. Dr E.J.M. Feskens, Dr M. Lahaniati, Prof. Dr Taufiqurrachman Nasihun, M.Kes., Sp.And, and Dr D. Wahidin for the time and efforts to evaluate this thesis.

My paranymphs, Diego and Ixchel, thank you for being great friends during my PhD life. Diego, who always ask 'How are you?" with the slow motion and smooth voice admiring me and supporting me to -albeit slow- but for sure finishing my PhD. Ixchel, you are my sister in TOX, thank you for all the heart-talk sessions and for being a real friend that I can trust during our $\mathrm{PhD}$ journeys.

To my Indonesian friends in Wageningen, thanks for being a real family in Wageningen when we are far from our home country. To all of the parents and their children in Wageningen: OBS de Tarthorst's Ouders (Mbak Aulia, Mbak Andra, Mas Zukri, Teh Nia, Mbak Nurul, Mbak Najmi, Mbak Mutia, Mbak Hanum, Mas Anto, Mbak Fifi, Mas Anto (Satria), Mas Hardi, Mas Edo, Pak Darmanto, Pak Gede, Mbak Ningrum, Mbak Ika, Mbak Lia); OBS de Wereld Ouders (Mbak Hermi, Mbak Uli, Mbak Ita, Bundo Rovanty, Mbak Dian, Mbak Lia, Mbak Natal, Mbak Ayu, Mbak Fitri, Mbak Vinna), thank you for sharing experiences in parenting, cooking, playing together and keep watching my sons after school or during the weekend. I also would like to thank the PhD-Post Doct Indonesian Association for the sharing about PhD life in WUR, especially for Pak Eko, Pak Fariz, Pak Gede, Pak Ery, Pak Iman, Pak Dikky, Pak Dadan, Pak Fajar, Mas Ayusta, Mbak Ita, Mas Alim, Mas Gumi (and Mbak Gendis), Mas Hachi, Mbak Windi (and Mas Firin), Mbak Aviv, Mbak Atik, Mbak Nila, Vina, Mas Farid, Teh Novi, Kang Indra, Mbak Mega, Mbak Hikmah, Mas 
Asrul, Mas Satria, Mbak Uun, Mbak Eva, Mas Emil, Ana, Mas Ludi and many others that I could not mention one by one. Thanks to Yasin Taklim Wageningen, Indonesian Students'Association in Wageningen (PPIW), TPQ Wageningen and PCINU Belanda for the gathering. The previous Indonesian MSc students at WUR: Mas Anan and Mbak Khusnul, thank for the friendship during your thesis at TOX; Mbak Lisa, Mbak Isna, Mbak Atina, Mas Rausan, Mas Ikrom, Mas Iqbal, Mas Yitno, Mbak Astin for the nice friendship and helping to take care my sons during my Hajj; Mbak Icha and Mas Arif thanks for being caregiver, friend, and chef of my sons after their school day during the $2^{\text {nd }}$ and $3^{\text {rd }}$ year of my PhD; Mas Adhiet and Mbak Adi thanks for carrying my samples from Indonesia to Wageningen; Hendy thanks for collecting my samples in Solo. Thanks to current MSc students: Mas Garry for designing the cover of this thesis; Mas Kukuh for connecting me with Mas Garry; Mas Ikbar, Mas Yanda, Mas Nuve thanks for caring my sons to Jumah prayer when my husband was absent.

Thanks to my Pakistanese friend, Aulia and her parents for the discussion on traditional use of saffron, sending me a nice picture of saffron which published in the graphical abstract of my crocetin paper, and for the delicious dinner. Hajj Family 2018: Ustadz Fatah and Yai Hasyim, thank you for being our spiritual mentors. Bu Yeni (Pak Wim), Bu Armis, Bu Berni, Bu Ita (Pak Akmal), Bu Efi (Mr. Daniel), Bu Maya (Pak Oscar), Bu Leni, Bu Teti, Bu Anita, Bu Sunu, Bu Nurhayati, Bu Riana, Bu Lilis, Bu Lilis (geulis), Mas Fikri, Pak Yuli, Mbak Vica and Mohammad thank you for the togetherness before, during and after the Hajj. My special thanks to Bu Iik who called me "Nok" for sharing your personal life stories, giving kitchen stuffs, and sewing my dress when I was a paranymph of my college.

I would like to thank my home university, Universitas Islam Sultan Agung (UNISSULA), especially Faculty of Medicine (FK) for keeping my employment. Pak Is (chair of Biology), Pak Iwang, Bu Puji (former Dean and Vice Dean) thank you for being supported me to achieve LPDP scholarship and to continue my PhD study in WUR; Pak Setyo, Bu Ijah dan Pak Hadi (current Dean and Vice Dean) thank for for allowing me to stay in Wageningen for another 1 year after I finished my PhD. Pak Anies (former Rector) thank you for visiting me during WISE 2017; Pak Prabowo, $\mathrm{Bu}$ Eni, Pak Bedjo (current rector and vice rectors) and Prof Imam who visiting during your meeting in Rotterdam. Colleagues in UNISSULA: my labmate Mbak Dina thanks for the heart-chat sessions and updating me the situation in UNISSULA; $\mathrm{Bu}$ Endang and Bu Minidian, thanks for the sharing about study in the Netherlands; $\mathrm{Bu}$ Dian, Bu Mila and Bu Ayu thanks for the chatting about batik, hajj, and Indonesian food; Bu Hesti thank for bringing oleh-oleh. I am indebted to Pak Harka who supported a part of my family allowance especially during the first year. Thanks to Mbak Aang, Mbak Okti, Mbak Eva, Mbak Fuah, Mas Andi, Mas Adin, Mas Didik Karno, Mas Hamdani, Mas Adji, Mbak Ekki, Pak Dwi, Mas Andika and 
Mas Wisnu for the arrangement of administrative matters I needed to keep my employment in track.

I would like to grateful my lecturers from Diponegoro University who visiting when they came to WUR: Prof Ocky, Prof Jeki and Bu Tita for sharing experinces on research grant and research collaboration; Bu Riri and Bu Resti for cooking class and oleh-oleh. Mas Purwanto thanks for offering free luggage.

I would like to thank my dearest family, Papa, Kakak and Adek. My dear husband Papa Achmad Sahri, thank you very much for your love, your support, and for always making me calmer to finalize my thesis. We are doing our PhDs together and with you at my side, my PhD journey can safely finish on time. Thank you for taking care of our sons and taking over the household duty during my courses or conferences outside Wageningen or my prolonged work in lab and office. Thank you for the map of my sampling location in the 3 published papers, the beautiful pictures for the graphical abstracts in all my papers and the great cover design and layout of this thesis. I would like to extend my gratitude to my husband's promotor, Prof. Dr Tinka Murk who gives him a flexible time to come at his office and even allow him to work at home in the meanwhile accompanying our sons. My dear sons, Syifa Brillant and Fadli Habile, thank you for being my advisor of my PhD-related stress. Kak Brillant, you are special, your silent is a gold, and you can feel what I felt. Dek Habile, your enthusiastic and talkative characteristics make me wake up from the misfortune of my works.

My extended thanks to: my son's teachers at OBS de Tarthorst especially their class teachers since in Group 1/2 until 4/5 (Juf Ditje, Juf Ann, Juf Marloes, Juf Els, Juf Martine, Juf Fleur, Juf Manon, Juf Marjan) and Plus Group (Yuf Marianne, Mister Jorik); Sekolah Indonesia den Haag (teachers: Bu Siska and Bu Hesty, commitee: Pak Mulyono); Habile's korfbal trainer (Allin), Brillant's chess trainer (Hans). Thanks to KVW parents especially Janneke, Elise, and Juf Sandra.

The most important persons throughout my life, my mother, Mboke and my father, Pake (almarhum) thank you for all your constant supports and endless love. Without your ridho to me, I would not have been able to achieve this $\mathrm{PhD}$. This degree is for you Mboke, also for you Pake (even we are in different realm). My grandfather, Pak Surat, thanks for your doa and endless love. Thanks also for my parents in law, Mimih and Abah (almarhum) for your ridho and doa to my little family. To all my sisters, Yu Yak (and Mas War), Sulis and Ayu; my niece Khoir; my nephew Imam; my aunts and uncles, my cousin's thanks for all your support and for always being there with Mboke. My sister Sulis, my cousin Ulfi and my brother in law Nana thank you for helping me to collect jamu samples.

Finally, I would like to thank my sponsor, Lembaga Pengelola Dana Pendidikan (LPDP) from The Ministry of Finance, The Republic of Indonesia for the financial support to my $\mathrm{PhD}$ journey. 


\section{About the Author}

Suparmi was born on $26^{\text {th }}$ June 1983 in Nganjuk, Indonesia. Before her PhD, she obtained her Bachelor's degree at Biology Department, Faculty of Science and Mathematics, Diponegoro University, Indonesia in 2005. Her BSc thesis on the effect of chitin supplementation in mice was published in a local journal. After one year of being a freelance teacher, she continued her education with a scholarship from Beasiswa Unggulan, Ministry of Education of Republic Indonesia to follow the MSc program in the field of natural pigments and its application for food and

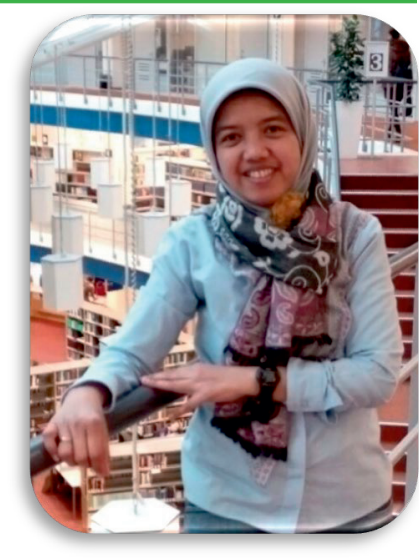
industry at Biology, Satya Wacana Christian University, Indonesia. She also was granted the research funding from the Beasiswa Peneliti, Penulis, Pencipta, Seniman, Wartawan, Olahragawan, dan Tokoh (P3SWOT) and published some research articles as first author at national journals and proceedings.

In October 2008, she was employed as a lecturer at Faculty of Medicine, Universitas Islam Sultan Agung, Semarang (UNISSULA) Indonesia. During these works, she received some grants from the Ministry of Research, Technology and Higher Education for research and research based-community services. Her research explored the beneficial effect of plant pigments, chlorophyll and carotenoids for food supplements with published research articles in local journals or magazines, accredited national journals and international journals. In November 2015, she was granted the StuNed Scholarship Programme Nuffic-Neso Indonesia for 2 weeks of Short Course: Right Based Approach to Food and Nutrition Security on $25^{\text {th }}$ January - $5^{\text {th }}$ February 2016 at CDI-Wageningen University and Research (WUR), The Netherlands.

In December 2016, she received a doctoral scholarship from the Indonesian Endowment Fund for Education, Ministry of Finance, Republic of Indonesia through a Beasiswa Pendidikan Indonesia Lembaga Pengelola Dana Pendidikan (BPI LPDP) for her PhD study at WUR. She started her PhD research described in this thesis at the Department of Toxicology WUR on 2nd May 2016. This PhD study brought practical opportunities for her to work to understand the food safety and risk assessment of herbal products from Indonesia. During her $\mathrm{PhD}$, she followed a postgraduate education program and registered as toxicologist-in-training, to become a European Registered Toxicologist after graduation. After completing her doctoral study and one year additional live in Wageningen, she will return to serve as a lecturer at her home university, UNISSULA. 


\section{List of publications}

\section{Peer reviewed publications}

S. Suparmi, D. Widiastuti, S. Wesseling, I.M.C.M. Rietjens. Natural occurrence of genotoxic and carcinogenic alkenylbenzenes in Indonesian jamu and evaluation of consumer risks. Food and Chemical Toxicology, 118 (2018), pp. 5367, https://doi.org/10.1016/j.fct.2018.04.059

S. Suparmi, A.J. Ginting, S. Mariyam, S. Wesseling, I.M.C.M. Rietjens. Levels of methyleugenol and eugenol in instant herbal beverages available on the Indonesian market and related risk assessment. Food and Chemical Toxicology, 125 (2019), pp. 467-478, https:/ / doi.org/10.1016/j.fct.2019.02.001

Suparmi, S., de, L., Spenkelink, A., Louisse, J., Beekmann, K., Rietjens, I. M. C. M., Combining in vitro data and physiologically based kinetic modeling facilitates reverse dosimetry to define in vivo dose-response curves for bixinand crocetin-induced activation of PPARY in humans. Molecular Nutrition and Food Research (2020), 64, 1900880, pp 1-9, https://doi.org/10.1002/mnfr.201900880.

S. Suparmi, Patrick P.J. Mulder, Ivonne M.C.M. Rietjens, Detection of pyrrolizidine alkaloids in jamu available on the Indonesian market and accompanying safety assessment for human consumption. Food and Chemical Toxicology, 138 (2020), 111230, pp. 1-13, https:/ / doi.org/10.1016/j.fct.2020.111230

S. Suparmi, S. Wesseling, I.M.C.M. Rietjens. Monocrotaline-induced liver toxicity in rat predicted by a combined in vitro-physiologically based kinetic modeling approach. Under review, Archives of Toxicology (2019).

\section{Abstracts/conference proceedings}

S. Suparmi, Laura de Haan, Albertus Spenkelink, Jochem Louisse, Karsten Beekmann, Ivonne M.C.M. Rietjens, 2017. Activation of peroxisome proliferator-activated receptor $\gamma($ PPAR $\gamma)$ - mediated gene expression by bixin and norbixin from pericarp Bixa orellana seed, In: Wageningen Indonesia Scientific Exposure 2017.

S. Suparmi, D. Widiastuti, S. Wesseling, I.M.C.M. Rietjens. 2018. Consumer risk analysis for jamu in Indonesia based on natural occurrence of genotoxic and carcinogenic alkenylbenzenes. In: Wageningen Indonesia Scientific Exposure 2018 and NVT Annual Meeting and Young Scientist Day.

S. Suparmi, A.J. Ginting, S. Mariyam, S. Wesseling, I.M.C.M. Rietjens. 2019. Are the levels of methyleugenol in instant herbal beverages available on the Indonesian market safe for human consumption? In: $40^{\text {th }}$ NVT Anniversary Annual Meeting 
Suparmi, A.J. Ginting, S. Mariyam, S. Wesseling, I.M.C.M. Rietjens. 2019. The importance to establish a maximum permitted level (MPL) for methyleugenol in Indonesia: A risk assessment study based on methyleugenol levels. In: Wageningen Indonesia Scientific Exposure 2019.

S. Suparmi, Laura de Haan, Albertus Spenkelink, Jochem Louisse, Karsten Beekmann, Ivonne M.C.M. Rietjens. 2019. In vitro-in silico-based prediction of peroxisome proliferator-activated receptor $\gamma$ (PPAR $\gamma$ ) activation by bixin and crocetin in humans, In: Toxicology Letters $314 S 1$ (2019) page S304

S. Suparmi, S. Wesseling, I.M.C.M. Rietjens. 2020. Prediction of in vivo monocrotaline-induced liver toxicity in rat using an in vitro-in silico approach. In: The Toxicologist: Late-Breaking Supplement, the Society of Toxicology 59th Annual Meeting (2020) 
Overview of Completed Training Activities

Discipline specific courses

Molecular Toxicology

PET 2016

Pathobiology

PET 2016

Risk Assessment

PET

2016

Organ Toxicology

PET 2017

Mutagenesis and Carcinogenesis

2017

Toxicogenomics

PET

2017

Epidemiology

PET

2018

Cell Toxicology

PET

2019

Meetings and conferences

Wageningen Indonesia Scientific Exposure (WISE)

39th NVT Annual Meeting and Young Scientist

Day

Wageningen Indonesia Scientific Exposure

(WISE)

Wageningen Indonesia Scientific Exposure (WISE)

40th Anniversary Annual Meeting Netherlands

Society of Toxicology (NVT)

55th Congress of the European Societies of

Toxicology (EUROTOX 2019)

WUR, The Netherlands 2017

Hilversum, The 2018

Netherlands

Indonesian Institute of 2018

Sciences, Indonesia

WUR, The Netherlands 2019

Ede, The Netherlands 2019

Helsinki, Finland 2019

General courses

Information Literacy Including Endnote

WGS

2016

Introduction

Reviewing a Scientific Paper

WGS

2016

VLAG PhD Week

VLAG

2016

The Essentials of Scientific Writing and

WGS

2016

Presenting

Laboratory Animal Science: Design and Ethics in

WUR

2017

Animal Experimentation

Orientation on Teaching for PhD Candidates

WGS

2017

Supervising BSc and MSc Thesis Students

WGS

2018

Philosophy and Ethics of Food Science and

VLAG

2019

Technology

Reviewing a Scientific Paper

WGS

2019

Start to Teach

WGS

2019

\section{Optional activities}

Thesis Proposal

TOX-WUR

Attending scientific presentations

TOX-WUR

2016-2020

General Toxicology

WUR

2016

Environmental Toxicology

WUR

2019

PhD Trip to Japan

TOX-WUR

2018 
The research described in this thesis was financially supported by the Indonesian Endowment Fund for Education (LPDP), Ministry of Finance, Republic of Indonesia through a Beasiswa Pendidikan Indonesia Lembaga Pengelola Dana Pendidikan (BPI LPDP) doctoral scholarship for Suparmi [contract number: PRJ365/LPDP/2016].

\section{Colophon}

Front cover: schematic image of weighing process of herbals and the resulting herbal preparation

Back cover: schematic image of Mbok jamu, a woman who sells fresh jamu carrying the jamu using gendong (long wide shawl) on the back of her body.

Cover \& layout design: M. Pramaditya Garry Hanantyo, Achmad Sahri \& Suparmi Printed by: Digiforce || Proefschriftmaken (www.proefschriftmaken.nl)

Financial support from LPDP and Toxicology Department, Wageningen University for printing the thesis is gratefully acknowledged. 



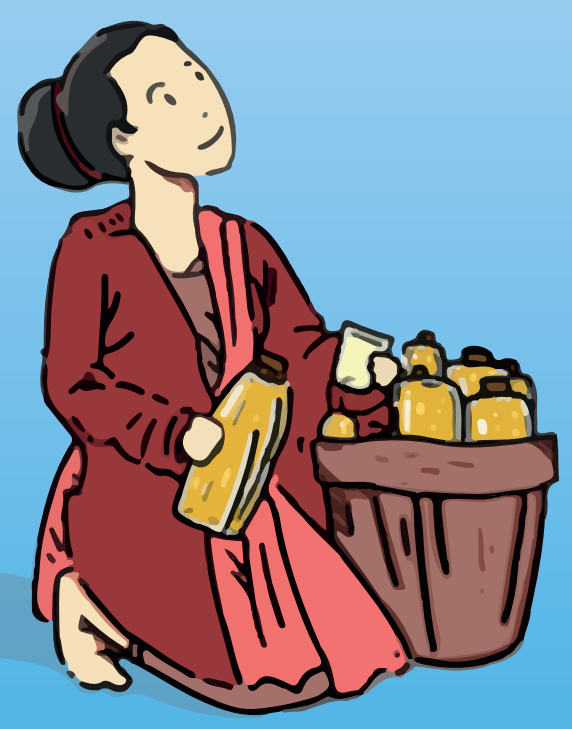

